\title{
P-203: Human Reliability Analysis (HRA) Training Course
}

\author{
US Nuclear Regulatory Commission \\ March 2016
}

Ronald Boring, PhD

David Gertman, PhD
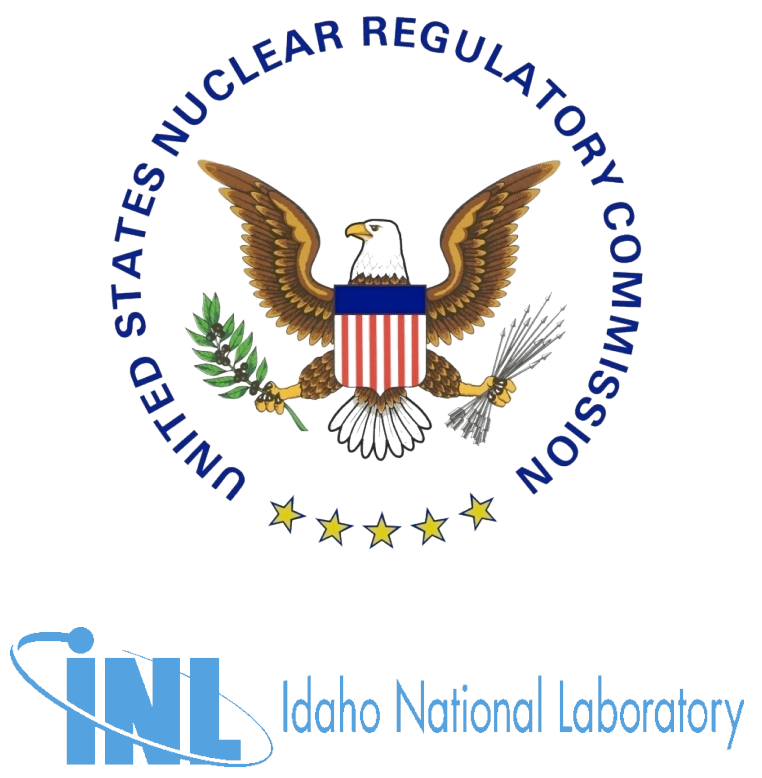


\section{DISCLAIMER NOTICE}

This report was prepared as an account of work sponsored by an agency of the United States Government. Neither the United States Government nor any agency thereof, or any of their employees, makes any warranty, expressed or implied, or assumes any legal liability of responsibility for any third party's use, or the results of such use, or any information, apparatus, product or process disclosed in this report, or represents that its use by such third party would not infringe privately owned rights. 


\section{TABLE OF CONTENTS}

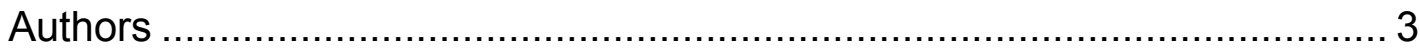

Acronyms

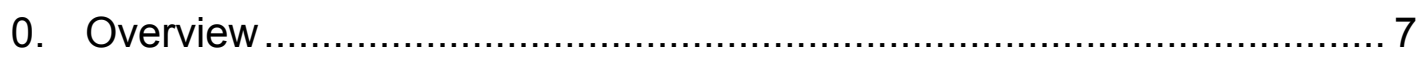

1. Introduction to Human Reliability Analysis (HRA) ............................... 12

2. Probabilistic Risk Assessment (PRA) and HRA ............................... 32

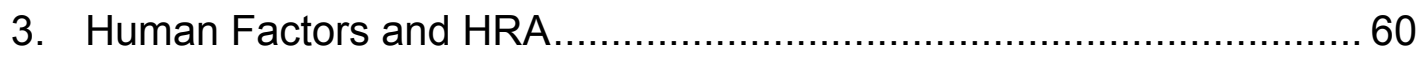

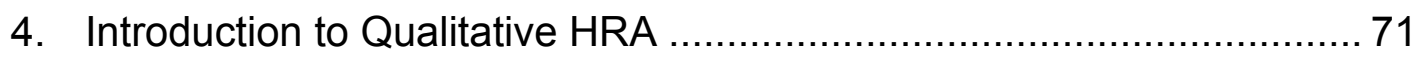

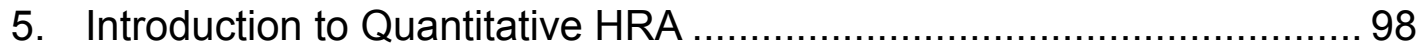

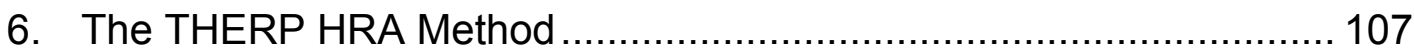

7. The SPAR-H HRA Method …..................................................... 129

8. EPRI HRA Methods: HCR/ORE and CBDT ................................... 139

9. The ATHEANA HRA Method ....................................................... 160

10. HRA Review and Advanced Topics ............................................. 177

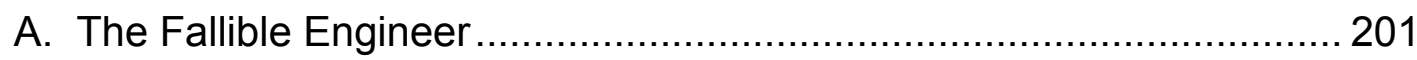

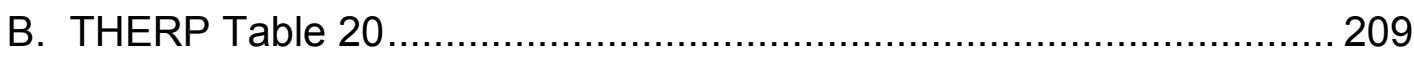

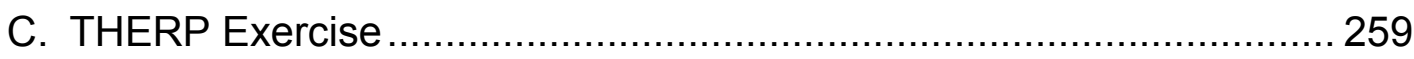

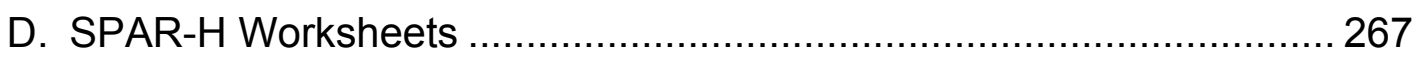

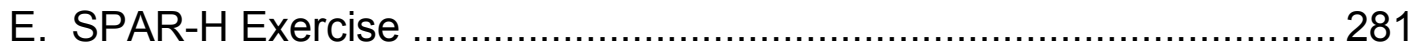

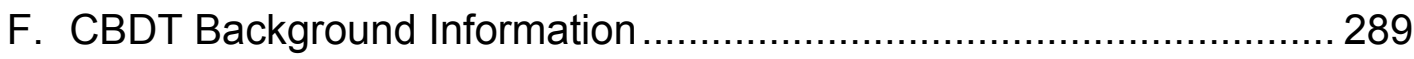




\section{INSTRUCTORS}

Dr. Ron Boring is an INL researcher and principal investigator with ten years of experience on human reliability analysis and human factors projects for the US Nuclear Regulatory Commission, NASA, and the US Department of Energy. He previously worked as a human reliability researcher at Sandia National Laboratories, a usability engineer for Microsoft Corporation and Expedia Corporation, and as a guest researcher in human-computer interaction at the National Research Council of Canada. He recently completed a one-year assignment as a visiting scientist at Halden Reactor Project in Norway. He has published over 120 scholarly articles in a wide variety of human reliability, human factors, and human-computer interaction forums. He has served on the organizing committees for international conferences held by the Human Factors and Ergonomics Society, IEEE, and the Association for Computing Machinery.

Dr. Dave Gertman has over 26 years of experience in providing human factors engineering, human performance assessment, and human reliability services for aerospace, undersea, nuclear, medical, and process control environments. He is a co-developer of the SPAR-H human reliability analysis method and has coauthored two textbooks: Human Factors Engineering Guidelines for HumanComputer Interface in Process Control and the Human Reliability and Safety Analysis Data Handbook. Dave is also the principle investigator for INL Control System Security Center (CSSC), where he is responsible for determining risk basis for cyber scenarios for various critical infrastructures. 


\section{P-203 ACRONYM LIST}

$\begin{array}{ll}\text { ACRS } & \text { Advisory Committee on Reactor Safeguards } \\ \text { ADV } & \text { atmospheric dump valve } \\ \text { AIT } & \text { Augmented Inspection Team } \\ \text { ANS } & \text { American Nuclear Society } \\ \text { ASME } & \text { American Society of Mechanical Engineers } \\ \text { ASEP } & \text { Accident Sequence Evaluation Program } \\ \text { ASP } & \text { Accident Sequence Precursor } \\ \text { ATHEANA } & \text { A Technique for Human Error Analysis } \\ \text { ATWS } & \text { anticipated transient without scram } \\ \text { BORA } & \text { Barrier Analysis in Operational Risk Assessment } \\ \text { BWR } & \text { boiling water reactor } \\ \text { BWST } & \text { borated water storage tank } \\ \text { CAHR } & \text { Communication Assessment Human Research } \\ \text { CBDT } & \text { Cause Based Decision Tree } \\ \text { CNS } & \text { central nervous system } \\ \text { CP } & \text { cognitive procedural } \\ \text { CR } & \text { control room } \\ \text { CREAM } & \text { Cognitive Reliability and Error Analysis Method } \\ \text { DHR } & \text { decay heat removal } \\ \text { DT } & \text { decision tree } \\ \text { EDF } & \text { Electricite de France } \\ \text { EF } & \text { error factor } \\ \text { EFC } & \text { error-forcing context } \\ \text { EFW } & \text { emergency feedwater } \\ \text { EOC } & \text { error of commission } \\ \text { EOO } & \text { error of omission } \\ \text { EOP } & \text { emergency operating procedure } \\ \text { ERF } & \text { emergency response facilities } \\ \text { EPRI } & \text { Electric Power Research Institute } \\ \text { FAB } & \text { feed and bleed } \\ \text { FSAR } & \text { final safety analysis report } \\ \text { HCR } & \text { losuman Cognitive Reliability } \\ \text { HE } & \text { human error } \\ \text { HEP } & \text { human error probability } \\ \text { HF } & \text { human factors } \\ \text { HFE } & \text { human failure event } \\ \text { HLR } & \text { high level requirement } \\ \text { HPI } & \text { high pressure injection } \\ \text { HPR } & \text { high pressure recirculation } \\ \text { HRA } & \text { human reliability analysis } \\ \text { HSI } & \text { human-system interface } \\ \text { I\&C } & \text { instrumentation and control } \\ \text { IE } & \text { initiating event } \\ \text { INL } & \text { Idaho National Laboratory } \\ \text { ISV } & \text { integrated system validation } \\ \text { JPM } & \text { joberformance measure } \\ \text { LERF } & \text { large early release frequency } \\ \text { LOMFW } & \text { los } \\ & \end{array}$




\begin{tabular}{|c|c|}
\hline LOSC & loss of seal cooling \\
\hline LPI & low pressure injection \\
\hline LPSD & low power and shutdown \\
\hline MAAP & Modular Accident Assessment Program \\
\hline MERMOS & $\begin{array}{l}\text { Méthode d'Evaluation de la Réalisation des Missions Opérateurs pour la } \\
\text { Sûreté }\end{array}$ \\
\hline MFW & main feedwater \\
\hline NPP & nuclear power plant \\
\hline NRC & Nuclear Regulatory Commission \\
\hline ORE & Operator Reliability Experiment \\
\hline$P$ & probability \\
\hline $\mathrm{P}_{\mathrm{c}}$ & probability of failure during cognition \\
\hline $\mathrm{P}_{\mathrm{e}}$ & probability of failure during execution \\
\hline PG\&E & Pacific Gas \& Electric \\
\hline PIF & performance influencing factor \\
\hline PORV & power operated relief valve \\
\hline PPL & Pennsylvania Power and Light \\
\hline PRA & probabilistic risk assessment \\
\hline PSF & performance shaping factor \\
\hline PTS & pressurized thermal shock \\
\hline $\mathrm{P}_{\mathrm{w} / \mathrm{od}}$ & probability without dependence \\
\hline PWR & pressurized water reactor \\
\hline RCS & reactor coolant system \\
\hline S & scenario \\
\hline SCR & secondary cooling recovered \\
\hline SDP & significance determination process \\
\hline SG & steam generator \\
\hline SHARP1 & Systematic Human Action Reliability Procedure (Revision 1) \\
\hline SPAR & Standardized Plant Analysis Risk \\
\hline SPAR-H & Standardized Plant Analysis Risk-Human \\
\hline SR & supporting requirement \\
\hline SRM & Staff Requirements Memorandum \\
\hline SRV & safety relief valve \\
\hline SSC & secondary side cooldown \\
\hline STA & shift technical advisor \\
\hline $\mathrm{T}$ & time \\
\hline TBV & turbine bypass valves \\
\hline THERP & Technique for Human Error Rate Prediction \\
\hline TMI & Three Mile Island \\
\hline TRC & time reliability curve \\
\hline UA & unsafe action \\
\hline V\&V & verification and validation \\
\hline
\end{tabular}




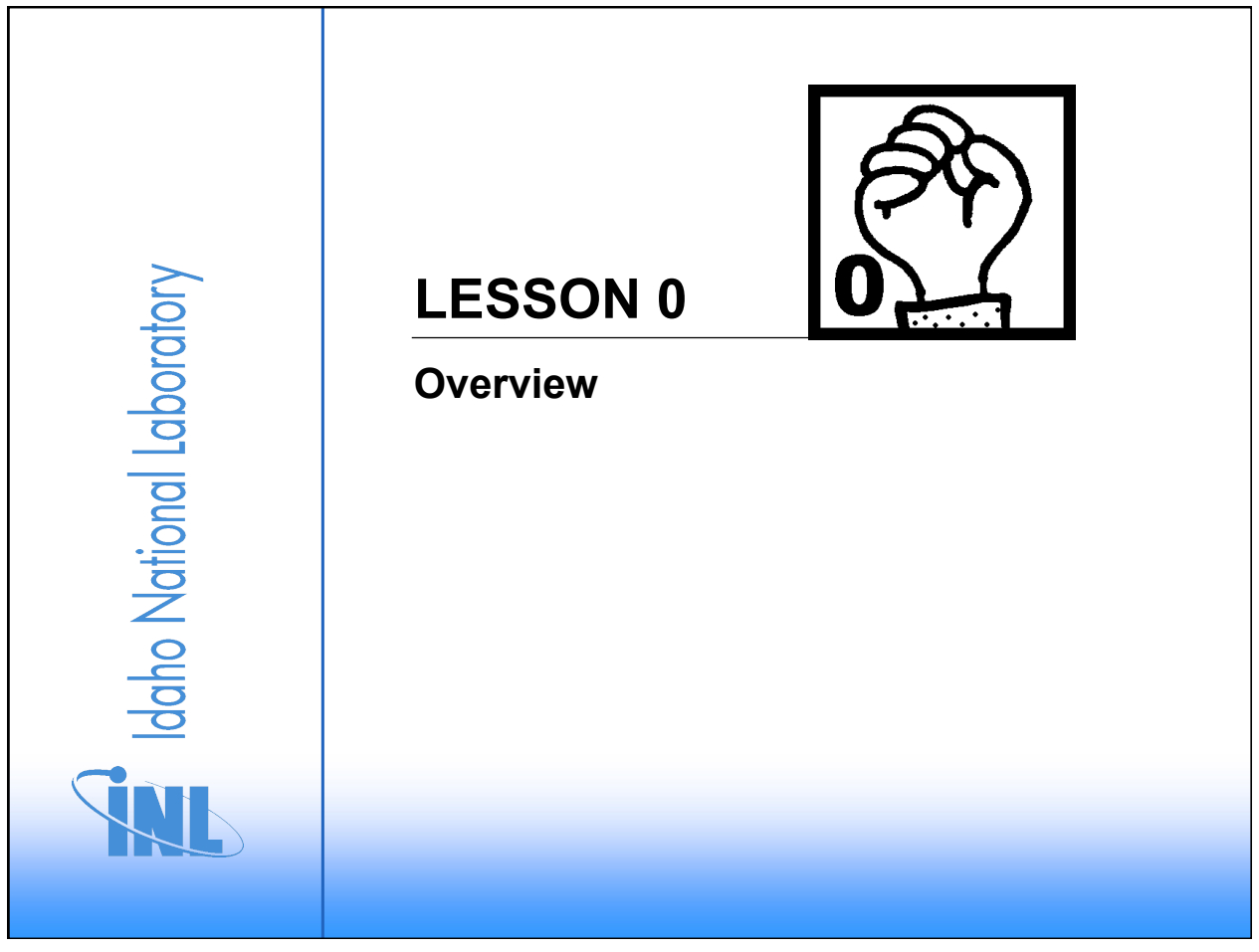

Instructors

- Ronald Boring, PhD

ronald.boring@inl.gov

- David Gertman, PhD

david.gertman@inl.gov 


\section{Author List}

The iterations of this course feature content developed by a number of people over the years, including:

- Ronald Boring (INL)

- Dana Kelly (INL)

- Robert Richards (INL)

- David Gertman (INL)

- Julie Marble (INL)

- Harold Blackman (INL)

- Susan Cooper (NRC)

- Jeffrey Julius (EPRI/Scientech)

- Stuart Lewis (EPRI)

- Alan Swain (Sandia)

- John Forester (Sandia)

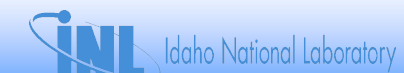

\section{Overall Course Objectives (1)}

At the end of this course, you should be able to:

$\checkmark$ Explain why human reliability analysis (HRA) is needed in developing a probabilistic risk assessment (PRA)

$\checkmark$ Describe how HRA results are integrated into a PRA model

$\checkmark$ Understand the underlying theories of human behavior that influence HRA methods

$\checkmark$ Explain what HRA is, especially in the context of nuclear power plant PRA and risk-informed applications

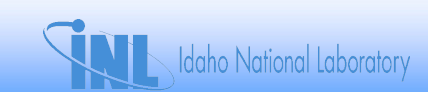




\section{Overall Course Objectives (2)}

At the end of this course, you should be able to:

$\checkmark$ Demonstrate ability to perform HRA by completing inclass exercises

$\checkmark$ List HRA quantification methods used by NRC and in the EPRI HRA calculator

$\checkmark$ Define human error probability (HEP)

$\checkmark$ Define dependency in the context of HRA and explain why consideration of dependency is important

$\checkmark$ Explain what a screening approach to HRA is and when it might be used rather than a detailed method

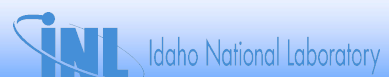

\section{Overall Course Objectives (3)}

At the end of this course, you should be able to (cont.):

$\checkmark$ Demonstrate a reasonable understanding of HRA IEEE and ASME standards and NRC and EPRl good practices

$\checkmark$ Communicate a reasonable, "HRA-informed" understanding of noteworthy events (including different levels of decomposition/analysis for different purposes) 


\section{Table of Contents: Lessons}

0. Overview (This Section)

1. Introduction to Human Reliability Analysis (HRA)

2. Probabilistic Risk Assessment (PRA) and HRA

3. Human Factors and HRA

4. Introduction to Qualitative HRA

5. Introduction to Quantitative HRA

6. The THERP HRA Method

7. The SPAR-H HRA Method

8. EPRI HRA Methods: HCR/ORE and CBDT

9. The ATHEANA HRA Method

10. HRA Review and Advanced Topics

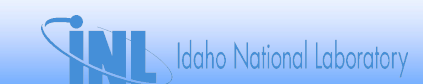

\section{Table of Contents: Appendices}
A. Owning Risk: The Fallible Engineer
B. THERP Table 20
C. THERP Exercise
D. SPAR-H Worksheets
E. SPAR-H Exercise
F. CBDT Background Information
G. CBDT Exercise 


\title{
Course Materials
}

\author{
Course Notes
}

Recommended Readings (Optional)

No Required Textbook

Till

\section{Available Readings in HRA}

- Sidney Dekker, The Field Guide to Understanding Human Error, $3^{\text {rd }}$ Edition, Ashgate, 2015.

- David Gertman \& Harold Blackman, Human Reliability \& Safety Analysis Data Handbook, Wiley Interscience, 1994.

- Erik Hollnagel, David Woods, and Nancy Leveson, Resilience Engineering: Concepts and Precepts, Ashgate, UK, 2006.

- Barry Kirwan, A Guide to Practical Human Reliability Assessment, Taylor \& Francis, 1994.

- James Reason, Human Error, Cambridge University Press, 1990.

- James Reason \& Alan Hobbs, Managing Maintenance Error: A Practical Guide, Ashgate, 2003.

- James Reason, The Human Contribution, Ashgate, 2008.

- Anthony Spurgin, Human Reliability Assessment Theory and Practice, CRC Press, 2009.

- Oliver Sträter, Cognition and Safety: An Integrated Approach to Systems Design and Assessment, Ashgate, 2005. 


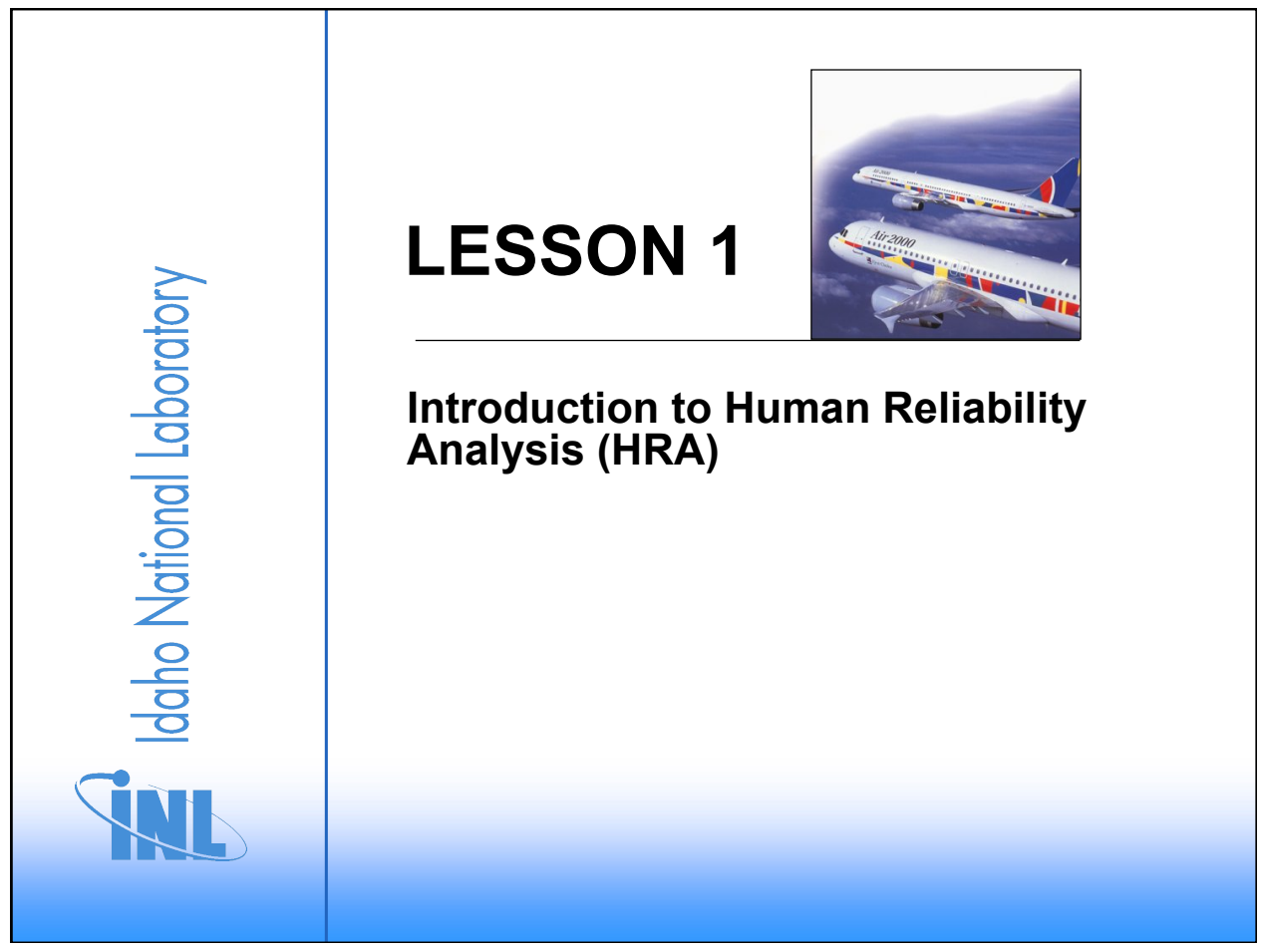

\section{Lesson 1 Objectives}

$\checkmark$ Review risk and reliability concepts and show how they relate to human error

$\checkmark$ Review significant nuclear incidents and underlying human error

$\checkmark$ Review standard terminology in HRA

$\checkmark$ Review brief history of HRA and different HRA methods 


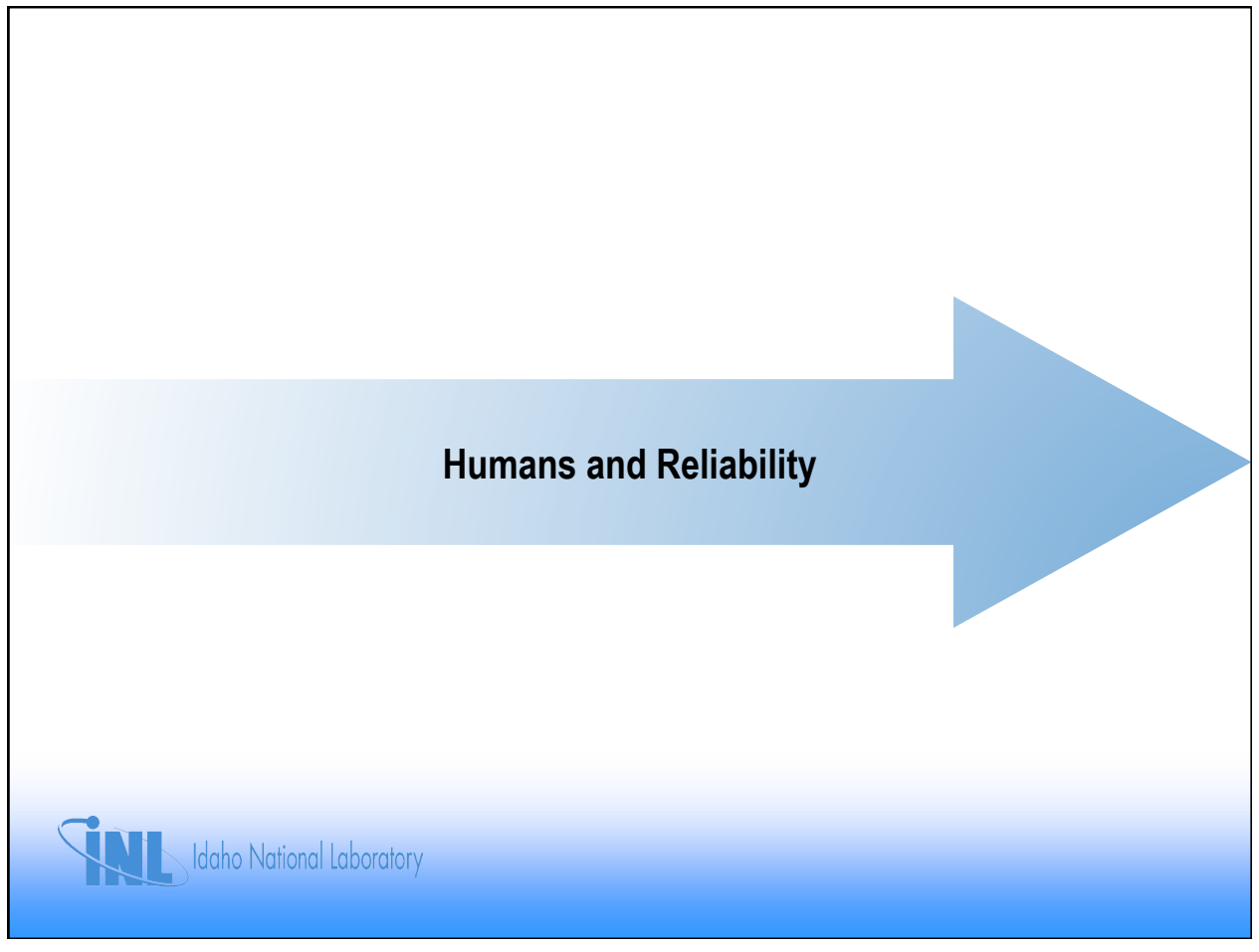

\section{Reliability Engineering}

\section{Reliability $=$ Likelihood of Success}

- A "high reliability" system is one that does not fail frequently

- A "low reliability" system is one that does fail frequently

- Most systems have a reliability life cycle-a product life

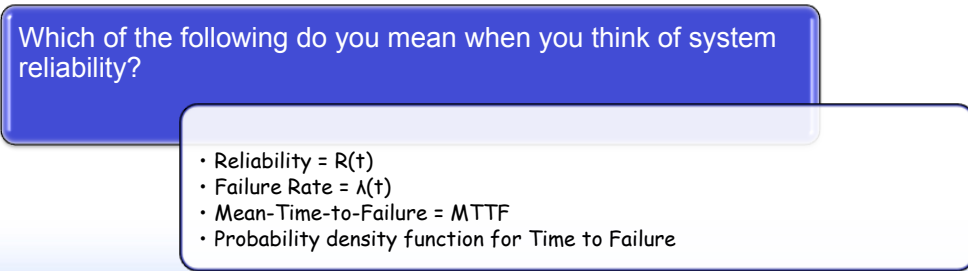

In Idaho National Laboratory 


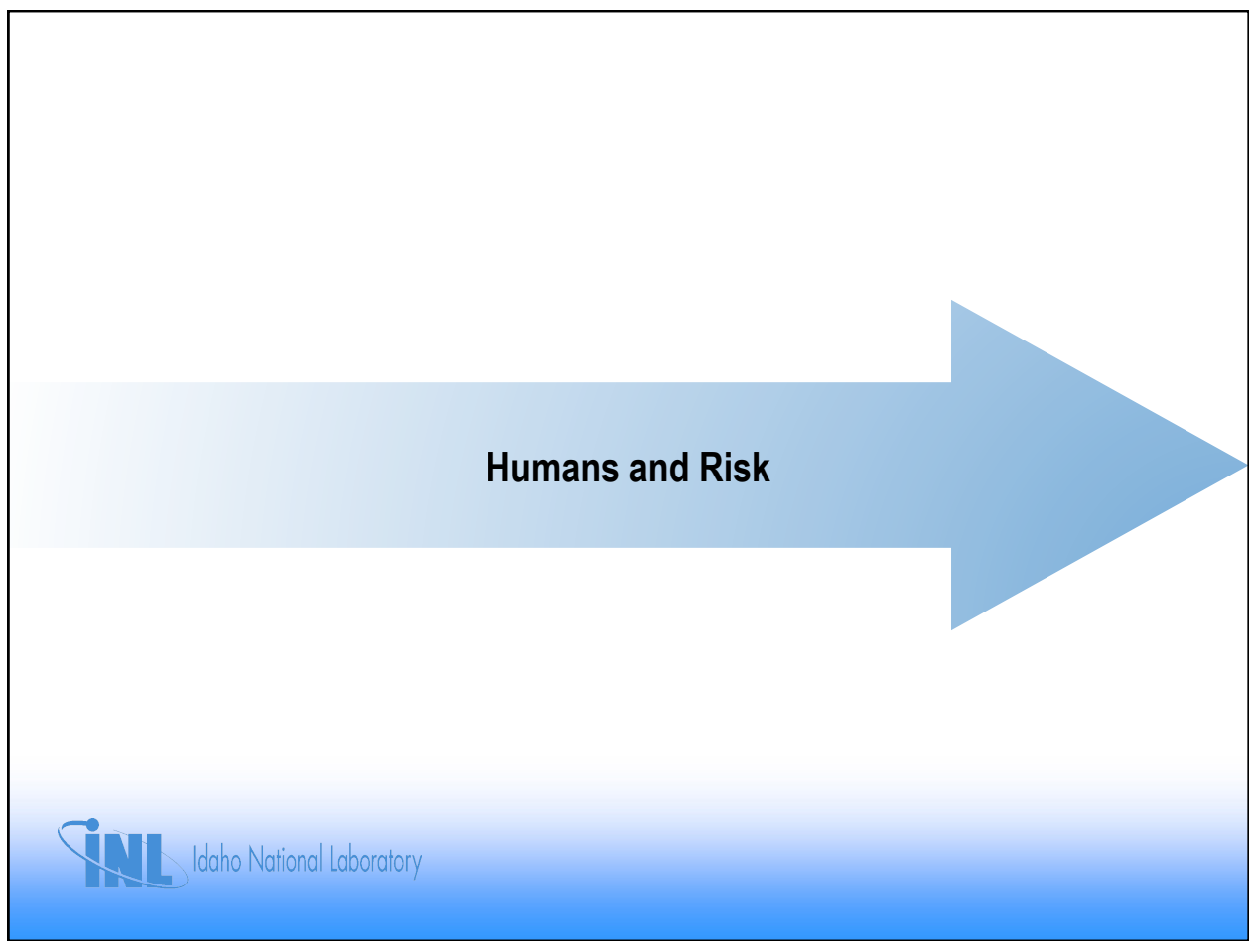

\section{What is Risk?}

\section{Definition of Risk}

- In the simplest of terms, risk is the likelihood of a hazard causing loss or damage

Risk is often framed in terms of the Risk Triplet (Kaplan and Garrick, 1981):

- What can go wrong? (Ścenario)

- What are the consequences? (C)

- How likely is it? (p)

Risk $\equiv\left\{\mathbf{S}_{\mathrm{i}}, \mathrm{C}_{\mathrm{i}}, \mathrm{p}_{\mathrm{i}}\right\}$

- Widely used, e.g.,

- NRC website

- ASME/ANS PRA Standard

\section{Idaho National Laboratory}




\section{What is Risk in Human Terms?}

\section{Definition of Human Risk}

- Risk is the likelihood of a human error causing loss or damage

\section{Definition of Human Error}

- Unwanted actions (or inactions) that deviate from expected and accepted courses of action

Human risk can also be framed in the Risk Triplet:

- What human actions can go wrong?

- What are the consequences of these actions?

- How likely are these actions?

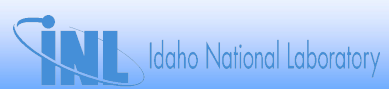

\section{HRA in Risk Assessment: The BIG Picture}

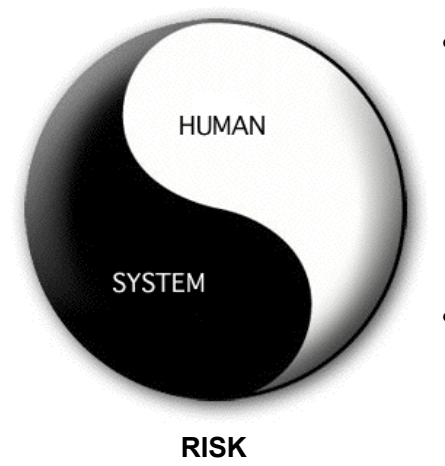

- Risk assessment looks at human-system activities and interactions, and identifies the pathways by which the system mission might fail

- In a number of safety critical applications, people may actually be the predominant source of risk, not the system or hardware 


\section{Definitions:}

Human Reliability Analysis (HRA) is:

- A study of human contribution to overall risk when interacting with a system

- Part of probabilistic risk assessment (PRA) that includes hardware and human reliability

- According to ASME RA-Sb-2013, HRA is:

- "A structured approach used to identify potential human failure events and to systematically estimate the probability of those events using data, models, or expert judgment"

\section{Human Error is Significant Part of Risk}

Percent of Incidents Where Human Error was a Root Cause

\begin{tabular}{ll}
$\rightarrow \quad$ Maritime Industry & $90 \%$ \\
$\rightarrow \quad$ Chemical Industry & $80-90 \%$ \\
$\rightarrow \quad$ Airline Industry & $60-87 \%$ \\
\hline Commercial Nuclear Industry & $65-85 \%$
\end{tabular}

From: D.I. Gertman \& H.S. Blackman, Human Reliability \& Safety Analysis Data Handbook, Wiley-Interscience, 1994.

A 2000 study by the US National Academies suggested medical errors resulted in 44,000-100,000 accidental deaths each year and as many as $1,000,000$ accidental injuries 


\section{Read and Discuss "The Fallible}

Engineer" (Appendix A)

\section{Discussion Topics}

-What happened?

-Who was responsible?

-Where does human error occur?

-Who is to blame?

-What are the implications for reactors?

\section{Siv. Laho National Laboratory}

Incidents in the Nuclear Industry 


\section{Factors Affecting Human Reliability}

\section{What Were Some Human Errors Behind These Events?}

- Three Mile Island

- Chernobyl

- Davis Besse

- H. B Robinson Fire

- Fukushima Dai-Ichi

\section{Three Mile Island (TMI)}

March 28, 1979, Londonderry Township, Pennsylvania:

- Minor malfunction in the secondary cooling circuit caused the Unit 2 reactor to shut down automatically. Backup system not initially available because of human failure to restore system. Pressurizer relief valve failed to close, but instrumentation did not reveal this, and much of the primary coolant was lost through the stuck-open relief valve. Because of failure to understand physics of what was happening in the reactor vessel, operators secured inventory makeup, and the residual decay heat in the reactor core caused partial meltdown and small release of fission products offsite
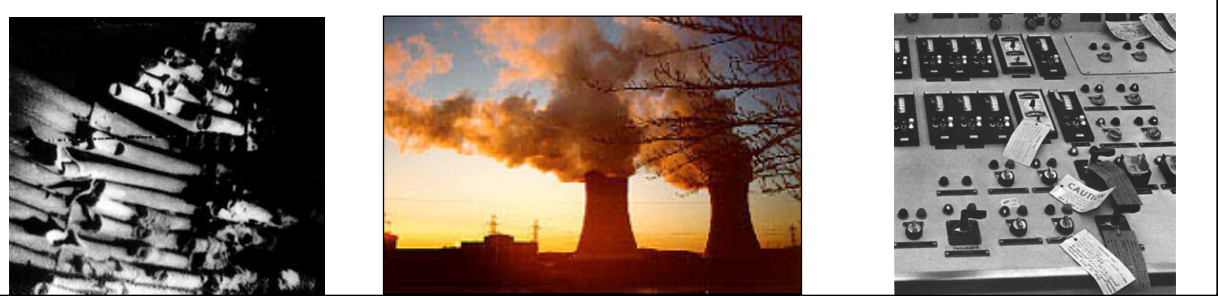


\section{Human Contributors to TMI}

- Poor human factors

- Valve indicator lights for pressurizer relief valve did not show true position of valve

- Limited training of personnel

- Lack of integrated plant knowledge led to inability to interpret additional cues about what was happening to the plant

- Too much emphasis placed on avoiding solid pressurizer

- Led to securing safety injection

- Overreliance on limited set of indicators

\section{Siv. Idoho National Laboratory}

\section{Chernobyl}

April 26, 1986, Pripyat, Ukraine:

- A poorly planned test of the ability of the turbine to provide power for cooling during spindown was executed late at night, and under time pressure. Key safety systems were disabled for the test, which shut down all core cooling, causing an uncontrolled nuclear reaction, meltdown, and significant radioactive release.
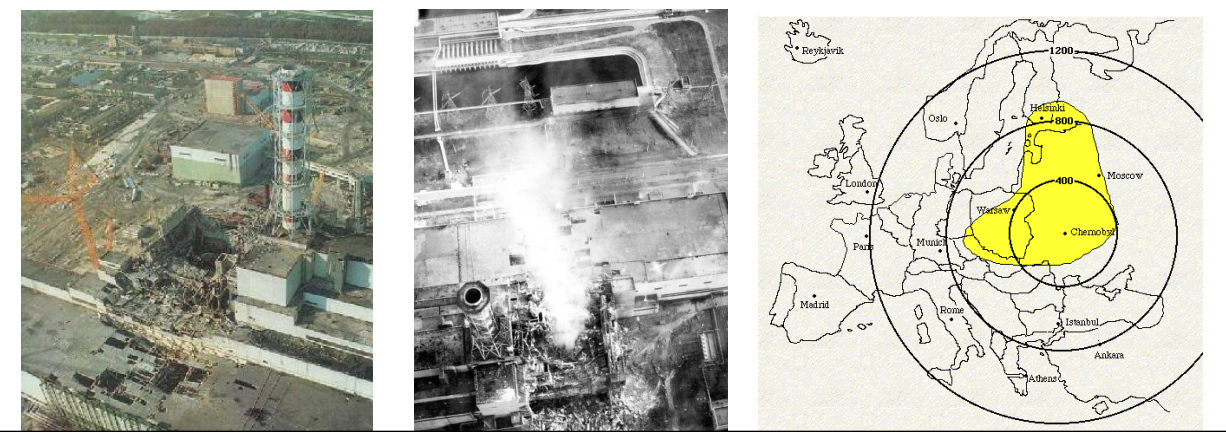


\section{Human Contributors to Chernobyl}

TABLE I

The Most Dangerous Violations of Operating Procedures AT CHERNOBYL-4*

\begin{tabular}{|c|c|c|c|}
\hline & Violation & Motivation & Consequence \\
\hline 1 & $\begin{array}{l}\text { Reducing operational } \\
\text { reactivity margin below } \\
\text { permissible limit }\end{array}$ & $\begin{array}{l}\text { Attempt to overcome } \\
\text { xenon poisoning }\end{array}$ & $\begin{array}{l}\text { Emergency protection } \\
\text { system was ineffective }\end{array}$ \\
\hline 2 & $\begin{array}{l}\text { Power level below that } \\
\text { specified in test program }\end{array}$ & $\begin{array}{l}\text { Error in switching } \\
\text { off local auto-control }\end{array}$ & Reactor difficult to control \\
\hline 3 & $\begin{array}{l}\text { All circulating pumps on with } \\
\text { some exceeding authorized } \\
\text { discharge }\end{array}$ & Meeting test requirements & $\begin{array}{l}\text { Coolant temperature close } \\
\text { to saturation }\end{array}$ \\
\hline 4 & $\begin{array}{l}\text { Blocking shutdown signal } \\
\text { from both turbogenerators }\end{array}$ & $\begin{array}{l}\text { To be able to repeat tests } \\
\text { if necessary }\end{array}$ & $\begin{array}{l}\text { Loss of automatic } \\
\text { shutdown possibility }\end{array}$ \\
\hline 5 & $\begin{array}{l}\text { Blocking water level and } \\
\text { steam pressure trips from } \\
\text { drum-separator }\end{array}$ & $\begin{array}{l}\text { To perform test despite } \\
\text { unstable reactor }\end{array}$ & $\begin{array}{l}\text { Protection system based on } \\
\text { heat parameters lost }\end{array}$ \\
\hline 6 & $\begin{array}{l}\text { Switching off emergency core } \\
\text { cooling system }\end{array}$ & $\begin{array}{l}\text { To avoid spurious } \\
\text { triggering of ECCS }\end{array}$ & $\begin{array}{l}\text { Loss of possibility to } \\
\text { reduce scale of accident }\end{array}$ \\
\hline
\end{tabular}

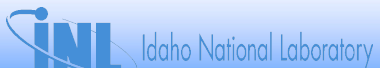

\section{Davis Besse}

\section{February 16, 2002, Oak Harbor, Ohio:}

- During refueling outage, inspection of vessel head penetration nozzles revealed that 3 control rod drive mechanism nozzles had through-wall axial cracking. Cracking was caused by borated water that had leaked from reactor coolant system to vessel head. Remaining thickness of vessel head found to be only $3 / 8$ inch thick stainless steel cladding. Rupture of cladding would have resulted in LOCA and potential damage to control rod drive mechanisms. The NRC investigation found there was ongoing evidence of boric acid corrosion, which had been systematically overlooked, and appropriate maintenance had been deferred.

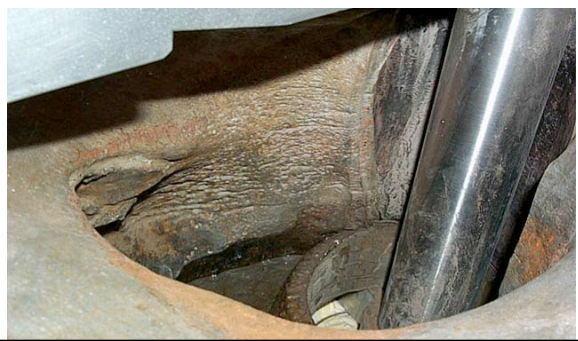




\section{Human Contributors to Davis Besse}

- Deferred maintenance

- Upcoming plant outage, causing workarounds

- Workarounds

- Indications of significant corrosion ignored

- Safety culture

- Lack of questioning attitude and acceptance of status quo at plant

- Persistence of multiple events

\section{H.B. Robinson}

\section{March 28, 2010, Hartsville, South Carolina:}

- During normal operations, the plant sustained damage to two 4$\mathrm{kV}$ buses and the unit auxiliary transformer when an arc flash occurred in a cable conduit and the bus supply circuit breaker failed to trip open on overcurrent. During recovery activities, operators inappropriately reset the main generator lockout relay, re-energizing the faulted bus, causing additional damage to electrical switchgear and a second electrical fire. An Alert was declared because the fire resulted in degraded safetyrelated systems required to achieve and maintain safe shutdown conditions.
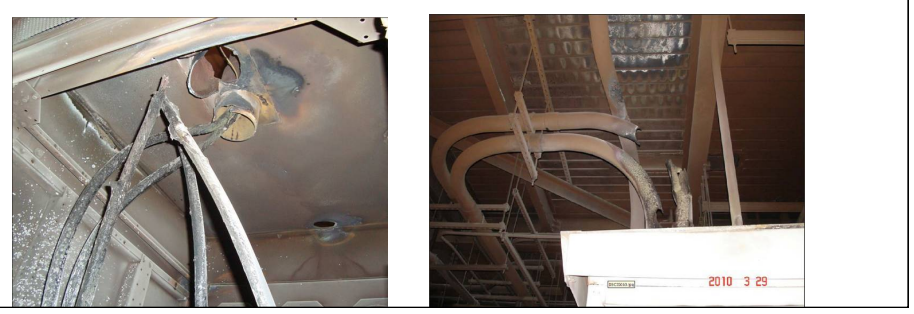


\section{Human Contributors to H.B. Robinson}

- The operating crew did not effectively manage resources to simultaneously handle the fire and plant transient

- Control room operators did not effectively monitor important control board indications and act promptly to control key plant parameters

- Previous simulator training conditioned the crewmembers with incorrect plant response

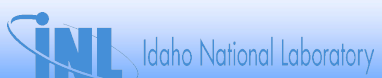

\section{Fukushima Dai-Ichi}

March 11, 2011, Fukushima, Japan:

- Offshore earthquake followed by $12 \mathrm{~m}$ tsunami wave damaged plant and disrupted offsite and backup power needed to cool reactor

- Crews lost all instrumentation and controls in control room

- Failed to restore power, resulting in hydrogen explosions and three reactor meltdowns and spent fuel leaks
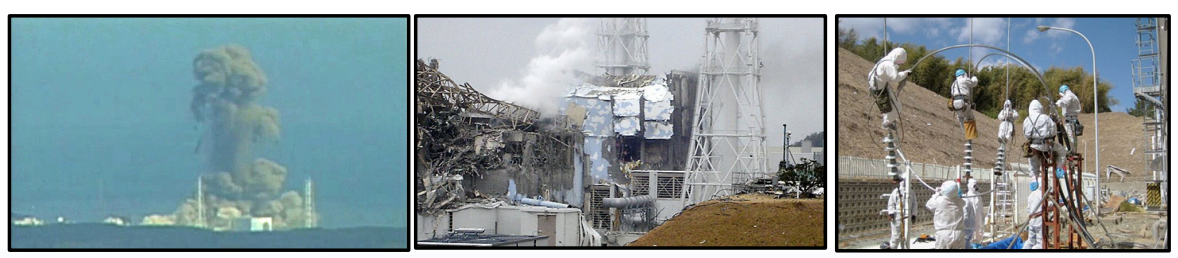

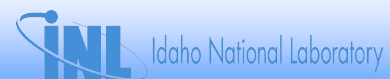




\section{Human Contributors to Fukushima}

- The plant was not designed to withstand a tsunami of that magnitude

- Plant safety backup systems such as emergency generators were equally vulnerable

- Crew and first responders not well trained on this magnitude of emergency response

- Authorities slow to react to event

- Failure to prioritize emergency response to plant in face of large scale damages in Japan

\section{NRC Response to Fukushima}

- ACRS - "indicate a potential industry trend of failure to maintain equipment and strategies required to mitigate some design and beyond design basis events"

- Outside reviewers - the venting from containment to reactor building is questionable (should vent to the atmosphere);SFP should have been inside containment, lack of availability of robots in a country that leads in that area - D'Auria et al (2012) 


\section{National Academies Report Recommendations (1)}

Recommends improving the availability, reliability, redundancy, and diversity of specific nuclear plant systems:

- DC power for instrumentation and safety system control

- Tools for estimating real-time plant status during loss of power

- Reactor heat removal, reactor depressurization, and containment venting systems and protocols

- Instrumentation for monitoring critical thermodynamic parameters including spent-fuel pools

- Hydrogen monitoring

- Communications and real-time information systems

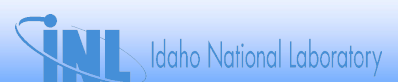

\section{National Academies Recommendations (2)}

- Strengthen and better integrate emergency procedures and severe accident guidelines

- More attention to training for operators and emergency response organizations (EROs)

- NRC and industry should strengthen their capabilities to identify, evaluate and manage the risks associated with beyond design basis events

- "They should pay particular attention to beyond design basis events that involve multiple nuclear power plants" (Recommendation $5.2 \mathrm{C}, \mathrm{p}$ 10)

*Historically, HRA methods don't account for severe damage to infrastructure, lack of real time information, involvement of EROs, crew ability to improvise, and where damage involves multiple reactor units.

- These are emerging topics being researched in HRA 


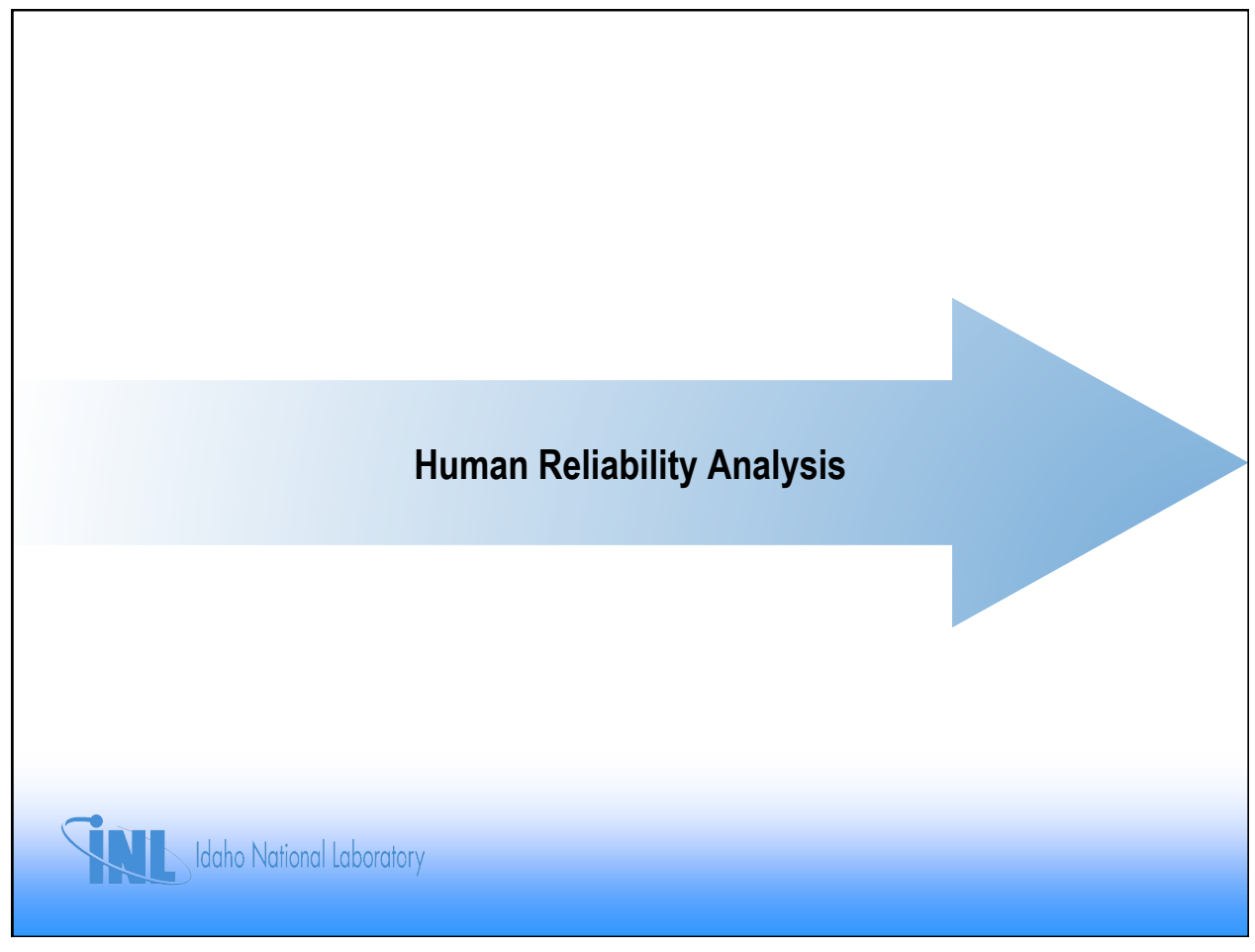

\section{Common Elements of HRA}

- human error (HE): any human action that exceeds some limit of acceptability, including inaction where required, excluding malevolent behavior

- human error probability (HEP): a measure of the likelihood that plant personnel will fail to initiate the correct, required, or specified action or response in a given situation, or by commission performs the wrong action. The HEP is the probability of the HFE

- human failure event (HFE): a basic event that represents a failure or unavailability of a component, system, or function that is caused by human inaction, or an inappropriate action

- performance shaping factor (PSF): a factor that influences human error probabilities as considered in a PRA's human reliability analysis and includes such items as level of training, quality/ availability of procedural guidance, time available to perform an action, etc.

Source: ASME/ANS RA-Sb-2013 


\section{Three General Phases of HRA}

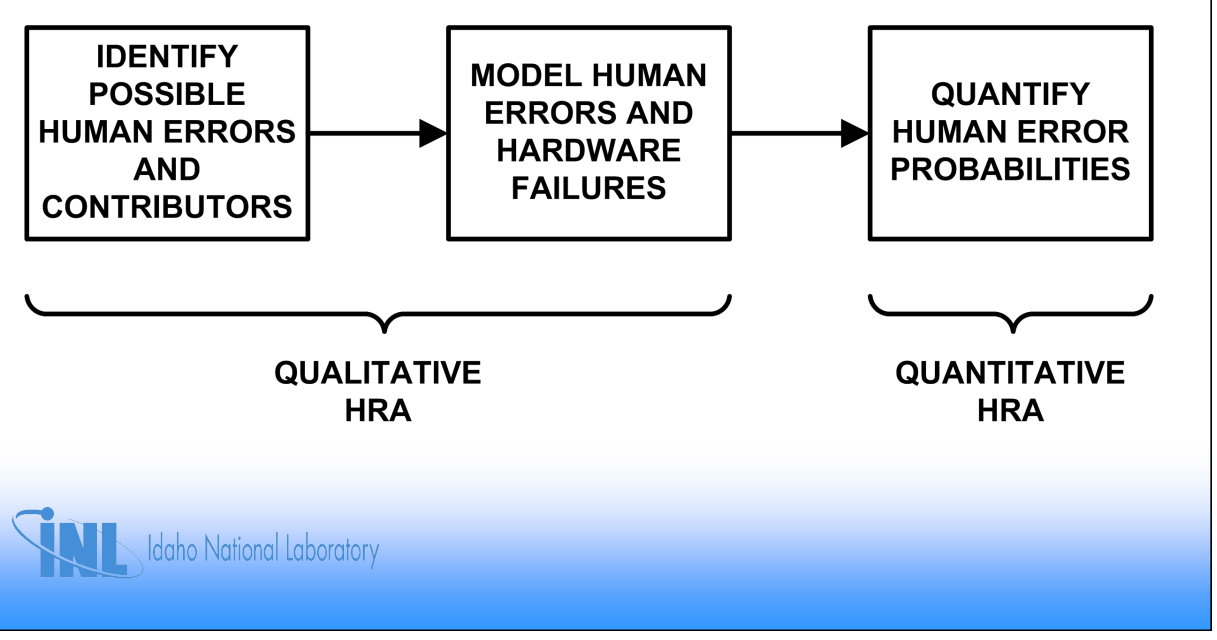

\section{Qualitative v. Quantitative HRA}

Qualitative HRA

- Focused on identification and modeling of the human failure event (HFE)

- Commonly employs some form of task analysis to identify potential human errors (HEs)

- Commonly looks at performance shaping factors (PSFs)

Quantitative (Probabilistic) HRA

- Focused on producing human error probability (HEP)

- Screening analysis performed for all HFEs

- Detailed quantitative analysis for subset of all HFEs (several dozen in typical commercial reactor HRA)

Qualitative and quantitative HRA are complementary

- Qualitative HRA supports detailed quantification especially

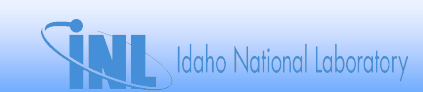




\section{Some Context}

PRA - Probabilistic Risk Assessment = Hardware and environmental contribution to risk

$\downarrow$

HRA - Human Reliability Analysis = Human

contribution to risk

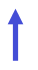

HF - Human Factors = Study of human performance when using technology

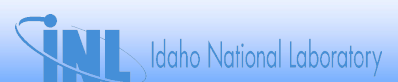

\section{When to Apply HRA}

\section{Retrospective HRA}

- Focused HRA to help identify risk significance of past incidents

- Estimate HEPs for salient HFEs given the context

- Identify ways to lessen likelihood of recurrence of incident

- Example: NRC's Significance Determination Process (SDP)

Prospective HRA

- Identify, model, and quantify HFEs in PRA more broadly to estimate risk

- Example: Licensee PRAs 


\section{HRA}

Is Developed Because:

- PRA reflects the as-built, as-operated plant

- HRA is needed to model the "as-operated" portion (and crosscuts many PRA tasks and products)

Produces:

- Identified and defined human failure events (HFEs)

- Qualitative evaluation of factors influencing human errors and successes

- Human error probabilities (HEPs) for each HFE

Contains:

- Qualitative and Quantitative aspects
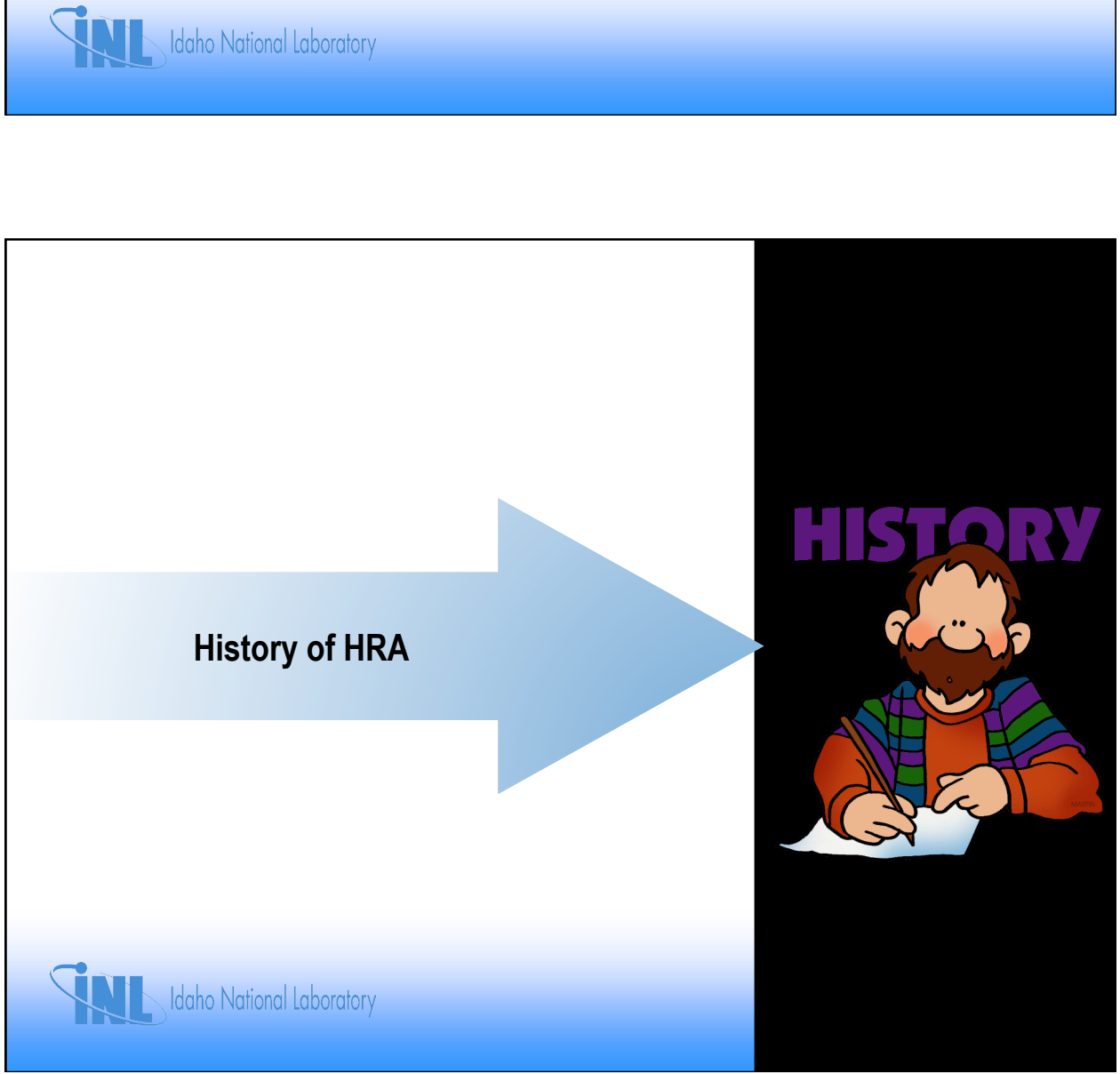


\section{History of HRA (Sample of Methods)}

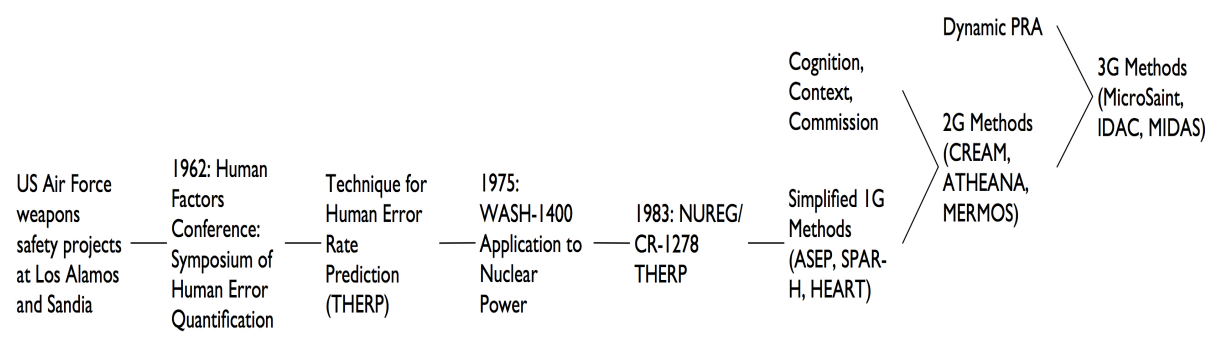

\section{STI Idaho National Laboratory}

\section{History of HRA}

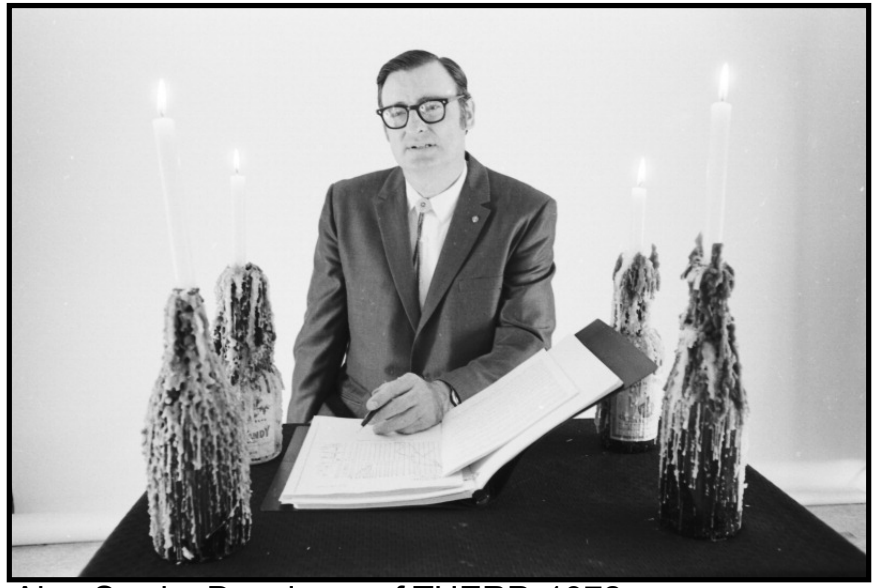

Alan Swain, Developer of THERP, 1972

\section{MTII Idaho National Laboratory}




\section{Three Generations of HRA}

- Numerous distinctions have been posited

- The four classificatory Cs of generational HRA distinguish first and second generation HRA:

\begin{tabular}{|c|c|c|}
\hline Classification & $\mathbf{1 G}$ & $\mathbf{2 G}$ \\
\hline Cognition & $\times$ No & $\checkmark$ Yes \\
\hline Context & $\times$ No & $\checkmark$ Yes \\
\hline Commission & $\times$ No & $\checkmark$ Yes \\
\hline Chronology & $\times$ Older & $\checkmark$ Newer \\
\hline
\end{tabular}

- Dynamic modeling approaches have been suggested as the third generation

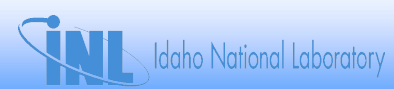

\section{Evolution of Selected HRA Methods}

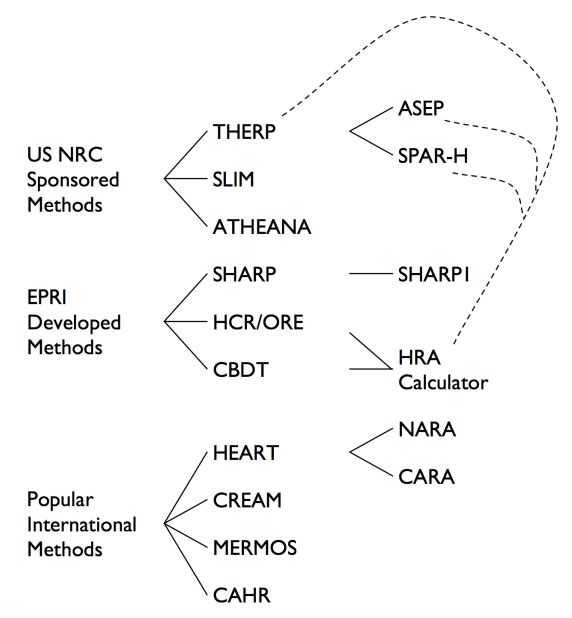

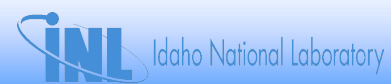




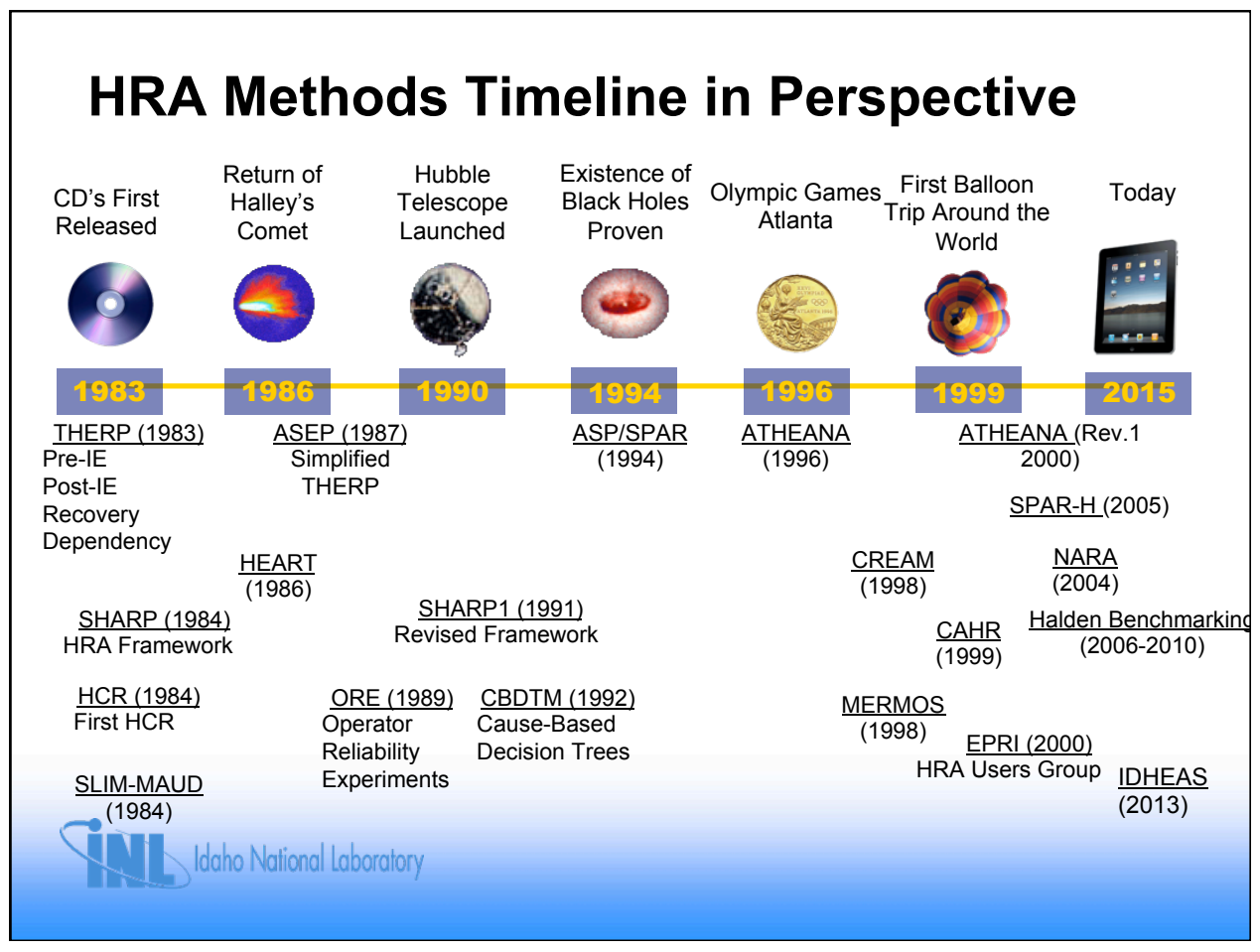

\section{Why So Many Different HRA Methods?}

Different Applications Have Refined HRA Through New Methods

- HRA methods developed for different purposes

- ASEP developed as simplified version of THERP

- SPAR-H developed to create method suitable for SDP and ASP

- ATHEANA originally developed in attempt to address errors of commission during low power/shutdown including decisions

- EPRI's CBDT developed for cognitive errors (e.g., diagnosis) for which time was not a driving influence on performance

- Complement to time-reliability correlation

- CREAM developed to better account for cognition

- MERMOS developed to address computerized procedures at EDF's N4 reactors

- CAHR developed in conjunction with German automobile industry 


\section{Lesson 1 Review}

- What is the Risk Triplet? How is it applied in HRA vs. PRA?

- What were the major human contributions to Three Mile Island, Chernobyl, Davis Besse, H.B. Robinson, and Fukushima?

- How is HRA defined?

- What are human failure events?

- What is a human error probability?

- What is qualitative vs. quantitative HRA?

- What is the difference between prospective and retrospective HRA?

- What's commonly considered the first HRA method?

- Why are there different HRA methods?

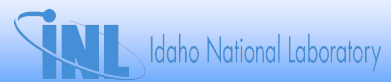

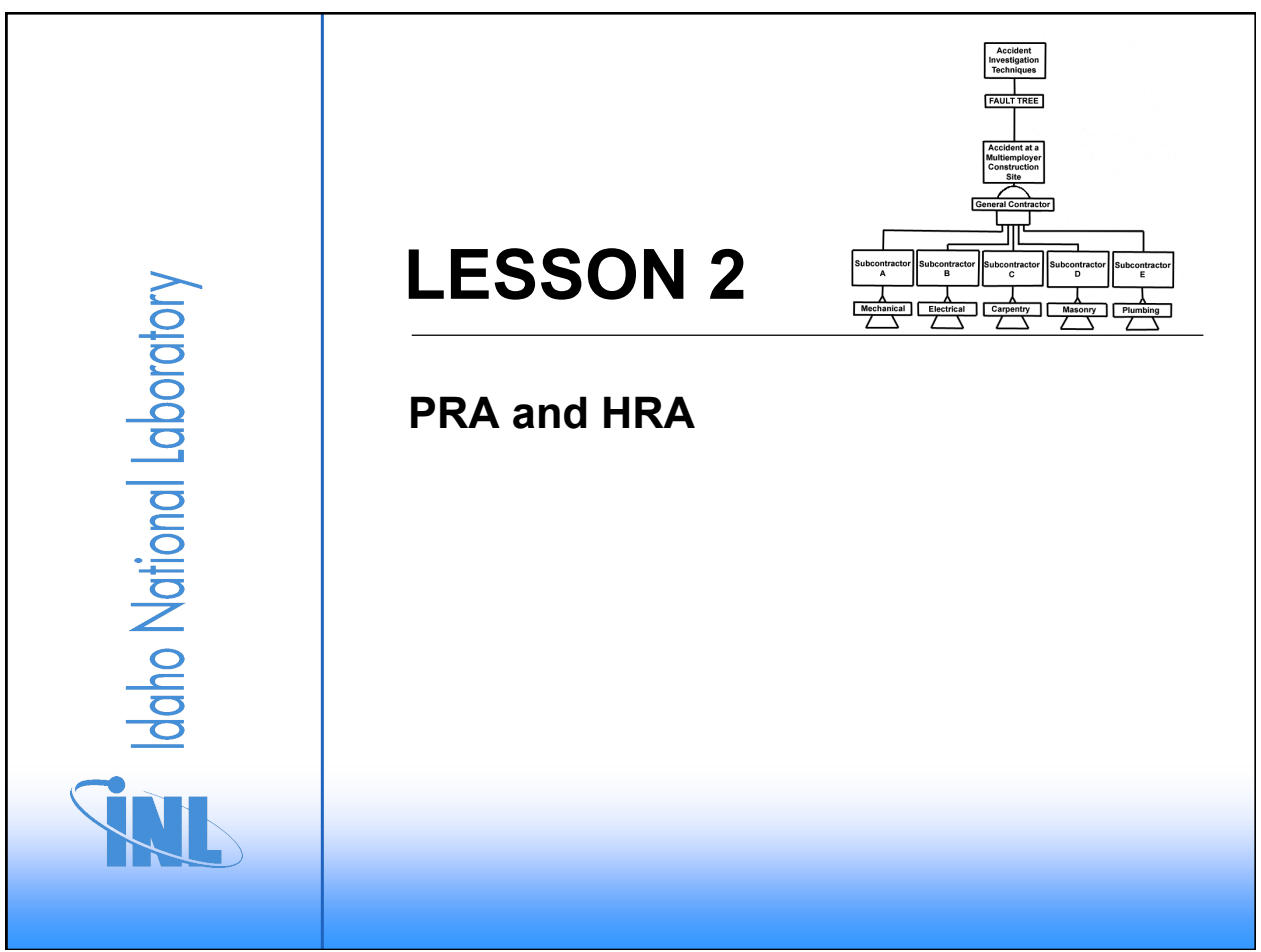




\section{Lesson 2 Objectives}

Describe process for integrating HRA with PRA

$\checkmark$ Provide example of how HRA is integrated into PRA

$\checkmark$ Overview integration approaches and guidance

- SHARP1

- IEEE 1082 Standard

- ASME/ANS PRA Standard

- HRA Good Practices (NUREG-1792)

\section{Till imbersent}

\section{What is PRA?}

Probabilistic risk assessment (PRA)

- Qualitative and quantitative assessment of the risk associated with the plant/system/process of interest

- Used to support risk-informed decision-making

- Models, methods, tools, and data are dependent on decision problem as well as plant/system/process

- Event tree/fault tree approach typical but not required

- Typically need to deal with unlikely scenarios, potentially with high consequences

PRA should reflect the as-built, as-operated plant

- HRA models the "as-operated" portion

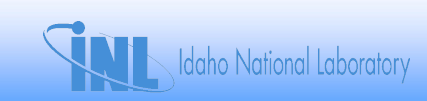




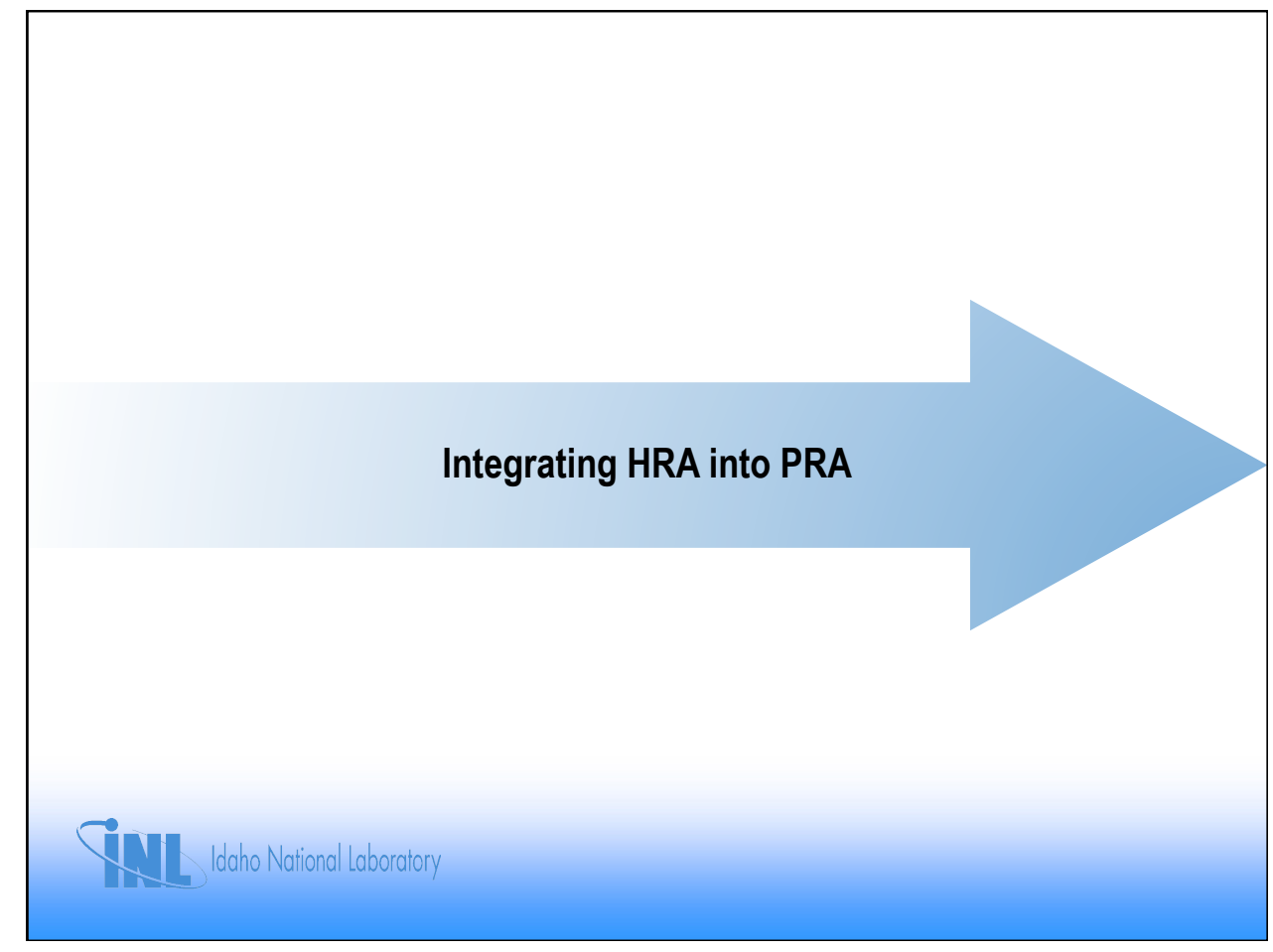

\section{How Does HRA Fit into PRA?}

- HRA starts with the basic premise that operators can be represented as either:

- A component of a system, or

- A failure mode of a system or component

- In terms of PRA models, operator failures can be:

- A top event in an event tree

- A basic event in a fault tree

- HRA identifies and quantifies the ways in which human actions initiate, propagate, or terminate fault and accident sequences

- Human actions with both positive and negative impacts are considered in striving for realism

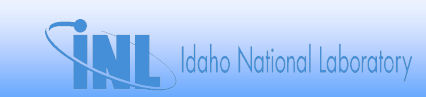




\section{Operator Actions in PRA}

The impacts of plant personnel actions are reflected in the PRA in such a way that:

- Both pre-initiating events and post-initiating events, including those modeled in linked system fault trees, are addressed

- Logic model elements are defined to represent the effect of such personnel actions on system availability (or unavailability) and on accident sequence development

- Plant-specific and scenario-specific factors are accounted for, including those factors that influence what activities are of interest or human performance

\section{Categories of HFEs (1)}

Operator actions can occur throughout the accident sequence:

- Before the initiating event (i.e., pre-initiator)

- Can cause the initiating event

- Occur after the initiating event (i.e., post-initiator)

Pre-initiator errors (or "latent errors")

- Not revealed or discovered until after initiating event occurs

- Usually occur outside the control room

- Examples:

- Failure to restore (both function \& configuration) following routine testing

- Failure to restore (both function \& configuration) following preventive maintenance

- Miscalibration of instruments, set points, etc.

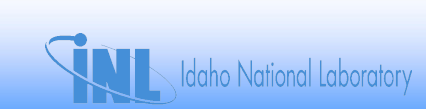




\section{Categories of HFEs (2)}

Operator actions can contribute to or cause initiating events (i.e., humaninduced initiators)

- Usually, these failures captured implicitly via inclusion in the data used to quantify initiating event frequencies

- For operating modes other than "full-power" or "at-power," however, humancaused initiating events can be significant (e.g., shutdown)

\section{Post-initiator errors occur after reactor trip}

- Represent failed operation of systems/components from the control room or locally

- Represent failures of actions required by Emergency Operating Procedures (EOPs), e.g.,

- Operation of systems/components that have failed to operate automatically, or require manual operation

- "Event Tree top event" operator failures modeled in the event trees (e.g., failure to depressurize the RCS in accordance with EOPS)

\section{Idaho National Laboratory}

\section{Other Ways to Categorize HFEs}

\section{Errors of omission (EOOs):}

- A human failure event resulting from a failure to take a required action, leading to an unchanged or inappropriately changed and degraded plant state (ASME)

- Example: Failure to open manual relief valve

Errors of commission (EOCs):

- A human failure event resulting from a well-intended but inappropriate, overt action that, when taken, leads to a change in the plant and results in a degraded plant state (ASME)

- Often, these events represent "good" operating practice, but applied to the wrong situation (especially, when understanding the situation is difficult)

- Example: Prematurely terminating safety injection because operators are concerned with overfilling the pressurizer ("going solid") 


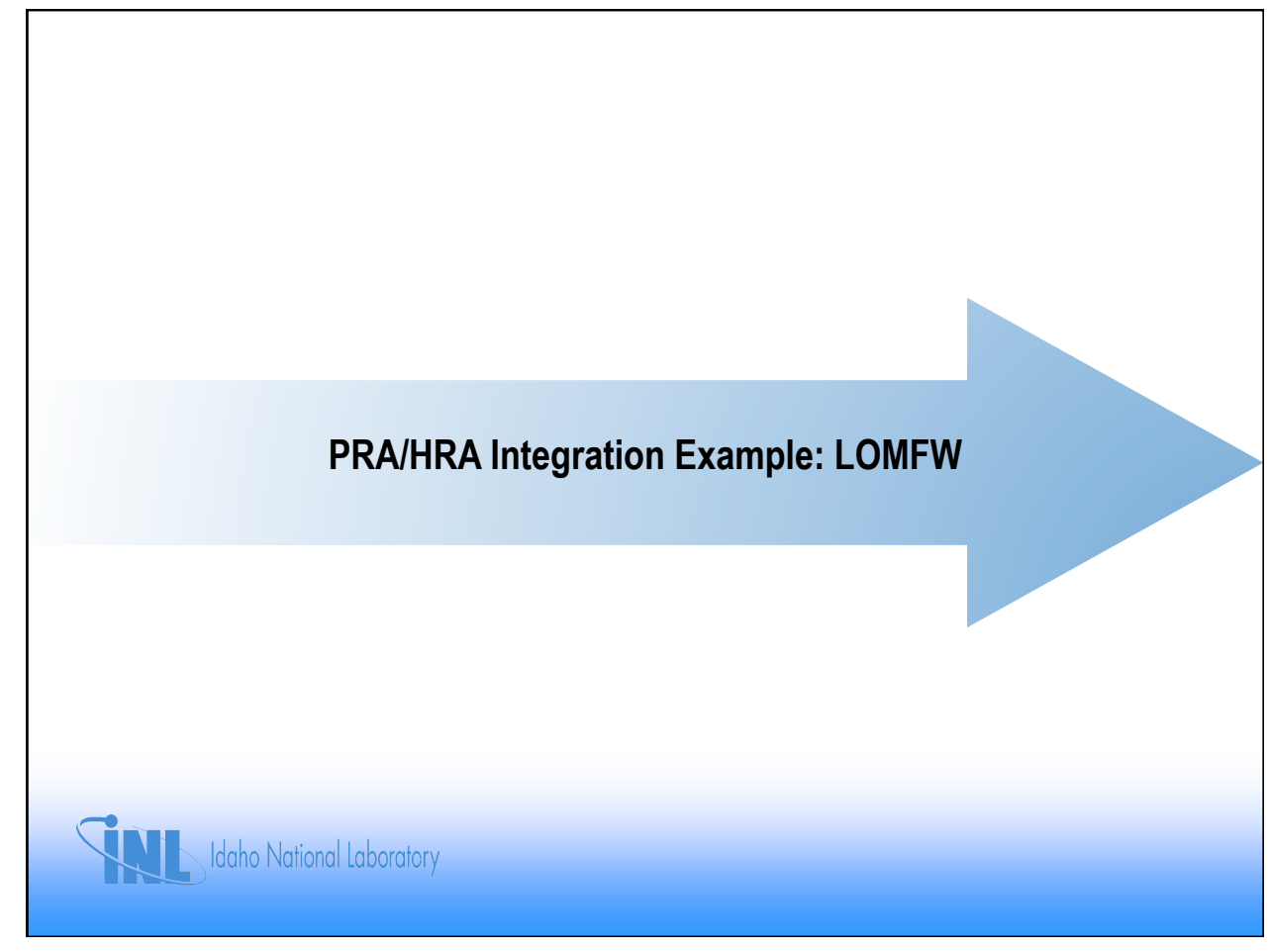

\section{Loss of Main Feedwater (LOMFW)}

- Safety functions required to prevent core damage

- Successful reactivity control

- Early decay heat removal and inventory control

- Long-term decay heat removal

- If the reactor fails to trip following the transient event, then the sequence transfers to the anticipated transient without scram (ATWS) event tree

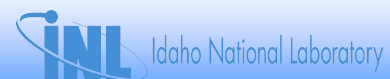




\section{Success Criteria for LOMFW}

- Successful operation of secondary cooling (emergency feedwater or EFW) can place the reactor in a stable condition provided no pressurizer power operated relief valves (PORV) or safety relief valves (SRV) open

- If a PORVISRV opens and fails to reclose, high pressure injection (HPI) is required to provide makeup flow to replenish the reactor coolant system (RCS)

- If HPI succeeds, then long term cooling is required. Long-term cooling is provided by either the low pressure injection (LPI) system in decay heat removal (DHR) mode in conjunction with RCS depressurization, or high pressure sump recirculation (HPR if the RCS is not depressurized)

\section{Success Criteria for LOMFW}

- Feed-and-bleed (FAB) cooling can provide successful decay heat removal if EFW is unavailable to remove heat from the secondary

- Feed-and-bleed cooling requires one PORV and one SRV or two SRVs to open and remove the decay heat while HPI provides makeup flow to replenish the lost RCS inventory 


\section{Event Tree Structure}

- The event tree structure represents the relationships among three functional event groupings

- The first grouping is reactor shutdown as represented by the RPS top event

- The next grouping is early decay heat removal/inventory control as represented by the EFW or main feedwater (MFW), FAB, and HPI events

- The final event grouping is long-term cooling as represented by the EFW or MFW, DHR, and HPR events

\section{LOMFW Event Tree}

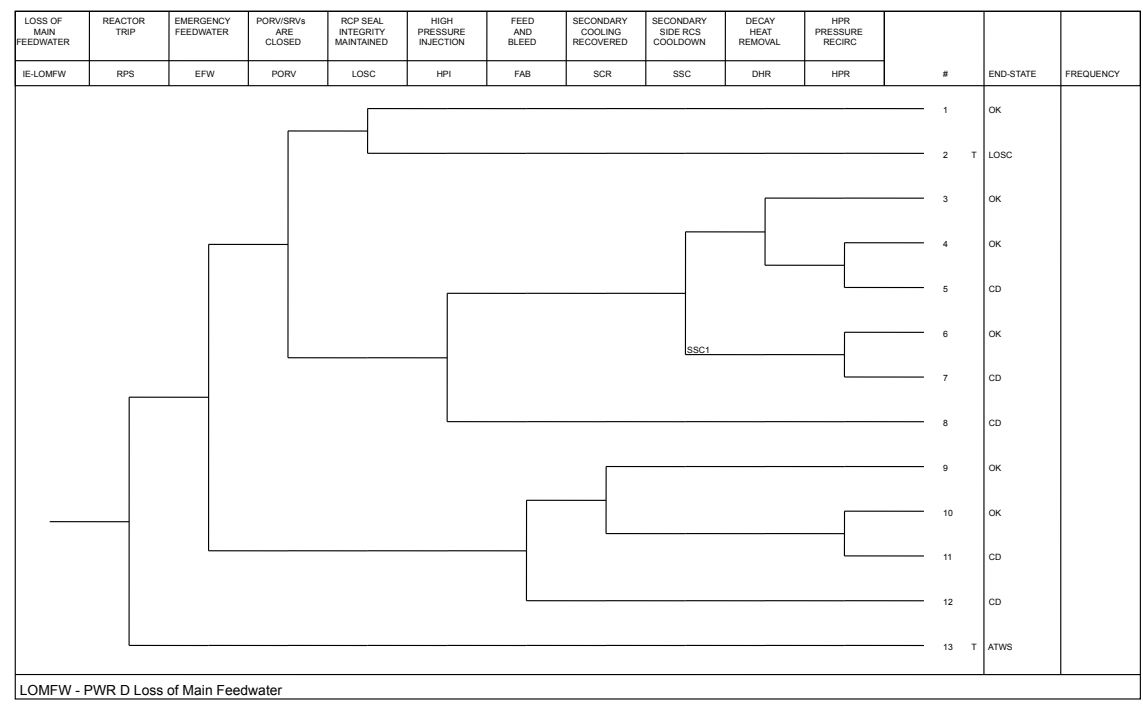




\section{LOMFW Event Tree}

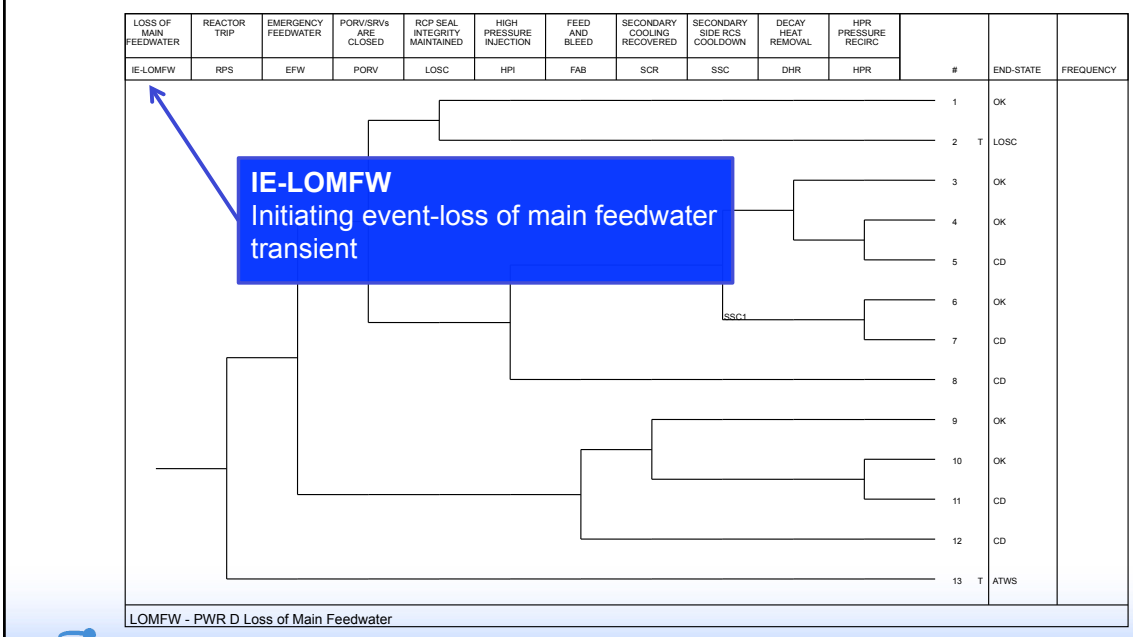

\section{LOMFW Event Tree}

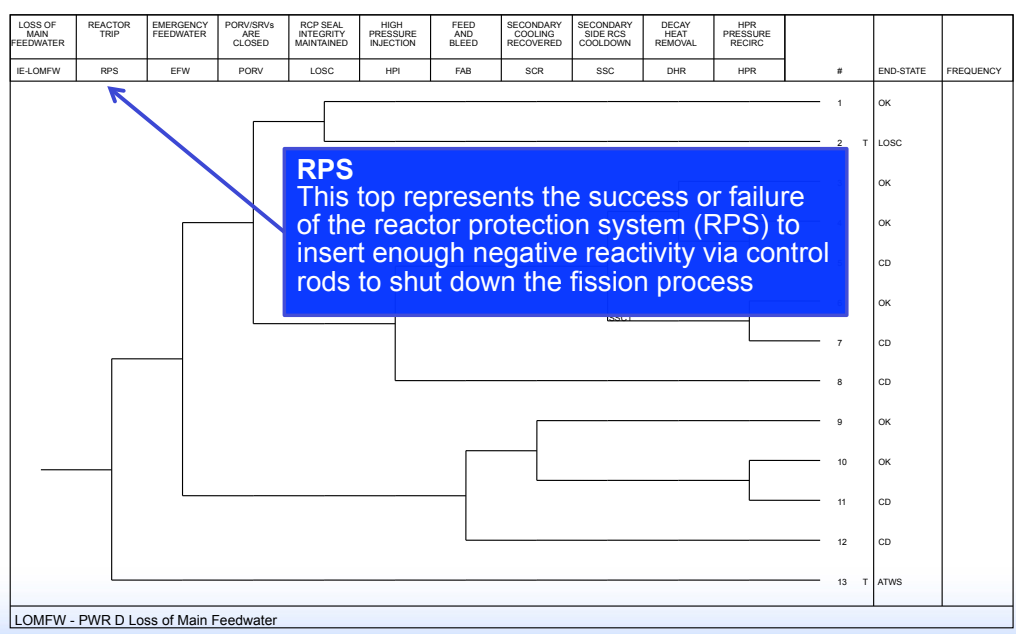

Idaho National Laboratory 


\section{LOMFW Event Tree}

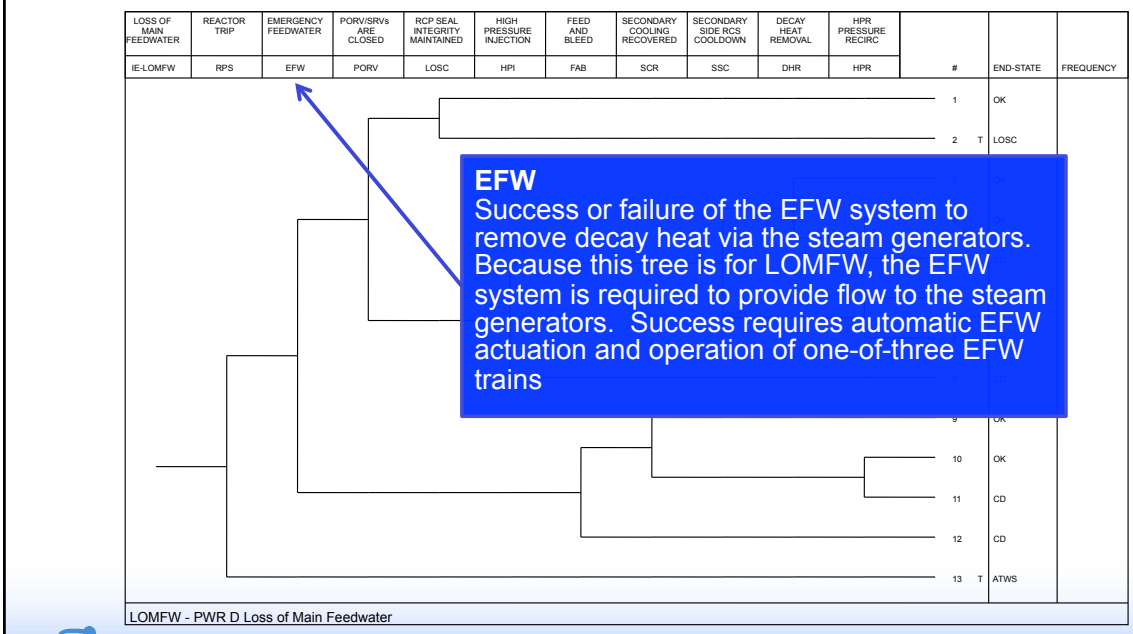

\section{LOMFW Event Tree}

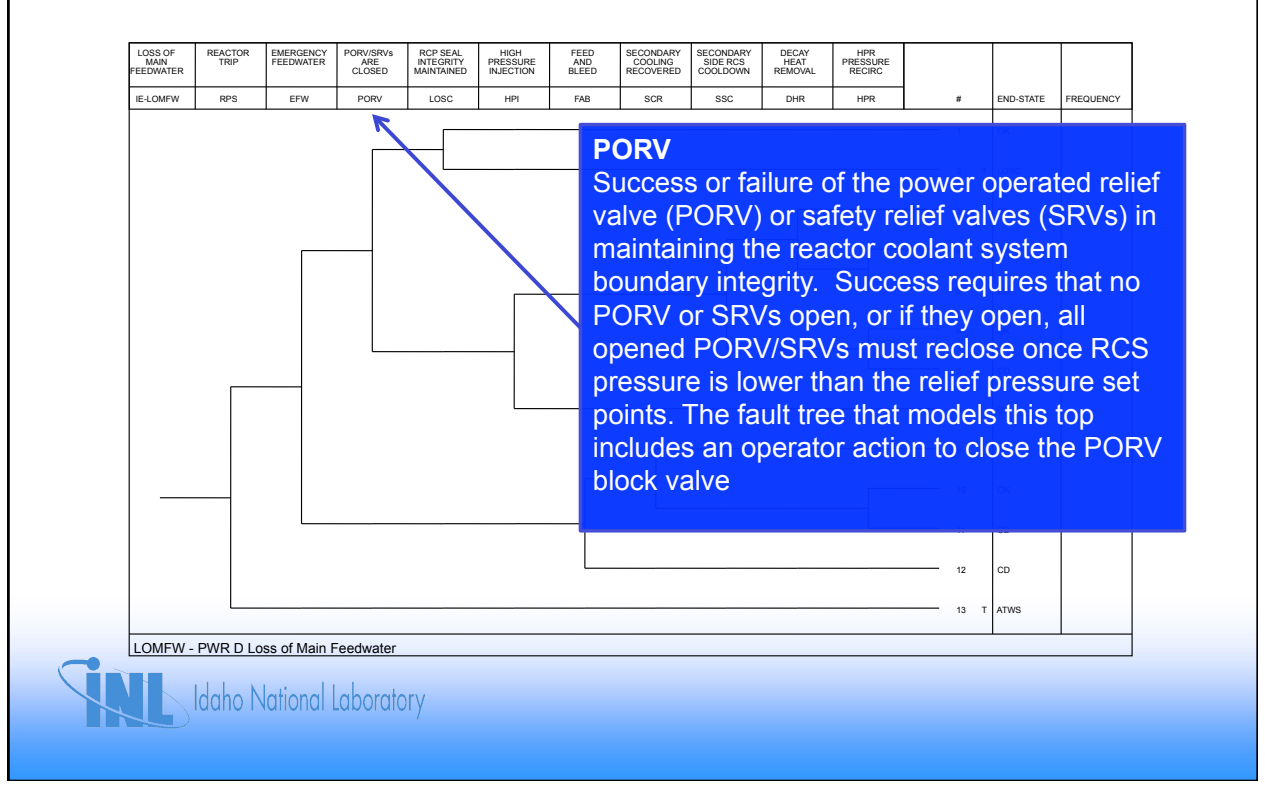




\section{LOMFW Event Tree}

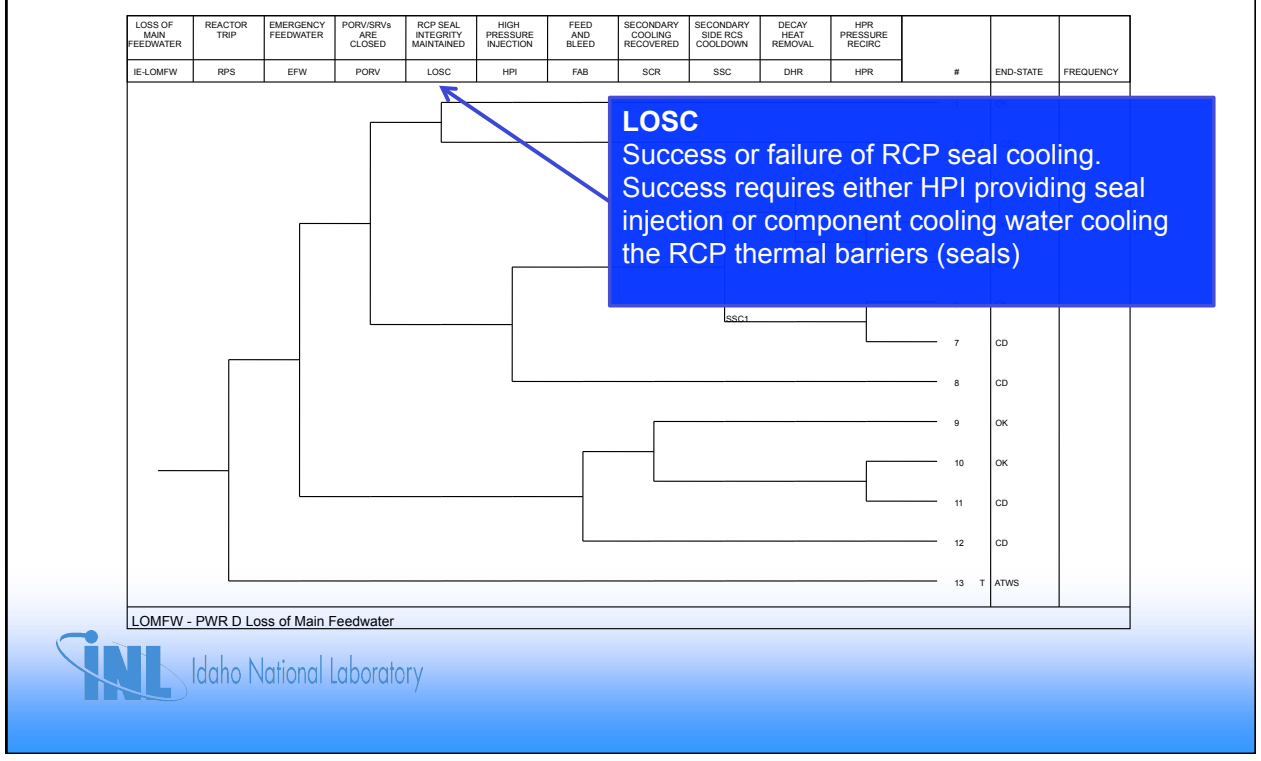

\section{LOMFW Event Tree}

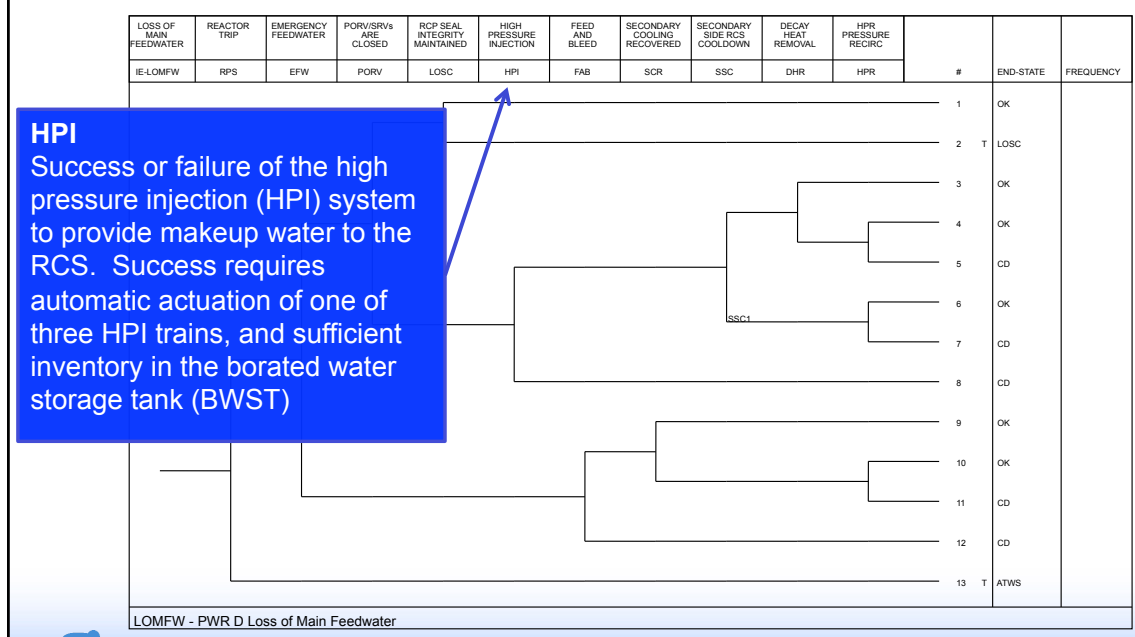

Idaho National Laboratory 


\section{LOMFW Event Tree}

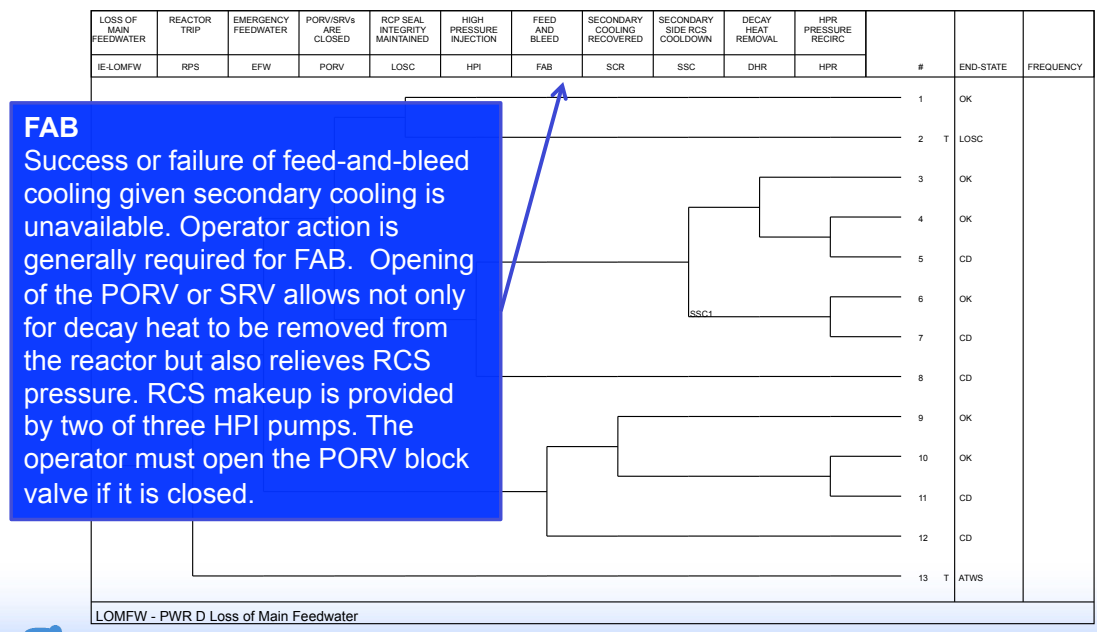

Idaho National Laboratory

\section{LOMFW Event Tree}

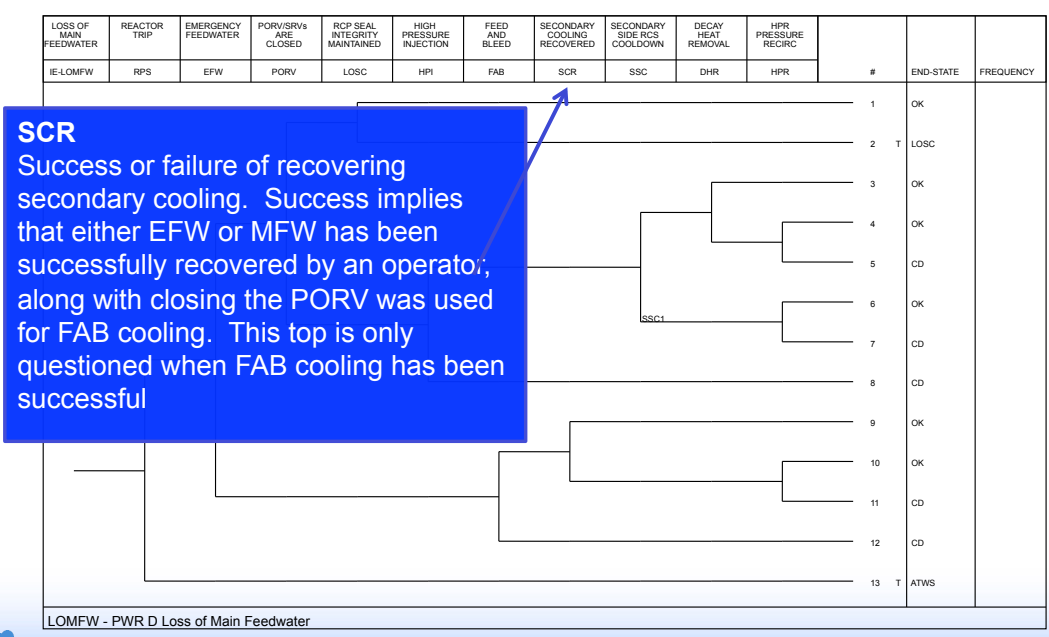

Idaho National Laboratory 


\section{LOMFW Event Tree}

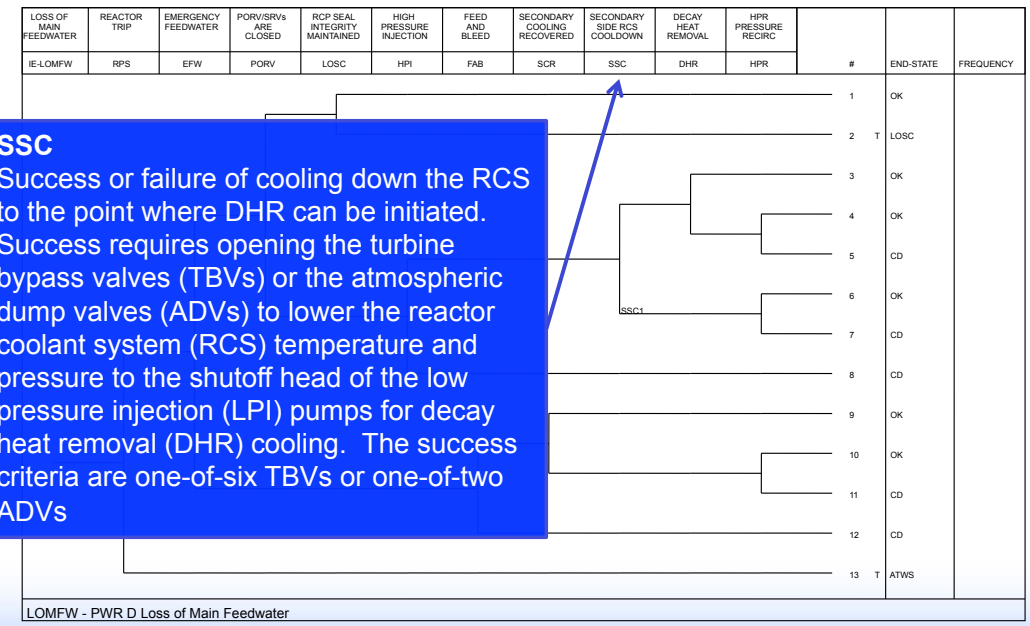

\section{LOMFW Event Tree}

Decay Heat Removal (DHR)

Success or failure of the DHR system. Success requires RCS pressure and temperature to be

within the requirements to allow the RCS hot leg (to LPI pump) suction valves to be opened. This

top requires an operator action to open the RCS hot leg suction valves to the pumps and align the pump discharge through the DHR heat

exchangers. The success criteria are one-of-two

LPI pumps providing sufficient flow through their respective heat exchangers (one-of-two)
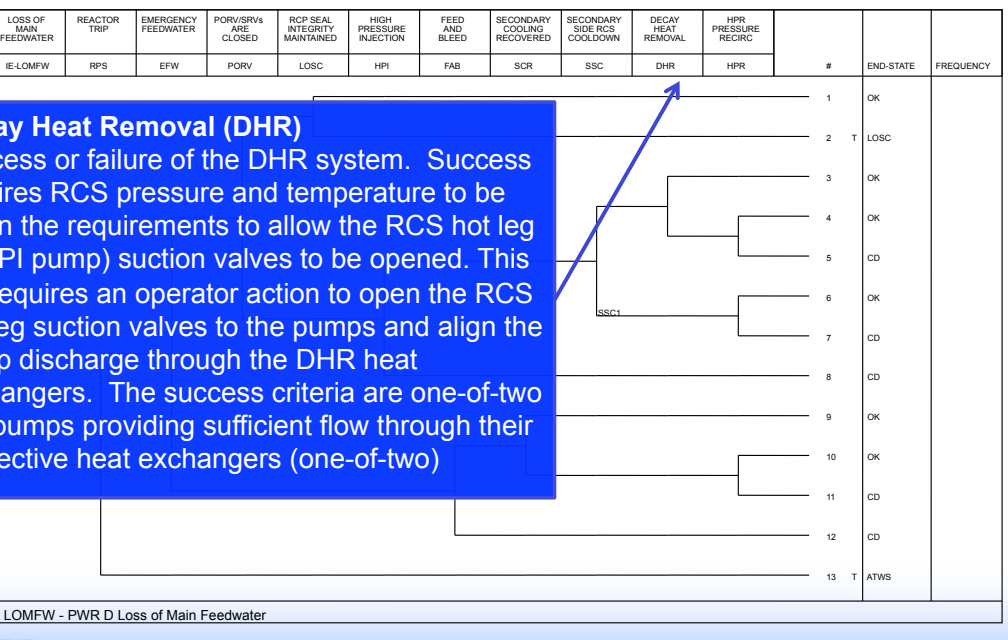

II Idaho National Laboratory 


\section{LOMFW Event Tree}

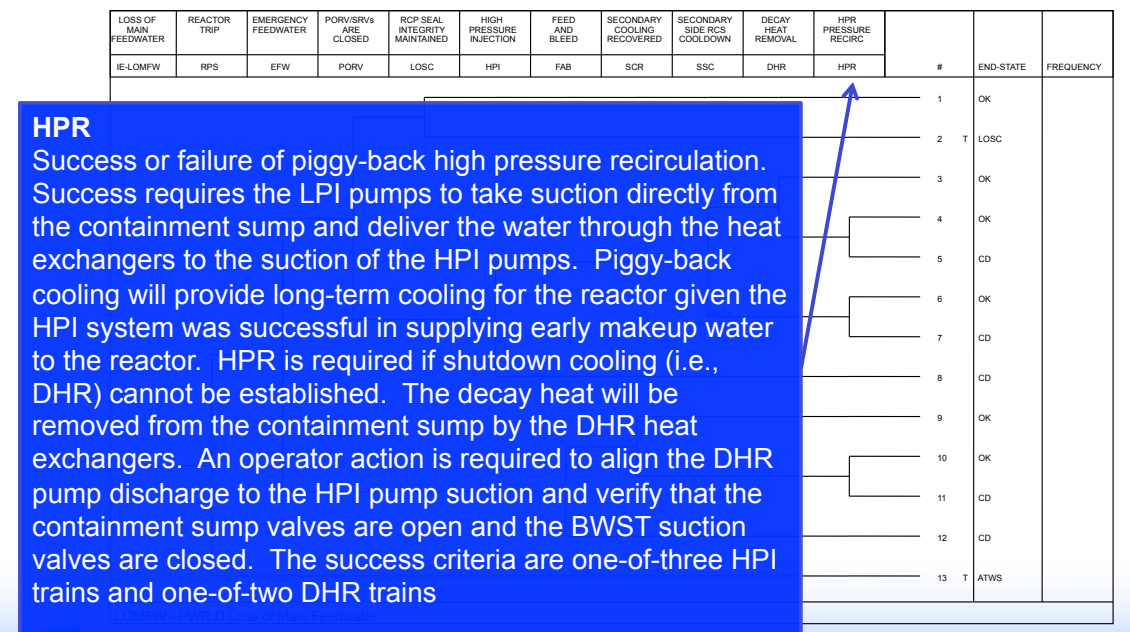

II Idaho National Laboratory

\section{What does a fault tree look like?}

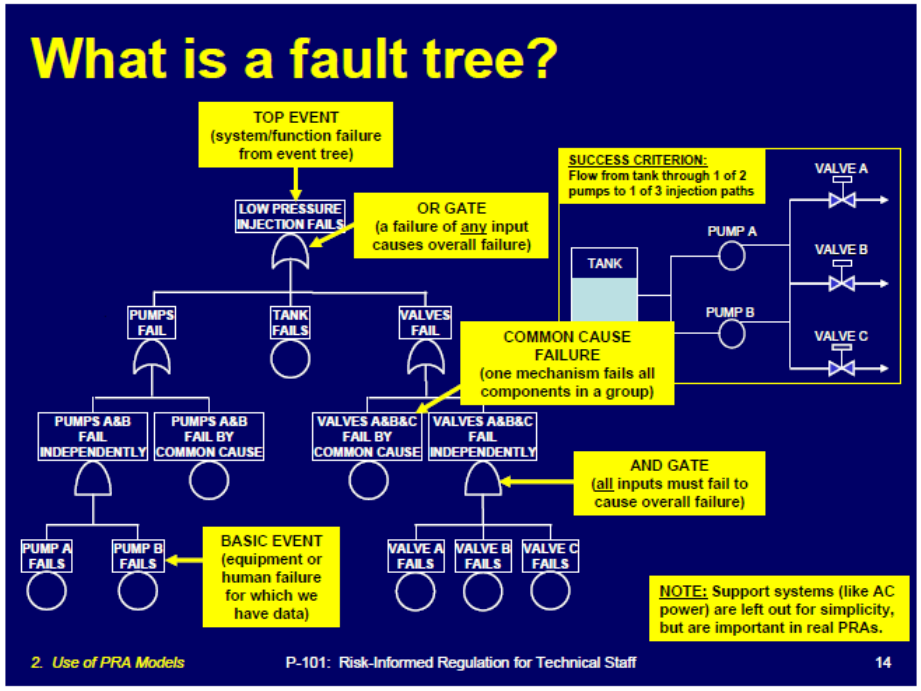




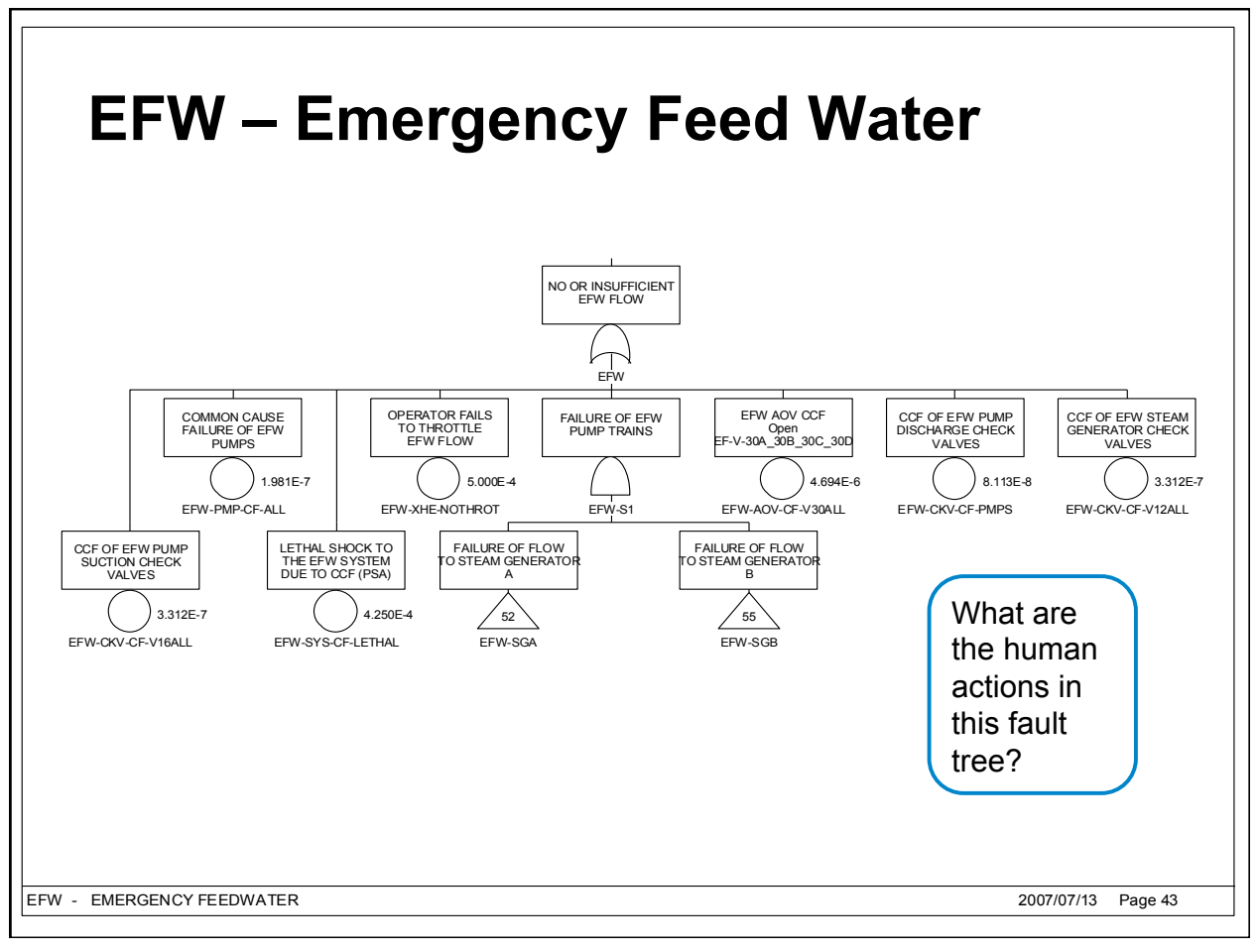

\section{FAB - Feed and Bleed Fault Tree}

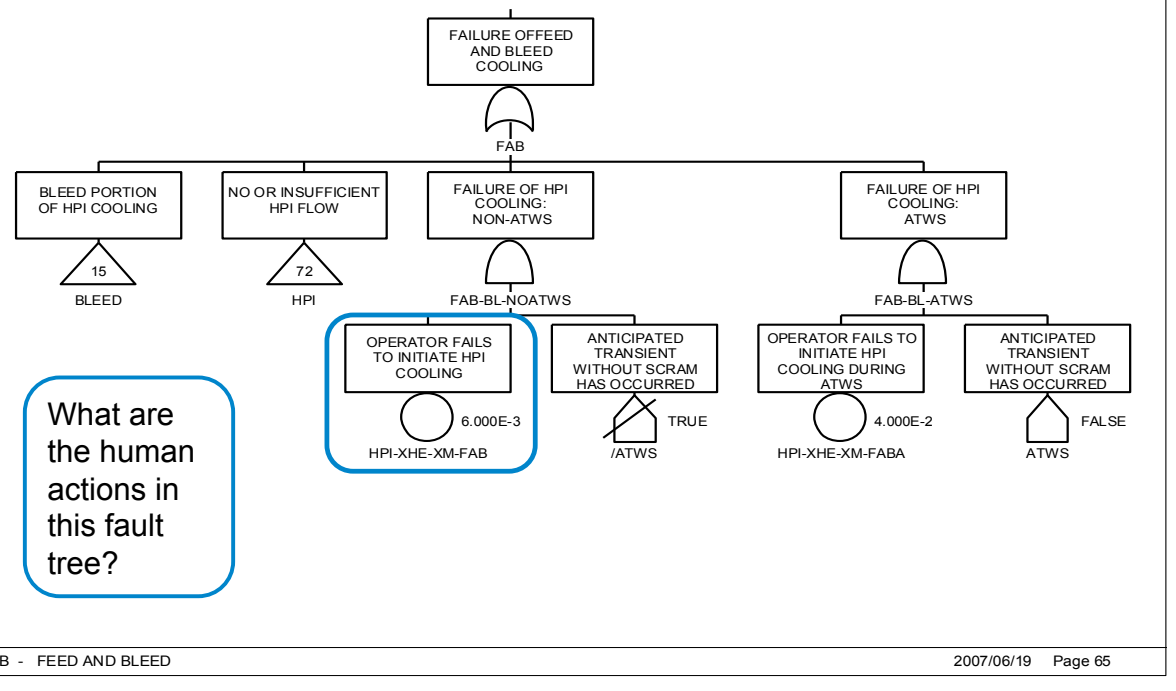




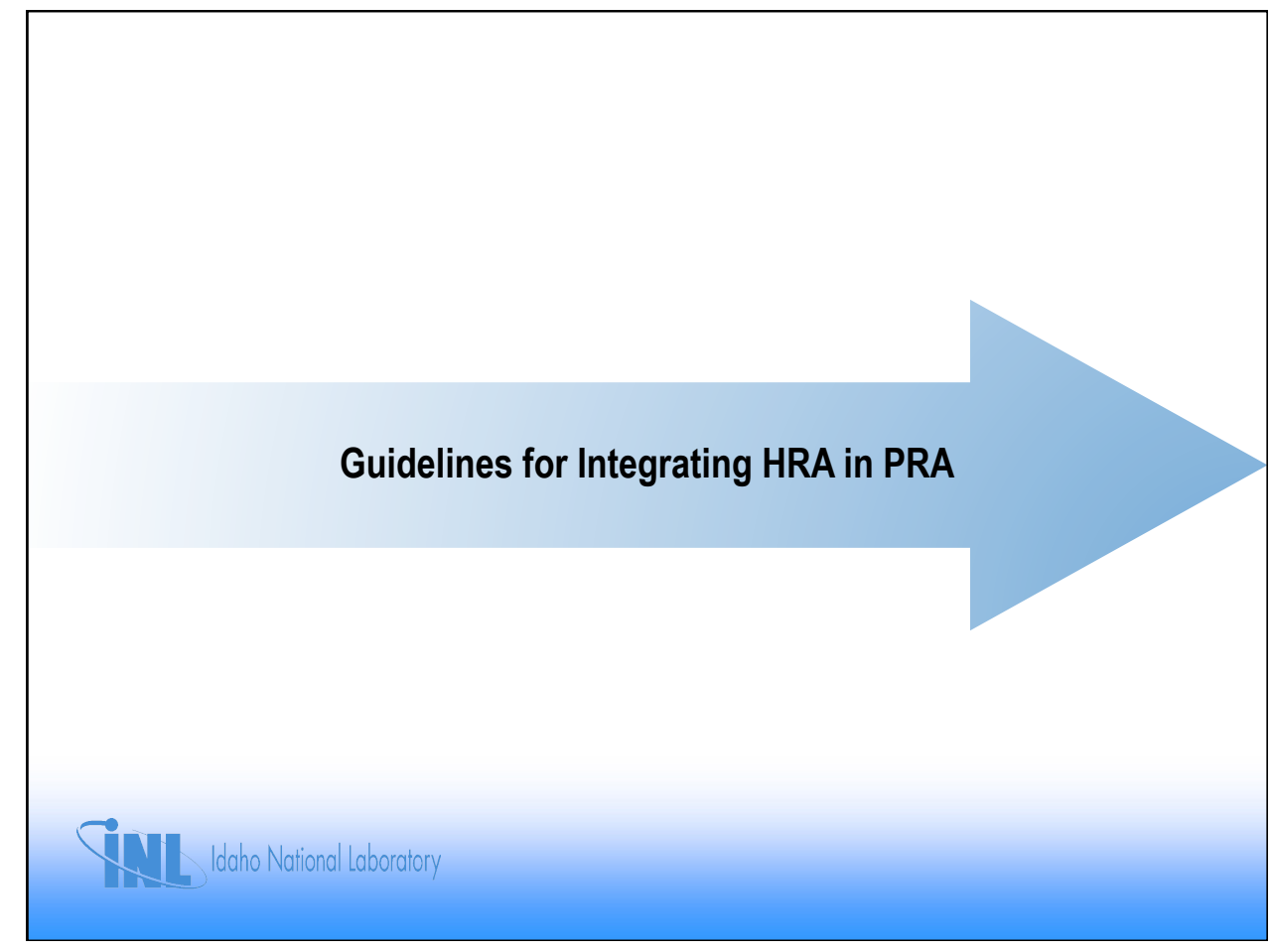

\section{Major Approaches for Integration}

Process of Integration

- EPRI's Systematic Human Action Reliability Procedure

- SHARP1

- Guide for Incorporating Human Action Reliability Analysis for Nuclear Power Generating Stations

- IEEE 1082/D7 (1997, expected release 2016)

\section{Characteristics of Good Integration}

- ASME/ANS Standard for Level 1 LERF PRA for NPPs

- ASME/ANS RA-Sb-2013

- NRC's Good Practices for HRA

- NUREG-1792 (2005)

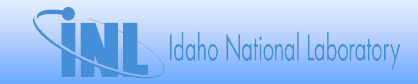




\section{Approaches Emphasize That}

- HRA is a part of entire PRA process

- HRA personnel should be included in team

- Screening precedes selected detailed analyses

- Phases include identification, modeling, and appropriate quantification as well as documentation

- Different methods may accomplish the same thing

- None of these guidance documents specifies a particular HRA method

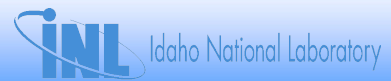

SHARP1 


\section{SHARP1}

Systematic Human Action Reliability Procedure, Rev 1

- SHARP originally developed by EPRI in 1984

- Revised as SHARP1 in 1992

- Initially proprietary, now publicly available from EPRI

- EPRI TR-101711 (December 1992)

- Involves 4 basic stages, which are iterated

1. HFE definition and integration into plant model

2. HFE quantification

3. Recovery analysis

4. Internal review

\section{SHARP1 Links from HRA to PRA}

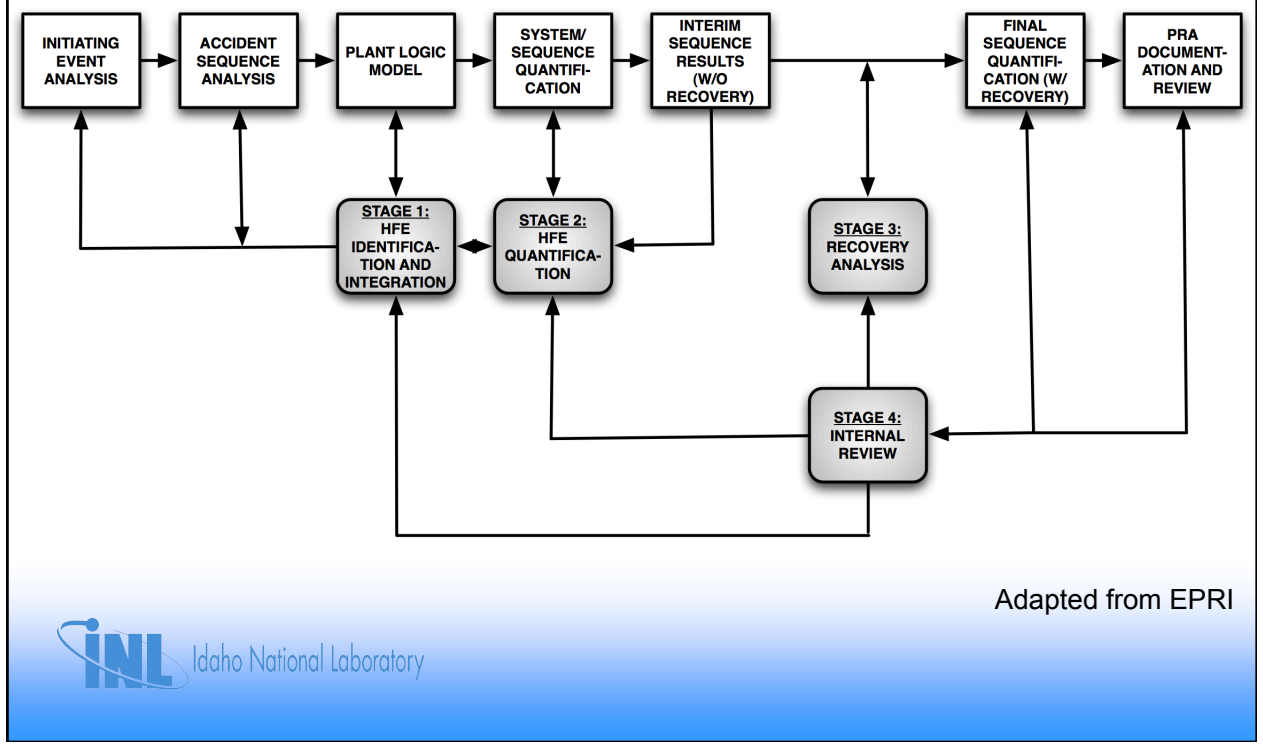




\begin{tabular}{|c|c|}
\hline \multirow{3}{*}{$\begin{array}{c}\text { SHARP1 S } \\
\text { - Four Stages } \\
=\end{array}$} & $\begin{array}{l}\text { Stage } 1-\text { Human Interaction Event } \\
\text { Definition and Integration } \\
\text { into Plant Logic Model }\end{array}$ \\
\hline & $\begin{array}{l}\text { 1. Definition } \\
\text { 2. Qualitative Screening } \\
\text { 3. Subtask Breakdown } \\
\text { 4. Impact Assessment } \\
\text { 5. Logic Model Integration }\end{array}$ \\
\hline & $\bullet$ \\
\hline \multirow[t]{8}{*}{ - 20 Total Steps } & $\begin{array}{c}\text { Stage } 2 \text { - Human Interaction } \\
\text { Event Quantification }\end{array}$ \\
\hline & $\begin{array}{l}\text { 1. Quantitative Screening } \\
\text { 2. Influence Factor Identification } \\
\text { 3. Representation } \\
\text { 4. Human Interaction Quantification } \\
\text { 5. Reassess Logic Model }\end{array}$ \\
\hline & $\checkmark$ \\
\hline & Stage 3 - Recovery Analysis \\
\hline & $\begin{array}{l}\text { 1. Definition } \\
\text { 2. Screening (based on feasibility) } \\
\text { 3. Logic Model Integration } \\
\text { 4. Influence Factors } \\
\text { 5. Representation } \\
\text { 6. Human Interaction Quantification }\end{array}$ \\
\hline & 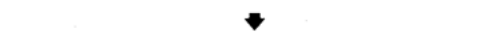 \\
\hline & Stage 4 - Internal Review \\
\hline & $\begin{array}{ll}\text { 1. Stage } 1 \text { Review } \\
\text { 2. Stage } 2 \text { Review } \\
\text { 3. Stage } 3 \text { Review } \\
\text { 4. } \text { Documentation } \\
\end{array}$ \\
\hline
\end{tabular}

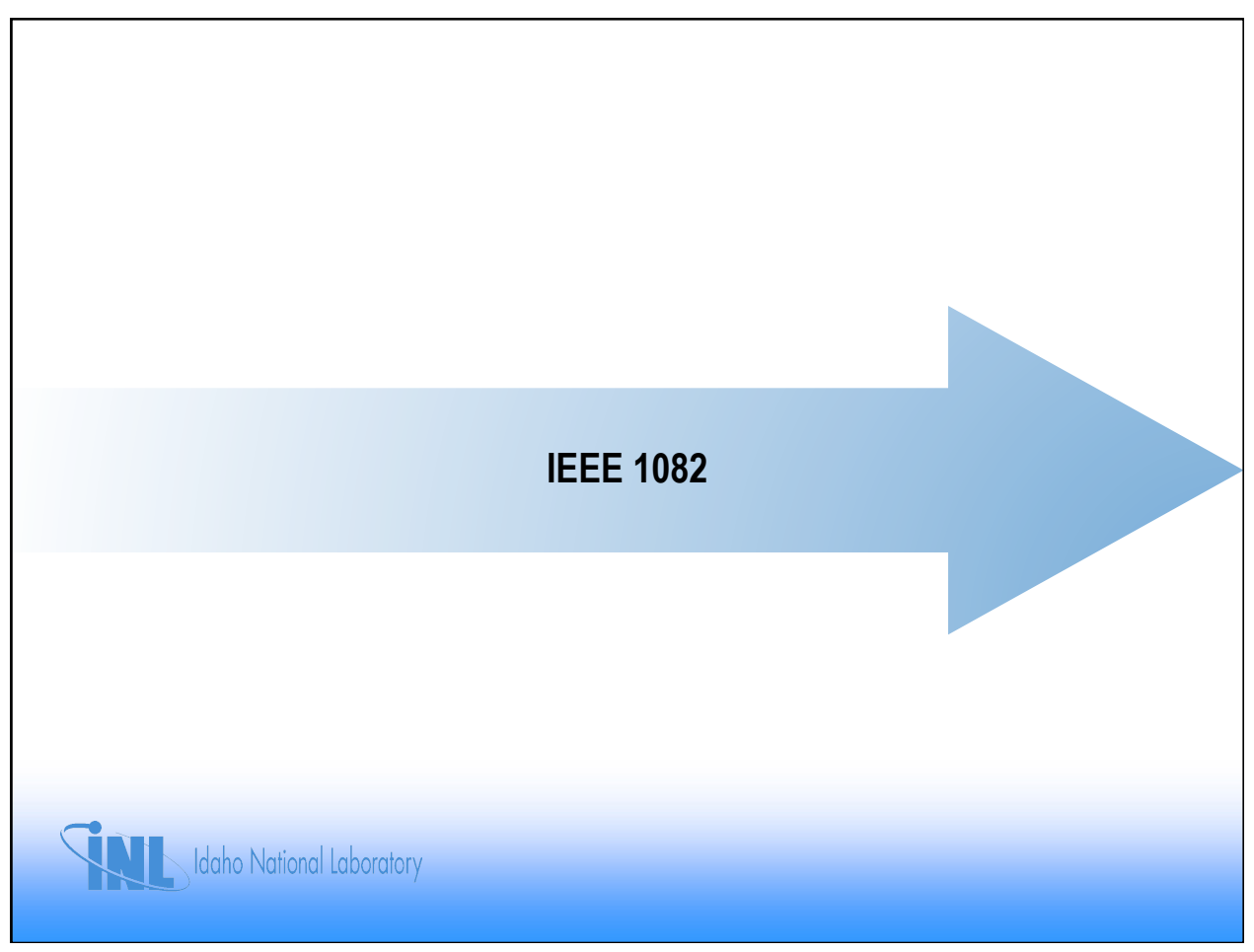




\section{IEEE STD 1082 (1997; draft rev 2016)}

\section{Guide for Incorporating Human Action Reliability}

Analysis for Nuclear Power Generating Stations

- Concise document (available through NRC library)

- Provides general framework for integrating HRAs into PRAs

- Describes outputs and decisions entailed in the 8 steps

- Emphasizes the importance of team training

\section{IEEE 1082 Steps}

1. Train the team

2. Familiarize team with plant

3. Build initial plant model

4. Screen human interactions

- Decision Point (Is event significant?): If no go to \#7

5. Characterize human interactions

6. Quantify human interactions

- Decision point (Is sequence recoverable?): If yes, go to \#5

7. Update plant model

8. Review results

Note that \#3 and \#7 are key PRA intersection points

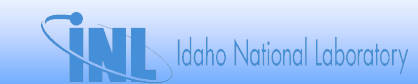




\section{IEEE 1082, Step 5: Characterizing Human Interactions}

- Type, location and design of controls/displays

- Feedback type, sensory mode, delay, and frequency

- Characteristics of procedures used

- Task loading for control room personnel in worst case conditions

- Management and organization and supervision for maintenance

- Quality, content, frequency, and specificity of training

- Worker competency relevant to PRA scenarios

\section{Idaho National Laboratory}

AMSE/ANS RA-Sb-2013 


\section{PRA Standard: Background}

Product of Nuclear Risk Management Coordinating Committee

- ASME Board on Nuclear Codes and Standards

- American Nuclear Society Standards Board

Includes PRA coverage for:

- Level 1 PRA

- Large early release frequency (LERF) for internal events at power

- External events (e.g., seismic, high wind, flood, other)

- Internal fire

- Low power and shutdown (LPSD; future revision)

\section{PRA Standard: Structure}

\section{Published as ASME/ANS RA-Sb-2013}

- Available online or through NRC library

\section{Structure}

- Three levels of Capability Categories, each with High Level Requirements (HLRs), which have Supporting Requirements (SRs)

- Capability Category I: Relative importance of the contributors at system or train level

- Capability Category II: Relative importance of the significant contributors at component level

- Capability Category III: Relative importance of the $\underline{\text { relevant contributors at component level }}$ 


\section{PRA Standard: HRA Applicable High Level Requirements (HLR)}

HLR-IE-A2 (Initiating Event Analysis-General)

- Include both equipment and human-induced events

HLR-IE-C11 (Initiating Event Analysis-Annual Frequency)

- Use plant specific HRA information for recovery actions

HLR-AS-B2 (Dependency)

- Identify dependencies for success/failure of preceding systems, functions, and human actions

\section{HLR-SC-A5 (Success Criteria-General)}

- If stable plant conditions not achieved in 24 hours using modeled plant equipment and human actions, perform additional evaluation

HLR-SC-C2 (Success Criteria-Documentation)

- Summarize success criteria for available mitigating systems and human actions

\section{PRA Standard: HRA Examples}

HLR-SY-A16 (Systems Analysis-General)

- Include HFEs that cause the system or component to be unavailable when demanded (pre-initiator human events)

\section{HLR-SY-A17 (Systems Analysis-General)}

- Include HFEs that are expected during the operation of the system or component (post-initiator human actions)

\section{HLR-SY-C2 (Systems Analysis-Documentation)}

- Document human actions necessary for operation of system

\section{HLR-QU-D (Quantification)}

- Significant contributors to CDF/LERF such as IEs, accident sequences, and basic events (equipment unavailability and HFEs) shall be identified

Many more for specific analyses (large early release, floods, etc.)

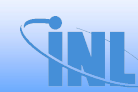




\section{PRA Standard: HRA-Specific HLRs}

\section{Pre-Initiator HRA}

- HLR-HR-A: Systematically identify routine activities that, if not completed correctly, may impact equipment availability

- HLR-HR-B: Screening of human activities to be addressed in model

- HLR-HR-C: For non-screened activities, HFE shall be defined

- HLR-HR-D: Assessment of probabilities for HFEs

Post-Initiator HRA

- HLR-HR-E: Systematically identify required operator responses

- HLR-HR-F: HFEs defined for impact of failure of operator responses

- HLR-HR-G: Assessment of probabilities of HFEs

- HLR-HR-H: Modeling of plausible recovery actions

Both Pre- and Post-Initiator HRA

- HLR-HR-I: Documentation of HRA
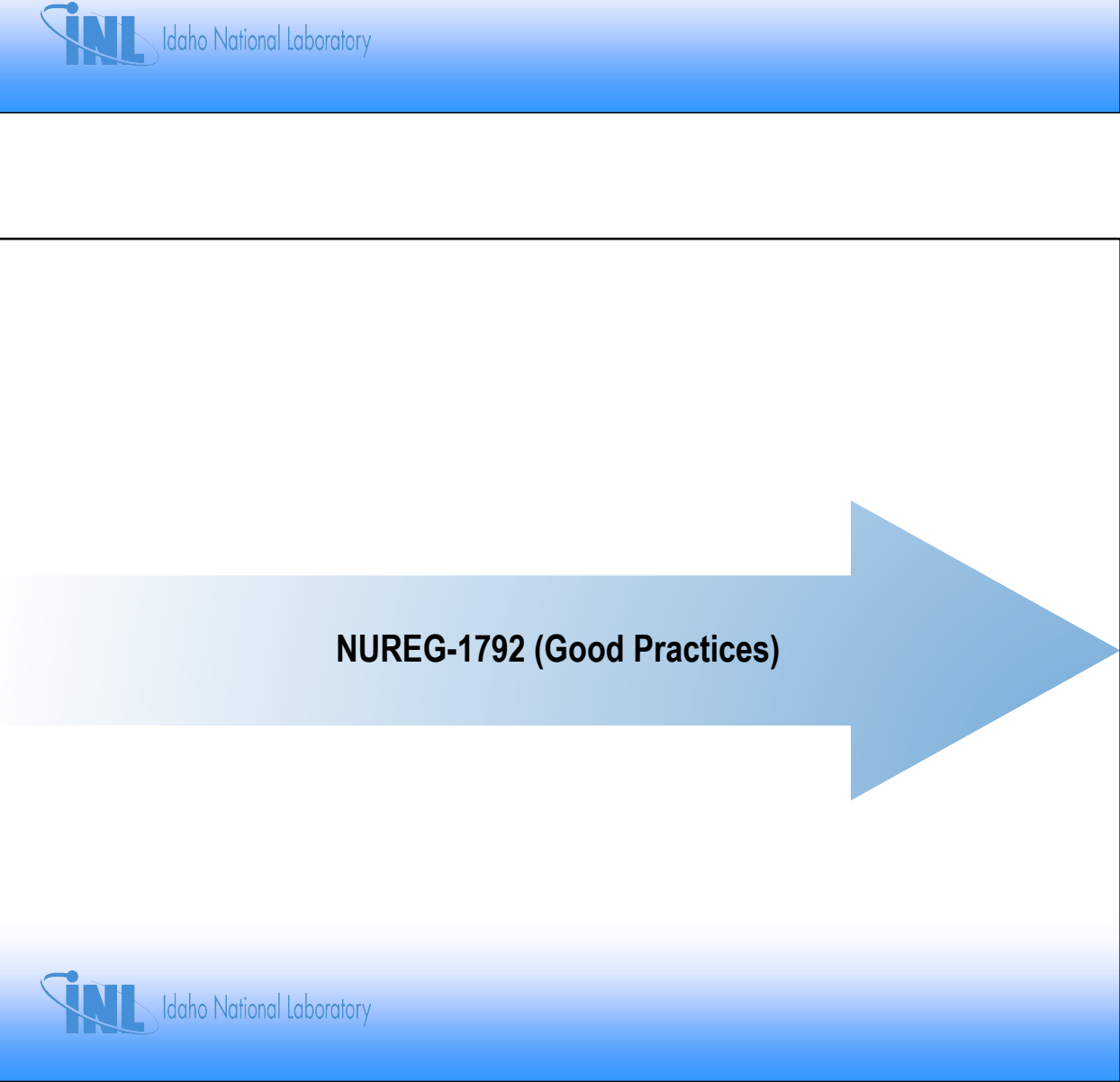


\section{HRA Good Practices}

\section{Background}

- Published as NUREG-1792 (2005)

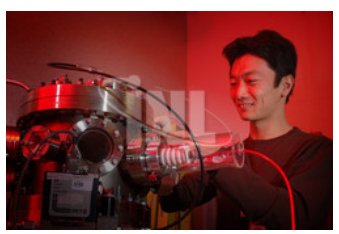

- Companion volume (NUREG-1842, 2006) evaluates good practices against different HRA methods

- Developed in response to NRC activities to address quality issues in PRA

- Provides a common baseline across methods

- Generic, not tied to a specific HRA method, "to ensure consistency and quality" (p. 5)

- Contains a cross reference table to the then-current ASME Standard for PRA for Nuclear Power Plant Applications (ASME RA-S-2002)

\section{STI Idaho National Laboratory}

\section{HRA Good Practices}

\section{Coverage}

- Addresses Pre-Initiator HRA, Post-Initiator HRA, errors of commission, and good practices audits

- For reactor, full power, internal events

- Supports REG Guide 1.200 (2004)

- Two main purposes:

- Guidance for performing HRAs

- Support the review of HRAs

- HRA must also meet the intent of NUREG-0711 (Rev. 2, 2004)

- Human Factors Engineering Program Review Model

- HRA is to be part of the human factors evaluation

- HRA must support Accident Sequence Precursor (ASP) requirements for event analysis 


\section{HRA Good Practices}

\section{Basics}

- Involve a multidisciplinary team

- Perform plant walk downs

- Identify pre-Initiators (look at procedures and actions; consider test and maintenance, calibration that could affect equipment credited in the PRA; determine whether misalignment or miscalibration could make equipment unavailable)

- Examine operational modes and routine operations that could affect plant outcome

- Consider other barriers and structures such as fire doors, drains, seismic restraints, etc.

- Screen out actions that have acceptable restoration signals, and checks or signs that help ensure that equipment will be reliably restored

- Cleary this requires a qualitative as well as quantitative analysis

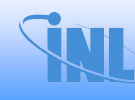

\section{Sample HRA Good Practices}

\section{Pre-Initiators}

- Quantification - Use screening values if they are conservative and values can account for dependency

- Account for Performance Shaping Factors (PSFs)

- More discussion in Lesson 4

- Account for plant specific recovery factors (compelling signals, testing, scheduled checks, independent verifications, etc.)

- Consider multiple recoveries or opportunities, but consider the possibility of dependencies among opportunities

- Consider dependencies among HEPs in the accident sequence

- Assess uncertainty in mean HEP values (excluding screening HEPs)

- Evaluate HEP reasonableness (relative to one another and in absolute terms) 


\section{Sample HRA Good Practices}

\section{Post-Initiators}

- Review procedures and simulator training as needed

- Identify post initiator actions by review of above in conjunction with plant functions, systems, and equipment as modeled in the PRA

- Determine how operators are to respond to different equipment failure modes

- Perform walk downs and talk-throughs, asking:

- Who does what?

- How long does it take?

- Are there special tools or environmental issues?

\section{SII Idaho National Laboratory}

\section{Sample HRA Good Practices}

\section{Performance Shaping Factors (PSFs)}

- The following PSFs should, at a minimum, be considered in HRA analyses:

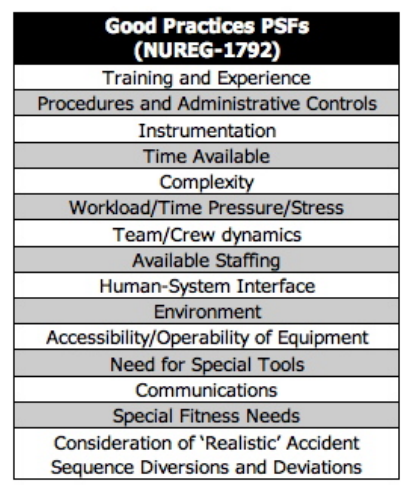

- We will discuss PSFs in depth later

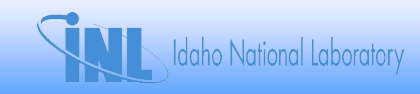




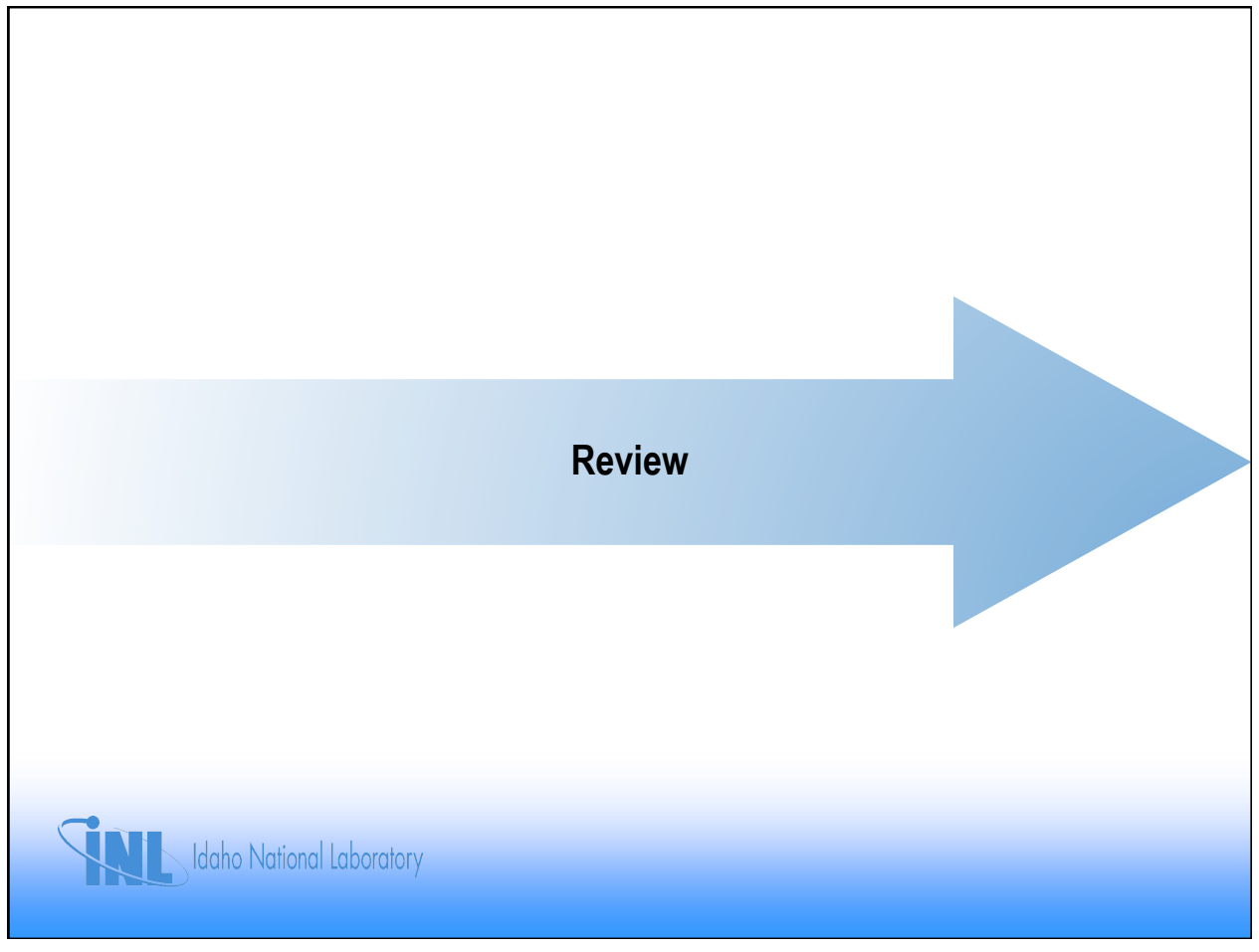

\section{Lesson 2 Review}

- What are human failure events?

- What are errors of commission and errors of omission?

- How can human actions be represented in event and fault trees?

- What's the basic process outlined in EPRI SHARP1?

- What are the key steps to integrating PRA and HRA in IEEE 1082?

- What are some sample High Level Requirements for HRA in the ASME/ANS PRA Standard?

- Where can you find a standard list of performance shaping factors for use in HRA?

- What are some pre-initiator considerations outlined in the Good Practices?

\section{YII Idaho National Laboratory}




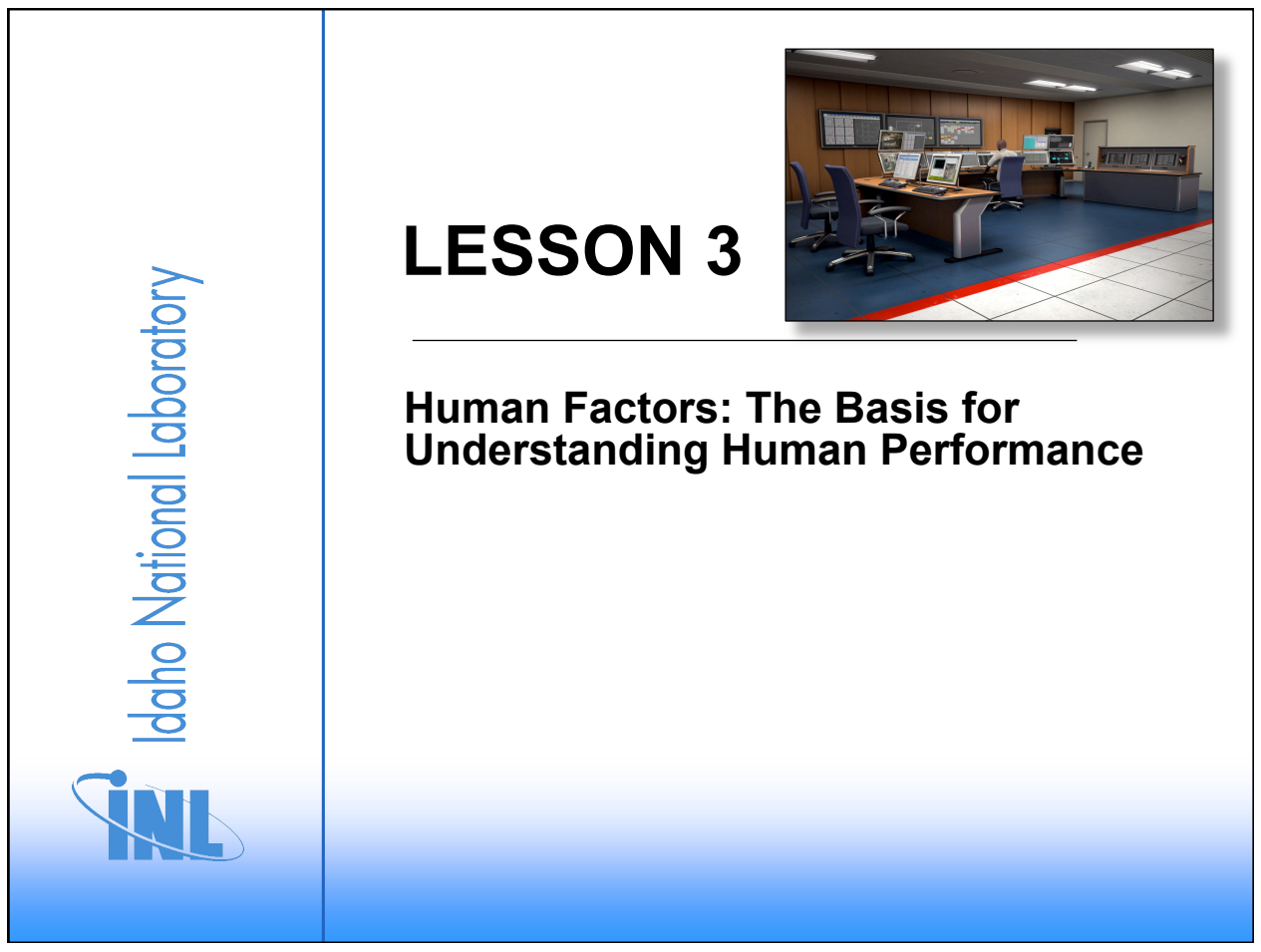

\section{Lesson 3 Objectives}

$\checkmark$ Gain a basic understanding of human factors and its general process

$\checkmark$ Learn how human factors and human reliability analysis are related

$\checkmark$ Understand how human factors relates to human error

$\checkmark$ Understand the process of integrating human reliability analysis into human factors 


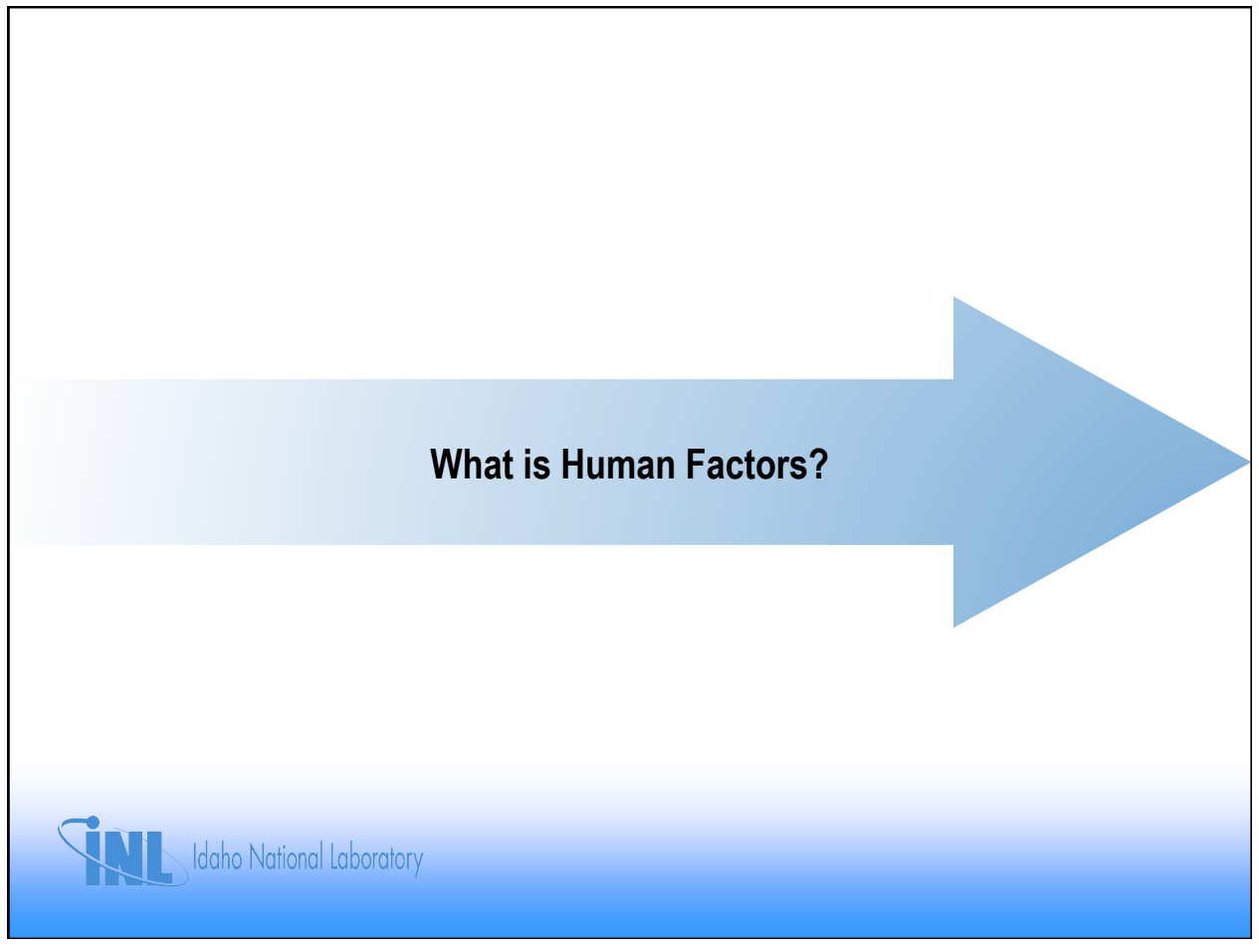

\section{What is Human Factors?}

Human factors is the study of humans interacting with technology

- Study of human performance when using technologies

- Study of designing technologies to optimize human performance when using those technologies

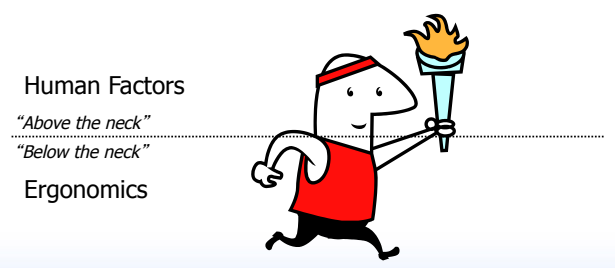

\section{Idaho National Laboratory}




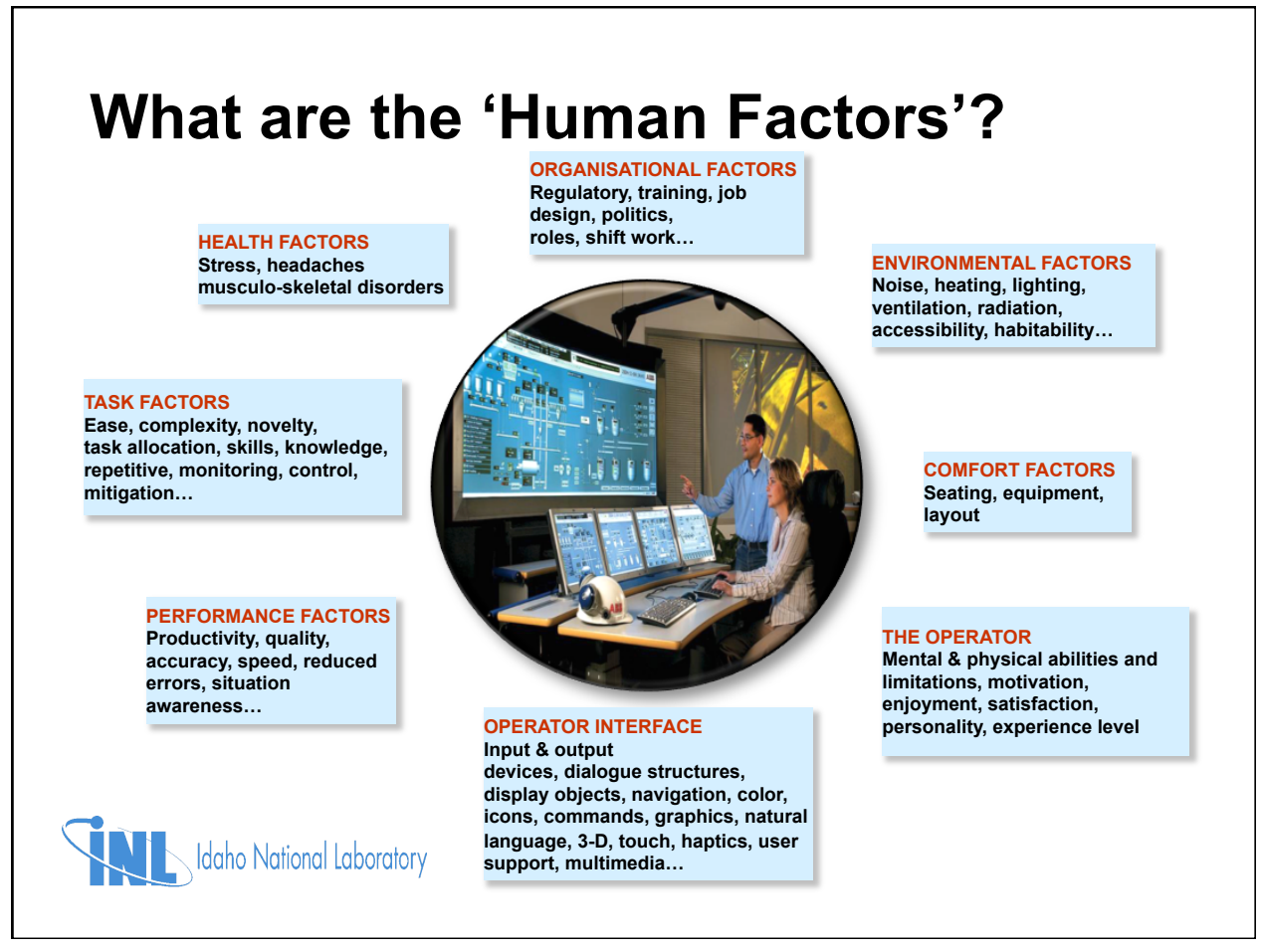

\section{Why Should We Care?}

\section{Human factors helps to:}

- Improve safety, productivity, performance

- Reduce need for training, system maintenance, user support

- Reduce errors, incidents/accidents and overall costs

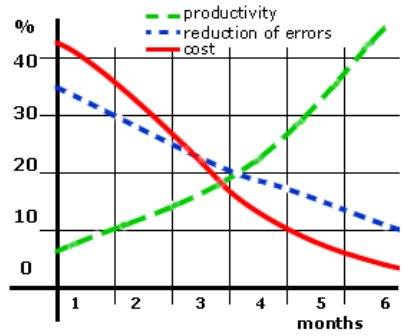

Improved system design results in improved safety, reduced costs, reduced errors, improved productivity and overall performance

(FAA Human Factors course: www2.hf.faa.gov/HFPortalNew/Training.aspx) 


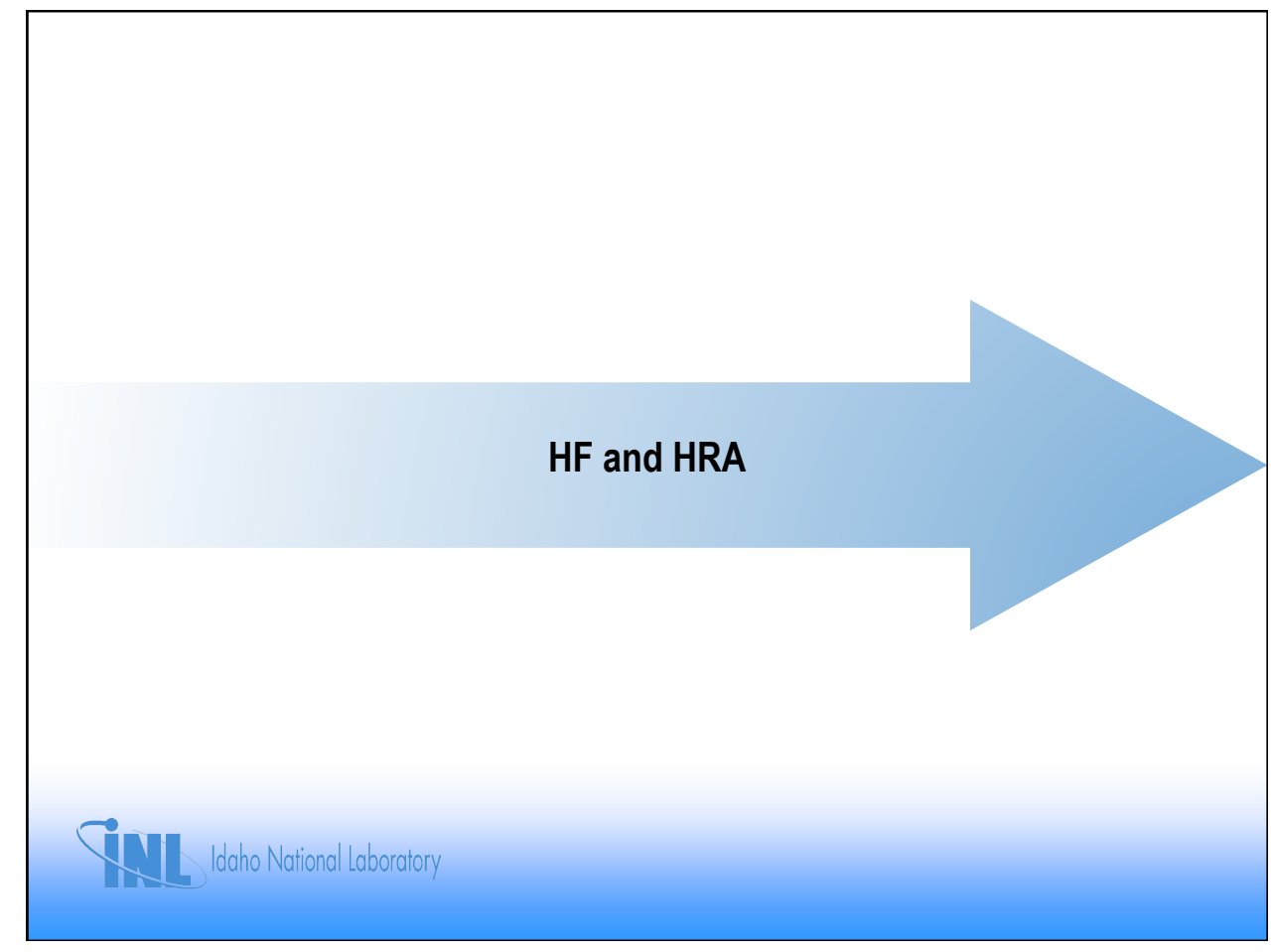

\section{Diverging Paths}

Traditional Human Factors

- Involved in design and testing of new technologies to be used by humans

- Much emphasis on usability, efficiency, enjoyment, and safety

Traditional Human Reliability Analysis

- Involved in assessment and modeling of designs in the context of a larger system safety

- HRA often used in predictive analysis, including a safety review of a designed system

- HRA rarely used in an iterative way as part of the system design process 


\section{A Little History}

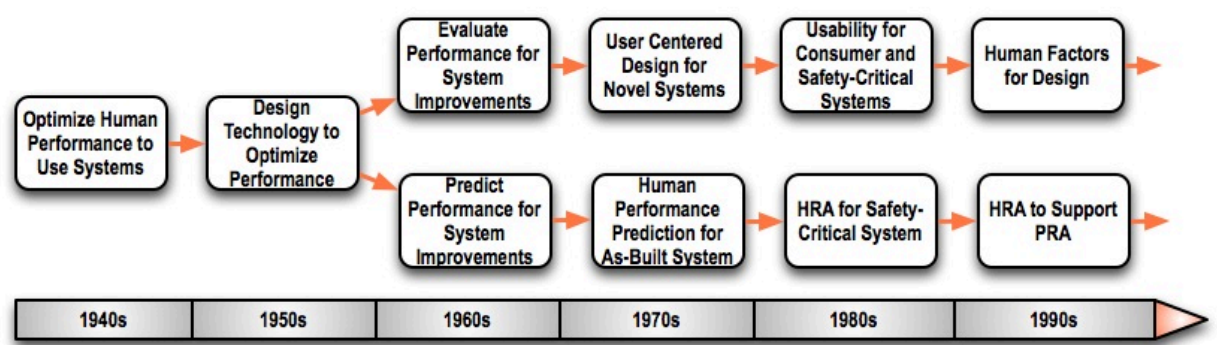

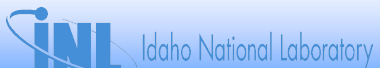

\section{Two Ways to Look at Humans}

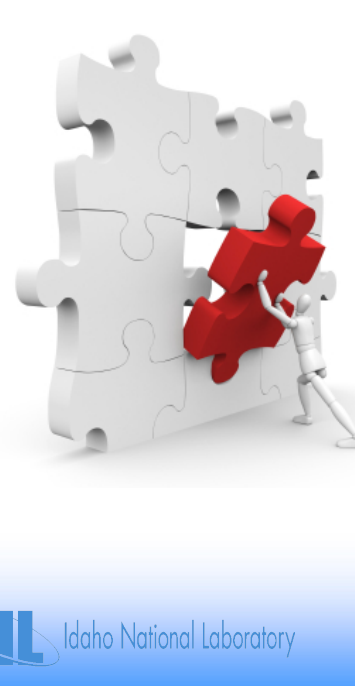

\section{Human Factors}

- Design: How do we improve the design of the system to complement the capabilities of the human?

\section{Human Reliability}

- Predict: How do we assess the human contribution to the overall system risk? 


\section{Human Factors Supports HRA}

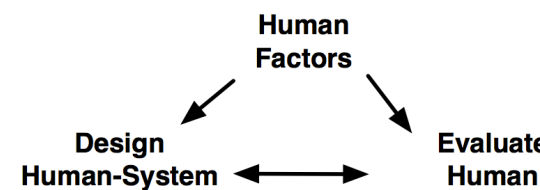

Interface

uman

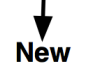

New

Upgrades

Performance

Existing

Systems and

Operations

Human Errors

and Performance

Human

Reliability

Analysis

\section{Human Factors Supports HRA}

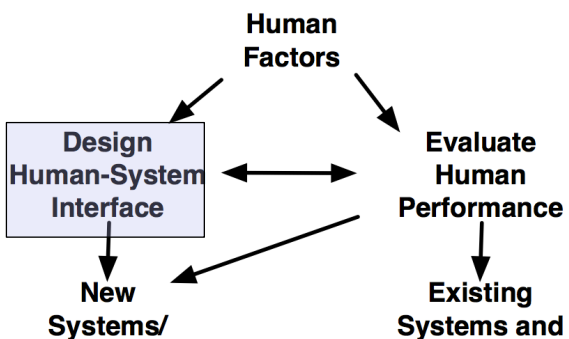

Systems/

Systems and

Upgrades

Operations

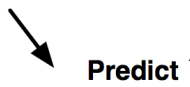

Human Errors

and Performance

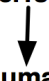

Human

Reliability

Analysis 


\section{Basic Principles of HSI}

- Systems exist to serve human need

- Systems must accommodate human abilities and limitations

- Complexity of systems determined by demand made on human cognitive processes

- Visual, Intellect, Memory, Motor activities

- Aim is to develop systems that:

- Reduce need for training

- Increase speed and accuracy

- Reduce complexity

- Reduce workload

- Support the process effectively and safely

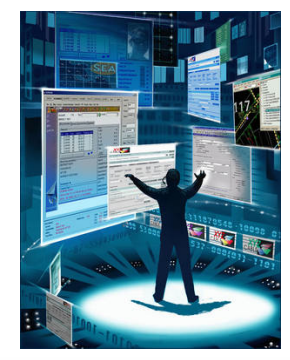

\section{Human Factors Supports HRA}

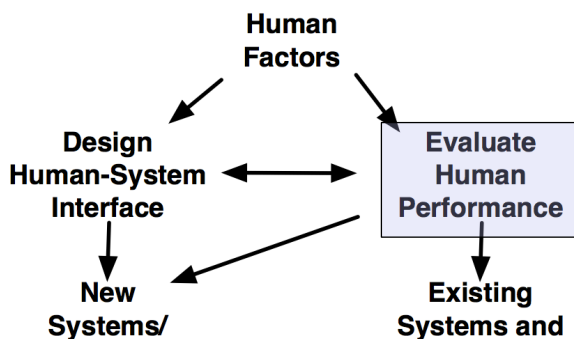

Systems/

Systems and

Upgrades

Operations

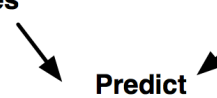

Human Errors

and Performance

Human

Reliability

Analysis 


\section{Source of Performance Problems}

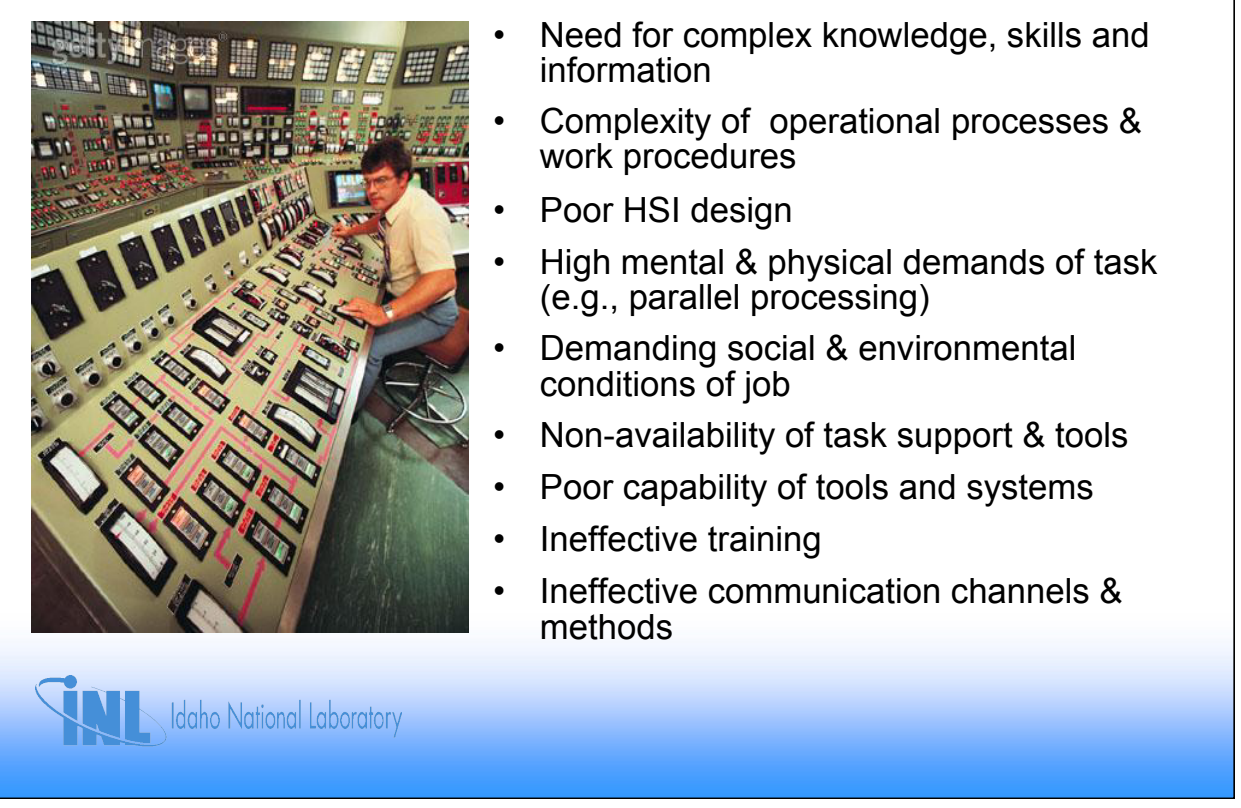

\section{Expectations for Minimum HF at Plant}

- Train operators to safety critical tasks

- Provide systematic training / retraining

- Talkthroughs / walkthroughs, simulations, drills, verification, examinations, certification, etc.

- Use procedures and checklists (as appropriate)

- Use threeway communication

- Use two-person rule, second checkers, proper supervision, etc.

- Minimize operator workload 


\section{Example of Bad Design}
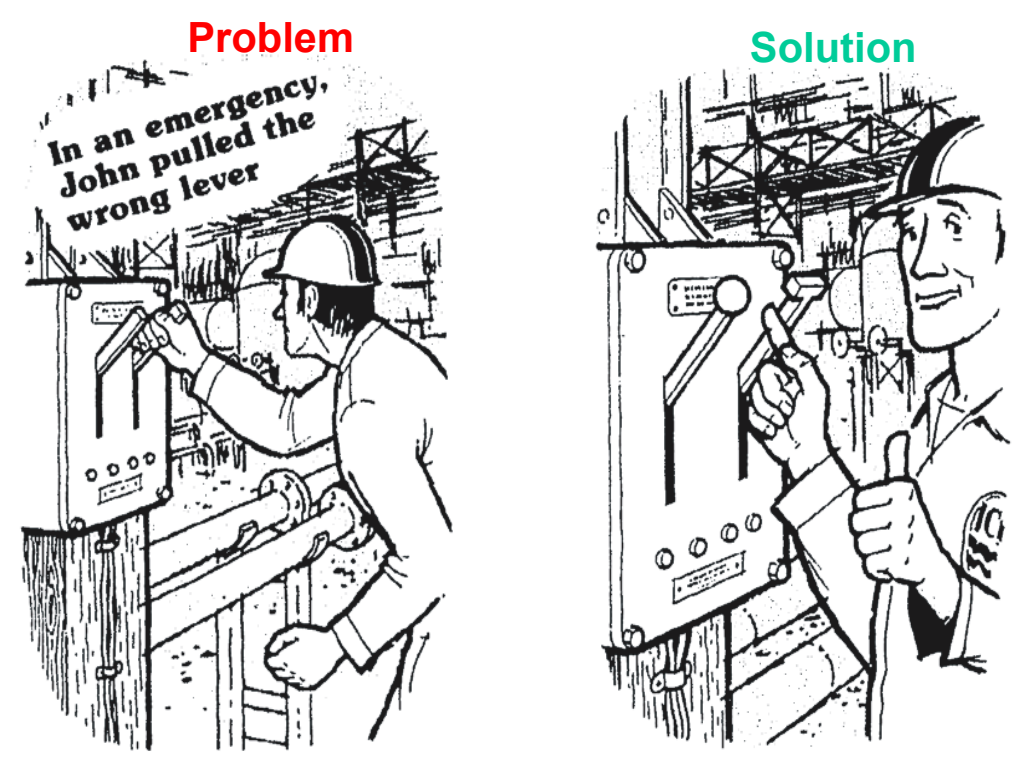

Human Factors Integrated into HRA 


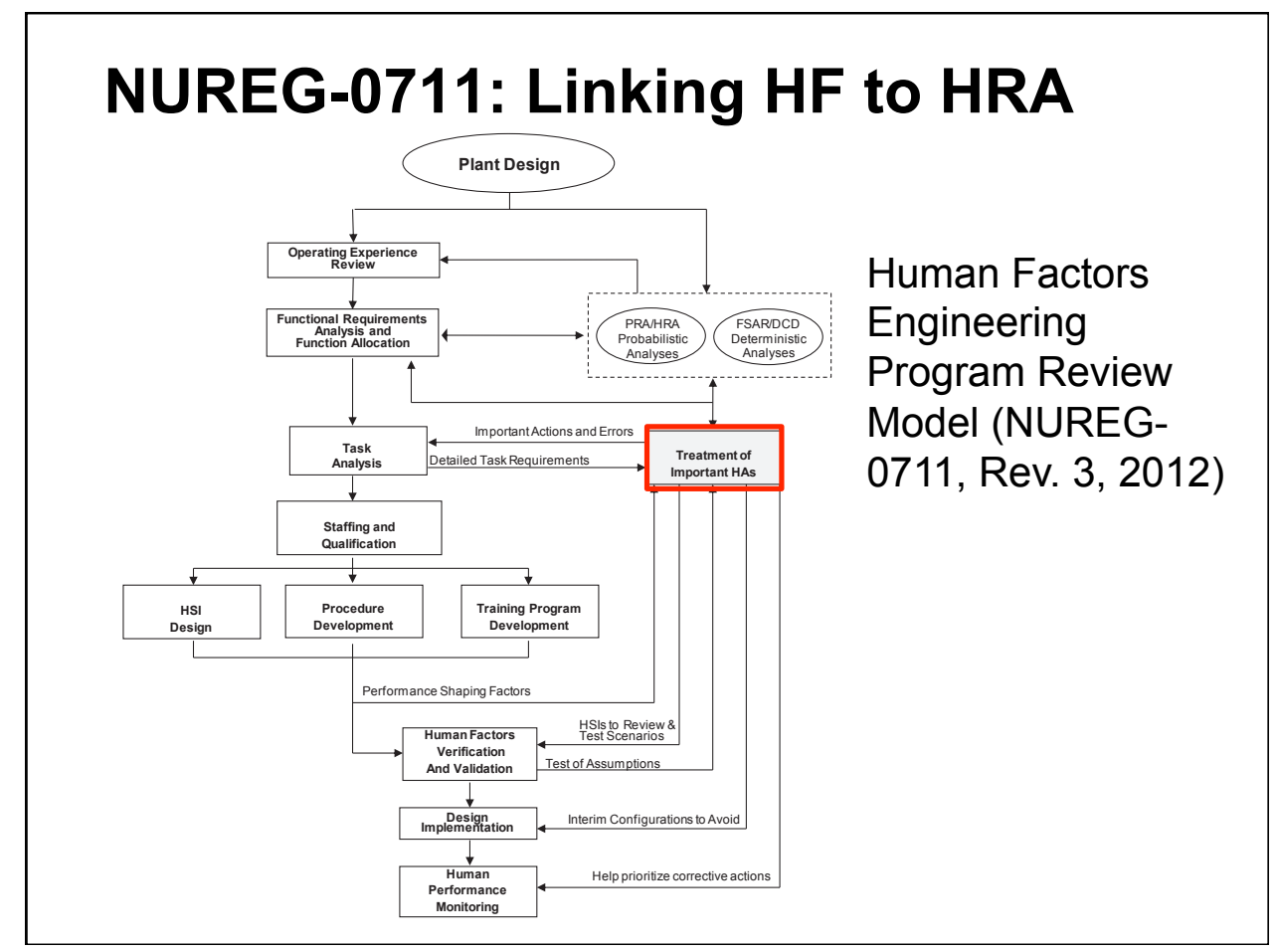

\section{HF Design \& Implementation Process}

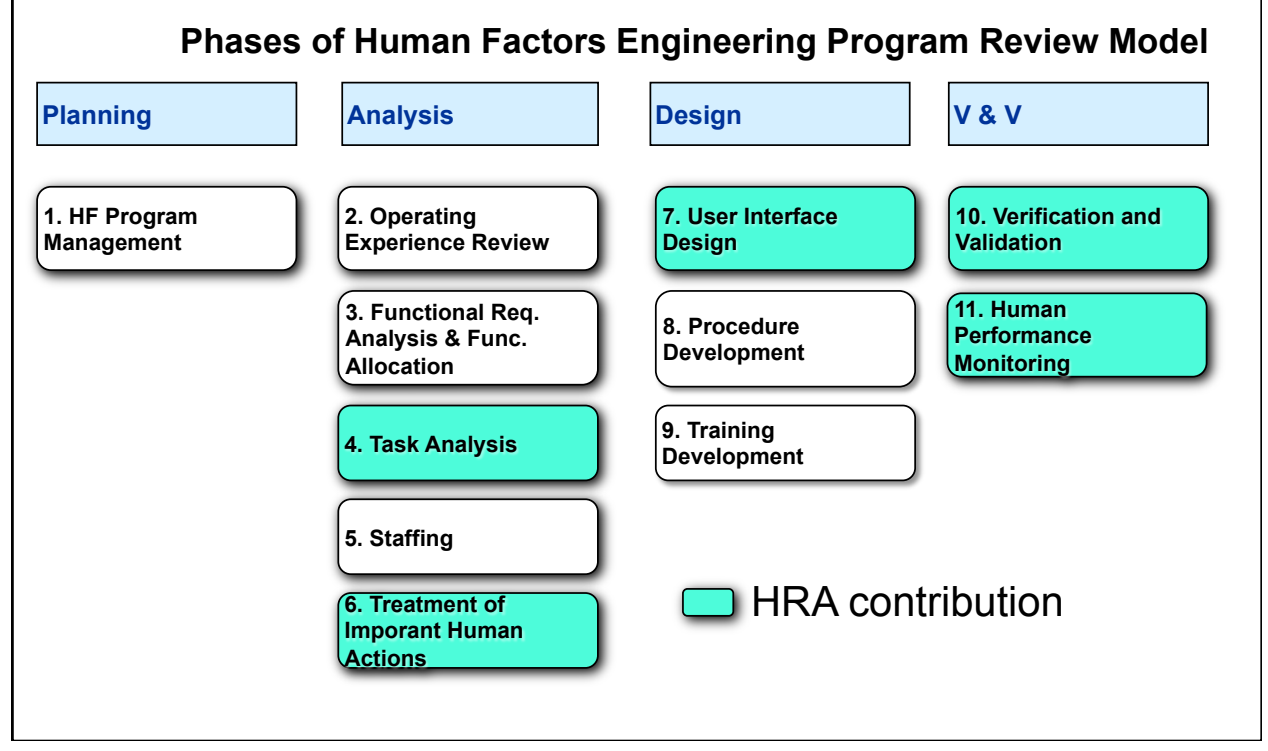




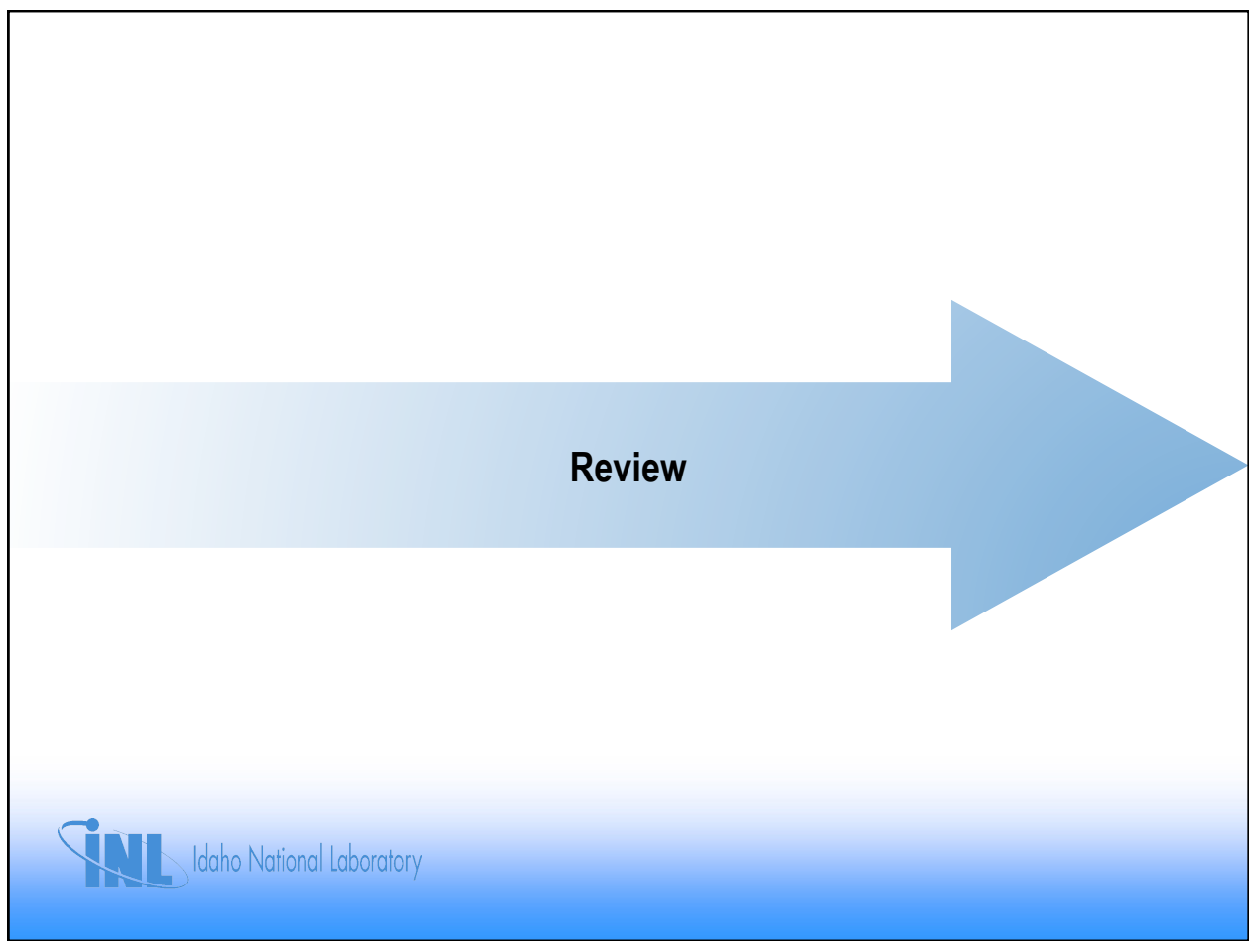

\section{Lesson 3 Review}

- How do human factors and HRA share a common history, and how did they diverge?

- What does human factors bring to HRA?

- What does HRA bring to human factors? 


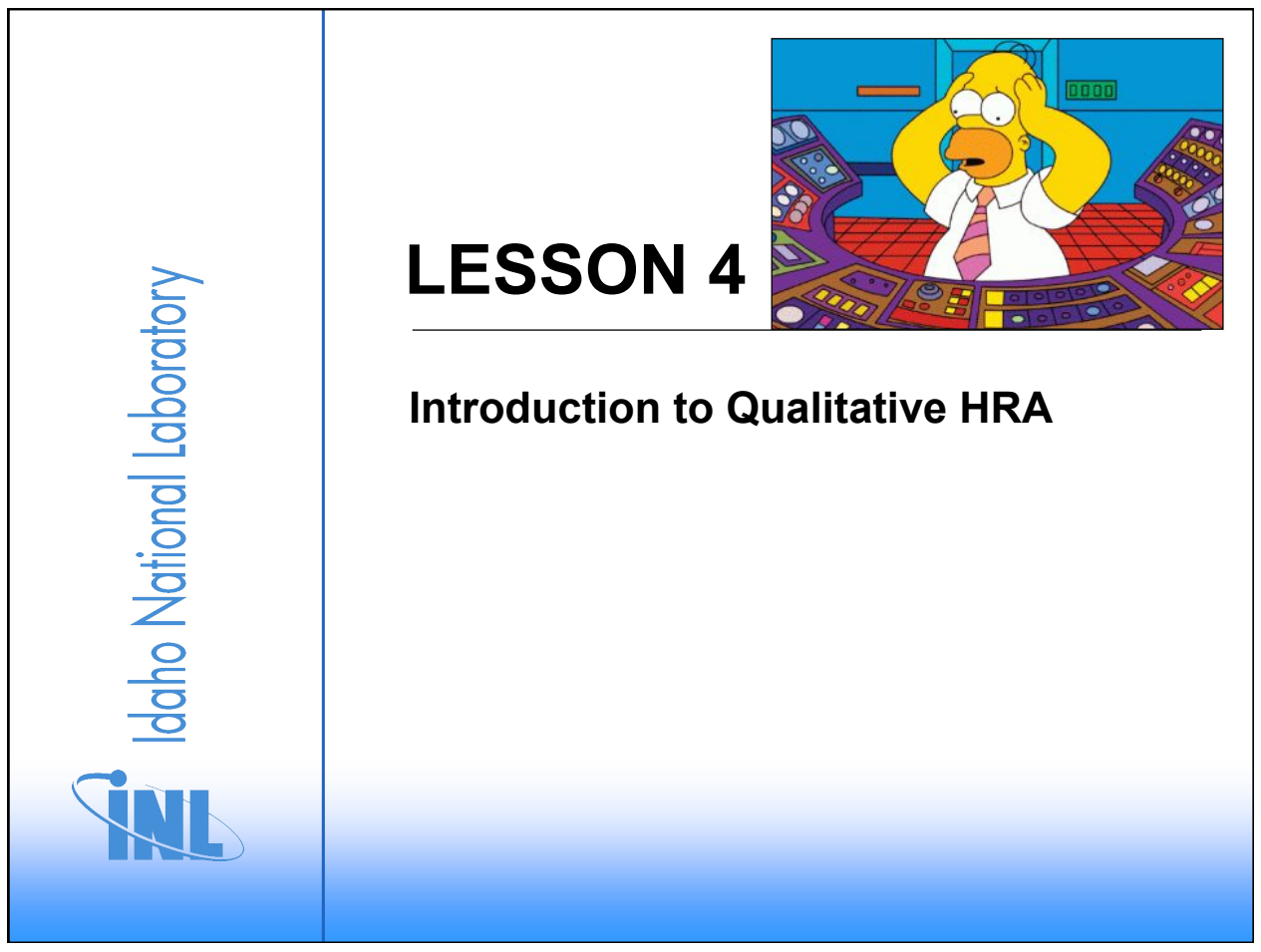

\section{Lesson 4 Objectives}

$\checkmark$ Introduce some of the uses of qualitative HRA

$\checkmark$ Review definitions and examples of human error

$\checkmark$ Introduce simple human-system interface model to explain opportunities for human errors

$\checkmark$ Discuss performance shaping factors

$\checkmark$ Discuss error taxonomies

$\checkmark$ Introduce task analysis 


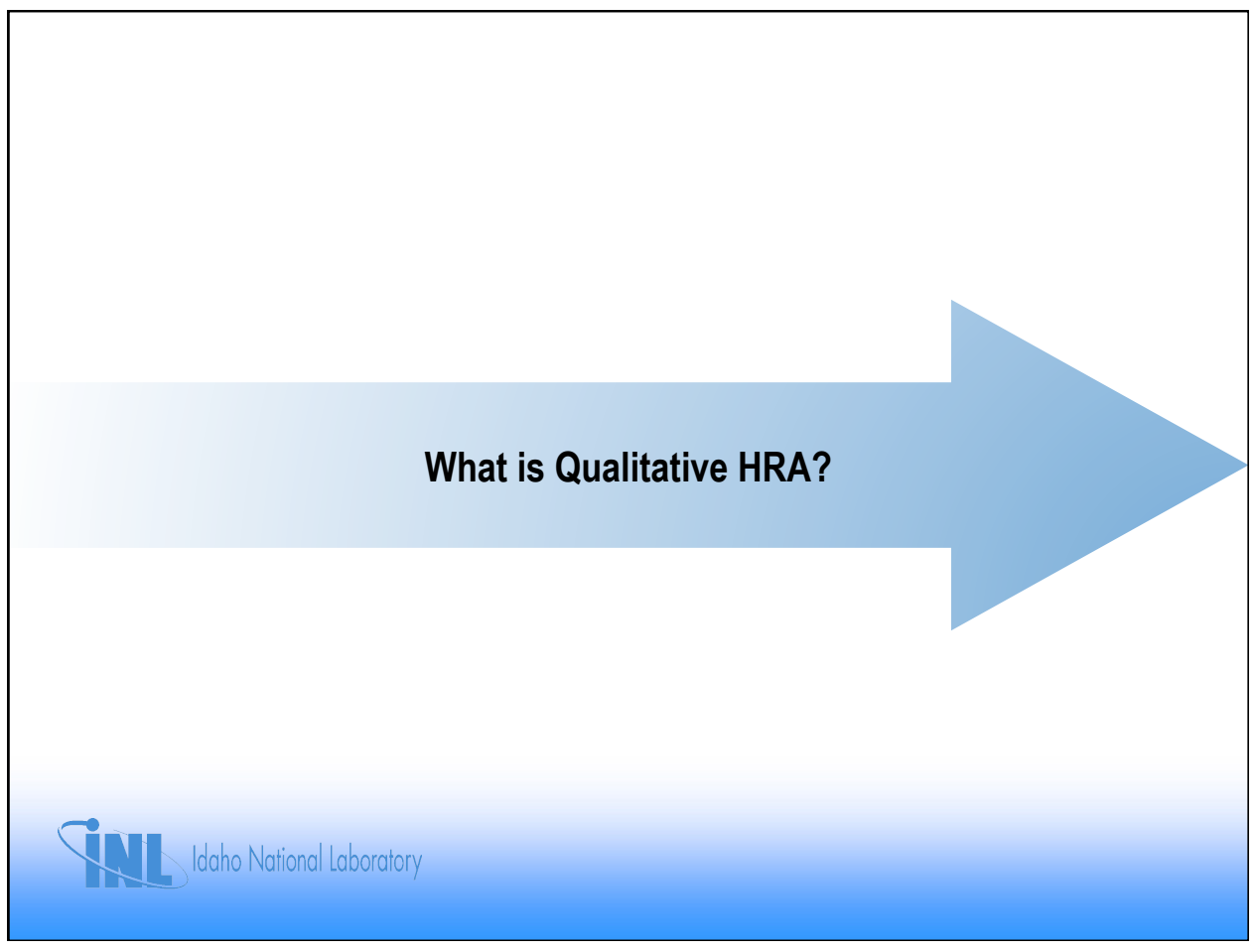

\section{Qualitative HRA}

\section{Purpose of Qualitative HRA}

- Apply human factors principles to understand sources of human error that can contribute to event outcomes

- Retrospectively: Understand what human errors contributed to the event and incorporate in the plant PRA

- Prospectively: Identify potential sources of human error, account for them in the plant PRA

\section{Benefits of Qualitative HRA}

- Helps ensure the realism of analysis

- It is inadequate to say that operator error occurred

- It is necessary to identify why that error occurred

- Different reasons underlying the same error outcome may result in different human error probabilities 


\section{Qualitative HRA: Understanding the Problem}

\section{Why do you need qualitative HRA?}

- To be able to identify, define, and model HFEs such that they are consistent with, for example:

- Specific accident sequence

- Associated plant procedures and operations

- Expected plant behavior and indications

- Engineering calculations that support the requirements for successful accident mitigation

- Consequences that are risk-significant

- To be able to select the appropriate quantification method

\section{Performing a Qualitative HRA}

How do you develop an understanding of the underlying problem you are analyzing?

- Perform an appropriately thorough qualitative analysis, performed iteratively and repeatedly throughout the entire HRA process until the final HRA quantification is done

Increasingly, there has been more focus on qualitative analysis in HRA/PRA guidance

- Joint EPRI/NRC-RES Fire HRA guidance (NUREG-1921/ EPRI TR 1019196)

- ATHEANA (NUREG-1624, Rev. 1, NUREG-1880)

- This emphasis is supported by, for example:

- "International HRA Empirical Study - Phase 1 Report (NUREG/IA-0216, Volumes 1 - 3) 


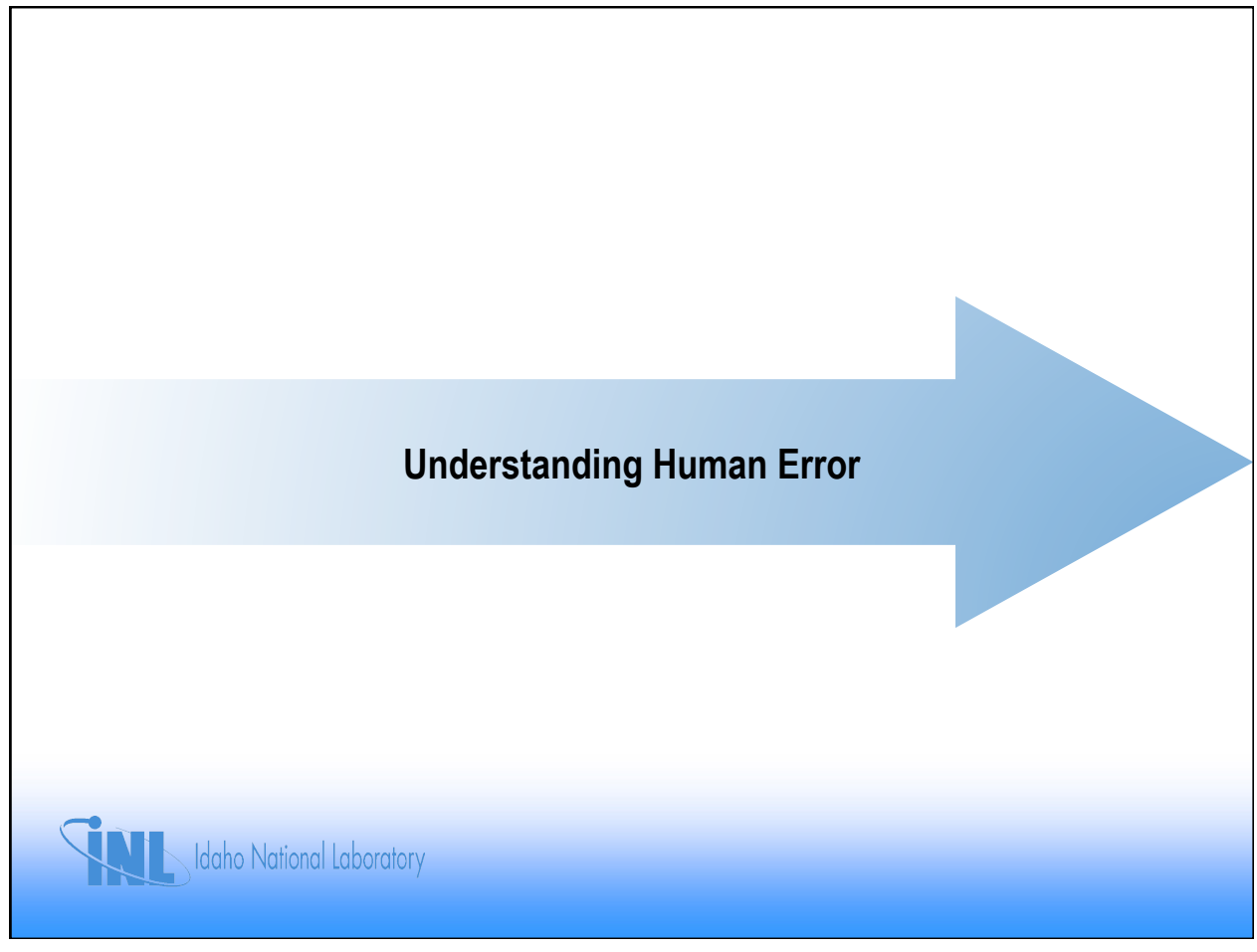

What do we mean by human error?

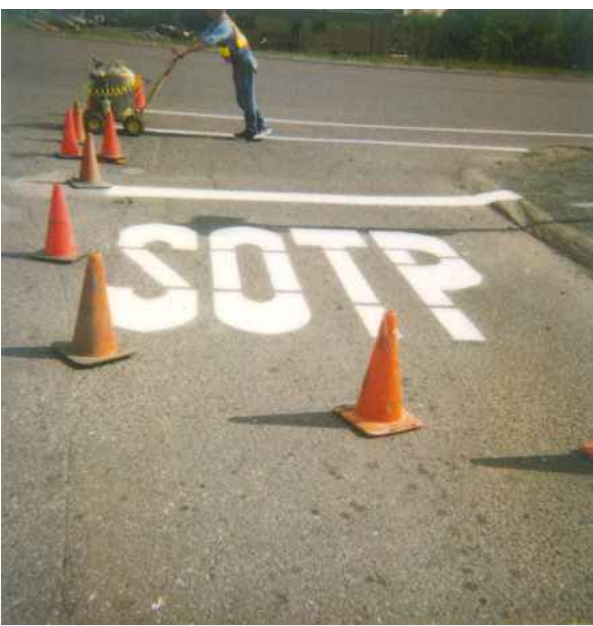

SiV. I caho National Laboratory 


\section{Human Error $=$ Human Failure}

- In the PRA community, the term "human error" has often been used to refer to human-caused failures of systems or components

- However, in the behavioral sciences, the same term is often used to describe the underlying psychological failures that may cause the human action that fails the equipment

- Therefore, the term human error is only used in a very general way, with the terms unsafe action and human failure event being used to describe more specific aspects of human errors

\section{Unsafe Action (UA)}

- Result in a degraded plant safety condition

\section{Human Failure Event (HFE)}

- A basic event that is modeled in the logic models of a PRA (event and fault trees), and that represents a failure of a function, system, or component that is the result of one or more unsafe actions

\section{Idaho National Laboratory}

\section{Human error has been shown to contribute from 50 to $70 \%$ of the risk at nuclear power plants}

From: E. A. Trager, Jr., Case Study Report on Loss of Safety System

Function Events, AEOC/C504, US NRC, 1985. 


\section{Importance of Human Error in Risk}

From NUREG/CR-6753 (2002)

\begin{tabular}{|l|l|l|l|l|l|l||}
\hline $\begin{array}{l}\text { Power } \\
\text { Plant }\end{array}$ & $\begin{array}{l}\text { Event } \\
\text { Date }\end{array}$ & $\begin{array}{l}\text { LER } \\
\text { Number }\end{array}$ & $\begin{array}{l}\text { SPAR } \\
\text { Analysis } \\
\text { CCDP }\end{array}$ & $\begin{array}{l}\text { Risk Factor } \\
\text { Increase } \\
\text { (CCDP/CDP) }\end{array}$ & $\begin{array}{l}\text { Event } \\
\text { Importance } \\
\text { (CCDP- } \\
\text { CDP) }\end{array}$ & $\begin{array}{l}\text { Human Error } \\
\text { Percent } \\
\text { Contribution } \\
\text { to Event } \\
\text { Importance }\end{array}$ \\
\hline $\begin{array}{l}\text { Wolf } \\
\text { Creek 1 }\end{array}$ & $1 / 30 / 96$ & $\begin{array}{l}482 / 96- \\
001\end{array}$ & $5.2 \mathrm{E}-03$ & 24,857 & $5.2 \mathrm{E}-03$ & 100 \\
\hline $\begin{array}{l}\text { Indian } \\
\text { Point 2 }\end{array}$ & $8 / 31 / 99$ & $\begin{array}{l}\text { AlT } 50- \\
246 / 99- \\
08\end{array}$ & $3.5 \mathrm{E}-04$ & 25 & $3.4 \mathrm{E}-04$ & 100 \\
\hline $\begin{array}{l}\text { McGuire } \\
2\end{array}$ & $12 / 27 / 93$ & $\begin{array}{l}370 / 93- \\
008\end{array}$ & $4.6 \mathrm{E}-03$ & 2.4 & $2.7 \mathrm{E}-03$ & 82 \\
\hline $\begin{array}{l}\text { Haddam } \\
\text { Neck }\end{array}$ & $6 / 24 / 93$ & $\begin{array}{l}213 / 93- \\
006 \&- \\
007 \text { AIT } \\
213 / 93- \\
80\end{array}$ & $2.0 \mathrm{E}-04$ & 4.3 & $1.5 \mathrm{E}-04$ & 48 \\
& & & & & \\
\hline
\end{tabular}

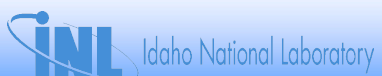

\section{Different Errors Contribute to Failure}

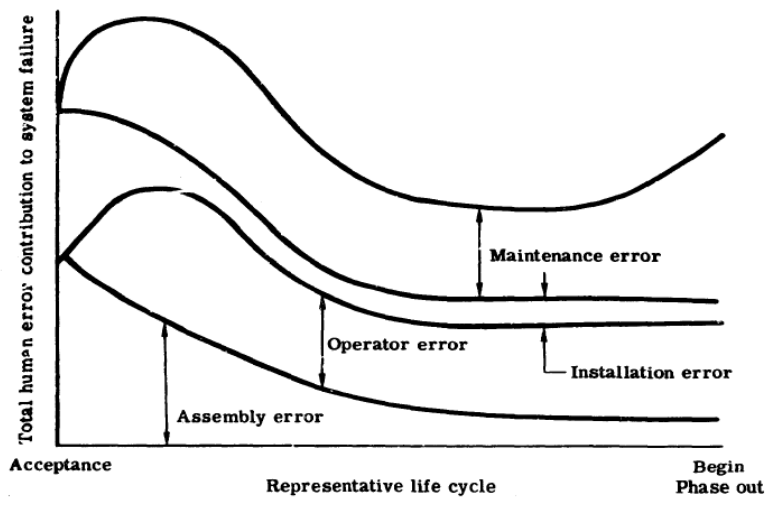

Proportional contribution of the different types of human error to overall failure across a manufactured product life cycle (Rigby, 1967) 


\section{Errors Can Occur Across Plant Operations}

NUREG-1774 chronicles crane operations from 1968 - 2002

- An average of $73 \%$ of incidents involved human performance

- Is the human performance component increasing?

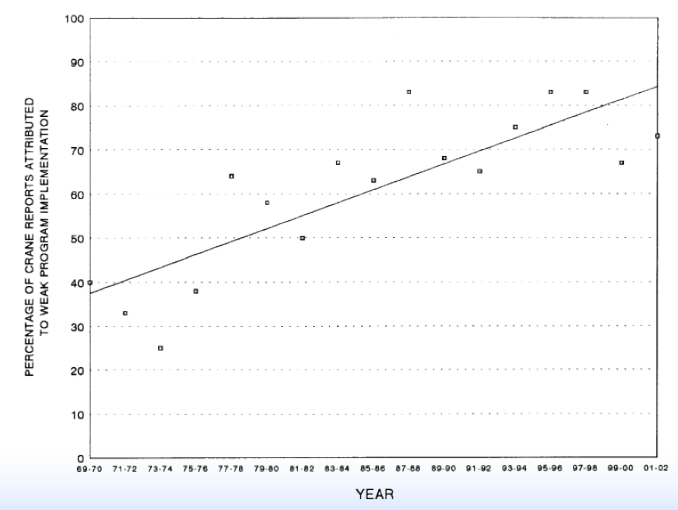

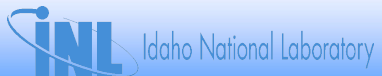

YEAR

\section{Human Errors in Crane Operations}

Largest human contributors to crane events in NUREG-1774

- Not following procedures

- Failure to establish the required ventilation prior to load movements in certain areas

- Failure to perform crane surveillance tests prior to use

- Failure to move loads over established safe load path areas

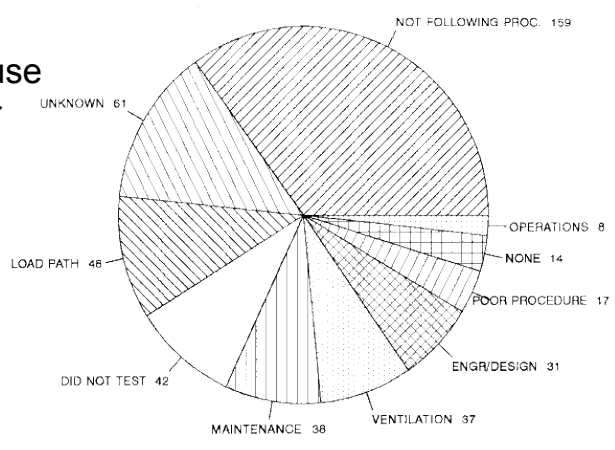

Figure 6: Principal reasons for crane events 


\section{Example Human Errors in Nuclear Power}

\section{CONDITION}

Too many alarms in the Control Room

The skill and knowledge required to operate equipment exceeds that planned in the current design.

The Human-System Interface design is found to be unusable or unacceptable during trials and reviews, and requires significant redesign.

Maintaining the wrong component because of inadequate identification.

The Human-System Interface gives inadequate indication to operator of system status.
ERROR

High operator workload limits the response time to threats and can lead to errors.

Full functionality of the design cannot be achieved. Additional training burden, potential errors. Failure to complete the project within time
and budget.

Production loss, environmental impact, equipment damage or injury.

Incorrect procedures performed, damage to $\square$ equipment or injury to personnel, etc.

\section{$\rightarrow$}

\section{Active and Latent Errors}

\section{Active Errors (Initiators and Post-Initiators)}

- Unsafe acts, failures of technological functions, or human errors that become the local triggering events that afterwards are identified as the immediate causes of an accident

- Considered to have immediate effects, e.g., operations error

\section{Latent Errors (Pre-Initiators)}

- Result in latent conditions in the system that may become contributing causes for an accident

- They are present within the system as unnoticed conditions well before the onset of a recognizable accident sequence

- Often caused by issues in assembly, maintenance, or configuration management

- e.g., a spare part that was incorrectly assembled

- e.g., maintenance personnel misconfigure wiring on a system only called into action every three months 


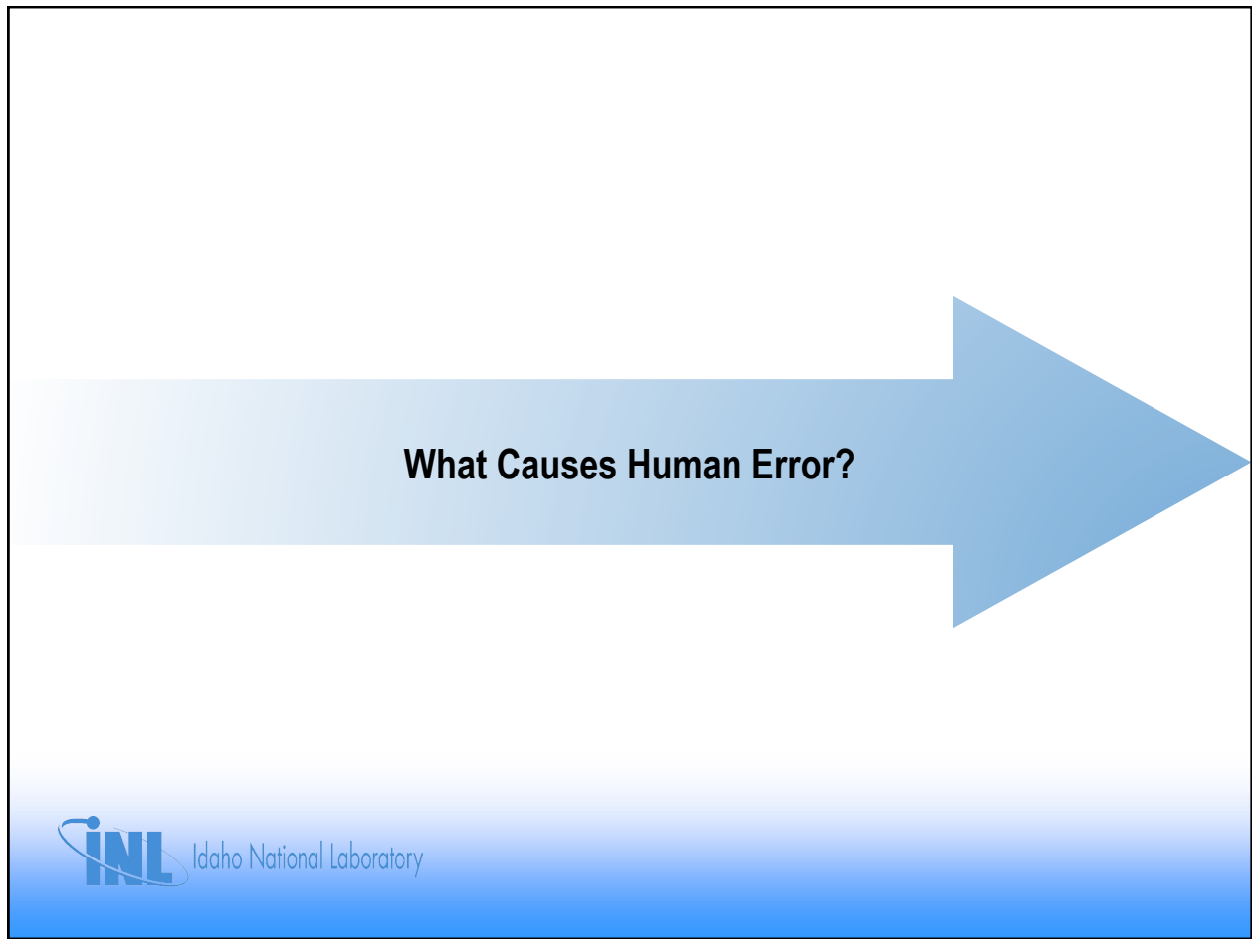

\section{Opportunities for Errors}

Humans are complex systems that must:

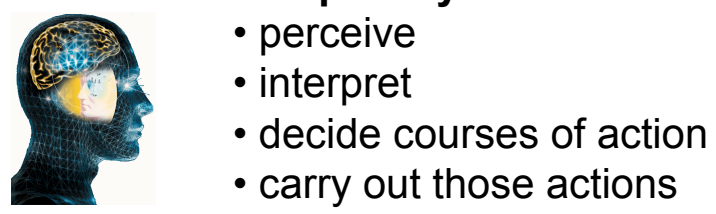

Each of these functions present opportunities for errors. 


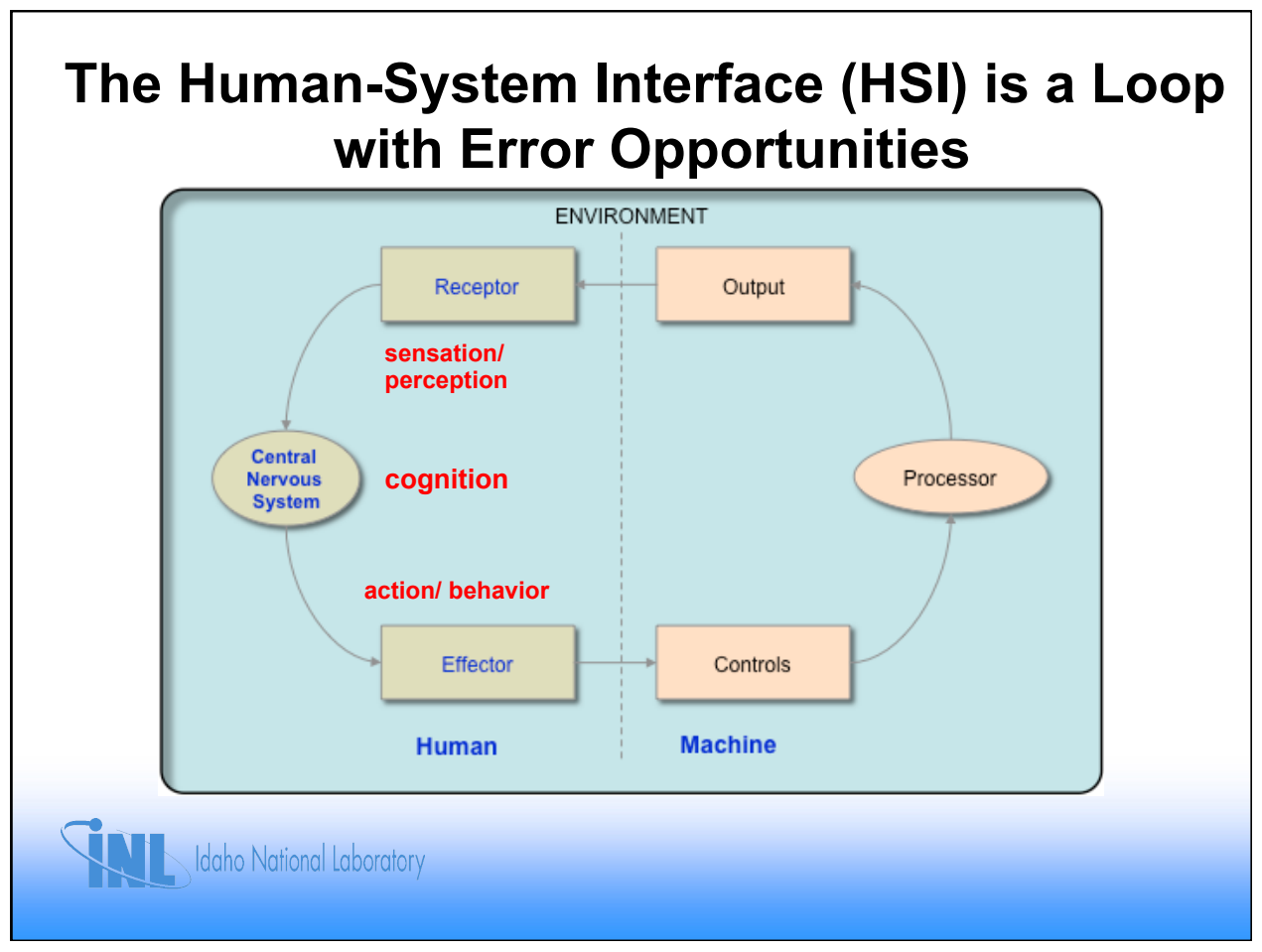

The Human-System Interface (HSI) is a Loop with Error Opportunities

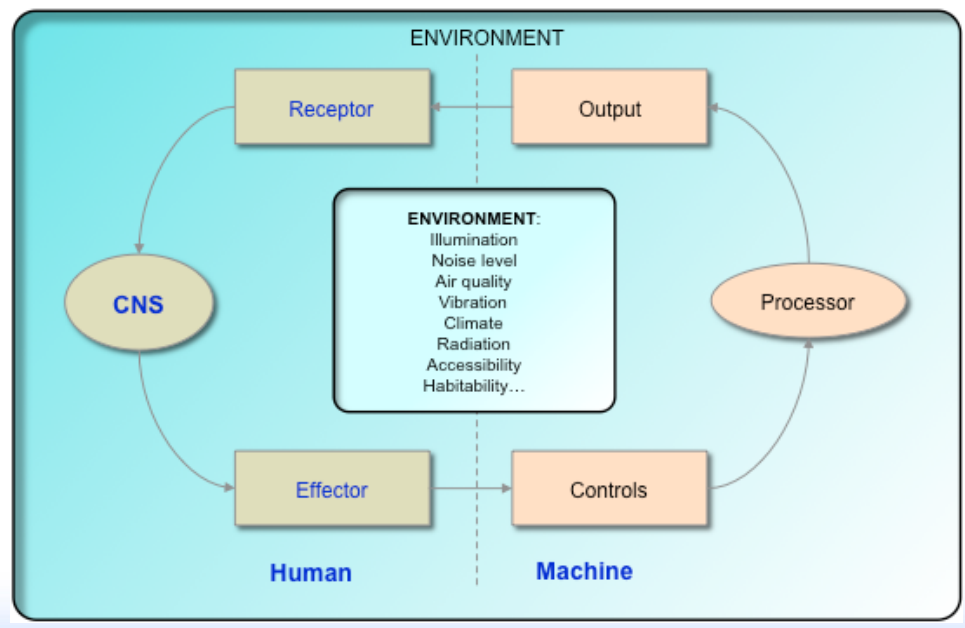

Sil Idaho National Laboratory 


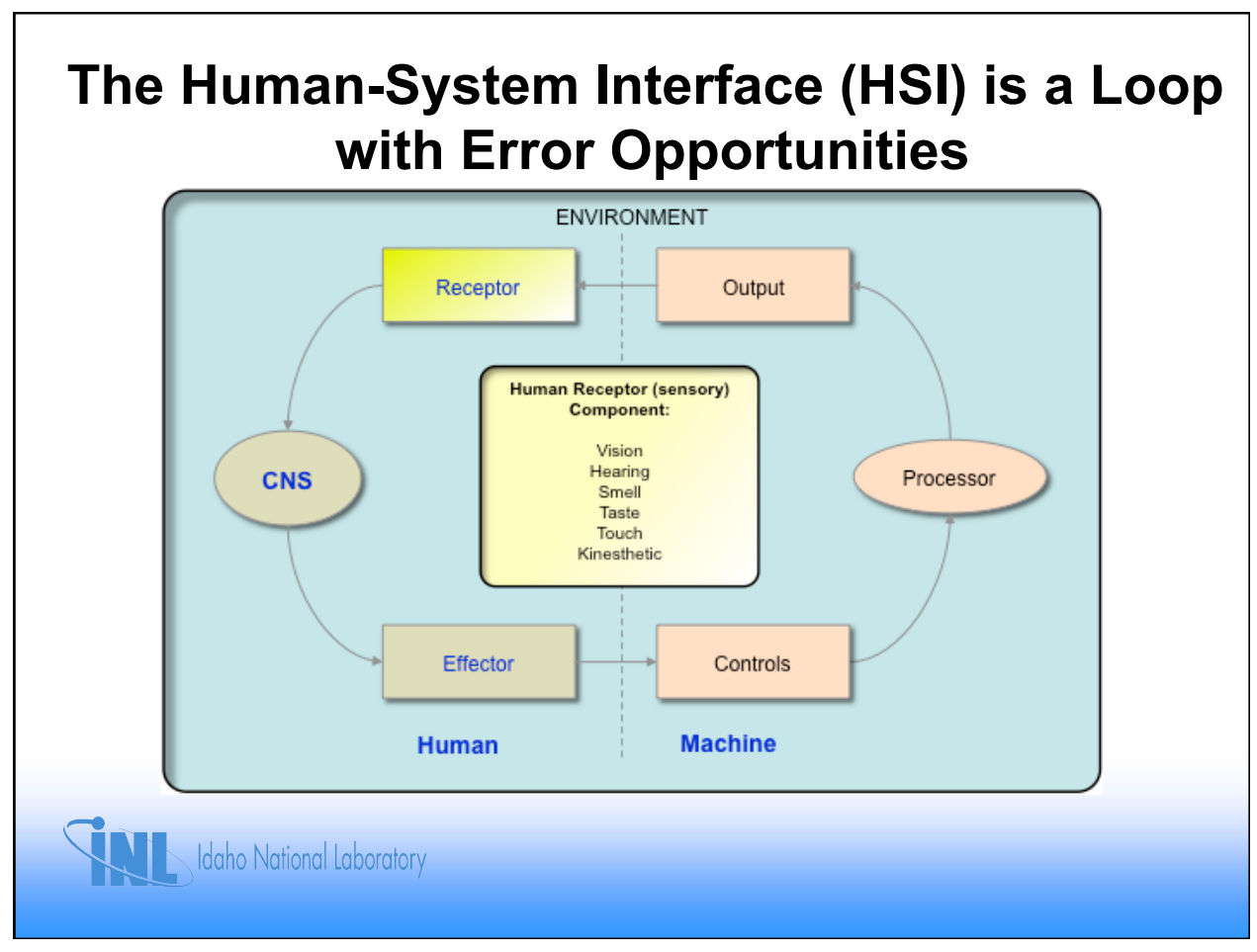

The Human-System Interface (HSI) is a Loop with Error Opportunities

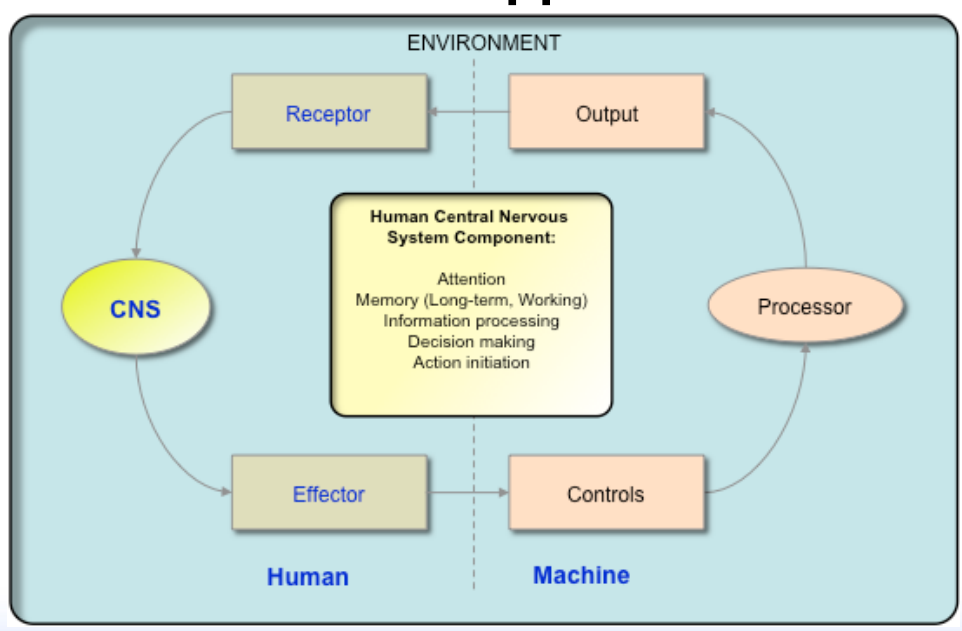

SII Idaho National Laboratory 

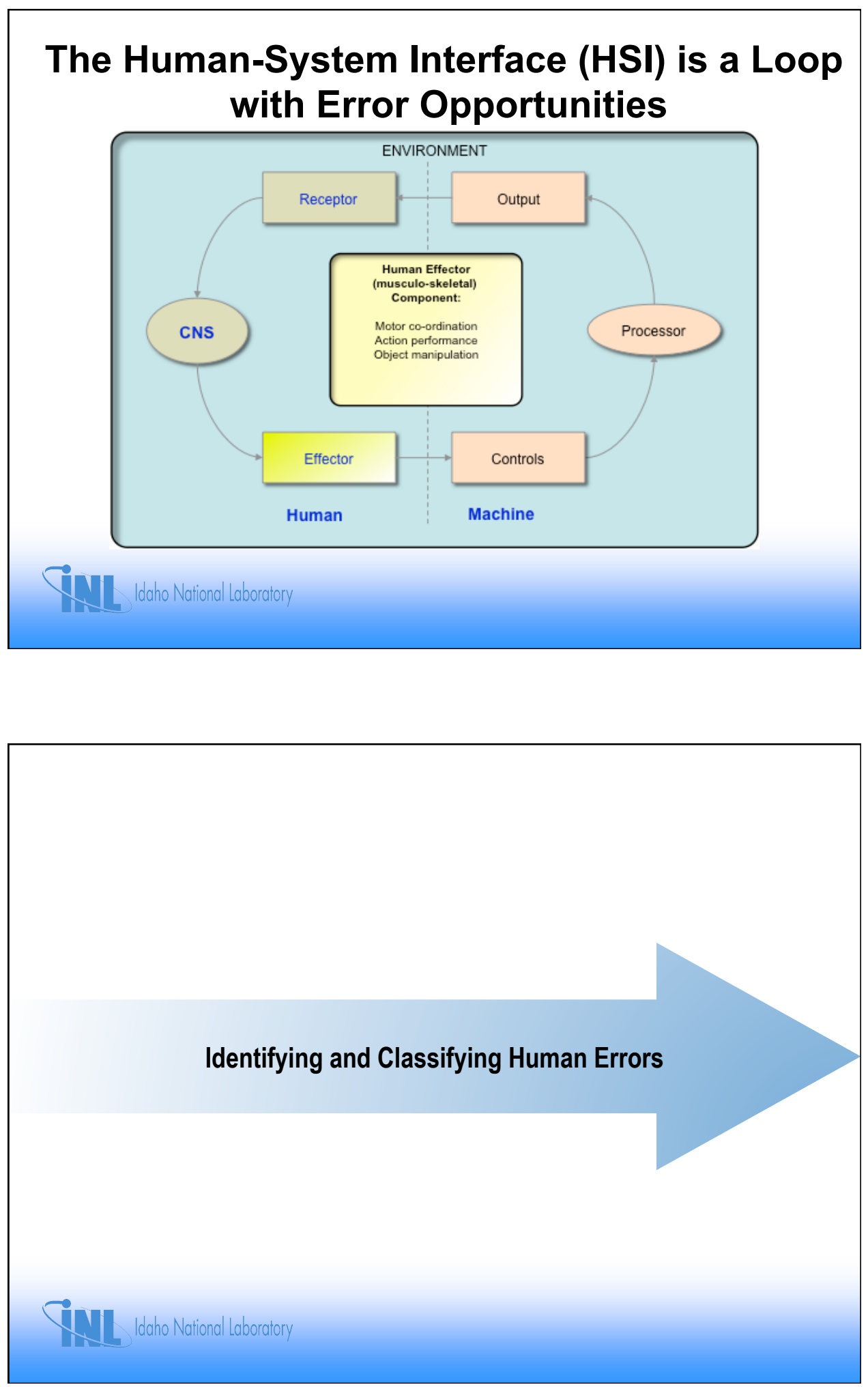


\section{Performance Shaping Factors}

Those factors that influence the performance and error likelihood of the human are called performance shaping factors (PSFs)

\section{ASME/ANS Definition of PSF:}

a factor that influences human error probabilities as considered in a PRA's human reliability analysis and includes such items as level of training, quality / availability of procedural guidance, time available to perform an action, etc.

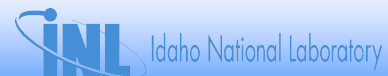

\section{Internal PSFs}

Internal PSFs are human attributes, such as skills, abilities, and attitudes, that operate within the individual, and which are brought to the job by the individual 
Exercise on human short-term memory ability (or lack thereof): Take out a blank sheet of paper. Listen to the list that the instructor reads to you. When the instructor has finished reading the list, quickly write all the items you can recall on the piece of paper.

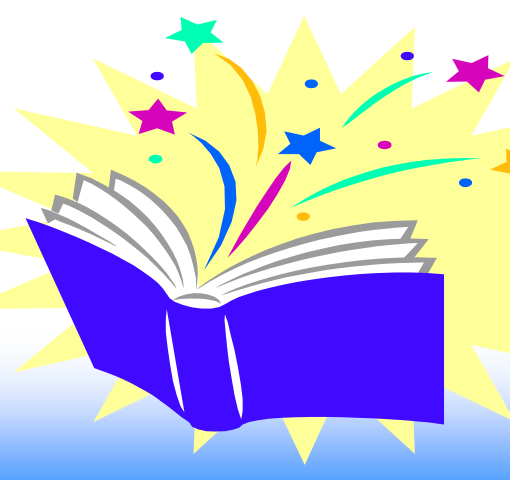

\section{Which Items are Recalled?}

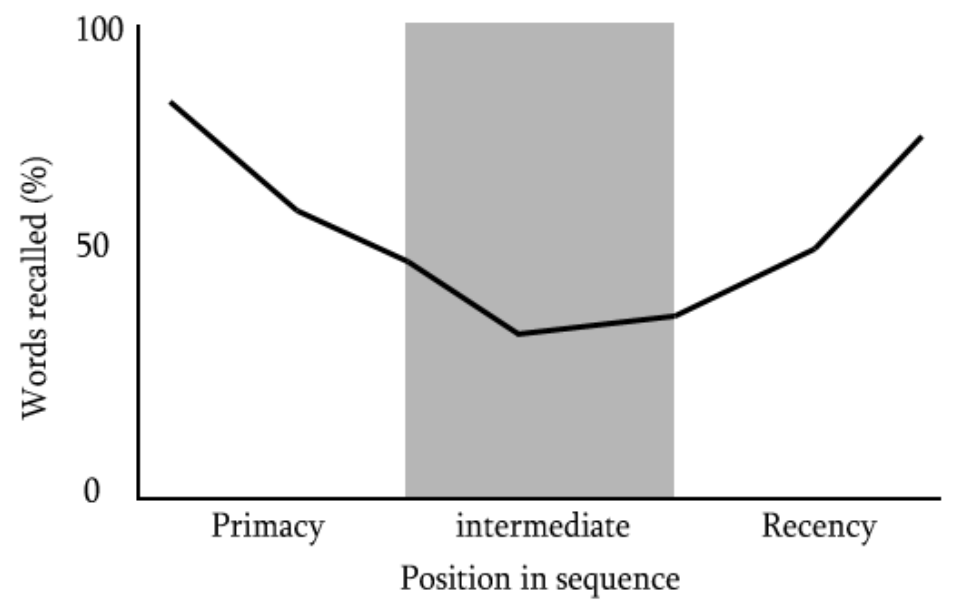




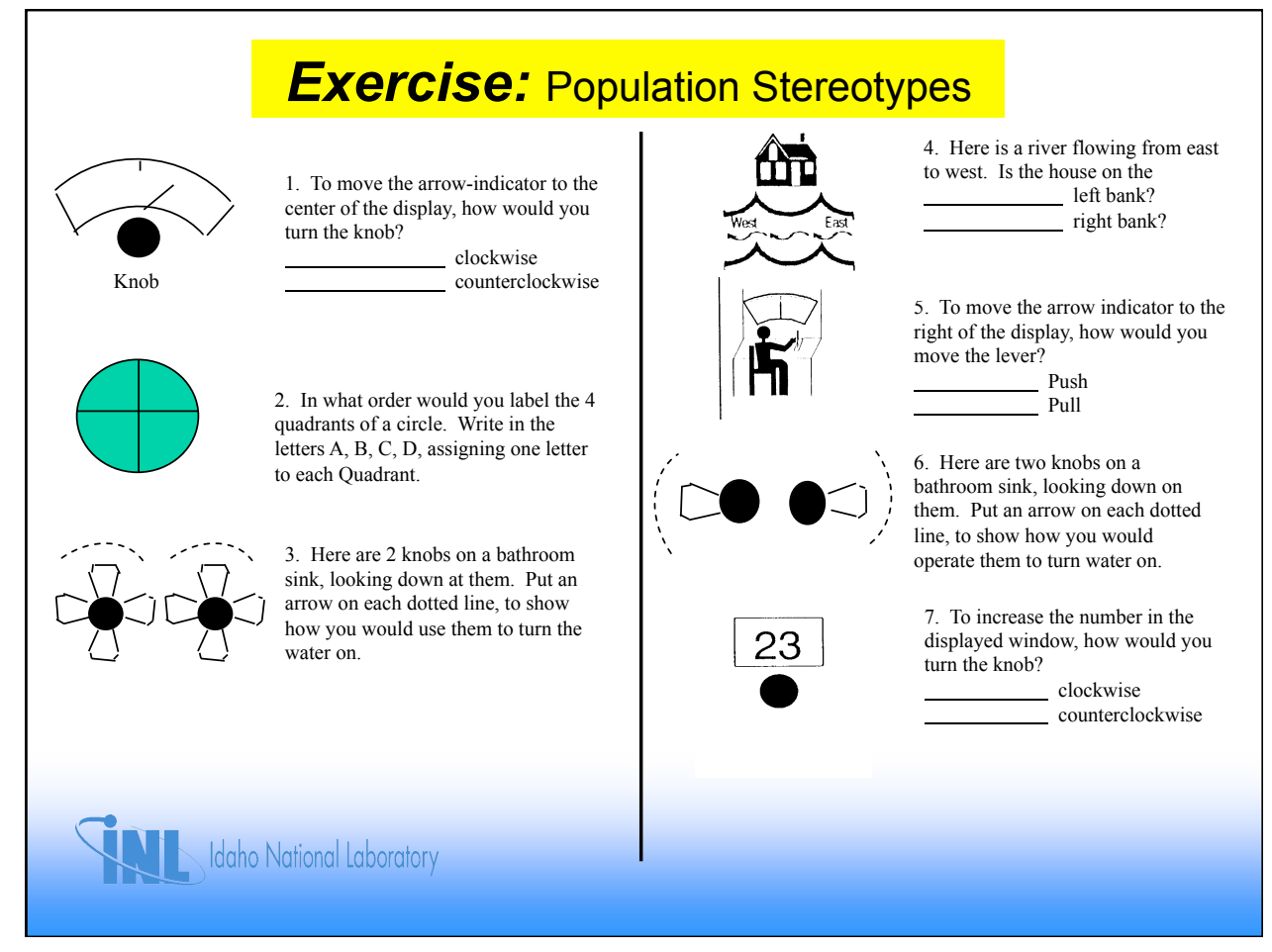

\section{Example: Stress as an Internal PSF}

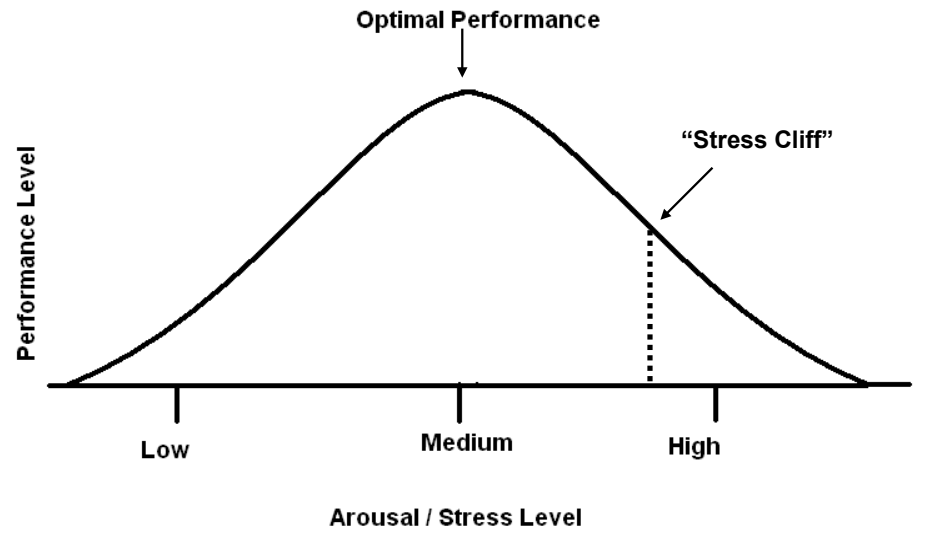

SII Idaho National Laboratory 


\section{Challenges of Using Internal PSFs}

While it is easy to "see" how internal PSFs affect behavior

they are not always easy to measure

and they may not have the same performance effect on everyone

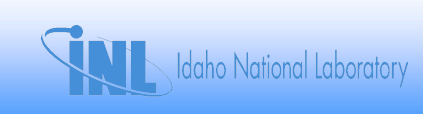

\section{External PSFs}

External PSFs are aspects of situations, tasks, and equipment characteristics that influence performance
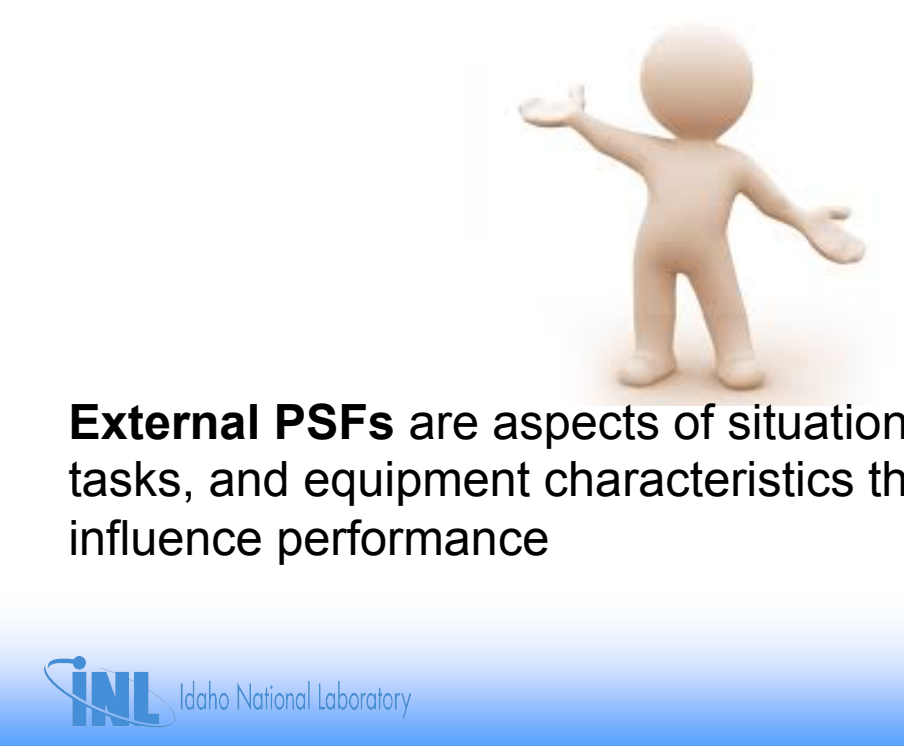


\section{Example: Noise as an External PSF}

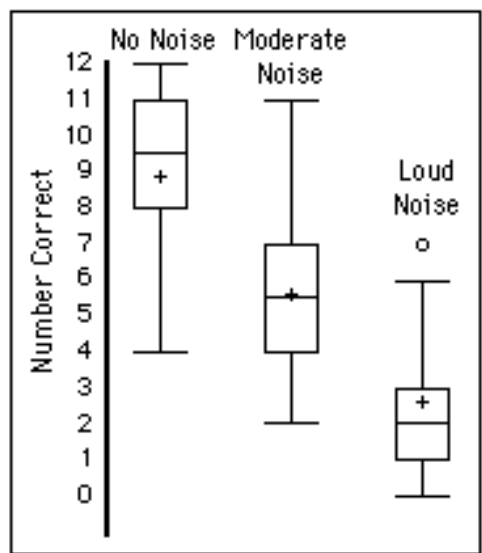

Figure 1. Box plots of the data for the three conditions.

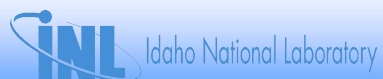

Exercise: What internal and external PSFs do you think may have been involved in this accident?

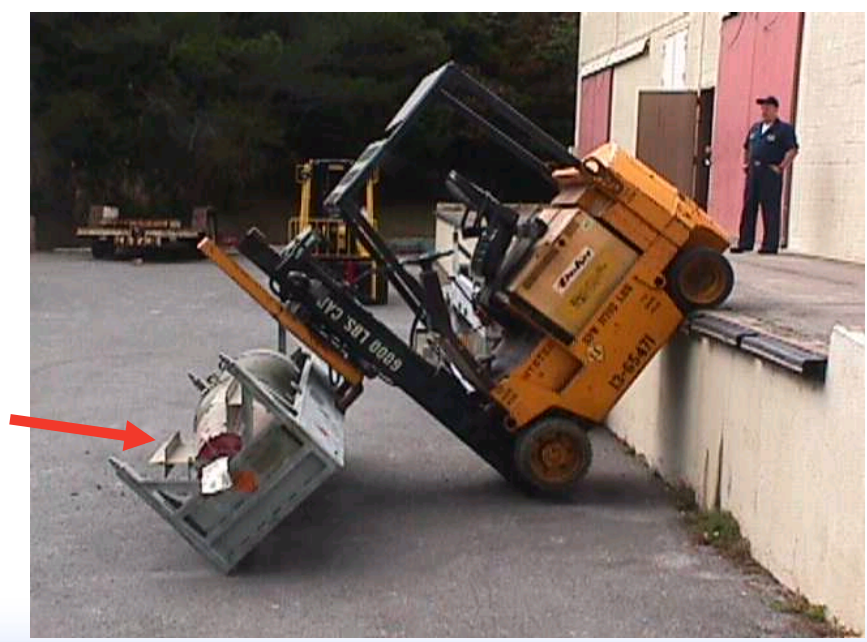




\section{PSFs in Augmented Inspection Team (AIT) Reports}

$\begin{array}{lc}\text { Human Error Type } & \text { AIT (40 teams) } \\ \text { Procedures } & 65 \% \\ \text { Training } & 40 \% \\ \text { Supervision } & 43 \% \\ \text { Human Engineering } & 40 \% \\ \text { Communications } & 35 \% \\ \text { Management \& Organization } & 83 \% \\ \text { Individual Issues } & 38 \% \\ \text { Workload } & 10 \% \\ \text { System Design } & 58 \% \\ \text { Work Environment } & 8 \%\end{array}$

Which are internal PSFs, and which are external PSFs?

\section{Till we}

\section{Good Practices PSFs}

\section{NUREG-1792 Identifies PSFs}

- Not exhaustive list, but minimum to be considered

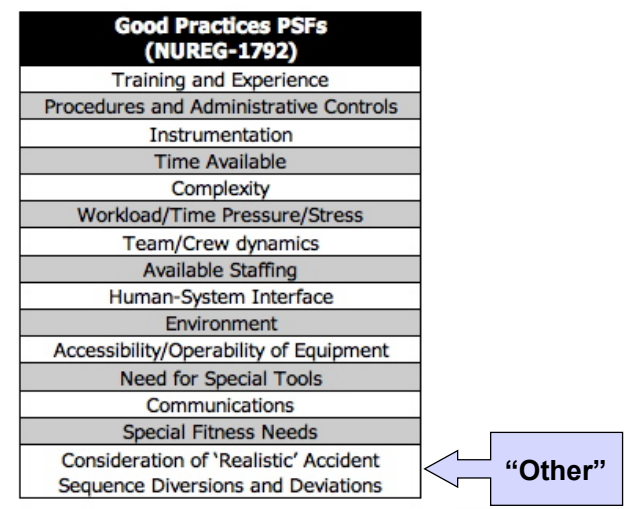

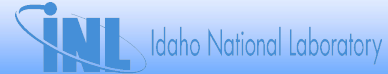




\section{Exercise: PSF Exercise}

1. Divide into groups

2. Problem definition: List all the performance shaping factors that might influence your performance during evacuating a building fire

3. For each performance shaping factor, identify and describe the mechanisms of how that factor affects the performance of the task

4. Describe how you might measure those factors

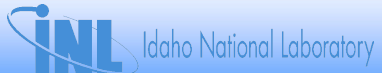

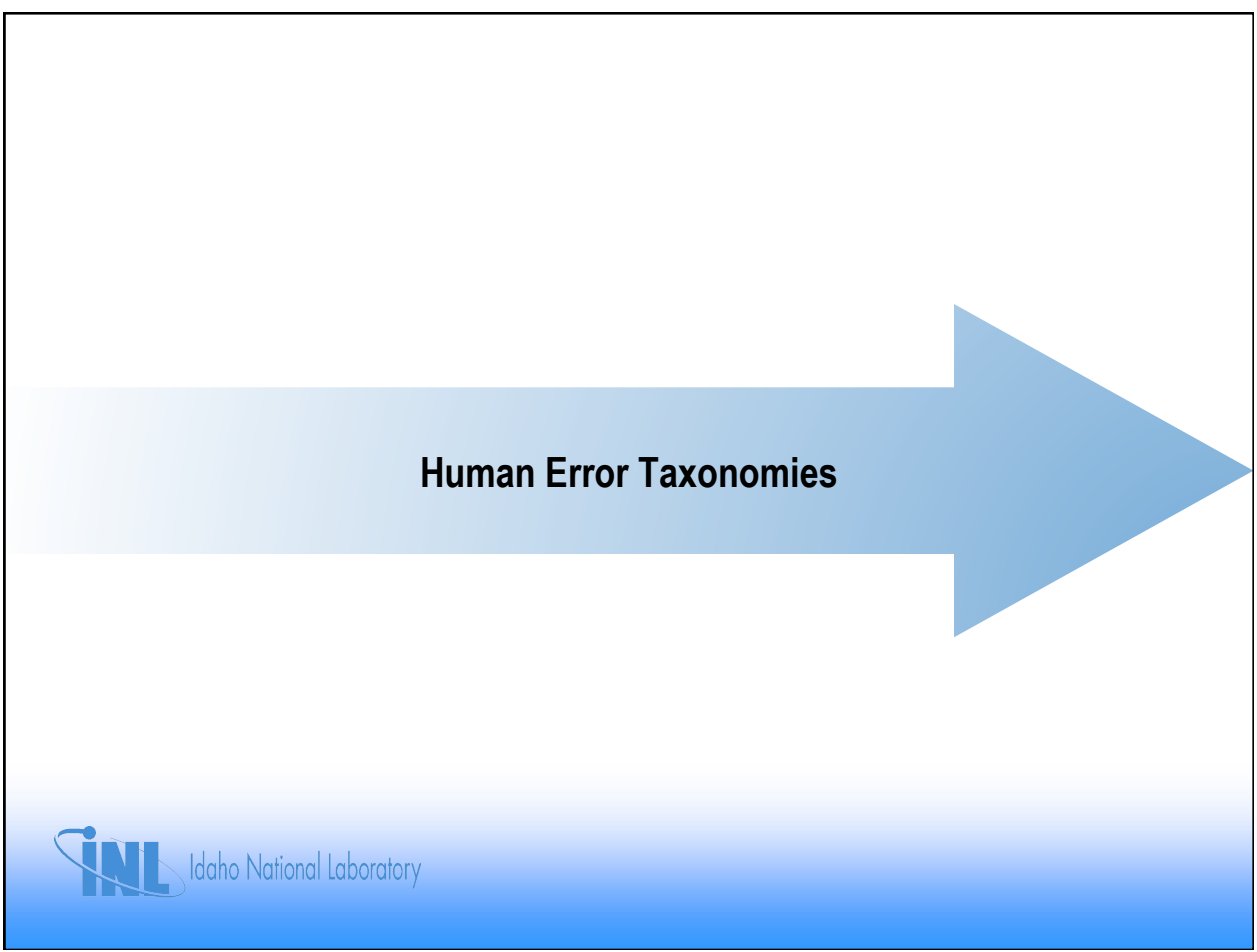




\section{Taxonomies of Human Error}

Taxonomy

- Systematic grouping according to laws and or principles

- Different HRA methods have different taxonomies

\section{Benefits}

- Aids analysts in identifying errors

- Ensures consistency in performance characterizations

- Helps analysts determine the underlying reasons for the error

We will examine three taxonomies:

- Swain and Guttman's Taxonomy (Commission/Omission)

- Rasmussen's Cognitive Taxonomy (Skill/Rule/Knowledge)

- Reason's Error Taxonomy (Slips/Lapses/Mistakes)

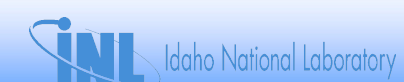

\section{Swain and Guttman's Taxonomy (1983)}

\section{Errors of omission}

- Fail to do something required

\section{Errors of commission}

- Do something you shouldn't do

\section{Sequence errors}

- Do something in wrong order

Timing errors

- Do something too slowly or too quickly 


\section{Rasmussen's Cognitive Taxonomy (1979)}

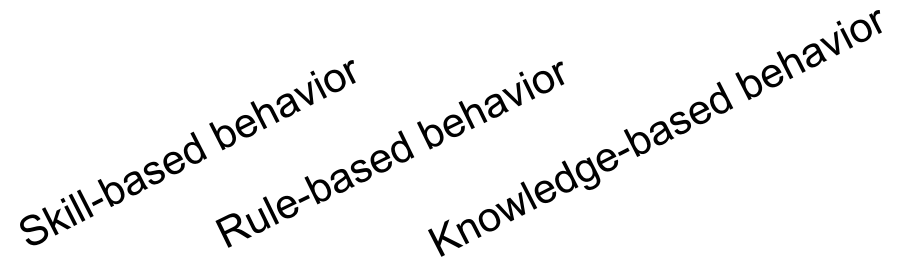

Behavioral Continuum

Skill-based = behavior that requires very little or no conscious control to perform or execute an action once an intention is formed (think: highly skilled and automatic)

Rule-based $=$ the use of rules and procedures to select a course of action in a familiar work situation (think: following procedures)

Knowledge-based = type of control that must be employed when the situation is novel and unexpected (think: operators have to rely on problem solving, which requires a lot of resources; they are not old pros at this)

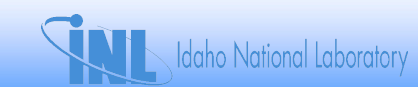

\section{Performance Modes}

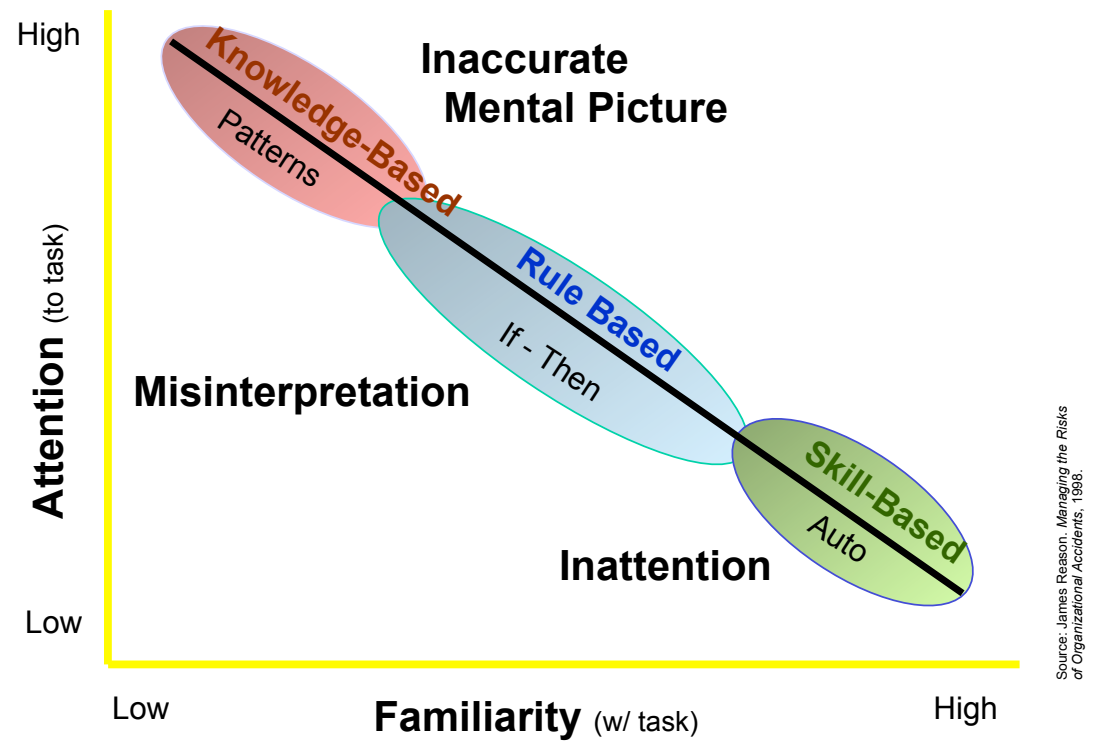




\section{Reason's Error Taxonomy (1980)}

\section{Slips}

- Good intentions, right mental model, but do something wrong

- An error of commission

\section{Lapses}

- Good intentions, right mental model, but fail to do something

- An error of omission

\section{Mistakes}

- Good intentions, wrong mental model

\section{Violation}

- Willful circumvention

- Not necessarily violation in the sense of malevolent intent; can also be "heroism" or "mentality of there's a better way to do something"

\section{Gint}

\section{Exercise on Taxonomies}

\section{Select an appropriate classification for each of these errors:}

1. An operator turns off an automated control system

2. A worker fails to clean out filings after installing a new pipe fitting

3. A disgruntled electrician reverses two wires on a switch

4. A painter leaves an emergency diesel generator inoperable after an outage

5. An operator fails to identify a steamline break immediately due to a missing alarm

6. A coworker enters a radioactive area without proper protective gear to remove an injured worker

7. The crew responds incorrectly initially to a plant upset that isn't covered in the procedures

8. A carpenter lacerates his leg with a circular saw during maintenance activities

9. Spent fuel personnel do not check to see if the lid is seated properly on a spent fuel canister

What PSFs might have been at play?

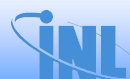




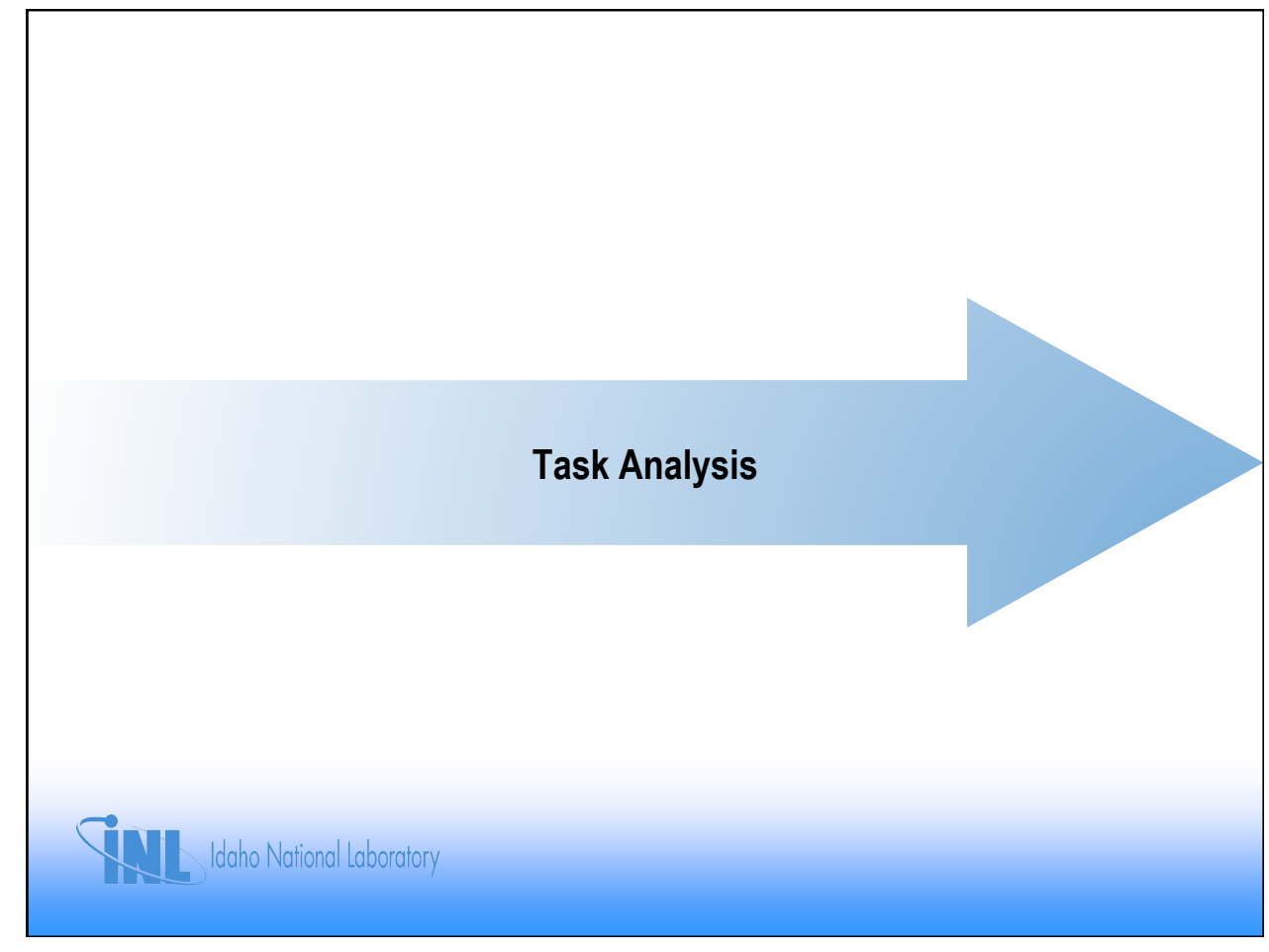

\section{Task Analysis}

A technique to help identify human activities in a task

- Think of it as the steps in a procedure of human actions, even though there may be no formal procedure

- May have different levels of task decomposition

- Can model high-level tasks such as everything related under a common task goal (e.g., establish heat sink)

- Can model low-level tasks such as all activities required (e.g., identify switch, turn switch to "off" position, verify it is off by disappearance of green "on" light)

- Functional system goals are starting points for identifying human tasks to be performed. 


\section{Task Analysis Steps}

- Capture each major decision or decision-action in the sequence of human and hardware activities

- Human actions may be clustered according to a highlevel goal (e.g., "establish core cooling") with sub-goals

- It is useful to treat tasks and subtasks as successful/ safe vs. unsuccessful/unsafe

- It is useful to treat actions chronologically

- For event investigation, actions are usually placed chronologically in a timeline

- For prospective risk modeling, the analyst considers the sequential risk significant activities that take place in response to plant operations and off-normal (abnormal, emergency) conditions

\section{Tabular Task Analysis Example}

\begin{tabular}{|c|c|c|c|c|c|c|c|c|}
\hline $\begin{array}{c}\text { Task } \\
\text { No. }\end{array}$ & $\begin{array}{c}\text { Task } \\
\text { Description }\end{array}$ & $\begin{array}{c}\text { Tark } \\
\text { Performer }\end{array}$ & $\begin{array}{c}\text { Location/ } \\
\text { System }\end{array}$ & $\begin{array}{c}\text { Procedure } \\
\text { Step }\end{array}$ & $\begin{array}{c}\text { Time } \\
\text { Required }\end{array}$ & PSFs & $\begin{array}{c}\text { Success/ } \\
\text { Failure }\end{array}$ & Performance Notes \\
\hline 1 & Trip Reactor & $\begin{array}{c}\text { ator } \\
\text { antro1s }\end{array}$ & Pane1 4 & $\begin{array}{c}\text { Aop-16, } \\
\text { Step 15 }\end{array}$ & 30 sec & Stress & Success & We11 trained task \\
\hline & & & & & & & & \\
\hline & & & & & & & & \\
\hline & & & & & & & & \\
\hline & & & & & & & & \\
\hline & & & & & & & & \\
\hline & & & & & & & & \\
\hline
\end{tabular}




\section{Task Analysis Exercise}

- Develop a task analysis (i.e., identify the steps/ sequence required) for earlier exercise of "respond to station blackout"

- Hint: think safety-critical functions, performance, etc.

- Identify any performance shaping factors revealed by this task analysis

- Report out and discuss

\section{I. Idaho National Laboratory}

\section{What Do We Mean by Human Error?}




\section{What Might Have Caused This Error?}

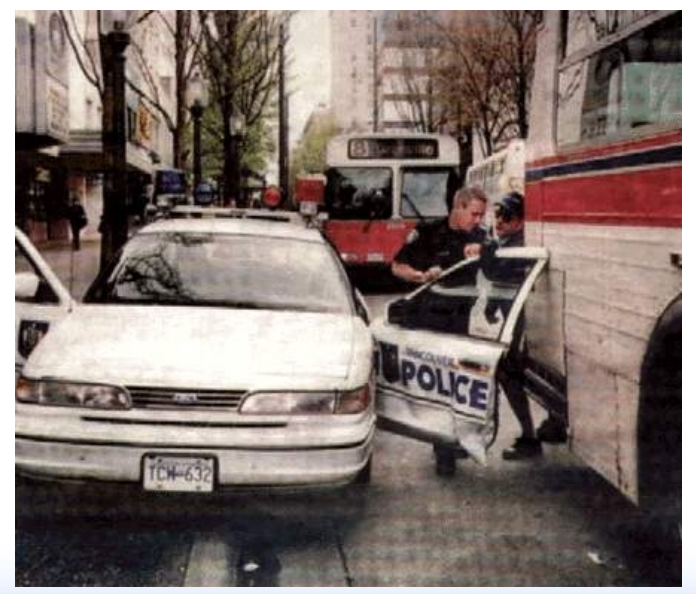

\section{Old and New Views of Human Error}

Sidney Dekker in The Field Guide to Understanding Human Error (2015) suggests that the concept of "human error" may be misleading

The Old View of Human Error: The "Bad Apple" Theory

- Humans are unreliable

- Human errors cause accidents

- Failures come as unpleasant surprises

The New View of Human Error

- Human error is the effect or symptom of deeper trouble

- Human error is systematically connected to people's tools, tasks, and operating environment

- Human error is not the conclusion of an investigation but rather the starting point

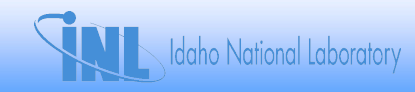




\section{Old and New Views of Human Error (cont.)}

Dekker suggests that the "old view" oversimplifies

- Somebody didn't pay enough attention

- If only somebody had caught the error, then nothing would have happened

- Somebody should have put in a little more effort

- Somebody thought that taking a safety shortcut was not such a big deal

The "new view" tries to capture the complexity of the situation

- Safety is never the only goal of a worker

- People do their best to reconcile goals and make trade-offs (efficiency vs. safety)

- Nobody comes to work to do a bad job!

- A system isn't automatically safe unless safety is created in the organization-this is the safety culture of the organization

- New tools and technologies introduce new opportunities for errors

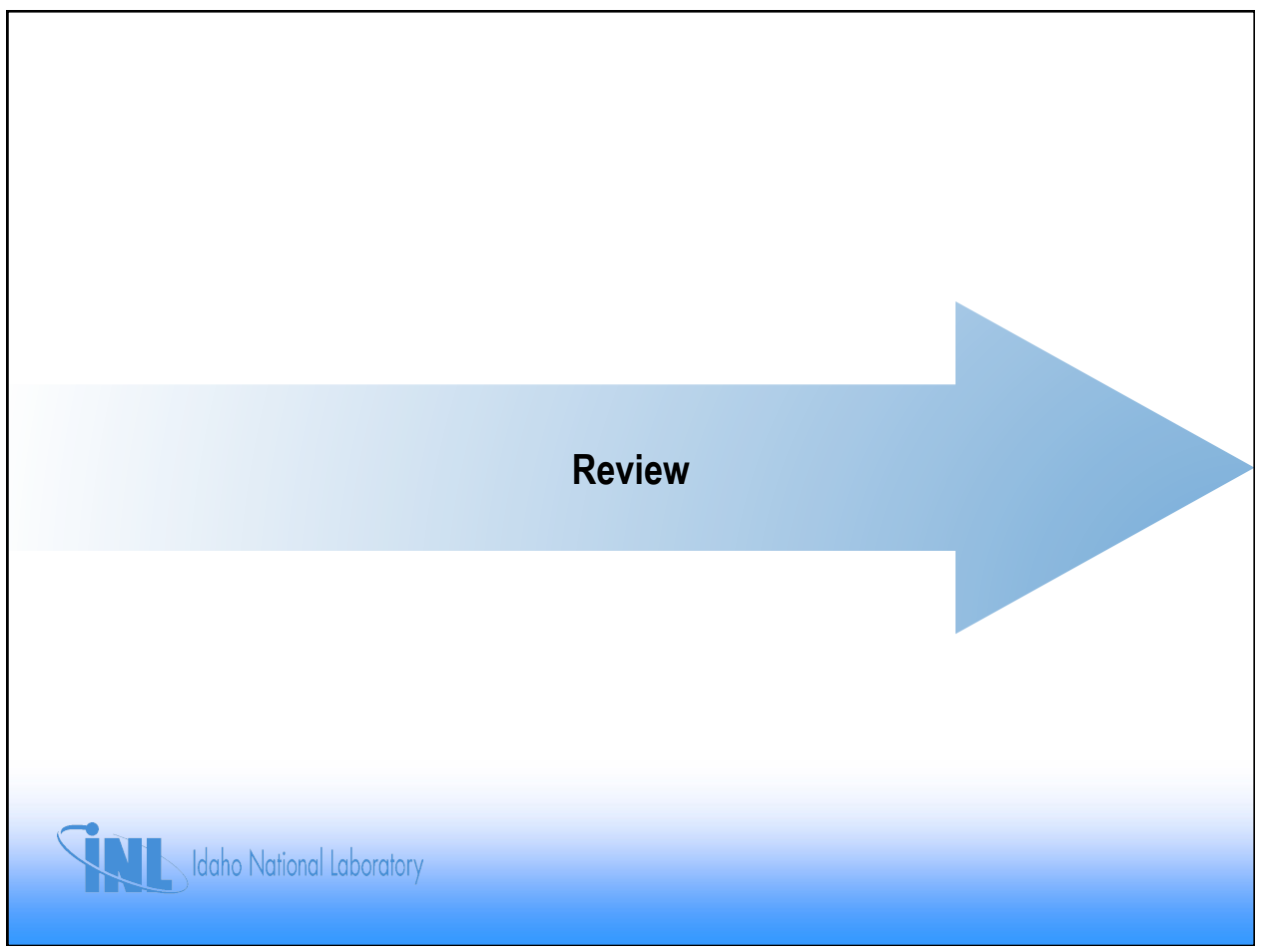




\section{Lesson 4 Review}

- What is the purpose of a qualitative analysis in HRA?

- What is human error?

- What is a human failure event?

- What is a latent error?

- What is an internal PSF?

- What is an external PSF?

- What is the difference between a slip, lapse, and mistake?

-What's the difference between an error of commission vs. omission?

- What is skill based behavior?

- What is a task analysis used for in HRA?
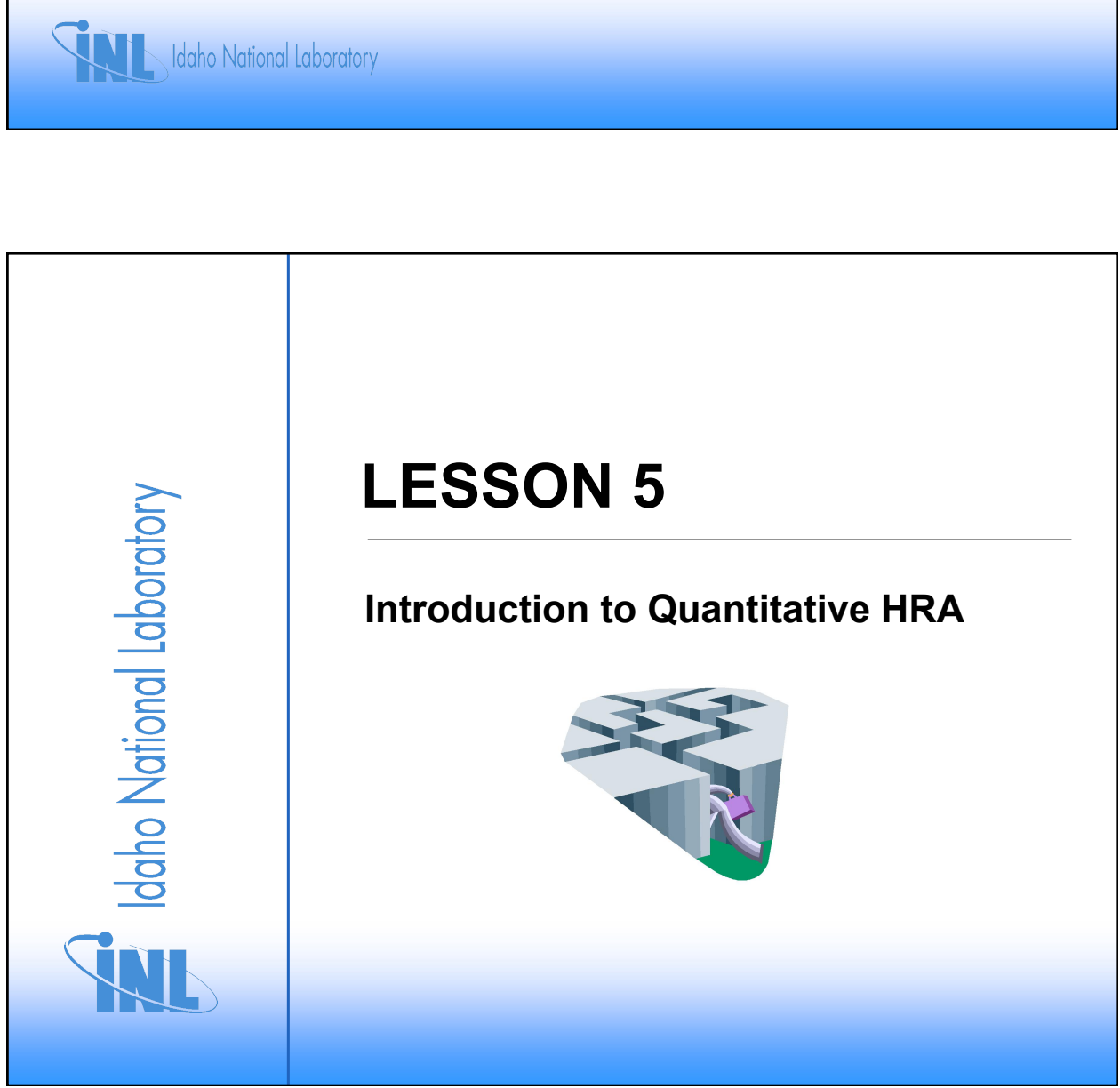


\section{Lesson 5 Objectives}

$\checkmark$ Introduce the role of quantification in HRA

$\checkmark$ Distinguish between screening and detailed quantification

$\checkmark$ Introduce concepts related to the human error probability such as nominal HEP, recovery, and dependence

$\checkmark$ Understand basic principles of uncertainty

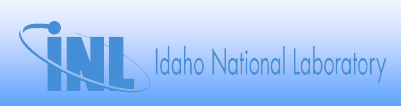

What is Quantitative HRA? 


\section{Quantifying a Human Failure Event (HFE)}

- Quantification is a major goal of most HRAs

- Support risk-informed decision making

- Quantifying is the process of assessing the probability of the HFE(s)

- The steps involved in the calculation depend on the method being used

- The data for the calculations may come from databases, simulations, expert judgment, and the HRA methods themselves

- The result is typically called a Human Error Probability (HEP)

- Various intermediate products may be created

\section{Why Quantify HRA Models?}

- Quantification is an essential part of PRA

- Quantification supports the assessment of importance of PRA scenarios (HFEs)

- Quantification allows analyst to obtain operator action importance measures (e.g., Fussell-Vesely; Risk Achievement Worth)

- Quantification enables prioritization of prevention/ mitigation activities (risk management)

- Quantification enables the evaluation of alternatives (design, operations, etc.) 


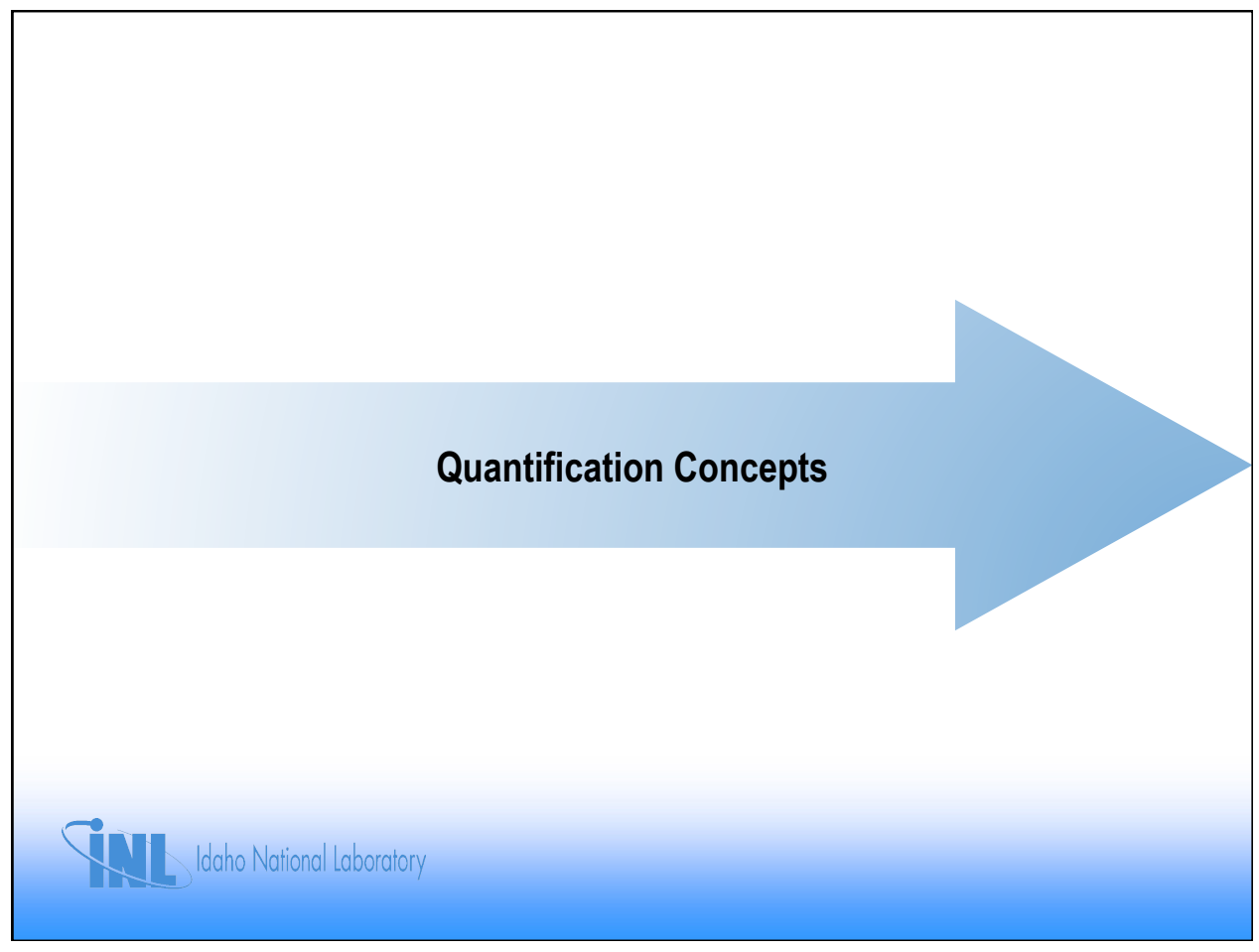

\section{Two Levels of Realism}

1. Screening Analysis

- Conservative level useful for determining which human errors are the most significant detractors from overall system safety

- An HEP for a modeled HFE may be set to a high value (e.g., 0.5) to determine if it might be risk significant

- Conservative values are higher than analysts would normally use

- Determine if the HFE affects the event outcome

\section{Detailed Analysis}

- HFEs that are found to be potentially significant contributors are analyzed in greater detail using more realistic quantification

- HRA and PRA are iterative, such that there is a process of refinement and more detailed analysis for risk significant HFEs 


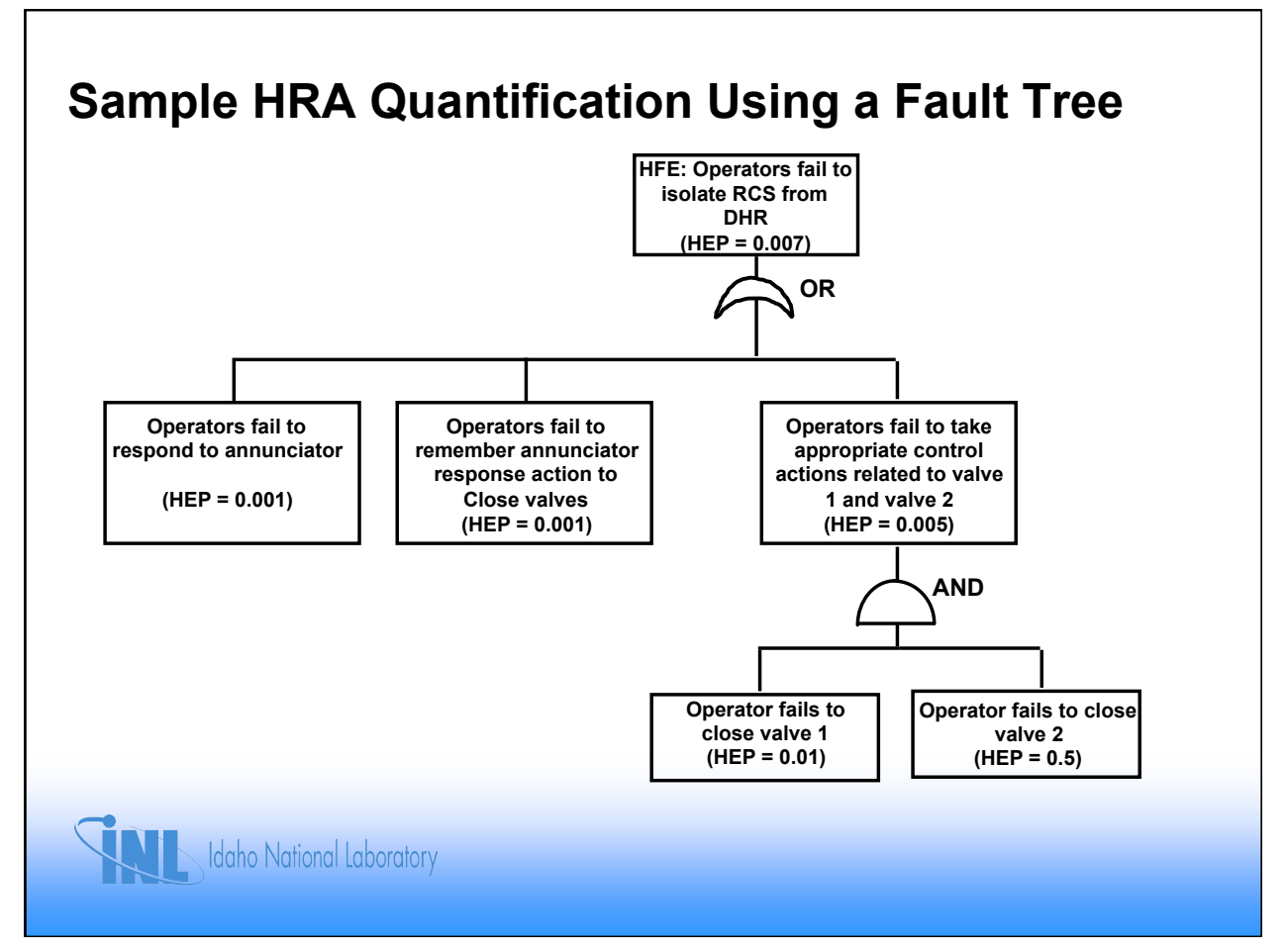

\section{Human Error Probability (HEP)}

Nominal Error Rate (Nominal HEP)

- Generic error rate for a type of activity

- Typically provided by the method

Base Error Rate (Base or Basic HEP)

- Nominal HEP modified for influences on performance such as PSFs

- These may increase or decrease the nominal HEP

Conditional Error Rate (Conditional HEP)

- Base HEP modified for any dependency or recovery factors in a sequence of events 


\section{HEP Ranges}

- Average or nominal performance in the range of $1 \mathrm{E}-2$ to $1 \mathrm{E}-3$ (error $1 / 100$ to $1 / 1000$ times)

- Exceptionally good performance may be seen in the range of $1 \mathrm{E}-4$ to $1 \mathrm{E}-5$ (error $1 / 10,000$ to $1 / 100,000$ times)

- Better than some hardware!

- Poor performance may be seen in the range of 1.0 or $1 \mathrm{E}-1$ (error all the time or $1 / 10$ times)

- These values feature much greater unreliability than is typical for hardware

- Temptation to want to drive HEP lower, but this is not realistic

\section{STI Idaho National Laboratory}

\section{Dependence}

Dependence $($ Dependency $)=$ Relationship between HFEs

- Dependence with Negative Influence

- Error on HFE1 increases likelihood of error on HFE2

- Dependence with Positive Influence

- Success on HFE1 decreases likelihood of error on HFE2

\section{Simply Restated}

- $P(H F E 2 \mid H F E 1)>P(H F E 2)$ negative influence

- $\mathrm{P}(\mathrm{HFE} 2 \mid \mathrm{HFE} 1)<\mathrm{P}(\mathrm{HFE} 2)$ positive influence 


\section{Visualizing Dependency}

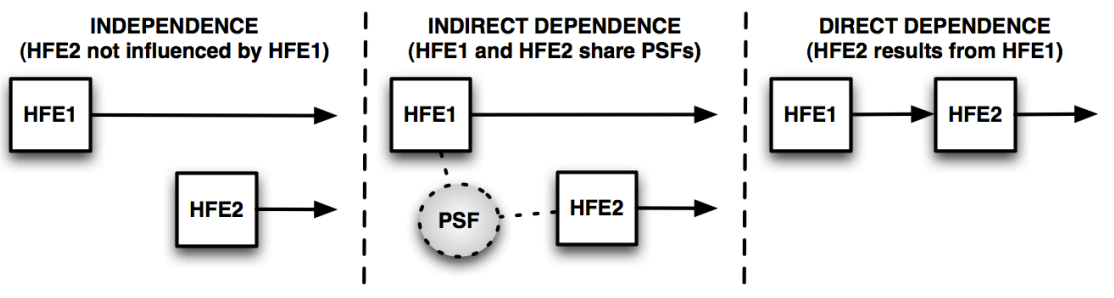

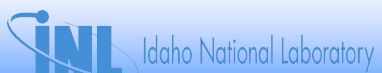

\section{Uncertainty Quantification}

\section{Aleatory Uncertainty}

- The uncertainty inherent in a nondeterministic (stochastic, random) phenomenon

- In principle, aleatory uncertainty cannot be reduced by the accumulation of more data or additional information

- Sometimes called "randomness"

\section{Epistemic Uncertainty}

- The uncertainty attributable to incomplete knowledge about a phenomenon that affects our ability to model it

- In principle, epistemic uncertainty can be reduced by the accumulation of additional information

- Sometimes called "modeling uncertainty" 


\title{
Uncertainty Quantification (cont.)
}

\author{
Uncertainty Calculation
}

- Provided or calculated as part of method

- Represents aleatory and epistemic uncertainties

- Can be presented as Error Factor (EF)

- Ratio of 95 th/50th or 50th/5th

- Upper Bound (UB) $=\mathrm{HEP}{ }^{*} \mathrm{EF}$

- Lower Bound (LB) = HEP / EF

- Usually uniform distribution

- Same EF for each tail

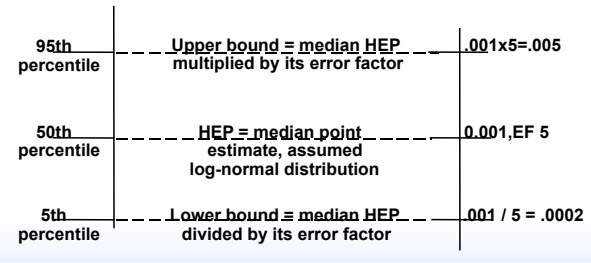

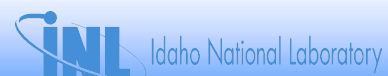

\section{HRA Quantification Approaches}

Performance Shaping Factor Adjustment Methods (e.g., SPAR-H)

- PSFs serve as multipliers on nominal error rates

Decision Tree Methods (e.g., CBDT)

- Finite number of quantification values that are determined by a decision tree (similar to an event tree)

Scenario Matching Methods (e.g., THERP)

- HFEs matched to similar pre-quantified scenarios

Expert Estimation Methods (e.g., ATHEANA)

- Subject matter experts provide estimates of likelihood of HFEs

Simulation Methods (e.g., ADS-IDAC)

- Dynamic human performance models run through iterative (Monte Carlo simulation) to produce frequency estimates

- Approach still in development and not yet ready for general quantification We will explore each of these approaches (except simulation) in separate methods lessons 


\section{Beware of Mismatches!}

Human error probability for routine repetitive tasks:

$3 \times 10^{-3}$ to $1 \times 10^{-2}$ per individual operation (THERP)

Concert pianist, performing K.453, 1st movement:

3996 individual, critical

keystrokes

Expected errors per performance: $3996 \times\left(3 \times 10^{-3}\right) \approx 12$ to $3996 \times(1$

$\left.\times 10^{-2}\right) \approx 40$ errors

A DOOMED REPUTATION!

What makes this unlikely?

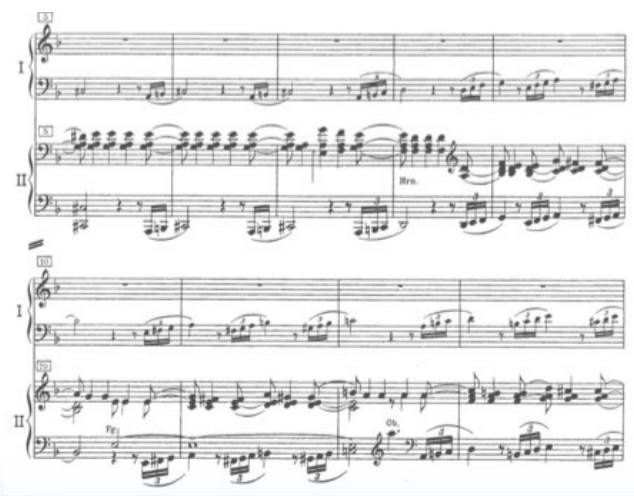

Idaho National Laboratory

Review 


\section{Lesson 5 Review}

- Why is screening used as part of HRA?

- What is the nominal HEP?

- What is the basic HEP?

- What is the conditional HEP?

- What is negative dependence?

- What is aleatory uncertainty?

- What is epistemic uncertainty?

- What is an error factor?

- What are some different approaches to calculating the HEP?

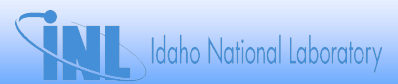

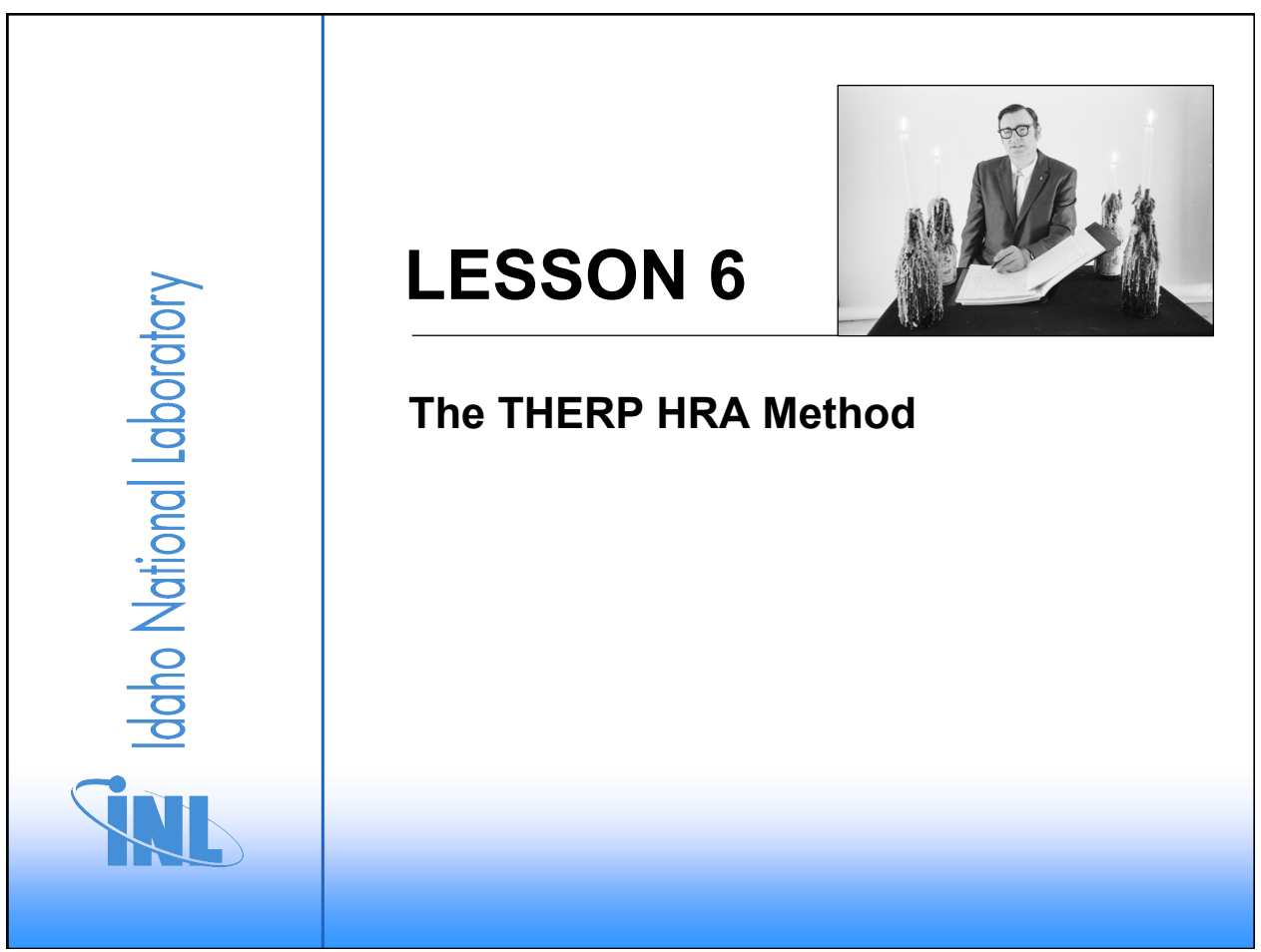




\section{Lesson 6 Objectives}

$\checkmark$ Understand origin of THERP

$\checkmark$ Understand how THERP works

- Basic steps

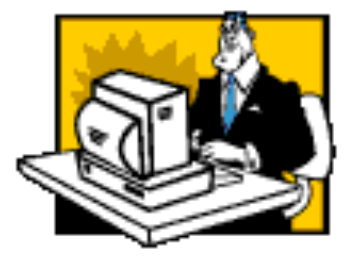

- Role of HRA event tree and how to read one

- How HEPs are produced

- Treatment of dependence and recovery

- Treatment of uncertainty

$\checkmark$ Relationship of ASEP to THERP

\section{SiV. Idaho National Laboratory}

Background on THERP 


\section{THERP Sources}

- A Technique for Human Error Rate Prediction

- NUREG/CR-1278 (1983) by Alan Swain and Henry (Hank) Guttman

- Useful additional guidance found in NUREG/CR-2254 (1983):

A Procedure for Conducting a Human Reliability Analysis for Nuclear Power Plants

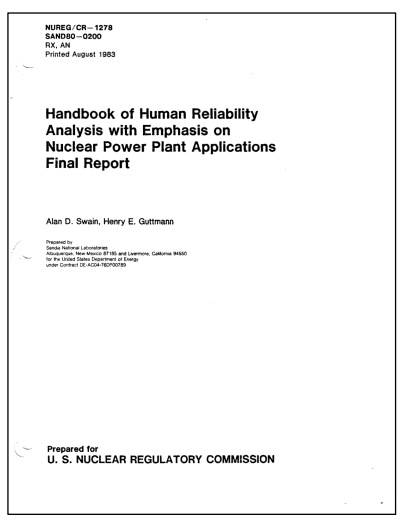

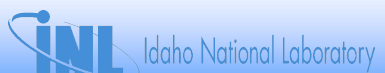

\section{THERP Background}

- Developed by Alan Swain and Henry Guttman at Sandia National Laboratories for US NRC in early 1980s

- Precursors to THERP go back to 1962

- Parts of what became THERP appeared in WASH-1400

- Based on data gathered from reactor control room, weapons manufacturing, and chemical processing activities, as well as expert estimation

- Most widely used HRA method 


\section{THERP Background}

- Uses HRA event tree modeling to identify human errors and successful actions as part of HFE

- Unique to THERP and different from PRA event and fault trees

- Latest incarnation of THERP in EPRI HRA Calculator software is more limited

- Applied only to execution portion of HFE

- Paired with ASEP

- No HRA event trees

\section{THERP Background}

- For quantification, provides tables of nominal HEPs categorized by type of human action

- Provides limited number of PSFs to modify the values in the tables

- Modified HEPs called basic HEPs in THERP

- Can be quantified at the subtask level

- Considered a complete method because it addresses both qualitative and quantitative analysis

- Many HRA methods only address quantification 


\section{Five Steps of THERP}

\section{Qualitative Analysis}

1. Define human failure events

2. Employ task analysis to identify human subtasks within the HFE Quantitative Analysis

3. Predict error rates for each relevant human operation

4. Determine effects of human errors on system failure rate

Use Qualitative-Quantitative Analysis to Improve System

5. Recommend changes to reduce system failure rate to an acceptable level

Repeat: A separate task analysis is done for each HFE

(Adapted from Alan Swain's THERP Course)
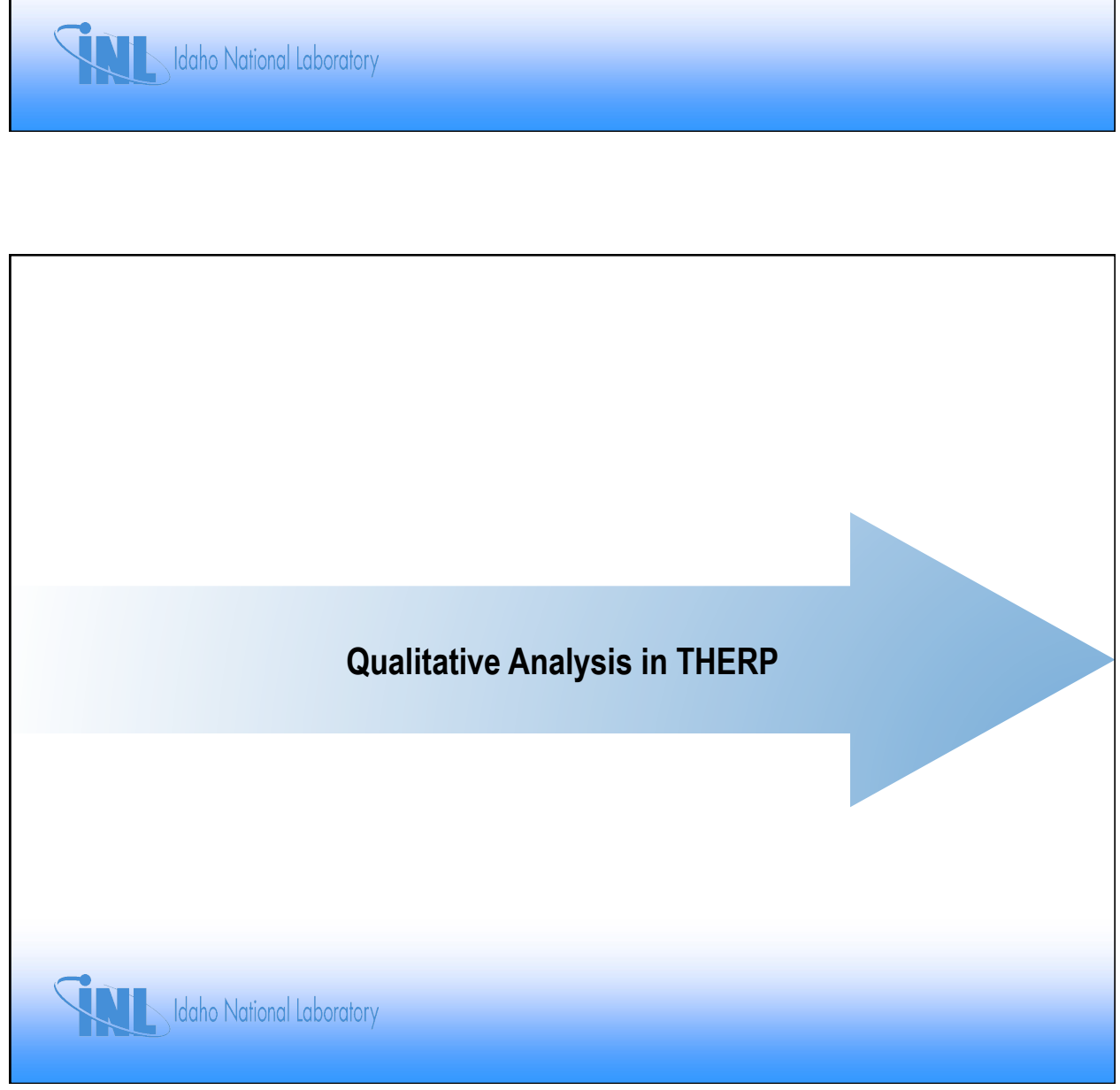


\section{Starting Point of THERP is Task Analysis}

- Decomposes HFE into constituent subtasks, often based on governing procedural steps

- Requires resources to gather and analyze information related to task performance, PSFs, etc.

- In support of HRA task analysis, THERP recommends:

1. Multidisciplinary team of analysts

2. Site visits

3. Walkthroughs and talkthroughs

4. Simulator observations

\section{STI Idaho National Laboratory}

\section{HRA Event Tree}

- Used to account for human actions in terms of successful and unsuccessful (error) outcomes

- Graphical representation of decomposition of HFE into separate subtasks

- HRA event trees no longer widely used but still have uses:

- Represent recovery information well (at subtask level)

- Allow clear delineation of probability of success and probability of failure/error

- Show sequence of HFE constituent subtasks better than fault trees 


\section{Sample HRA Event Tree}

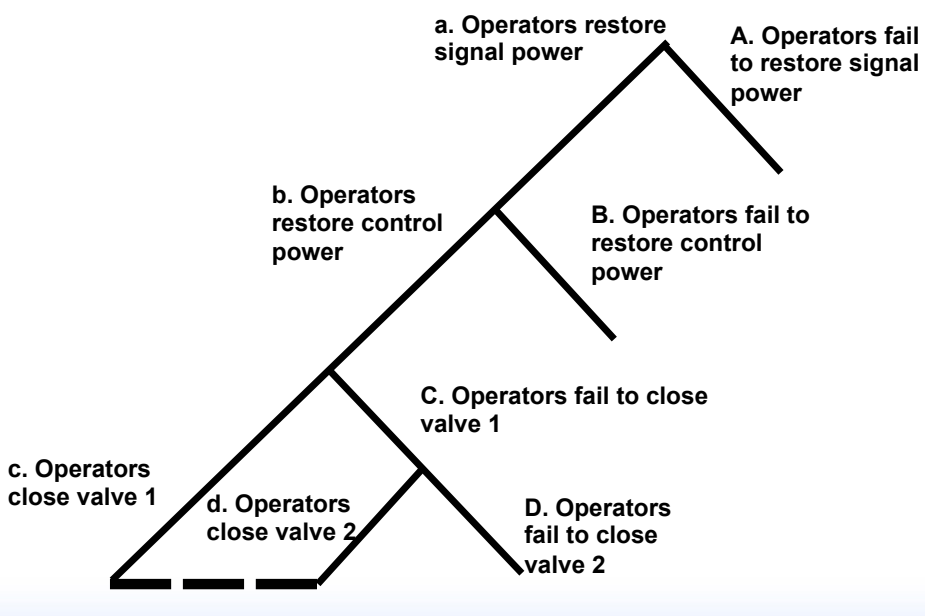

\section{STI Idaho National Laboratory}

An HRA event tree consists of one or more binary branches (correct/incorrect actions)

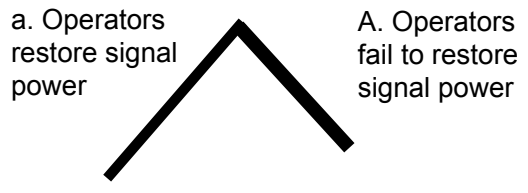




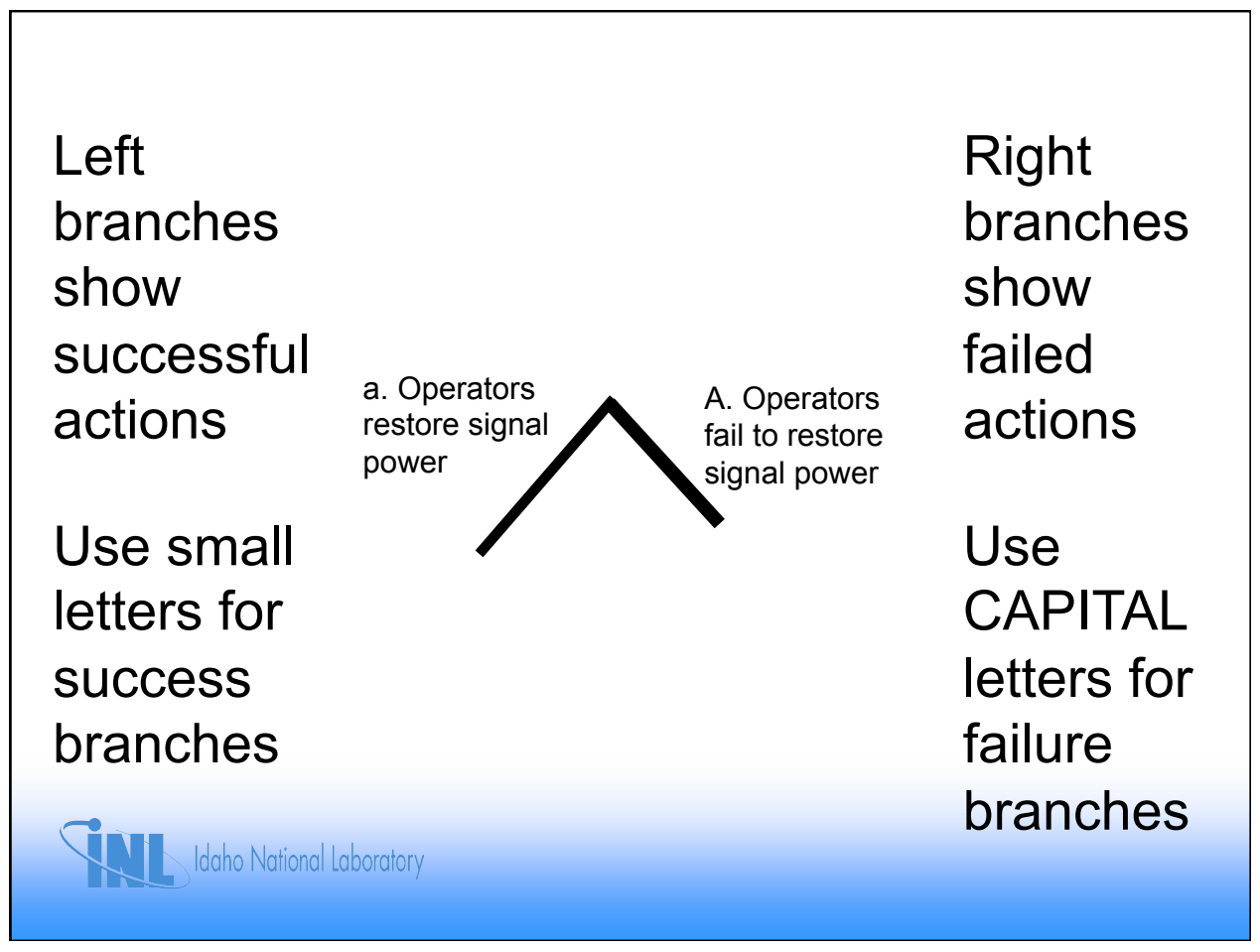

Success branch descriptions are often omitted from tree diagram as they are always the successful complement of the failure statements!

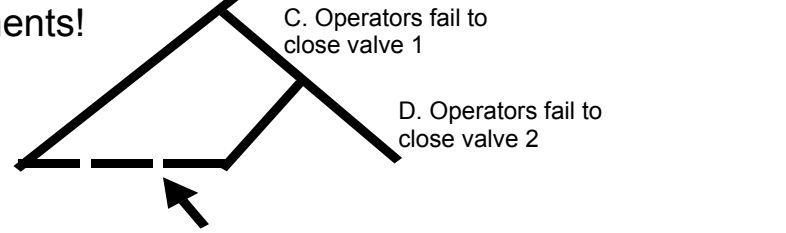

Recovery is shown as dashed line after some failure back to a success path 

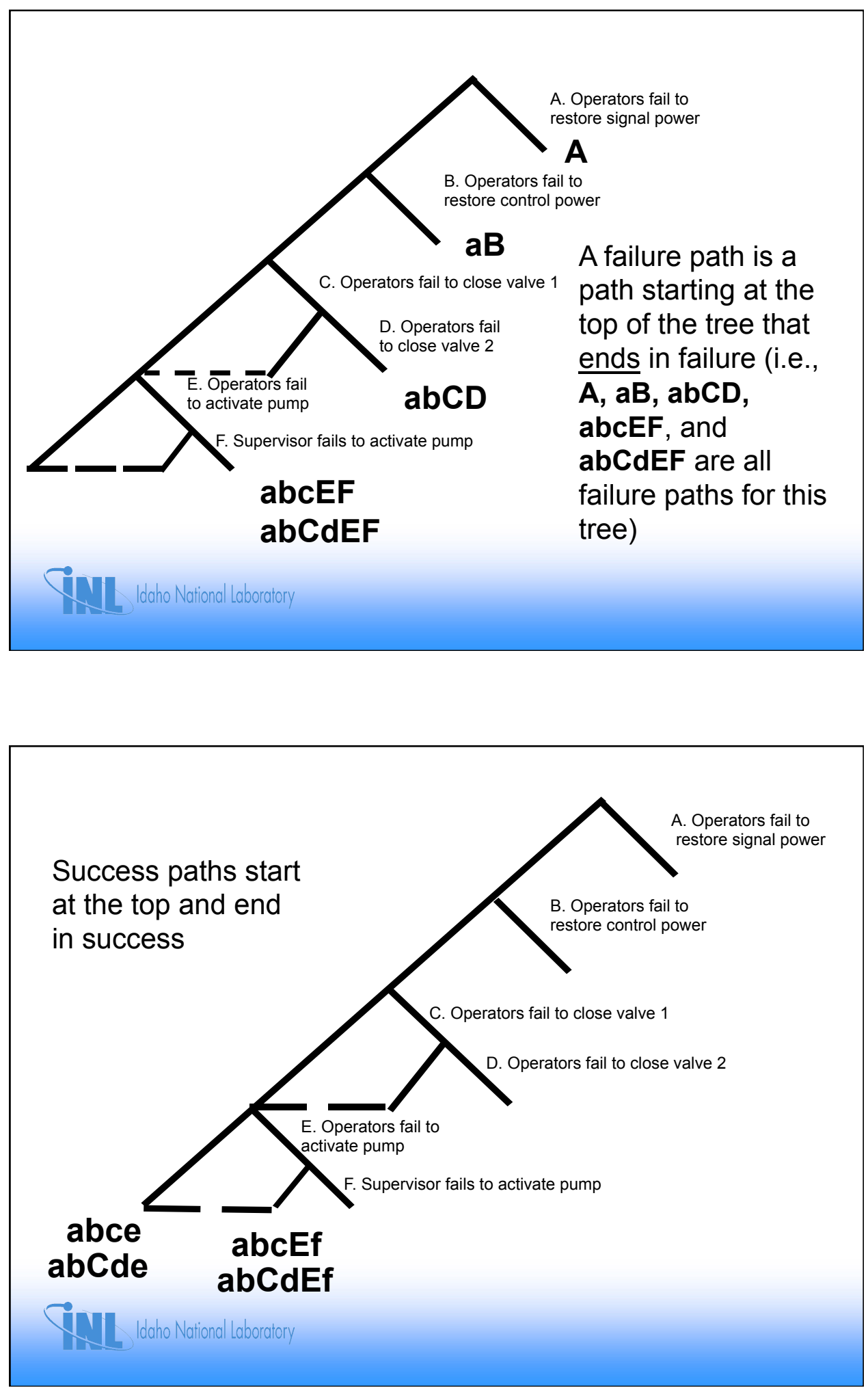


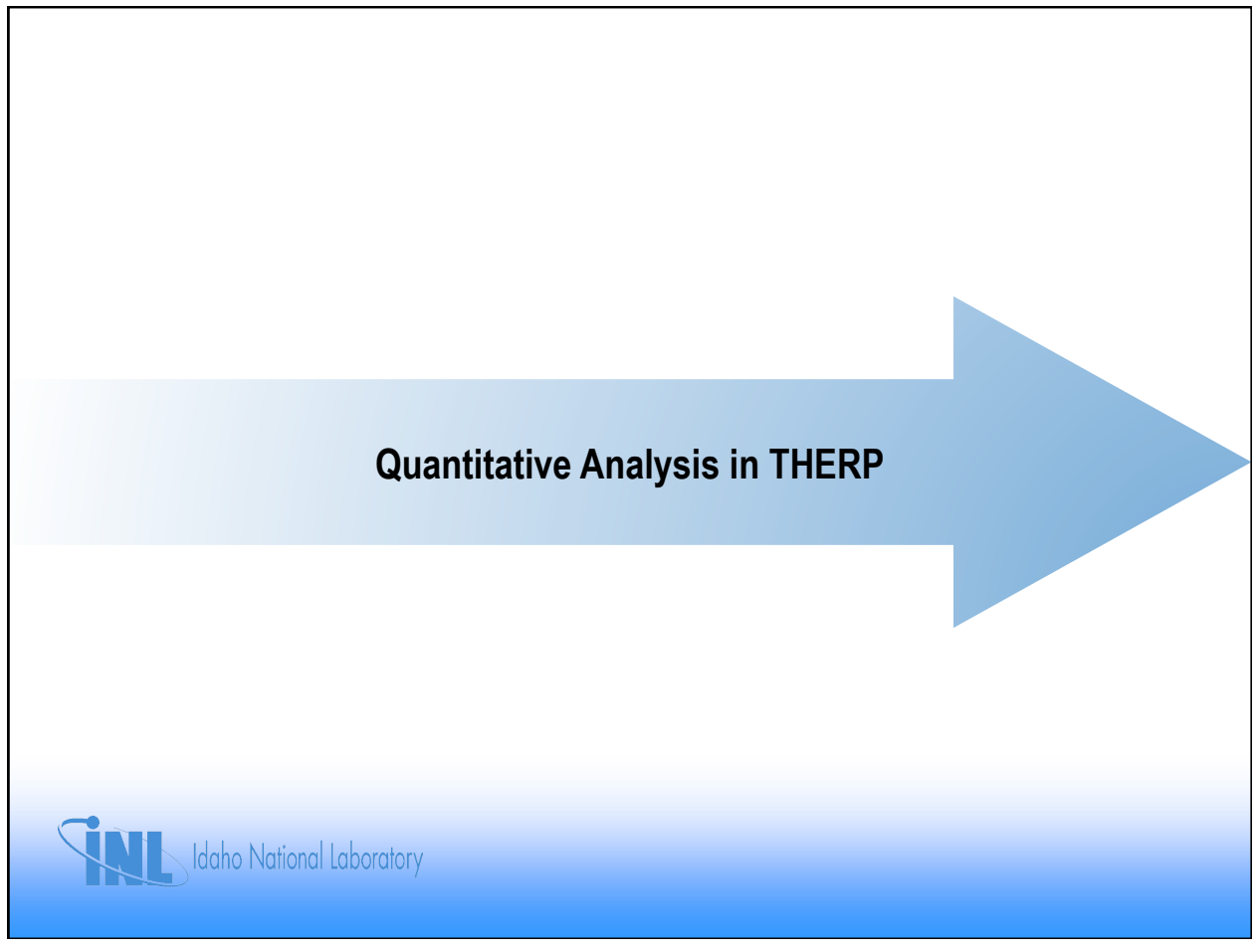

\section{Navigating THERP Tables}

All THERP Quantification Values are Summarized in Table 20 of NUREG/CR-1278

- Figure 20-2 from THERP serves as a table of contents

- Screening

- Diagnosis

- Errors of Omission

- Errors of Commission

- PSFs

- Uncertainty Bounds

- Recovery Factors 


\section{Navigating THERP Tables (Continued)}

- Figure 20 -1 of THERP Handbook provides overall logic for using THERP and tables

- Pages 20 -11 through 20 -13 provide table of contents to all 27 THERP quantification tables

- Given an HRA Event Tree, to quantify a branch, find the correct table and sub-item

- Match the subtask to an entry in the THERP tables

- From this perspective, THERP is a task-matching approach

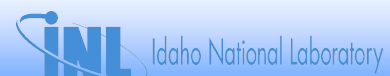

\section{Quantification in THERP}

1. Within the selected THERP table, choose the best fitting Nominal HEP and error factor

- Nominal HEP represents the median of lognormal distribution

2. Modify this value as needed to account for three PSFs

- Stress

- Task type

- Level of experience/training

- Multiply by $1,2,4,5$, or 10 -see Table $20-16$

- Yields a Basic HEP

3. Modify Basic HEP by dependency value

- See Table 20-17

- Resulting HEP is called a Conditional HEP

- Note that THERP does not historically consider dependence between HFEs, only among subtasks within a single HFE 


\section{Quantification in THERP (Continued)}

4. Multiply probabilities along each failure path

5. Sum up all failure path probabilities to obtain total HEP

6. Perform sensitivity analysis by making reasonable changes to Nominal, Basic, or Conditional HEPs or by changing model (adding or removing failures and/or recoveries)

\section{Y.1. Idaho National Laboratory}

\section{Dependence in THERP}




\section{THERP Treatment of Dependence}

\section{THERP Definitions}

- Dependence is "Determination of how the probability of failure or success on one [sub]task may be related to the failure or success on some other [sub]task"

- "Two [subtasks] are independent if the conditional probability of one [subtask] is the same whether or not the other [subtask] has occurred. That is, independence is the case in which the probability of success or failure on [sub]Task ' $\mathrm{B}$ ' is the same regardless of success or failure on [sub]Task 'A'"

- "If [subtasks] are not independent, they are dependent"

\section{THERP Treatment of Dependence}

\section{Two types of dependence in THERP: Direct}

- Direct dependence exists when the outcome of one subtask directly affects the outcome of a second subtask

- Failure on subtask "A" causes an auditory signal that results in more careful performance on subtask " $B$ "

- Failure on subtask "A" causes extreme anxiety with a resultant increase in probability of failure on subtask "B"

- Failure on subtask "A" causes subtask "B" to be more difficult with an associated increase in probability of failure 


\section{THERP Treatment of Dependence}

Two types of dependence in THERP: Indirect

- Indirect dependence occurs when some PSF or set of PSFs influences the relationship between subtasks such that the dependence between them changes

- If the PSF merely raises or lowers the HEPs for subtasks without changing the relationship between them, this is not an example of indirect dependence

- A high level of stress tends to increase HEPs across subtasks but does not necessarily affect dependence

- Stress affects dependence only if it also causes a systematic change in behavior across events (e.g., if stressed operators defer decisions to shift supervisorsomething they would not do in an unstressed state)

Recall: Similar definitions of dependence in Lesson 5

- THERP approach is still basis for most dependence in HRA

- THERP is intra-HFE-not inter-HFE-dependence

\section{THERP Quantitative Dependence Model}

\section{THERP covers five levels of dependence, from zero} dependence (independence) to complete dependence

- Treated both success and failure paths

- Dependence usually considered only in failure paths

- Success path = dependence between two events with successful outcomes

- Failure path = dependence between two events with unsuccessful outcomes (human error) 


\section{THERP Quantitative Dependence Model}

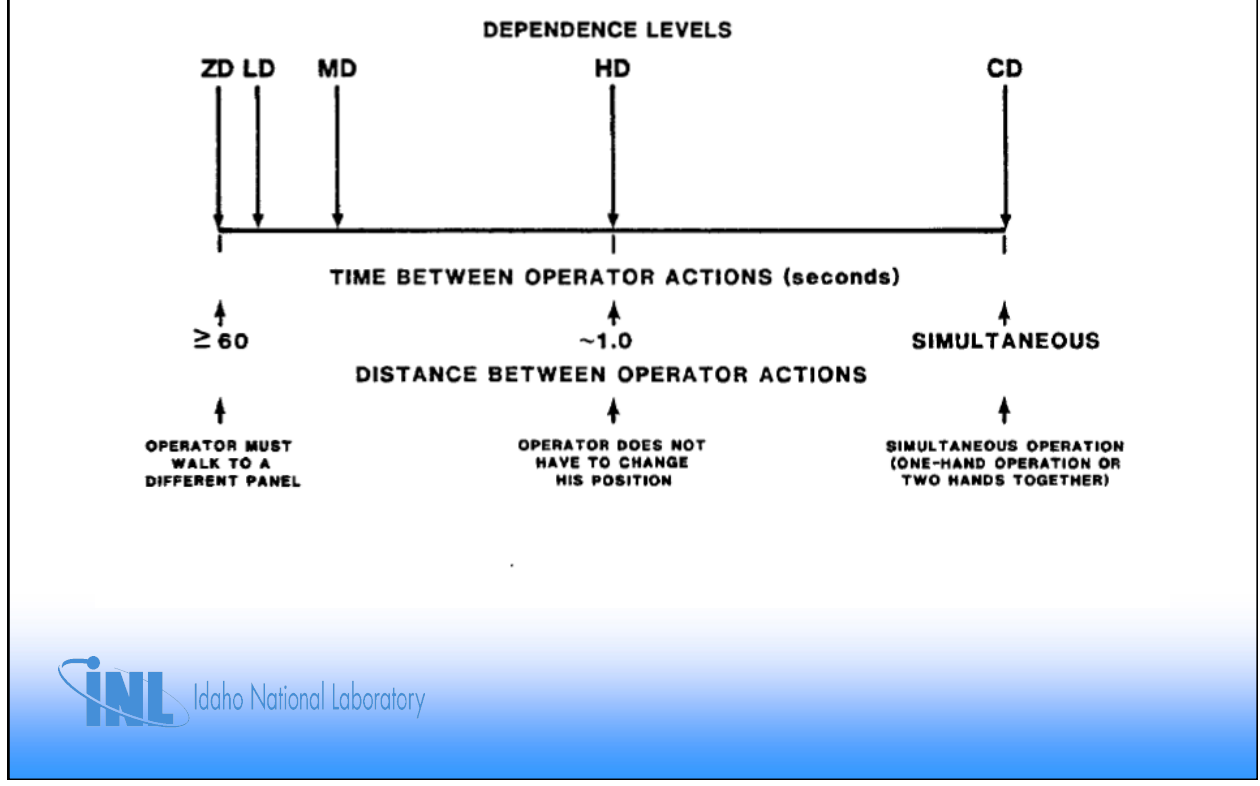

\section{THERP Quantitative Dependence Model}

\begin{tabular}{|c|c|c|c|c|}
\hline $\begin{array}{c}\text { Level of } \\
\text { Dependence }\end{array}$ & Success Equations & Equation No. & Fallure Equations & Equation No. \\
\hline ZD & $\operatorname{Pr}\left[S_{N^{*}}\left|S_{N_{N-11^{*}}}\right| Z D\right]=n$ & $(10-9)$ & $\operatorname{Pr}\left(\mathbf{F}_{{ }^{N N^{n}}}\left|\mathbf{F}_{n_{N-1}}\right| \mathrm{ZD}\right)=N$ & $(10-14)$ \\
\hline LD & $\operatorname{Pr}\left(S_{n^{*}{ }^{*}}\left|S_{N_{N-1 n}}\right| L D\right)=\frac{1+19 n}{20}$ & $(10-10)$ & $\operatorname{Pr}\left[F_{{ }^{\prime} N^{*}}\left|F{ }^{N-1 *}\right| L D\right]=\frac{1+19 N}{20}$ & $(10-15)$ \\
\hline MD & $\operatorname{Pr}\left[\mathrm{s}_{n \mathrm{~N}^{*}}\left|\mathrm{~s}_{n \mathrm{~N}-1}\right| \mathrm{MD}\right]=\frac{1+6 \mathrm{n}}{7}$ & $(10-11)$ & $\operatorname{Pr}\left[F_{N^{n}}\left|F_{n N-1^{n}}\right| M D\right]=\frac{1+6 N}{7}$ & $(10-16)$ \\
\hline HD & $\operatorname{Pr}\left[S_{{ }^{*} N^{n}}\left|s_{{ }^{N}-11^{n}}\right| H D\right]=\frac{1+n}{2}$ & $(10-12)$ & $\operatorname{Pr}\left(F_{{ }^{\prime N} N^{n}}\left|F_{n^{\prime} N-1^{n}}\right| H D\right)=\frac{1+N}{2}$ & $(10-17)$ \\
\hline CD & $\operatorname{Pr}\left[\mathrm{S}_{\mathrm{NN}^{\prime \prime}}\left|\mathrm{S}_{\mathrm{NN}-1^{*}}\right| \mathrm{CD}\right]=1.0$ & $(10-13)$ & $\operatorname{Pr}\left[F_{{ }^{\prime N}}\left|P_{n N-1 m}\right| C D\right)=1.0$ & $(10-18)$ \\
\hline
\end{tabular}




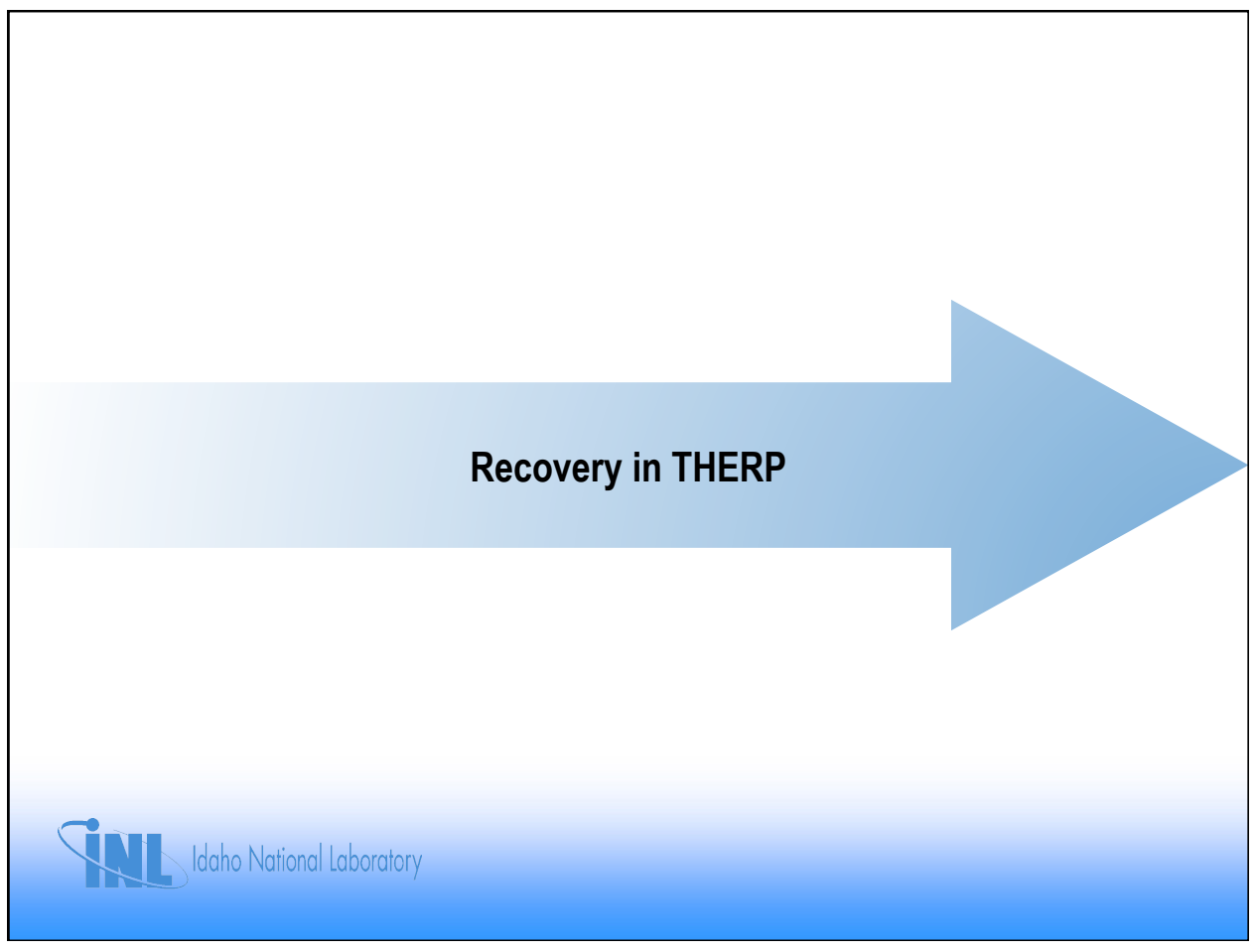

\section{Definition of Recovery in THERP}

A recovery factor is any element of a nuclear power plant (NPP) system that acts to prevent deviant conditions from producing unwanted effects. It can be anything that prevents a deviant condition, mitigates its effects, or provides the opportunity for detecting it so that its effects can be avoided or limited.

If a human error is made and is not detected and corrected, it is designated as an unrecovered error

If recovery factors resulted in detection and correction of the error in time to prevent undesirable effects, the error is designated as a recovered error

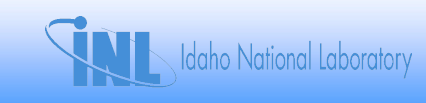




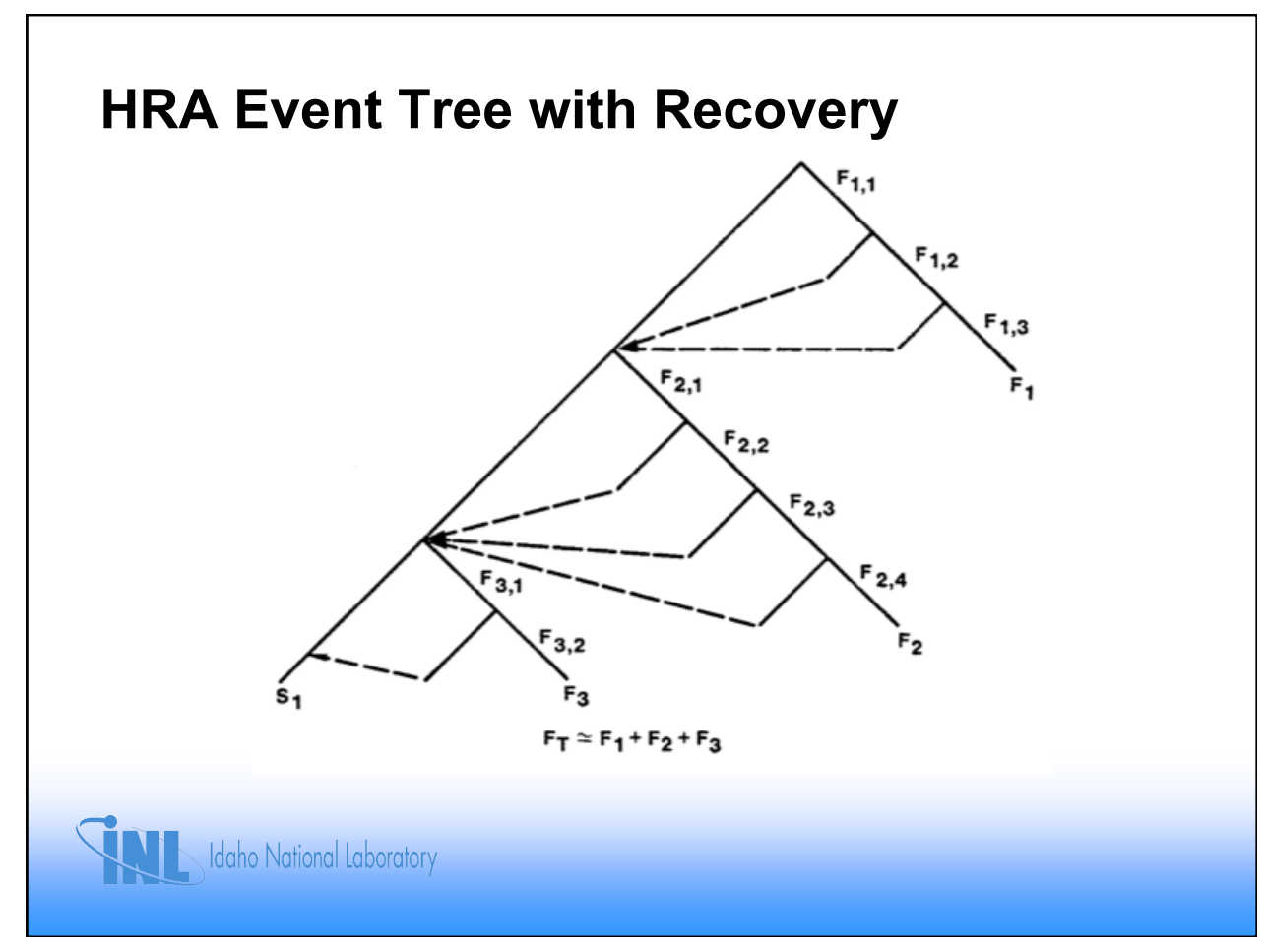

\section{Recovery Probability in THERP}

- The probability of nonrecovery must be multiplied by the HEP for the original error to produce an estimate of an unrecovered human error

- This is done at the subtask level

- These are not recovery factors at the sequence level

- For example, the probability that an operator fails to restore a valve to the proper position (the original error) and the probability that a checker fails to detect that error (the failure of recovery) must be combined to obtain the estimated probability of the error occurring and remaining unrecovered. 


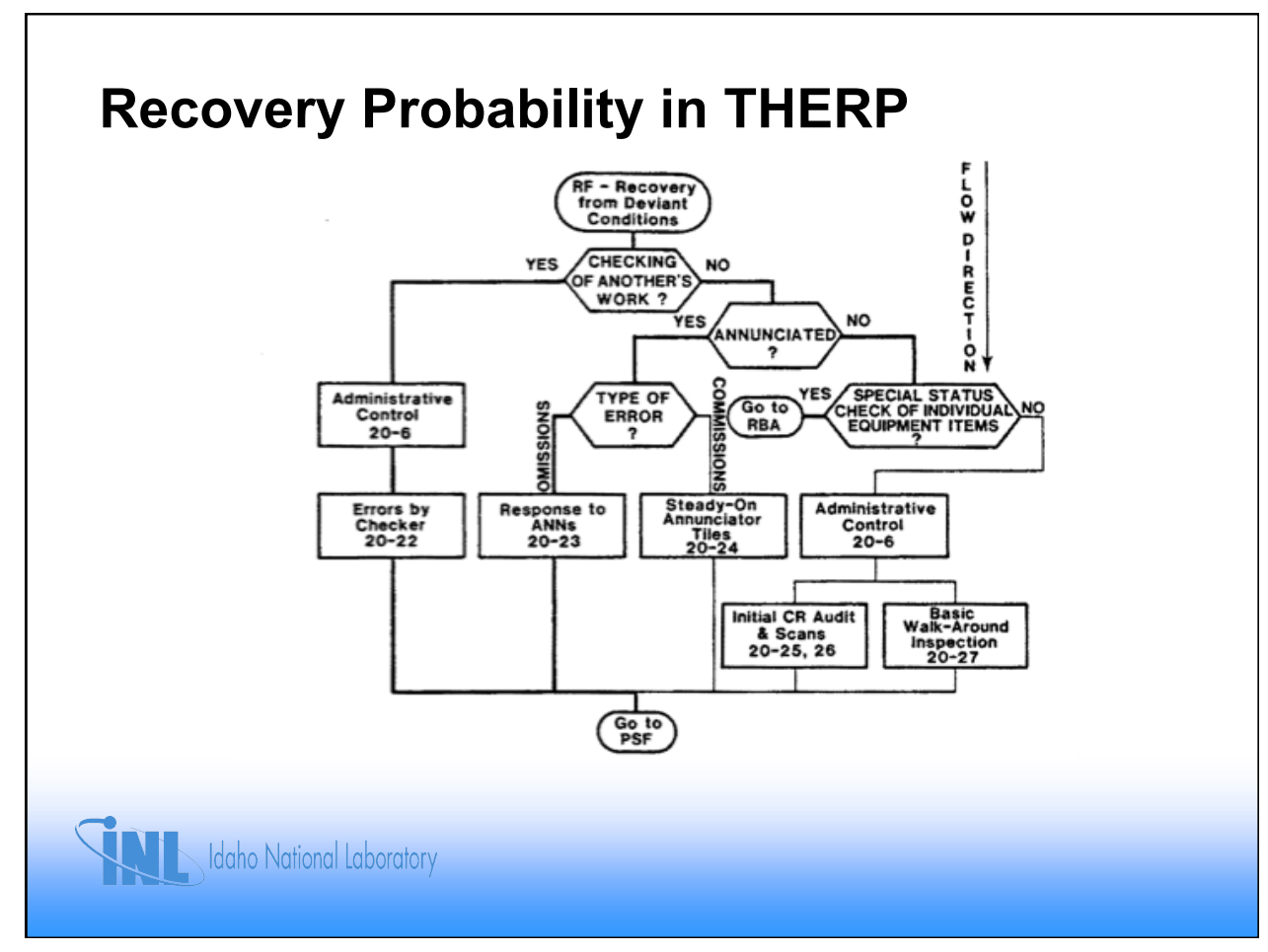

\section{Probability that Second Checker Fails}

\begin{tabular}{|c|c|c|c|}
\hline Item & Checking Operation & HEP & EF \\
\hline (1) & $\begin{array}{l}\text { Checking routine tasks, checker using vritten } \\
\text { aaterials (includes over-the-shoulder inspections, } \\
\text { verifying position of localiy operated valves, } \\
\text { switches, circuit breakers, connectors, ete., and } \\
\text { checking written 1ists, tags, or procedures for } \\
\text { accuracy) }\end{array}$ & $\cdot 1$ & 5 \\
\hline (2) & Sase as above, but without written materials & .2 & 5 \\
\hline (3) & $\begin{array}{l}\text { Special short-term, one-of-a-kind checking with } \\
\text { alerting factors }\end{array}$ & .05 & 5 \\
\hline \multirow[t]{2}{*}{ (4) } & $\begin{array}{l}\text { Checking that involves active participation, such as } \\
\text { special measurements }\end{array}$ & .01 & 5 \\
\hline & $\begin{array}{l}\text { Given that the poeition of a locally operated valve } \\
\text { 1s checked (item above), notieing that it is not } \\
\text { completely opened or elosed: }\end{array}$ & .5 & 5 \\
\hline (5) & Position indicator". only & .1 & 5 \\
\hline (6) & Position indicator"* and a rising sten & .5 & 5 \\
\hline (7) & Neither a position indicator"* nor a rising ster & .9 & 5 \\
\hline (8) & $\begin{array}{l}\text { Checking by reader/checker of the task perforser in } \\
\text { a two-man team, or checking by a second checker, } \\
\text { routine task (no credit for wore than } 2 \text { checkers) }\end{array}$ & .5 & $\mathbf{s}$ \\
\hline (9) & $\begin{array}{l}\text { Checking the status of equipwent if that status } \\
\text { affects one's safety when perforwing his tasks }\end{array}$ & .001 & $\mathbf{s}$ \\
\hline (10) & $\begin{array}{l}\text { An operator checks change or restoration tasks } \\
\text { performed by a caintainer }\end{array}$ & $\begin{array}{l}\text { Above } \\
\text { HEPs } \\
+2\end{array}$ & 5 \\
\hline
\end{tabular}




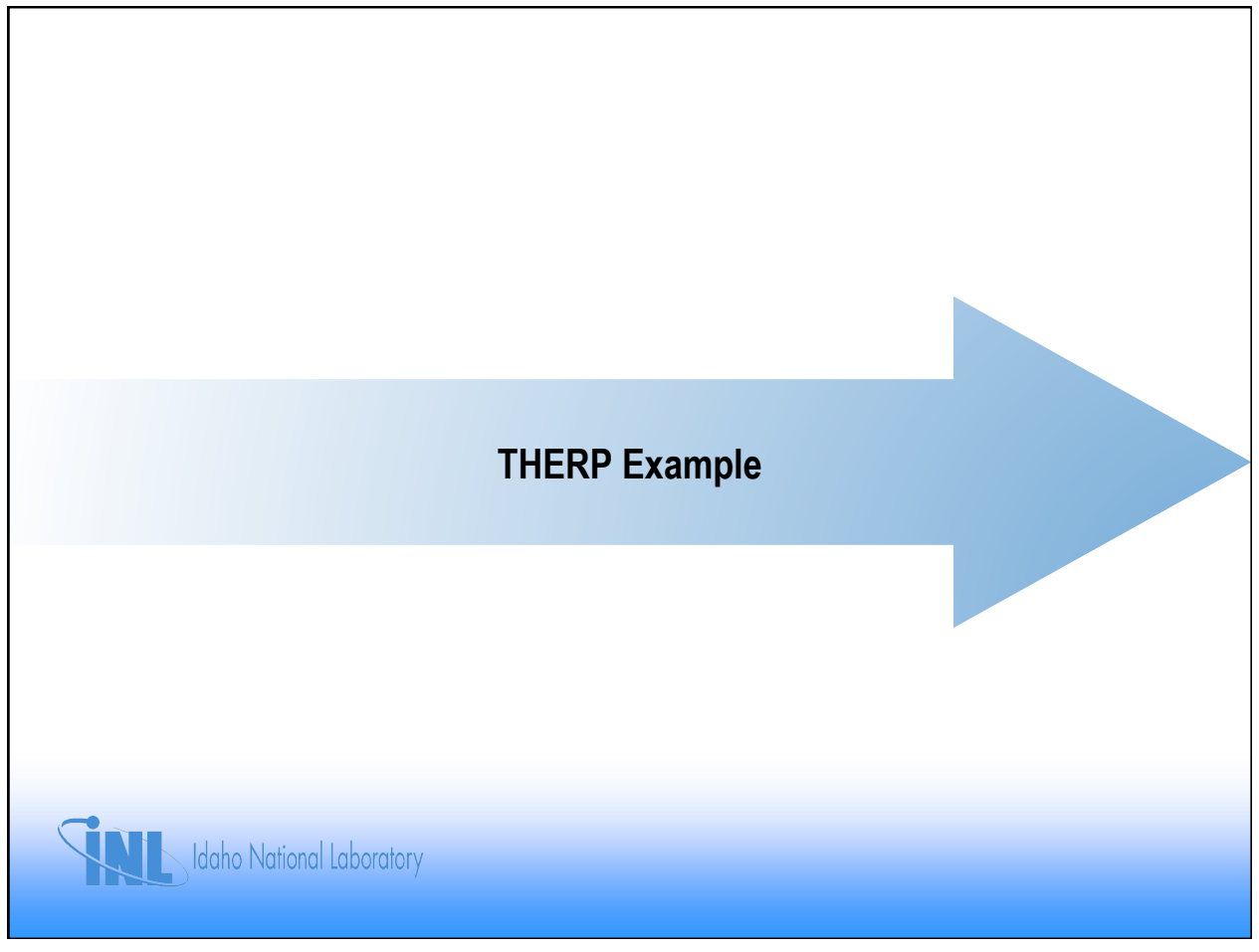

\section{Exercise: THERP Quantification}

- See Appendix B for THERP Table 20

- See Appendix C for THERP Exercise 


\section{THERP and ASEP}

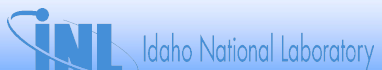

\section{ASEP (NUREG-CR/4772), Briefly Noted}

- Developed by Swain in mid-1980s in support of NRCsponsored PRAs

- Accident Sequence Evaluation Program (ASEP)

- Intended to be a simplification of THERP that could be applied by PRA analysis, without extensive Human Factors support

- Provides separate guidance and quantification for pre- and post-accident tasks

- Distinguishes between screening values and nominal values (those values that are quantified at a more explicit level than the screening values)

- Provides simplified tables for both pre/post accident phases and screening/nominal analysis, with resulting HEPs and Error Factors

- Recovery and dependence modeling similar to THERP 

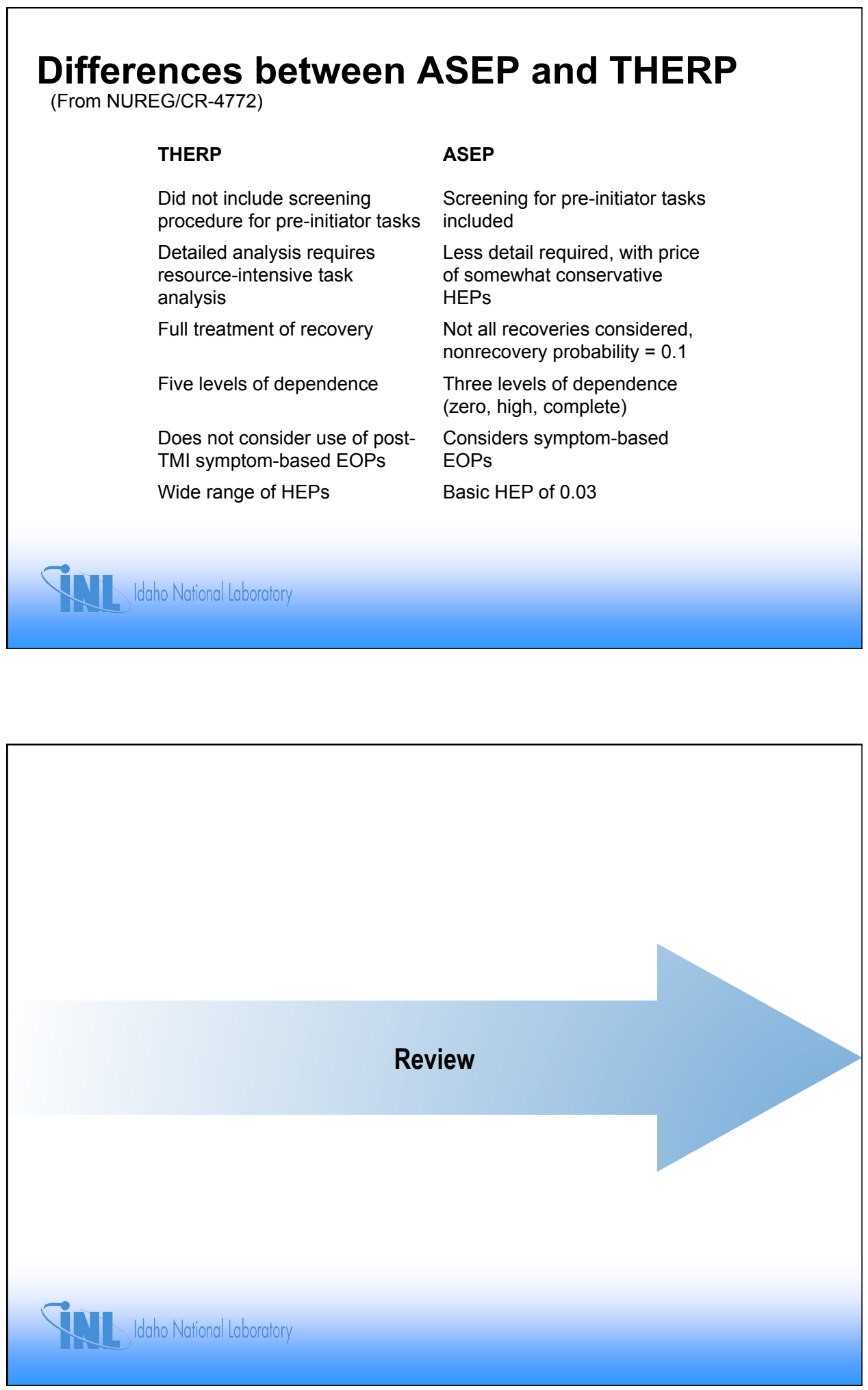
NUREG-1842 Good Practices Summary of THERP

\begin{tabular}{|c|c|c|c|c|c|c|}
\hline METHOD & SCOPE & $\begin{array}{c}\text { UNDERLYING } \\
\text { MODEL }\end{array}$ & $\begin{array}{c}\text { UNDERLYING } \\
\text { DATA }\end{array}$ & $\begin{array}{l}\text { QUANTIFICATION } \\
\text { APPROACH }\end{array}$ & STRENGTHS & LIMITATIONS \\
\hline THERP & $\begin{array}{l}\text { Identification, } \\
\text { modeling, and } \\
\text { quantification } \\
\text { of pre-initiator and } \\
\text { post-initiator } \\
\text { HFEs. } \\
\text { Does not provide } \\
\text { guidance for } \\
\text { screening of pre- } \\
\text { initiator HFEs, } \\
\text { but does provide } \\
\text { gunidance for post- } \\
\text { initiator screening. } \\
\text { Includes a five- } \\
\text { level dependence } \\
\text { model. }\end{array}$ & $\begin{array}{l}\text { Nominal HEPs } \\
\text { selected for tasks } \\
\text { and subtasss, } \\
\text { then modified by } \\
\text { multiplicative PSF } \\
\text { model, five-level } \\
\text { dependence } \\
\text { model, and } \\
\text { recovery. } \\
\\
\text { General model of } \\
\text { influences on } \\
\text { human behavior } \\
\text { is considided, } \\
\text { describing a large } \\
\text { range of potential } \\
\text { PSFs. }\end{array}$ & $\begin{array}{l}\text { Includes judgment } \\
\text { and sparse } \\
\text { empirical and } \\
\text { experience-based } \\
\text { data (largecly } \\
1960 \text { vintage) } \\
\text { mostly from } \\
\text { non-numlear } \\
\text { experience. }\end{array}$ & $\begin{array}{l}\text { Based on (and provides guidance } \\
\text { for) performing a detailed task } \\
\text { analysis of the human events } \\
\text { modeled. } \\
\text { Provides a fixed set of PSFs } \\
\text { and related descriptions that are } \\
\text { interpreted for the event being } \\
\text { analyzed using analyst } \\
\text { judgment. HEPs are then } \\
\text { "looked-up" in tables and } \\
\text { curres. or a basic HEP is } \\
\text { assigned multipliers to reflect the } \\
\text { impact of PSFs. } \\
\text { A time/reliability correlation } \\
\text { (TRC) is used to quantity } \\
\text { diagnosis HFEs based on } \\
\text { available time and adjustments } \\
\text { based on considering a few } \\
\text { PSFs. } \\
\text { Allows use of expert judgment } \\
\text { to incorporate effects of PSFs } \\
\text { that are not explicitily part of } \\
\text { the THERP tables and curves. }\end{array}$ & 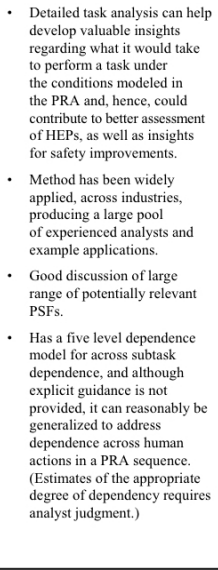 & 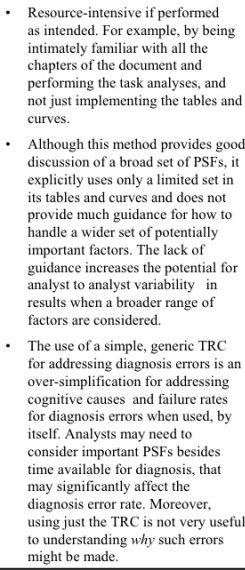 \\
\hline
\end{tabular}

NUREG-1842 Good Practices Summary of ASEP

\begin{tabular}{|c|c|c|c|c|c|c|}
\hline METHOD & SCOPE & $\begin{array}{l}\text { UNDERLYING } \\
\text { MODEL }\end{array}$ & $\begin{array}{c}\text { UNDERLYING } \\
\text { DATA }\end{array}$ & $\begin{array}{c}\text { QUANTIFICATION } \\
\text { APPROACH }\end{array}$ & STRENGTHS & LIMITATIONS \\
\hline ASEP & $\begin{array}{l}\text { Quantification } \\
\text { techniquut that } \\
\text { addresses } \\
\text { pre intitiotor } \\
\text { and post-initiator } \\
\text { screening } \\
\text { and nominal HEPs } \\
\text { (simplification } \\
\text { of THERP). } \\
\text { Includes a } \\
\text { simplified version } \\
\text { of the THERP } \\
\text { dependence } \\
\text { model. }\end{array}$ & $\begin{array}{l}\text { Pre-initiator: } \\
\text { Generic crror rate } \\
\text { for all pre-initiator } \\
\text { failures, modified } \\
\text { by "checking-e } \\
\text { type" of recovery } \\
\text { probabilities. } \\
\text { Post-initiator: } \\
\text { Summation of } \\
\text { a diagnosis failure } \\
\text { probability (based } \\
\text { on THERP's TRC } \\
\text { as to the available } \\
\text { time to diagnose) } \\
\text { and response } \\
\text { exeeution failure } \\
\text { probability } \\
\text { (based on simple } \\
\text { representation } \\
\text { of complexity } \\
\text { of task and stress } \\
\text { level for operator). } \\
\text { Based to some } \\
\text { extent on THERP } \\
\text { uses a simple } \\
\text { model of cognition } \\
\text { and addresses the } \\
\text { relationship } \\
\text { among the terms } \\
\text { and potential } \\
\text { behavioral } \\
\text { influences. }\end{array}$ & \begin{tabular}{|l} 
Based on THERP, \\
it includes \\
judgment \\
and sparse \\
empirical \\
and experience- \\
based data (largely \\
19600 vintagec \\
mostly from non- \\
nuclear \\
experience. \\
Values are \\
purposely \\
intended to lead to \\
conservative HEP \\
estimates.
\end{tabular} & $\begin{array}{l}\text { Provides a fixed set of PSFs } \\
\text { and related descriptions that are } \\
\text { interpreted for the event being } \\
\text { analyzed using analyst } \\
\text { judgment. HEPs are then } \\
\text { "looked-up" in tables and } \\
\text { curves, or a basic HEP } \\
\text { is assigned multipliers to reflect } \\
\text { the impact of PSFs. }\end{array}$ & 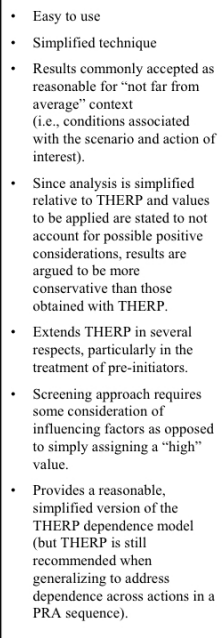 & 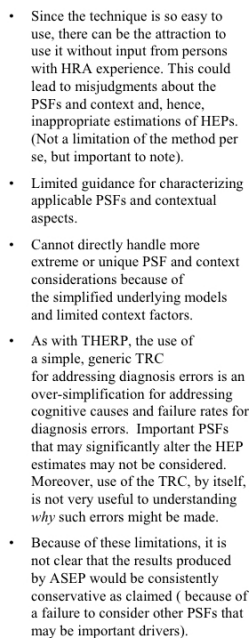 \\
\hline
\end{tabular}




\section{Lesson 6 Review}

- How are success and failure paths treated in HRA event trees?

- What are the basic steps of THERP quantification?

- Where are the nominal HEPs found in THERP?

- What PSFs does THERP consider?

- What is the difference between the way THERP treats dependence and the way subsequent HRA methods have tended to treat dependence?

- How is recovery treated in THERP?

- What are some differences between THERP and ASEP?

\section{SII Idaho National Laboratory}

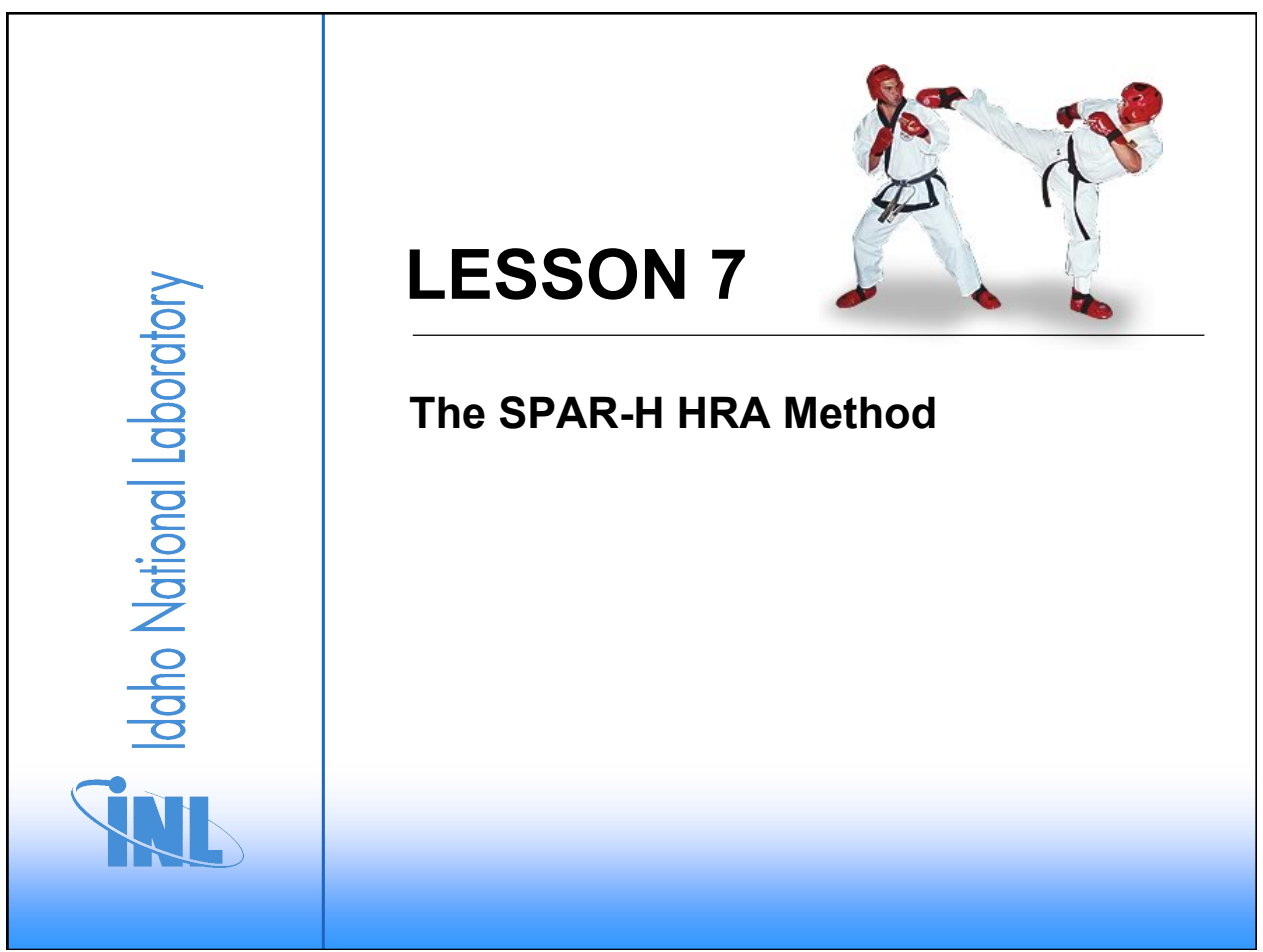




\section{Lesson 7 Objectives}

- Provide background on why SPAR-H was developed and for what applications

- Introduce the SPAR-H worksheets

- Overview the quantification process in SPAR-H

- Work through a SPAR-H example

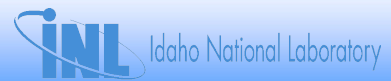

Background on SPAR-H 


\section{SPAR-H Background}

Standardized Plant Analysis Risk-Human (SPAR-H)

- Published as NUREG/CR-6883 (2005)

- Method was developed in three phases from mid-1990s to support NRC's Accident Sequence Precursor (ASP) program

- SPAR PRA models now exist in full-power models for each plant, including SPAR-H analyses for HFEs

- Being applied to low power and shut down models

\section{SPAR-H is used as a simplified HRA approach}

- Like ASEP, SPAR-H is a simplified approach based on THERP

- HEPs in SPAR-H derived from THERP

- Approach uses PSFs instead of sample scenarios, making it easier to generalize

- No formal qualitative analysis approach (beyond PSFs)

- Detailed qualitative analysis should make use of ATHEANA

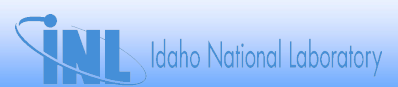

SPAR-H Process 


\section{SPAR-H Worksheet Process}

\begin{tabular}{|c|c|c|c|c|}
\hline Identify Ev & Determine Power Mode & Determine Work Type & Determine PSF Levels & Apply Corrections \\
\hline $\begin{array}{c}\text { Risk Significant } \\
\text { Human Errors and } \\
\text { Successful Human } \\
\text { Actions }\end{array}$ & $\begin{array}{l}\text { At-Power } \\
\text { vs. } \\
\text { Low Power/Shutdown } \\
\text { Worksheets }\end{array}$ & $\begin{array}{l}\text { Diagnosis } \\
\text { vs. } \\
\text { Action } \\
\text { Nominal HEP }\end{array}$ & $\begin{array}{l}\text { Negative, Nominal, and } \\
\text { Positive Level } \\
\text { Multipliers across } \\
\text { Eight SPAR-H PSFs }\end{array}$ & $\begin{array}{l}\text { Correction } \\
\text { Calculations for } \\
\text { Multiple Negative PSFs } \\
\text { and Dependency }\end{array}$ \\
\hline
\end{tabular}

\section{SPAR-H Worksheet Types}

- The current SPAR-H method has separate worksheets (see Appendix D) for:

- Diagnosis-type activities (e.g., determining whether to start a pump or not)

- Action-type activities (e.g., restoring a pump after it fails, performing a valve line-up)

- Different modes of power operation are included

- At power operations

- Low power and shutdown operations 


\section{SPAR-H Quantification}

- SPAR-H Worksheets are used to quantify HEPs by considering 8 PSFs that may increase/decrease likelihood of error

- Available time

- Stress/stressors

- Complexity

- Experience/training

- Procedures

- Ergonomics/HMI

- Fitness for duty

- Work processes

\section{Till wascases}

\section{SPAR-H Quantification}

- SPAR-H Worksheets are used to quantify HEPs by considering 8 PSFs that may increase/decrease likelihood of error

- Available time

- Complexity

Example: Available Time

- Procedures

- inadequate time $\rightarrow p($ failure $)=1.0$

- Fitness for duty

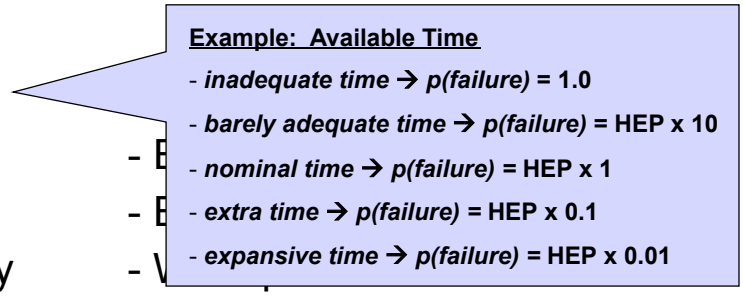




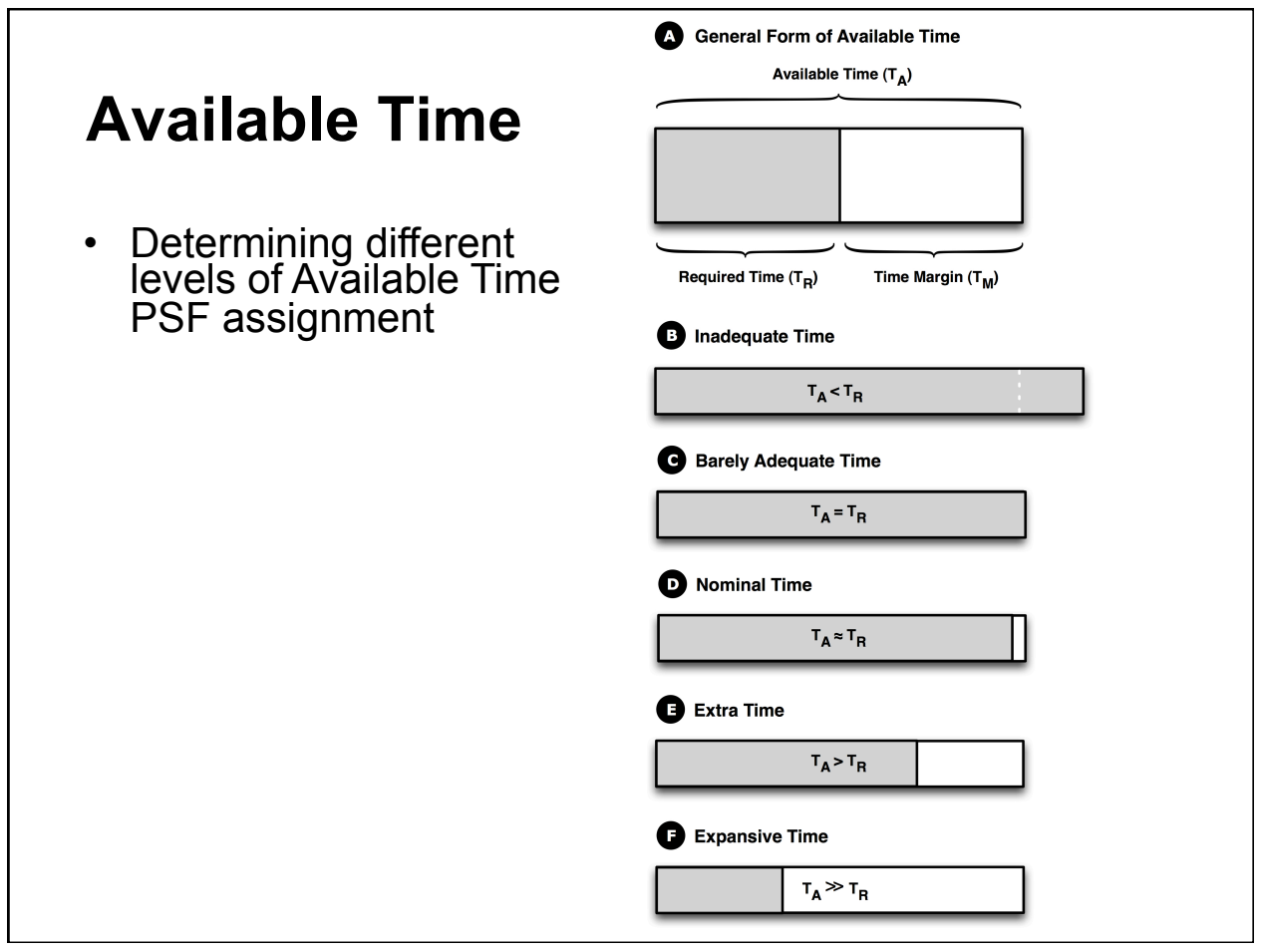

\section{SPAR-H Quantification Graphically}

- PSFs influence performance, which determines likelihood of human error probability

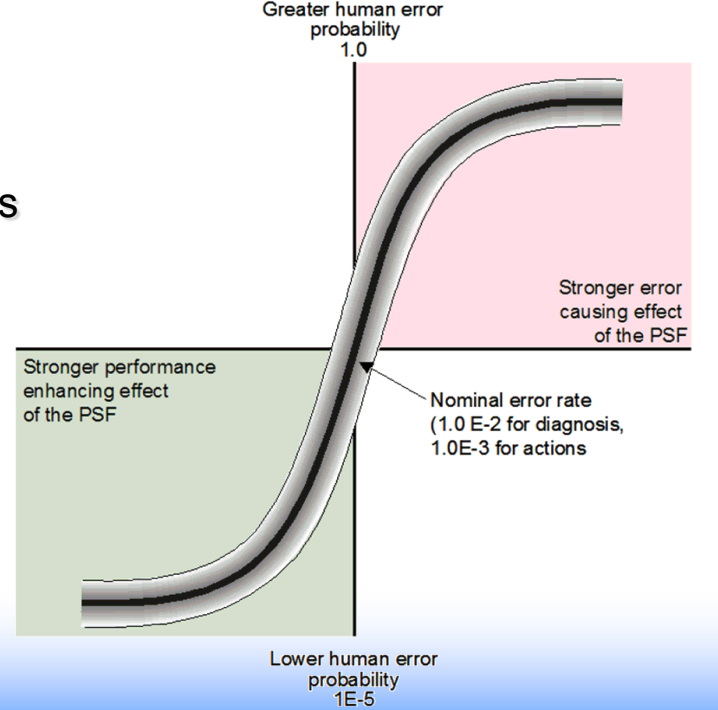




\section{SPAR-H Quantification of PSFs}

To estimate the HEP:

1. Begin with a "nominal" HEP value

$\rightarrow 1 \mathrm{E}-2$ for diagnosis

$\ni 1 \mathrm{E}-3$ for action

2. Multiply nominal HEP by the applicable PSF "factors"

- For example, if the context related to complexity is "highly complex," PSF factor has a value of 5

- Most factors are greater than one, but some are less than one (this allows for consideration of the positive influence of PSFs which may be present)

3. Repeat step 2 for each PSF

\section{SPAR-H Quantification of PSFs (cont.)}

PSF multipliers act to increase or decrease HEP

$H E P_{\text {overall }}=H E P_{\text {nominal }} \times P S F$

$$
\left\{\begin{array}{cccc}
0<P S F<1 & \Rightarrow H E P_{\text {overall }}<H E P_{\text {nominal }} & \therefore & \begin{array}{r}
\text { reliability } \\
\text { increases }
\end{array} \\
P S F=1 & \Rightarrow H E P_{\text {overall }}=H E P_{\text {nominal }} & \therefore & \begin{array}{r}
\text { reliability } \\
\text { stays same }
\end{array} \\
P S F>1 & \Rightarrow H E P_{\text {overall }}>H E P_{\text {nominal }} & \therefore & \begin{array}{r}
\text { reliability } \\
\text { decreases }
\end{array}
\end{array}\right.
$$




\section{SPAR-H Dependency Table}

\begin{tabular}{|c|c|c|c|c|c|c|}
\hline \multicolumn{7}{|c|}{ Dependency Condition Table } \\
\hline $\begin{array}{l}\text { Condition } \\
\text { Number }\end{array}$ & $\begin{array}{l}\text { Crew } \\
\text { (same or } \\
\text { different) }\end{array}$ & $\begin{array}{c}\text { Time } \\
\text { (close in time } \\
\text { or not close } \\
\text { in time) }\end{array}$ & $\begin{array}{l}\text { Location } \\
\text { (same or } \\
\text { different) }\end{array}$ & $\begin{array}{c}\text { Cues } \\
\text { (additional or } \\
\text { no } \\
\text { additional) } \\
\end{array}$ & Dependency & $\begin{array}{c}\text { Number of Human Action Failures Rule } \\
\square \text { - Not Applicable. } \\
\text { Why? }\end{array}$ \\
\hline 1 & \multirow[t]{8}{*}{$\mathrm{s}$} & \multirow[t]{4}{*}{ c } & \multirow[t]{2}{*}{$\mathrm{s}$} & na & complete & \multirow{17}{*}{$\begin{array}{l}\text { When considering recovery in a series } \\
\text { e.g., } 2^{\text {nd }}, 3^{\text {rd }}, \text { or } 4^{\text {th }} \text { checker } \\
\text { If this error is the } 3 \text { rd error in the } \\
\text { sequence, then the dependency is at } \\
\text { least moderate. }\end{array}$} \\
\hline 2 & & & & a & complete & \\
\hline 3 & & & \multirow[t]{2}{*}{ d } & na & high & \\
\hline 4 & & & & a & high & \\
\hline 5 & & \multirow[t]{4}{*}{ nc } & \multirow[t]{2}{*}{$\mathrm{s}$} & na & high & \\
\hline 6 & & & & $\mathrm{a}$ & moderate & \\
\hline 7 & & & \multirow[t]{2}{*}{$\mathrm{d}$} & na & moderate & \\
\hline 8 & & & & $\mathrm{a}$ & low & \\
\hline 9 & \multirow[t]{8}{*}{ d } & \multirow[t]{4}{*}{$\mathrm{c}$} & \multirow[t]{2}{*}{$\mathrm{s}$} & na & moderate & \\
\hline 10 & & & & a & moderate & \\
\hline 11 & & & \multirow[t]{2}{*}{$\mathrm{d}$} & na & moderate & \\
\hline 12 & & & & a & moderate & \\
\hline 13 & & \multirow[t]{4}{*}{$\mathrm{nc}$} & \multirow[t]{2}{*}{$\mathrm{s}$} & na & low & \\
\hline 14 & & & & a & low & \\
\hline 15 & & & \multirow[t]{2}{*}{$\mathrm{d}$} & na & low & \\
\hline 16 & & & & $\mathrm{a}$ & low & \\
\hline 17 & & & & & zero & \\
\hline
\end{tabular}

\section{SPAR-H Dependency Calculation}

Complete Dependence

- $\mathrm{HEP}=1$

High Dependence

- $\operatorname{HEP}=\left(1+\mathrm{P}_{\mathrm{w} / \mathrm{od}}\right) / 2$

Moderate Dependence

- $\mathrm{HEP}=\left(1+6 \times \mathrm{P}_{\mathrm{w} / \mathrm{od}}\right) / 7$

Low Dependence

- $\mathrm{HEP}=\left(1+19 \times \mathrm{P}_{\mathrm{w} / \mathrm{od}}\right) / 20$

Zero Dependence

- $\mathrm{HEP}=\mathrm{P}_{\mathrm{w} / \mathrm{od}}$ 


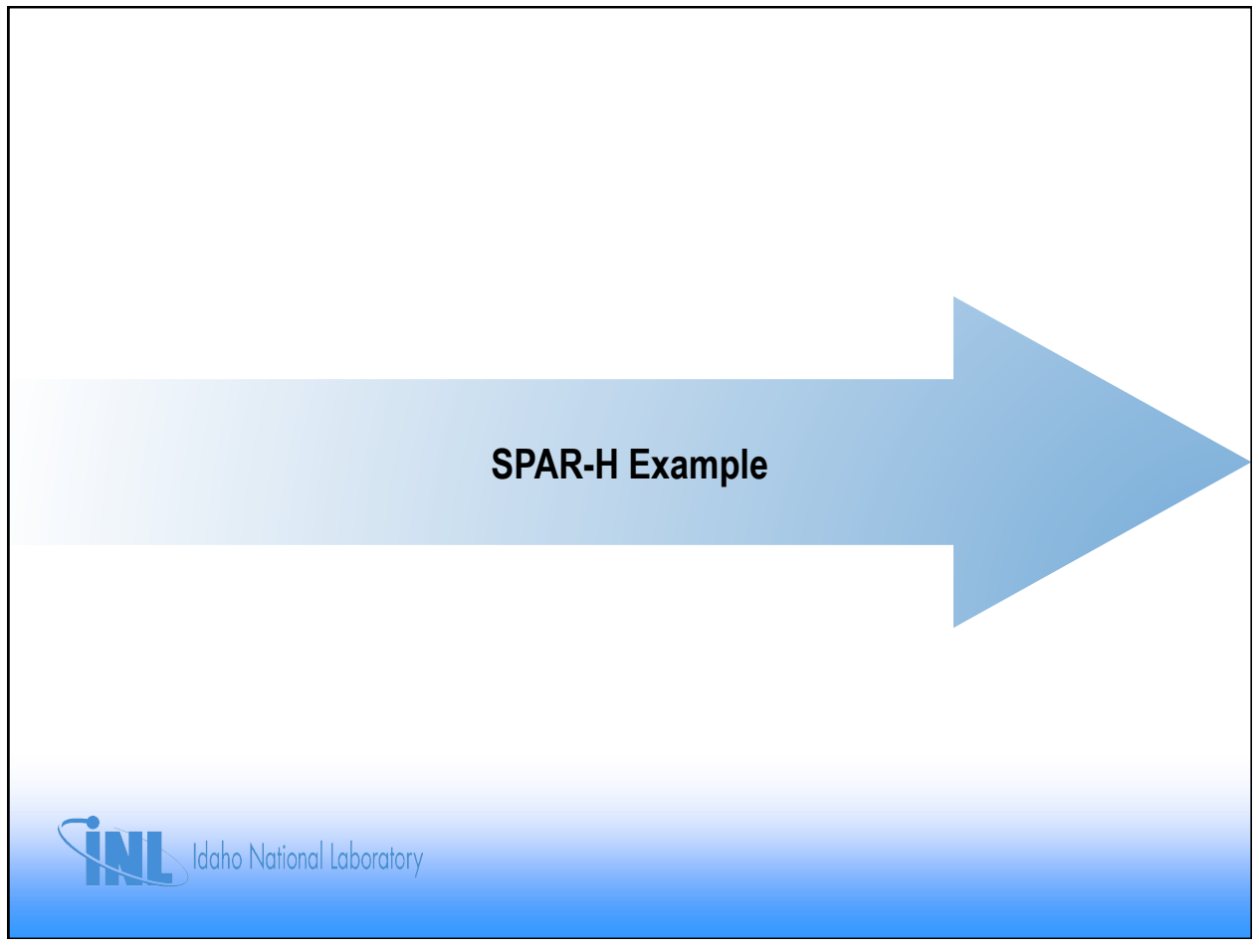

\section{SPAR-H Exercise}

- See Appendix E 


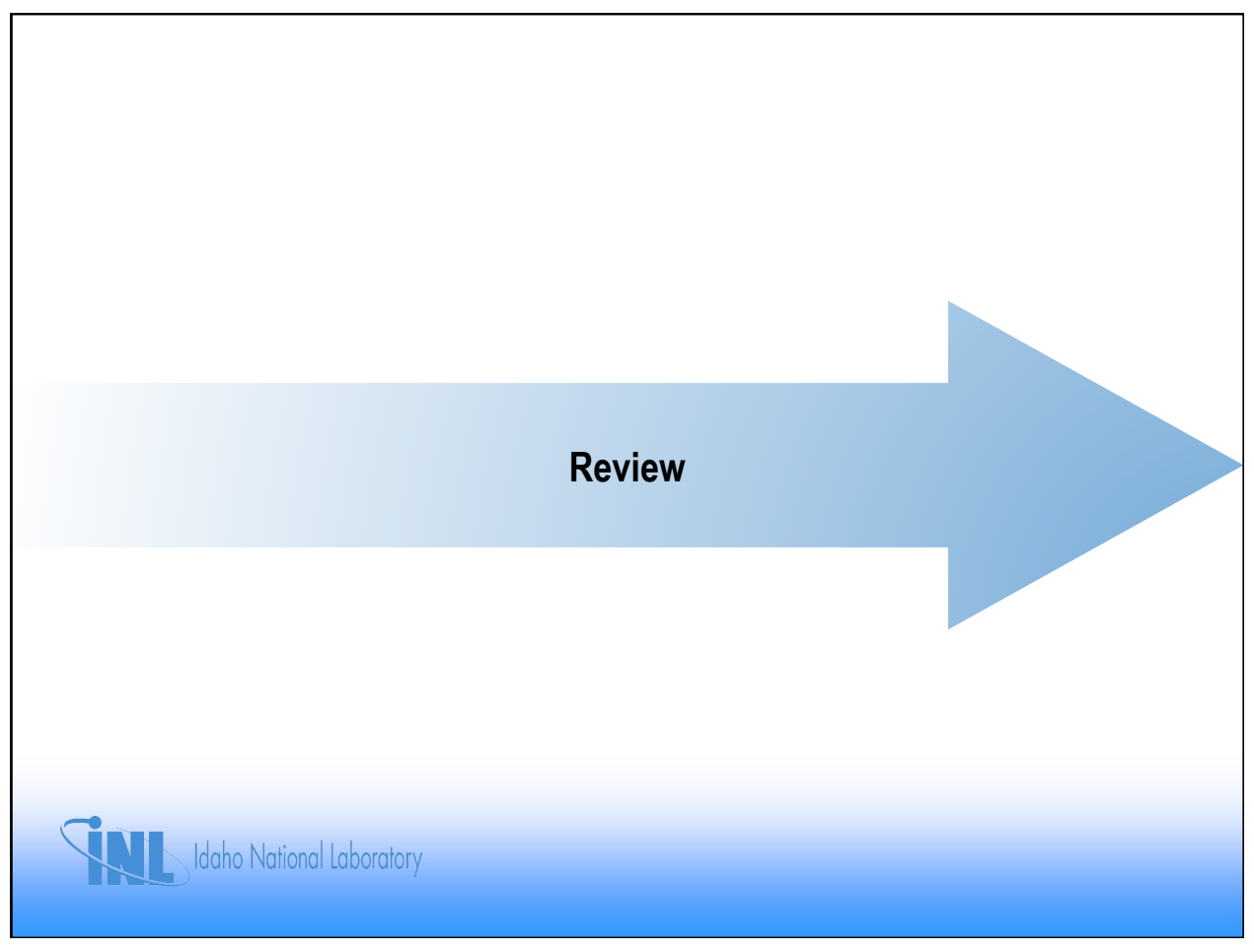

NUREG-1842 Good Practices Summary of SPAR-H

\begin{tabular}{|c|c|c|c|c|c|c|}
\hline METHOD & SCOPE & $\begin{array}{l}\text { UNDERLYING } \\
\text { MODEL }\end{array}$ & $\begin{array}{l}\text { UNDERLYING } \\
\text { DATA }\end{array}$ & $\begin{array}{l}\text { QUANTIFICATION } \\
\text { APPROACH }\end{array}$ & STRENGTHS & LIMITATIONS \\
\hline SPAR-H & $\begin{array}{l}\text { Quantification } \\
\text { technique } \\
\text { for action and } \\
\text { diagnosis HFEs. } \\
\text { Includes a THERP } \\
\text { like dependency } \\
\text { model with } \\
\text { additional } \\
\text { attributes. }\end{array}$ & $\begin{array}{l}\text { Generic error rate } \\
\text { of 0.001 for } \\
\text { action, and } 0.01 \\
\text { for diagnosis, } \\
\text { modified to } \\
\text { account for eight } \\
\text { PSFs and } \\
\text { dependence. } \\
\text { Does not classify } \\
\text { HFss as rec- } \\
\text { or post-initiators. } \\
\text { HFP is the sum of } \\
\text { the action HEP } \\
\text { and the diagnosis } \\
\text { HEP. } \\
\text { Discusses } \\
\text { a general } \\
\text { psychological } \\
\text { model of human } \\
\text { information } \\
\text { processing as its } \\
\text { basis. }\end{array}$ & $\begin{array}{l}\text { Gencric error rates } \\
\text { and PSF } \\
\text { multipliers are } \\
\text { apparently based } \\
\text { on the authors } \\
\text { observations' } \\
\text { revieus of event } \\
\text { statistics and on a } \\
\text { comparison with } \\
\text { data in existing } \\
\text { HRA methods. } \\
\text { Dependence } \\
\text { model based on } \\
\text { THERP } \\
\text { dependence } \\
\text { data/model, with } \\
\text { additional } \\
\text { attributes added. }\end{array}$ & $\begin{array}{l}\text { Uses a fixed set of eight PSFs } \\
\text { to adjust the genenic error rates } \\
\text { to reflect the scenario conditions. } \\
\text { Adjusts for dependence } \\
\text { essentially using the THERP } \\
\text { dependence model, but with } \\
\text { additional attributes added. }\end{array}$ & $\begin{array}{l}\text { - Simple underlying model } \\
\text { makes SPAR-H relatively } \\
\text { simple to use and results are } \\
\text { traceable. } \\
\text { - The eight PSFs included may } \\
\text { cover many situations where } \\
\text { more detailed analysis is not } \\
\text { required. Other methods are } \\
\text { suggested for adderessing } \\
\text { situations not covered by the } \\
\text { model. } \\
\text { - Even though the effects of } \\
\text { time on performance is treated } \\
\text { similar to that in the THERP } \\
\text { and ASEP TRCs, other } \\
\text { potentially important PSFs are } \\
\text { considered in conjunction with } \\
\text { the time factor. } \\
\text { - Provides a detailed discussion } \\
\text { of potential interaction effects } \\
\text { between PSFs (but see related } \\
\text { limitation). } \\
\text { - Acknowledges that } \\
\text { the method may not be } \\
\text { appropriate where more } \\
\text { realistic, detailed analysis of } \\
\text { diagnosis errors is needed. } \\
\text { - THERP like dependence } \\
\text { model can be used to address } \\
\text { both subtask and event } \\
\text { sequence dependence. }\end{array}$ & $\begin{array}{l}\text { Resolution of the PSFs may be } \\
\text { inadequate for detailed analysis. } \\
\text { - Despite detailed discussion } \\
\text { of potential interaction effects } \\
\text { between PFFs, treats PSFs } \\
\text { as independent. } \\
\text { - No explicit guidance is provided for } \\
\text { addressing a wider range of PSFs } \\
\text { when needed, but does encourage } \\
\text { analysts to use more recent context } \\
\text { developing methods if more detail is } \\
\text { neeeded for their application, } \\
\text { particularly as related to diagnosis } \\
\text { errors. } \\
\text { - Although authors checked } \\
\text { underlying data for consistency with } \\
\text { other methods, basis for selection of } \\
\text { final values was not always clear. }\end{array}$ \\
\hline
\end{tabular}




\section{Lesson 7 Review}

- When do you use Diagnosis vs. Action worksheets in SPAR-H?

- What are the nominal HEPs for Diagnosis and Action in SPAR-H?

- What are the eight PSFs in SPAR-H?

- What are the characteristics of a positive vs. negative PSF multiplier in SPAR-H?

- Does dependency increase or decrease HEPs in SPAR$\mathrm{H}$ ?

- How do you conduct a qualitative analysis in SPAR-H?

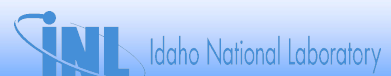

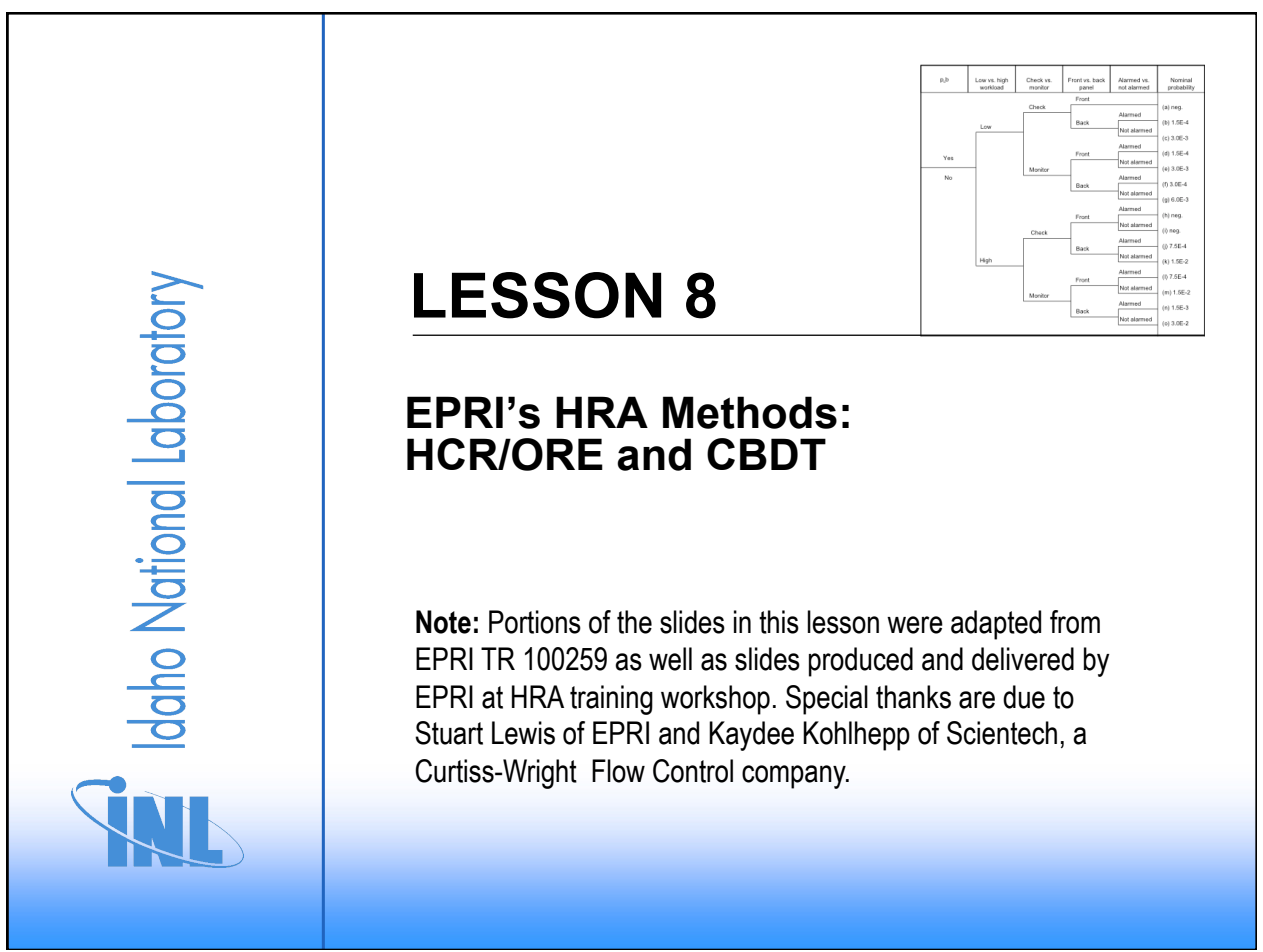




\section{Lesson 8 Objective}

$\checkmark$ Introduce two commonly used HRA methods and a tool developed by EPRI: the HCR/ORE and CBDT methods and the EPRI HRA Calculator

- HCR/ORE and CBDT methods: history, concept, usage, strengths and weaknesses

- EPRI HRA Calculator - history and glimpse of usage

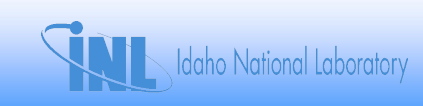

EPRI's Involvement in HRA 


\section{Electric Power Research Institute (EPRI) Involvement in HRA}

After TMI, EPRI led foundational HRA research and method development

- Very concerned with estimating the "front-end" cognitive portion of events

- Lots of attention to Rasmussen's Skill, Rule, and Knowledge constructs that were emerging

- E.g., How much of the operator behavior is affected by experience (skill) and availability of good procedures (rules)?

- $\mathrm{P}_{\mathrm{C}}$ - cognitive portion of human failure events being modeled

- $\mathrm{P}_{\mathrm{e}}$ - execution portion of modeled event

Conducted Operator Reliability Experiment (ORE) in the 1980s

- Collected data from simulator studies

- 3 BWR and 3 PWR nuclear power plants

-6 US utilities: Com Ed, PG\&E, Wisconsin Public Services, Philadelphia

Electric, PPL, Duke

-117 human interactions were observed

- More than 1000 data points gathered

\section{From Data to Tools}

\section{EPRI's team created two methods}

- Human Cognitive Reliability (HCR)/ORE

- Cause-Based Decision Trees (CBDT)

Eventually put these and other tools into the EPRI HRA Calculator

- Managed through EPRI, code maintained through Scientech (CurtissWright)

- Also supports ASEP, SPAR-H, Annunciator Response, and Screening

- THERP is used for execution portion of tasks

- Guided and reviewed by the EPRI HRA User Group 
Both HCR/ORE and CBDT are targeted to help analyze the cognitive portion of post-initiator events by estimating the non-response probabilities

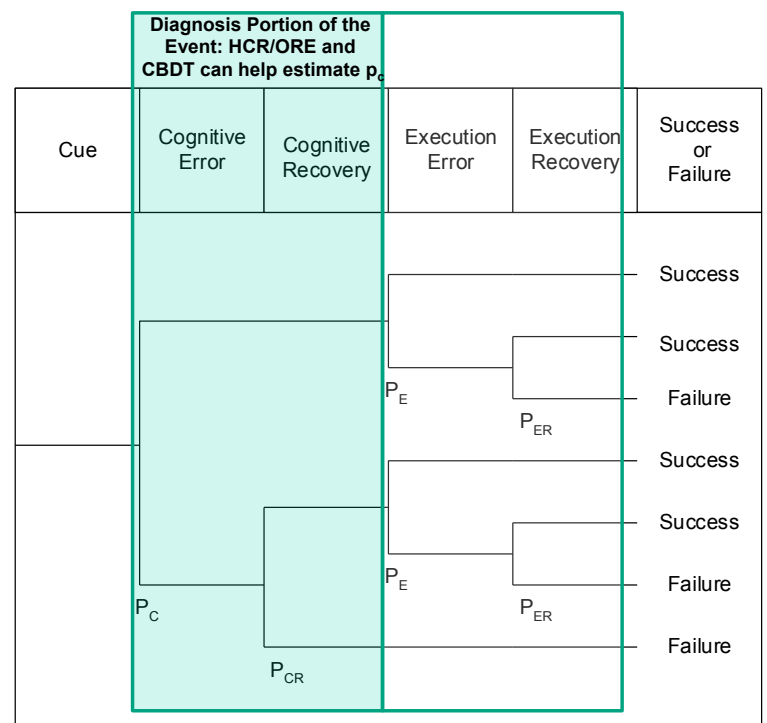

Big Picture Process for Calculating HEPs using HCR/ ORE and/or CBDT for the $p_{c}$ and THERP for the $p_{e}$

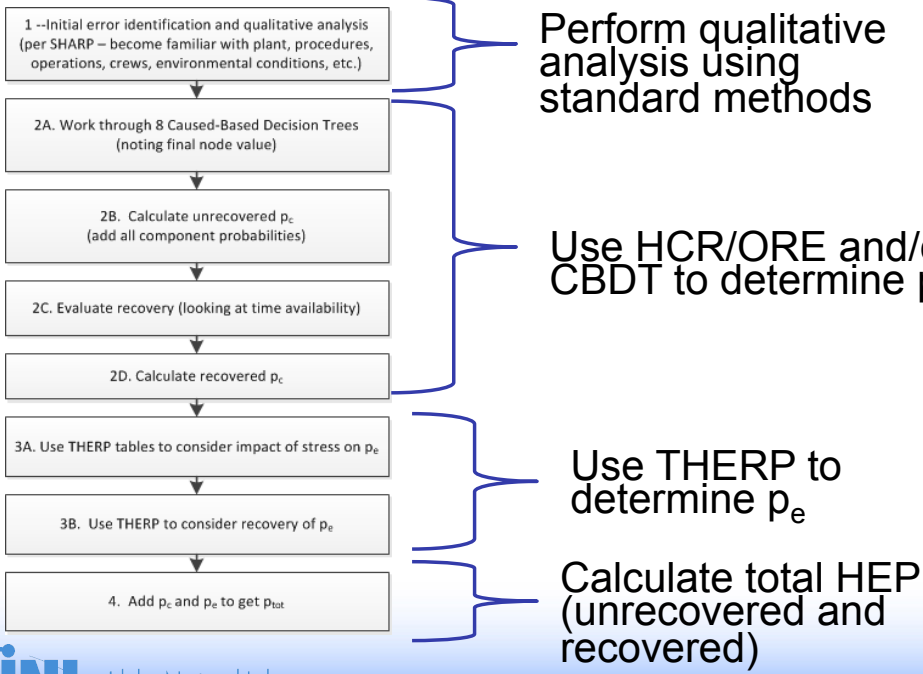

Perform qualitative analysis using standard methods

Calculate total HEP (unrecovered and recovered) 


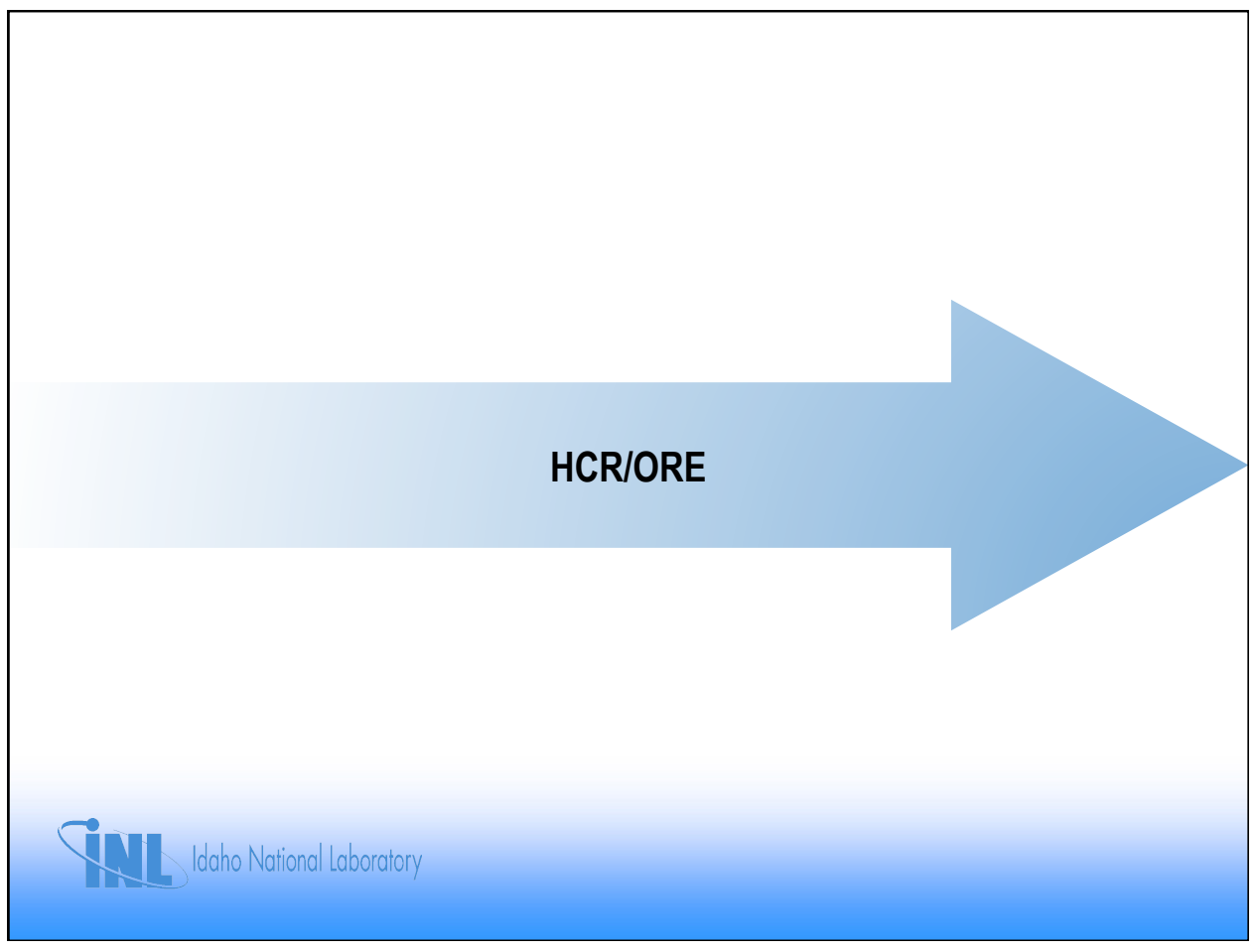

\section{Derivation of HCR/ORE}

Operator Reliability Experiment (ORE) was designed to gather data to validate or refute the putative relationship between available time and nonresponse probability

- Crews from six plants (3 PWR and 3 BWR) were involved in simulator studies

- Results supported cue-response: the hypothesis that there is a strong time relationship given limited time frames

- Additional factors were not empirically supported.

- Non-response correlation (i.e. failure to respond within appropriate time window) appears to be different for PWR than for BWR 


\section{Derivation of HCR/ORE (Continued)}

HCR/ORE Method was published in 1992 as EPRI TR-100259 (along with CBDT as an Appendix)

- Ideally suited for time-limited post-initiator events which primarily involve responding to immediate alarms

- $\mathrm{P}_{\mathrm{c}}$ (cognitive or diagnostic) portion of the event

- $P_{\mathrm{e}}$ (execution) portion handled with THERP

- Overly optimistic when used for non-time-limited events

- Implemented as part of the EPRI HRA Calculator

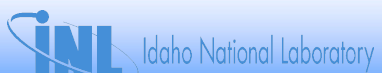

\section{Cue-Response Structures:*}

The 3 Types of Cognitive Procedurally (CP) Driven Actions Handled in HCR

* Note that CP4 and CP5 were described in EPRI TR-100259 but no data was collected for these types of actions)

CP1

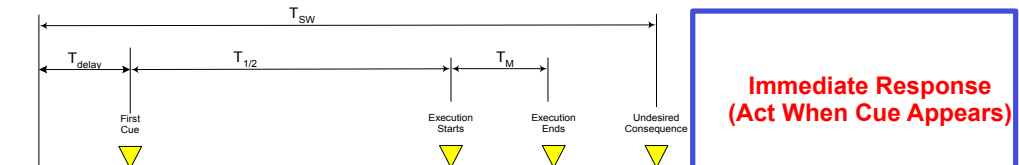

CP2

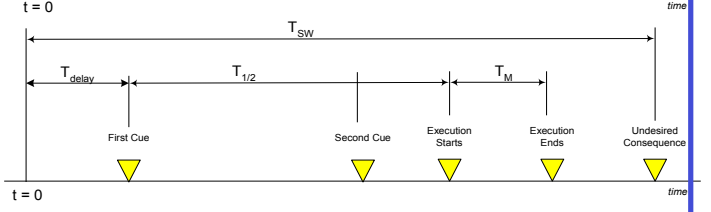

Delayed Response (Wait Until Second Cue)

CP3

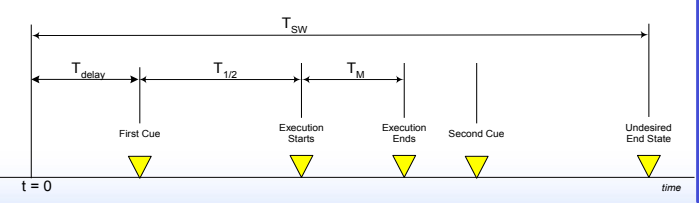

Trending Response (Act Before Second Cue)

Not clear how representative or comprehensive these

actions are! 


\section{HCR/ORE Curves: For Your Information}

\section{Non-Response Probability: Not an HEP!}
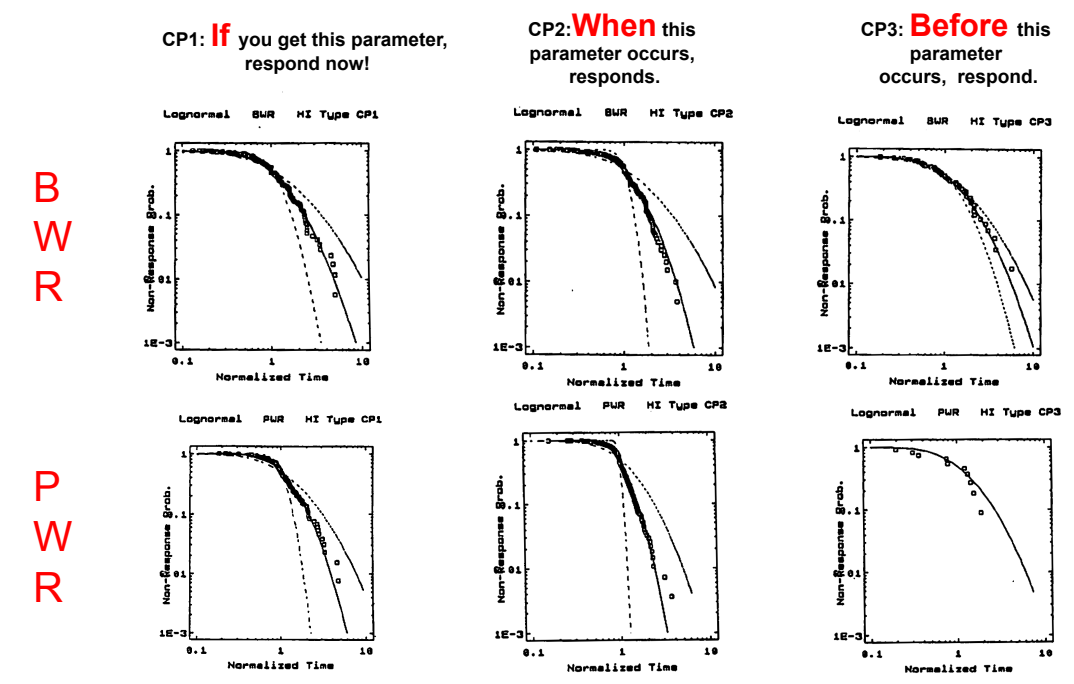

\section{Tuning the Resulting HEP:}

Selecting $\sigma$ based on cue-response structure

\begin{tabular}{|c|c|c|c|c|}
\hline \multirow{2}{*}{$\begin{array}{l}\text { Plant } \\
\text { Type }\end{array}$} & \multirow{2}{*}{$\begin{array}{l}\text { Cue- } \\
\text { Response } \\
\text { Structure }\end{array}$} & \multicolumn{3}{|c|}{$\begin{array}{l}\text { Values for } \sigma \text { (sigma is the logarithmic } \\
\text { standard deviation of normalized time) }\end{array}$} \\
\hline & & Average & $\begin{array}{l}\text { Upper } \\
\text { Bound }\end{array}$ & $\begin{array}{l}\text { Lower } \\
\text { Bound }\end{array}$ \\
\hline \multirow[t]{3}{*}{ BWRs } & $\mathrm{CP} 1^{*}$ & 0.70 & 1.00 & 0.40 \\
\hline & CP2 & 0.58 & 0.96 & 0.20 \\
\hline & CP3 & 0.75 & 0.91 & 0.59 \\
\hline \multirow[t]{3}{*}{ PWRs } & $\mathrm{CP}^{*}{ }^{*}$ & 0.57 & 0.88 & 0.26 \\
\hline & CP2 & 0.38 & 0.69 & 0.07 \\
\hline & CP3 & 0.77 & * & * \\
\hline
\end{tabular}

* If unsure, start with CP1 


\begin{tabular}{|c|c|c|c|c|c|c|}
\hline \multicolumn{7}{|c|}{ NUREG-1842 Good Practices Summary of HCR-ORE } \\
\hline \begin{tabular}{|l|} 
MЕтноD \\
\end{tabular} & SCOPE & $\begin{array}{c}\text { INDERLYING } \\
\text { MODEL } \\
\end{array}$ & $\begin{array}{c}\text { UNDERIYING } \\
\text { DAIA }\end{array}$ & $\begin{array}{c}\text { QUANTHFCATION } \\
\text { APPROACH } \\
\end{array}$ & STRENGTHS & LIMITATIONS \\
\hline HCR ORE & 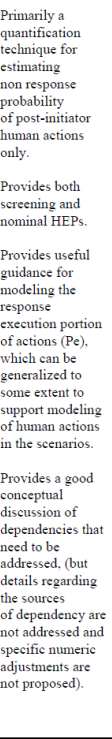 & 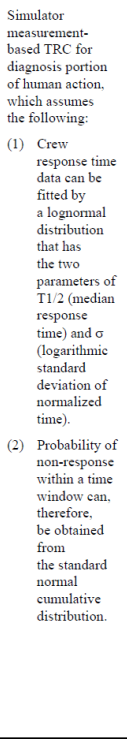 & 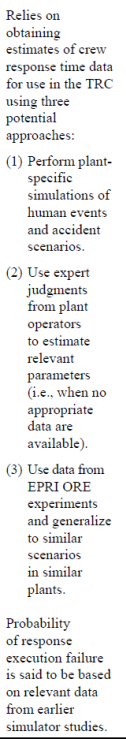 & 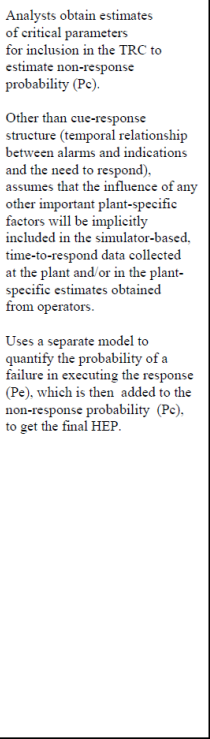 & 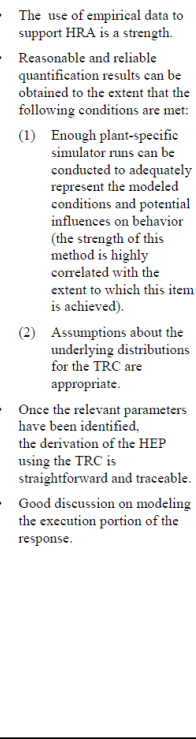 & 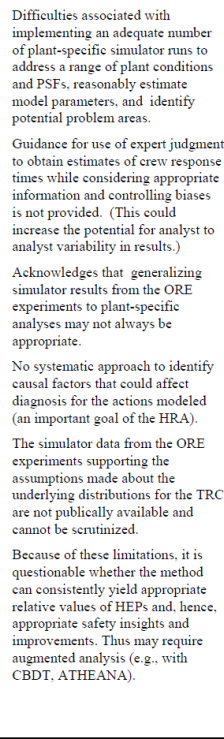 \\
\hline
\end{tabular}

\section{What if there is no serious time limitation?}

- The ORE project spawned another method to handle these cases:

- Cause-Based Decision Tree (CBDT)

- Used for control room actions (or local actions) with an important cognitive component 


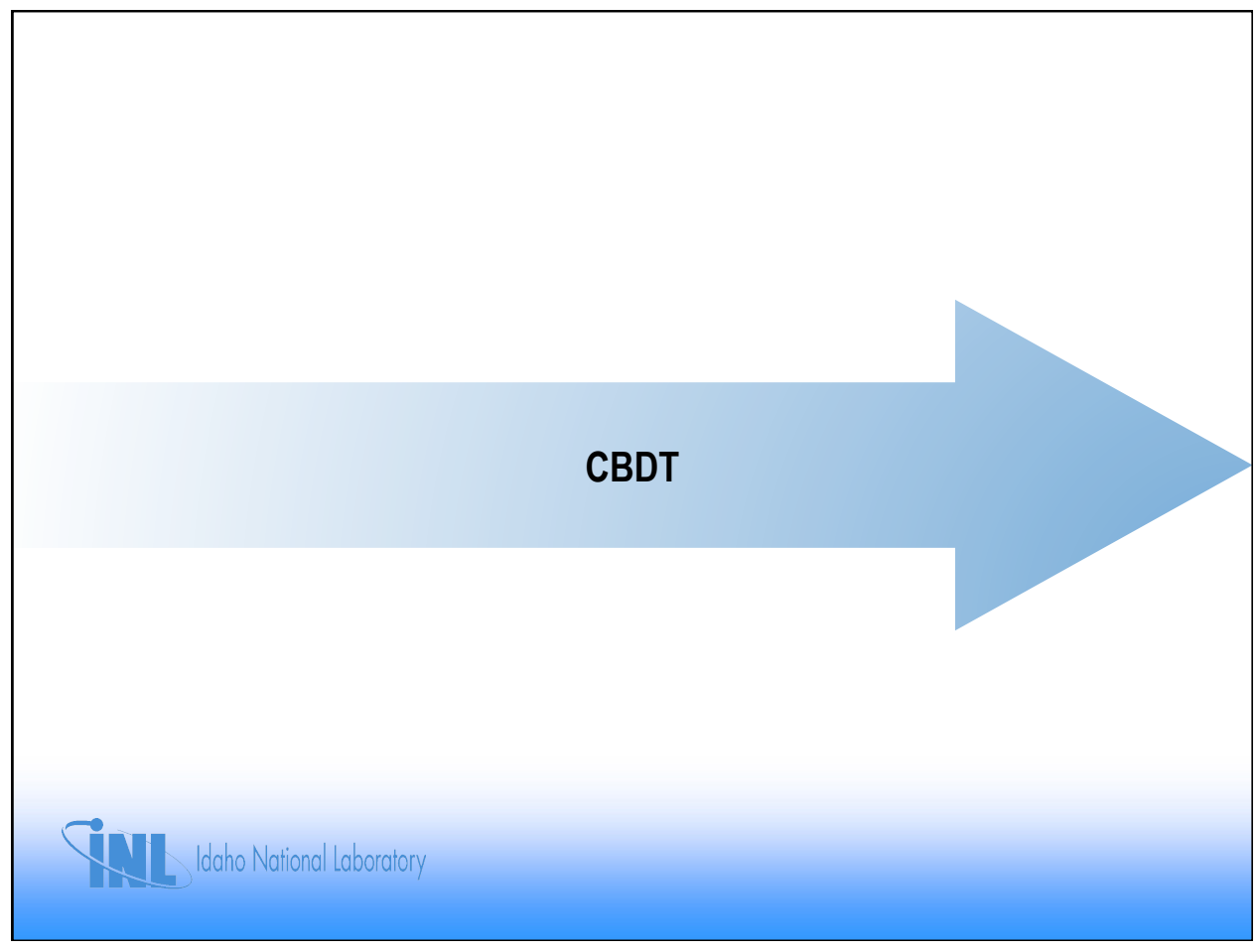

\section{EPRI'S CAUSE-BASED DECISION TREE (CBDT) METHOD}

CBTD is a simplified framework for quantifying the $p_{c}$ (cognitive/ diagnostic) portion of an HEP

- Method published in 1992 EPRI TR-100259 (as Appendix to HCR/ORE report)

- Typically used when time is not a limiting factor

- EPRI TR-100259 provides detailed guidance as to when to use CBDT

- Developed by A. Beare and G. Parry and others and designed to put a lower limit on HCR/ORE values

- Probabilities for some events adapted from THERP

- Specific data derivation that came from the THERP tables is documented in Attachment A to EPRI TR-100259, Appendix A, Tables A-1 to A-8

- Typically less conservative than ASEP 


\section{The CBDT Method is ...}

- An analytical approach based on identification of failure mechanisms and compensating factors

- Applicable to rule-based behavior (e.g. when procedures are used)

- Specifically designed for post-initiator HFEs

- For modeling HFEs where cognition takes place as in the control room (similar to HCR/ORE)

- However, can be used for estimating cognitive portion of local actions

- Included as a primary method in the EPRI HRA Calculator $®$

- Widely used by industry

\section{CBDT Failure Mechanisms}

\begin{tabular}{|c|c|l|}
\hline $\begin{array}{c}\text { Failure } \\
\text { Modes }\end{array}$ & Designator & \multicolumn{1}{c|}{$\begin{array}{c}\text { Failure Mechanism } \\
\text { Description }\end{array}$} \\
\hline \multirow{3}{*}{$\begin{array}{c}\text { 1. Operator- } \\
\text { Information } \\
\text { Interface }\end{array}$} & $\mathbf{p}_{\mathbf{c}} \mathbf{a}$ & Data not available \\
\cline { 2 - 3 } & $\mathbf{p}_{\mathbf{c}} \mathbf{b}$ & Data not attended to \\
\cline { 2 - 3 } & $\mathbf{p}_{\mathbf{c}} \mathbf{c}$ & Data misread or miscommunicated \\
\hline \multirow{3}{*}{$\begin{array}{c}\text { 2. Operator- } \\
\text { Procedure } \\
\text { Interface }\end{array}$} & $\mathbf{p}_{\mathbf{c}} \mathbf{d}$ & Information misleading \\
\cline { 2 - 3 } & $\mathbf{p}_{\mathbf{c}} \mathbf{e}$ & Relevant step in procedure missed \\
\cline { 2 - 3 } & $\mathbf{p}_{\mathbf{c}} \mathbf{f}$ & Misinterpret instruction \\
\cline { 2 - 3 } & $\mathbf{p}_{\mathbf{c}} \mathbf{g}$ & Error in interpreting logic \\
\hline
\end{tabular}




\section{CBDT Format}

- Each of the 8 failure mechanisms is modeled using an event tree with binary branches

- All trees have at least 3 questions (most have 4) placed in the "events" slots along the top

- Most criteria are phrased as yes/ no questions

- Using insights gained from qualitative analysis, analysts answer the questions to select a path

- The method provides basic guidance

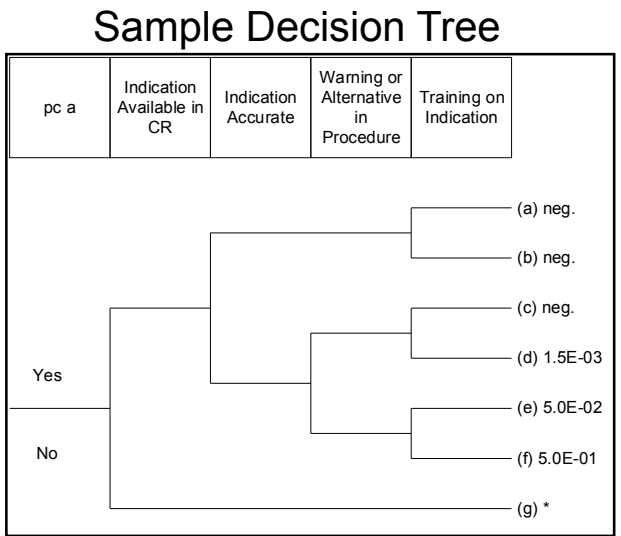

Neg. = negligible effect from nominal HEP * = almost guaranteed to fail

\section{Path HEP Calculations}

- As the analyst selects a path through tree, the probabilities are adjusted by pre-determined modifiers

- With the end products being listed next to each final path, the analyst need only copy that final value to a worksheet (to include all 8 failure mechanisms)

- All the path values and logic have been incorporated into the EPRI HRA Calculator

- The predefined values can be modified in special cases

HRA Calculator ${ }^{\circledR}$ partial screen

Sample Decision Tree

showing modifiers and a selected path
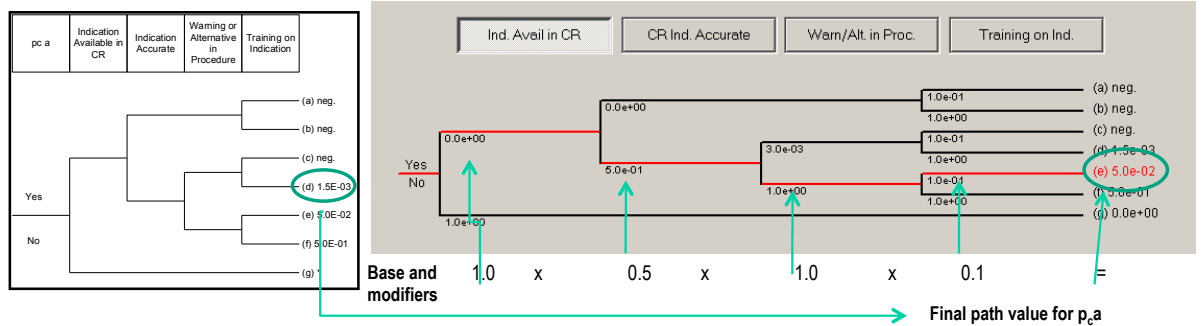


\section{The CBDT “Forest”}

The next 8 slides show each tree

Then a summary slide shows all questions but no notes

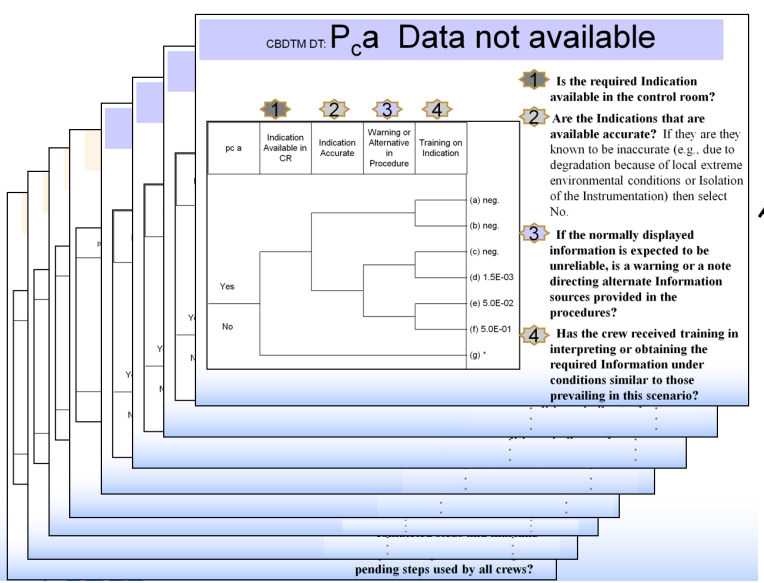

See Appendix $\mathbf{F}$ for lists of the questions for each tree

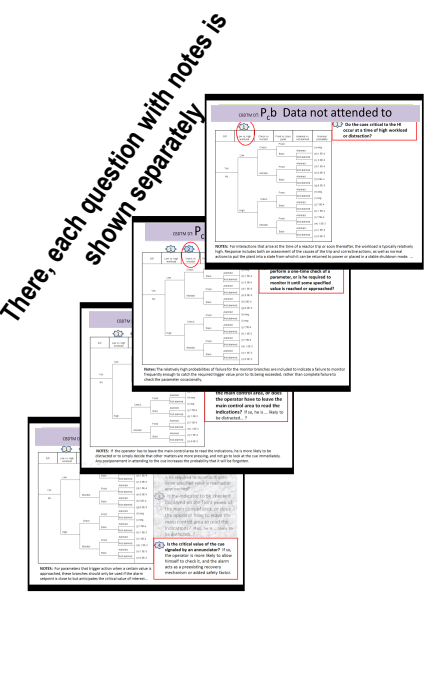

\section{$\mathrm{P}_{\mathrm{c}} \mathrm{a}$ Data Not Available}

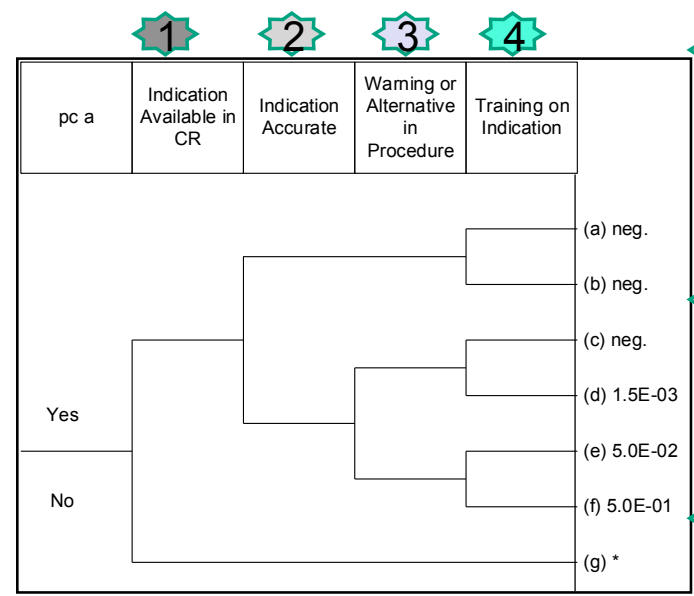

Is the required Indication available in the control room?

23 Are the Indications that are available accurate? If they are they known to be inaccurate (e.g., due to degradation because of local extreme environmental conditions or Isolation of the Instrumentation) then select No.

33 If the normally displayed information is expected to be unreliable, is a warning or a note directing alternate Information sources provided in the procedures?

43 Has the crew received training in interpreting or obtaining the required Information under conditions similar to those prevailing in this scenario? 


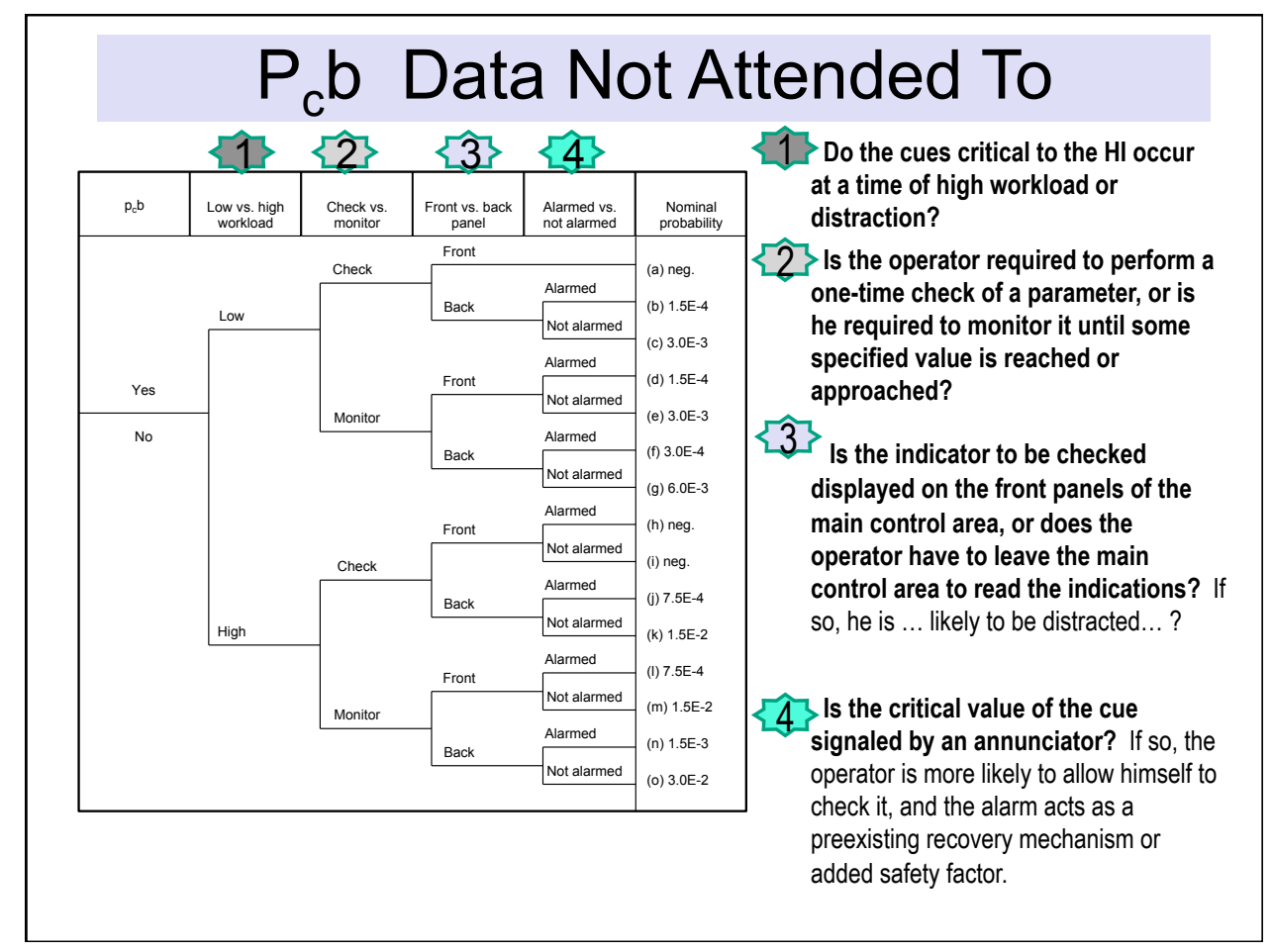

\section{$P_{c} c$ Data Misread or Miscommunicated}

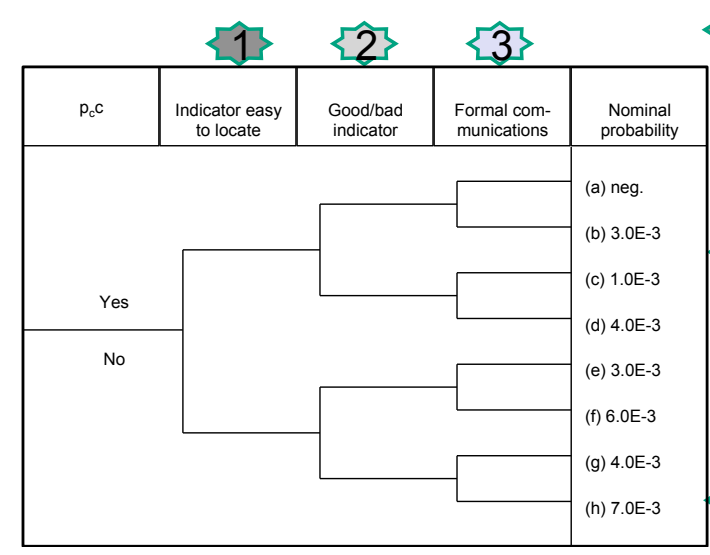

Are the layout, demarcation, and labeling of the control boards such that it is easy to locate the required indicator?

23 Does the required have human engineering deficiencies that are conducive to errors in reading the display? If so the lower branch is followed.

33 is a formal or semi-formal communications protocol used in which the person transmitting a value always identifies with what parameter the value is associated? 

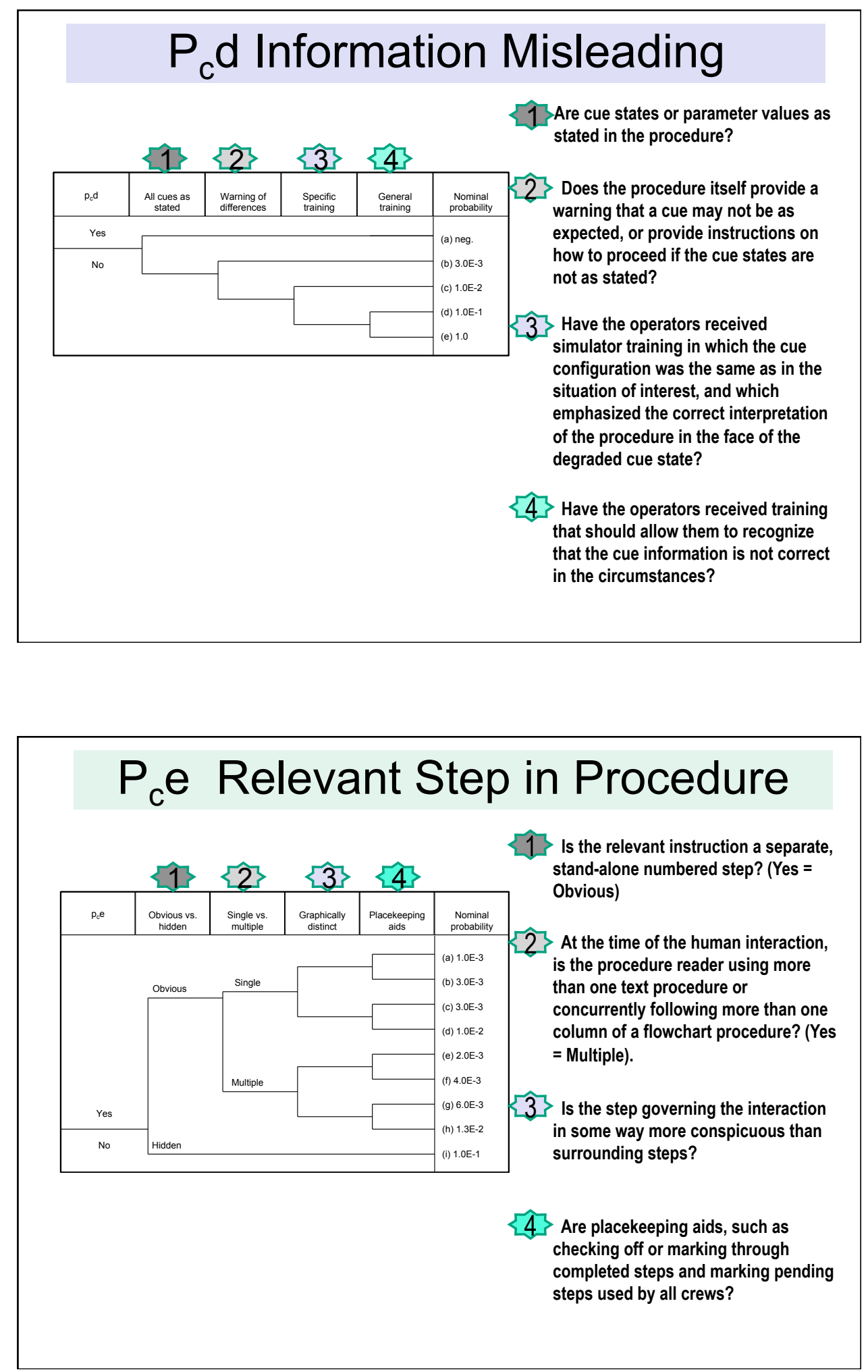

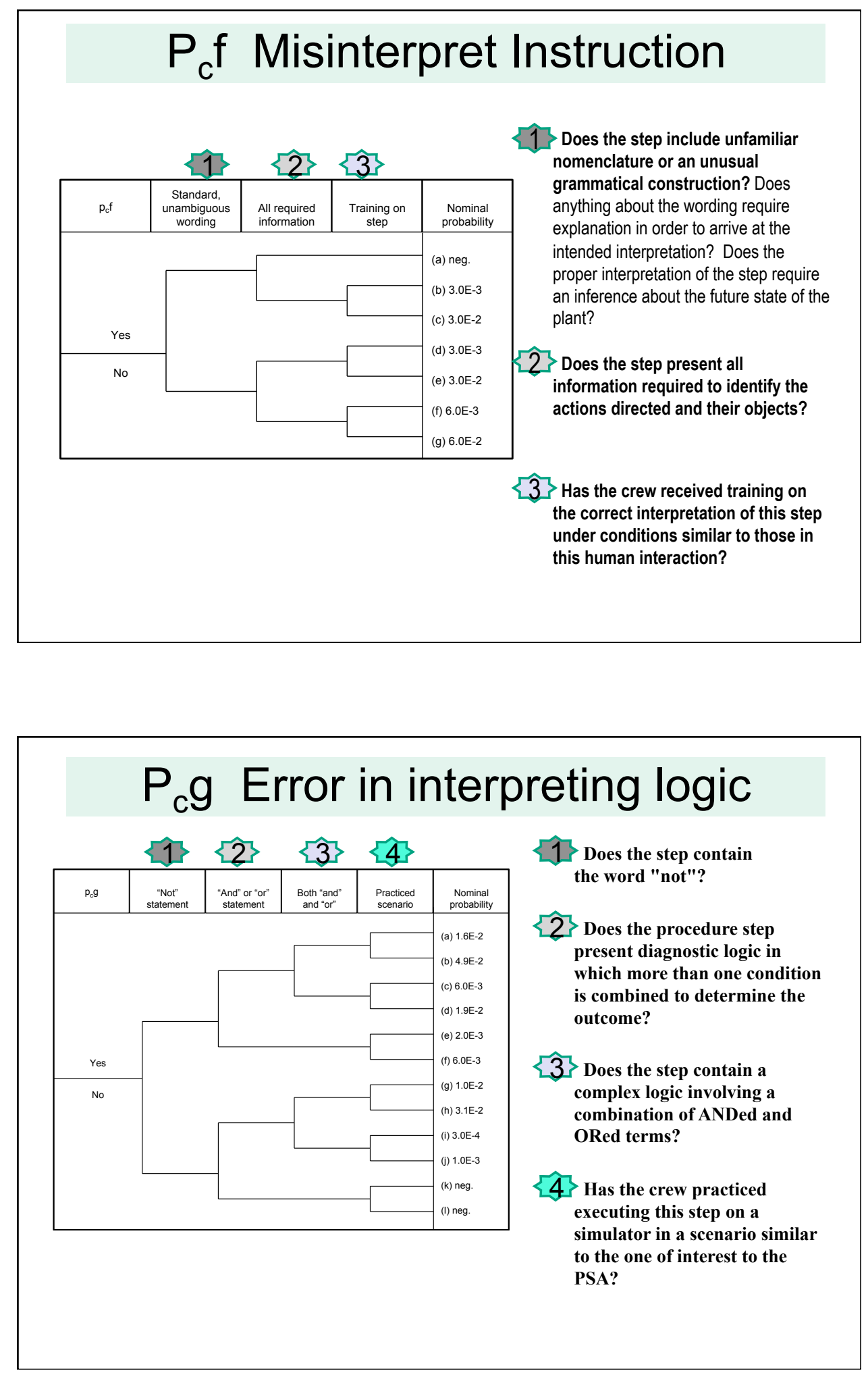


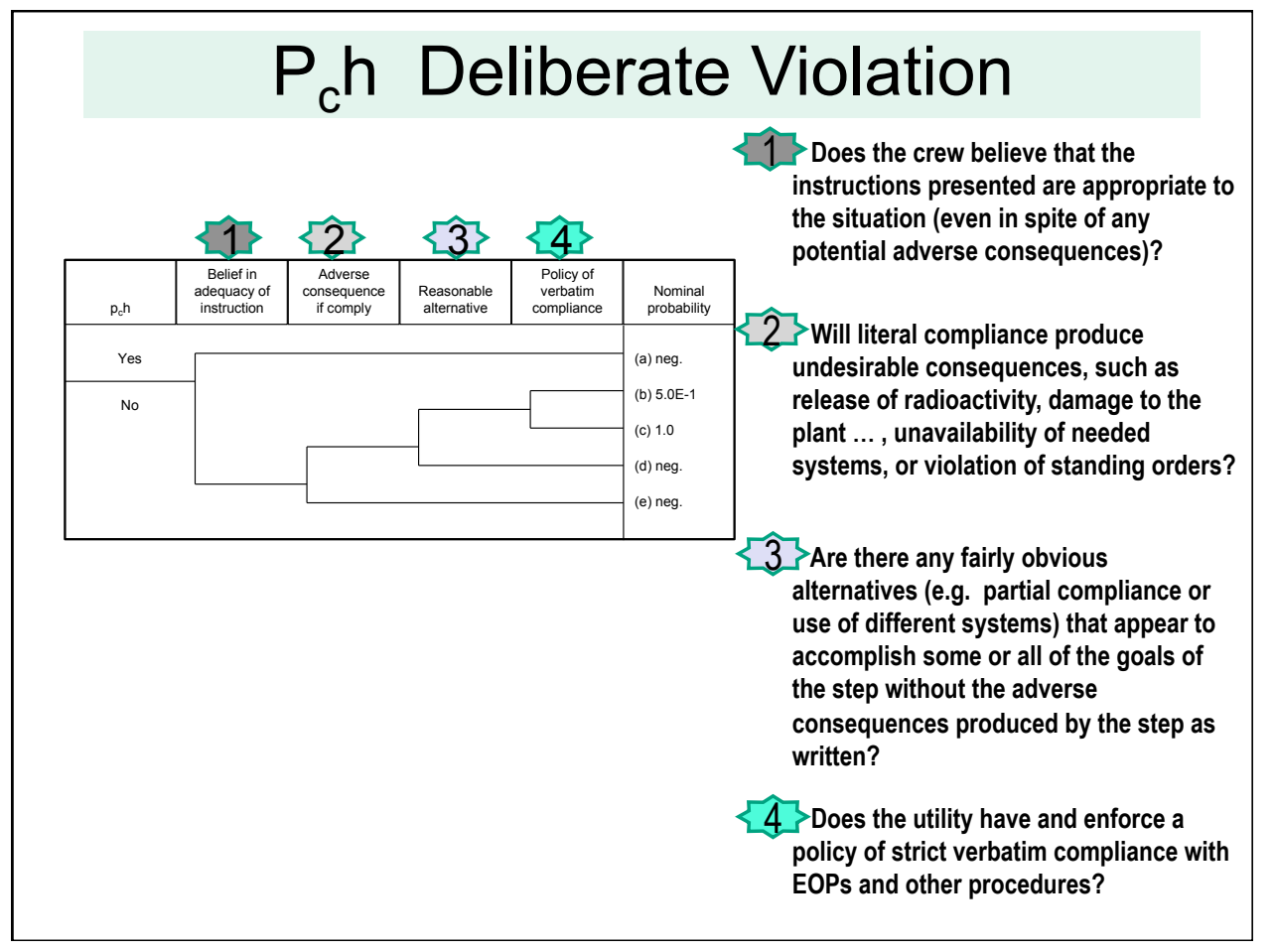

\section{CBDT Unrecovered Quantification}

$$
\begin{aligned}
& \text { Engineering } \\
& \text { Speak } \\
& p_{c}=\sum_{i=1,2} \sum_{j} p_{i j} p_{n r}^{j i}
\end{aligned}
$$

Where $p_{i j}$ is the probability of mechanism $j$ of the mode $i$ occurring initially for the $\mathrm{HI}$, and the $p_{n r}^{i}$ is the probability of nonrecovery from mechanism $j$ in mode $i$.

\section{Plain English}

Sum of all the 8 failure mechanism HEPs 


\section{Sample CBDT Output for $\mathbf{P}_{\mathrm{c}}$}

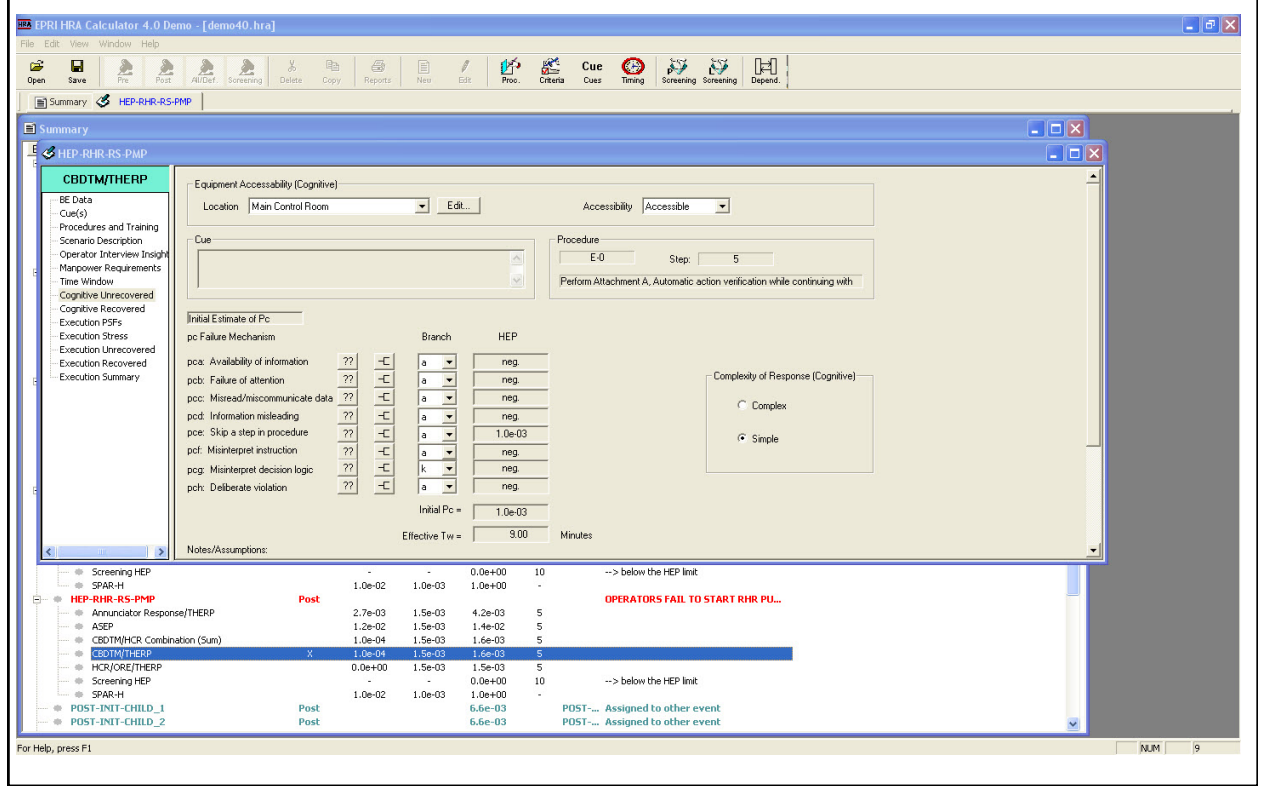

\section{CBDT: Calculating $p_{c}$ Recovery}

Revisitation is the major source of recovery -5 factors considered:

- Self-Review

- Extra Crew

- STA Review

- Shift Change

- ERF Review

Impact (modifier value) determined by a specific applicability table

- When credible, most often use THERP Dependence level calculation

- For example: Self-review is only credited for two trees ("Data not attended to" and "Relevant step in procedure missed")

- How many factors should be credited?

- General rule: only credit the single, most certain recovery factor especially when the time window is less than an hour

- Exceptional case: When the window is several hours, it may be justifiable to credit more than one factor 


\section{Application of Recovery Factors}

\begin{tabular}{|c|c|c|c|c|c|c|c|}
\hline Tree & Description & Branches & Self-Review & Extra Crew & STA Review & Shift Change & ERF Review \\
\hline$p_{c} a$ & Data not available & all & NC & 0.5 & NC & 0.5 & 0.5 \\
\hline$p_{0} b$ & $\begin{array}{c}\text { Data not attended } \\
\text { to }\end{array}$ & all & $x$ & NC & $x$ & $x$ & $x$ \\
\hline$p_{0} c$ & $\begin{array}{l}\text { Data misread or } \\
\text { miscommunicated }\end{array}$ & all & NC & NC & $\mathrm{x}$ & $\mathrm{x}$ & $x$ \\
\hline$p_{c} d$ & $\begin{array}{r}\text { Information } \\
\text { misleading }\end{array}$ & all & NC & 0.5 & $\mathrm{x}$ & $x$ & 0.1 \\
\hline$p_{c} e$ & $\begin{array}{l}\text { Relevant step in } \\
\text { procedure missed }\end{array}$ & $a-h$ & $x$ & 0.5 & NC & $x$ & $x$ \\
\hline$p_{c} e$ & $\begin{array}{l}\text { Relevant step in } \\
\text { procedure missed }\end{array}$ & $\mathrm{i}$ & 0.5 & 0.5 & $\mathrm{x}$ & $\mathrm{x}$ & $x$ \\
\hline$p_{c} f$ & $\begin{array}{c}\text { Misinterpret } \\
\text { instruction }\end{array}$ & all & NC & 0.5 & $x$ & $x$ & $x$ \\
\hline$p_{0} g$ & $\begin{array}{c}\text { Error in } \\
\text { interpreting logic }\end{array}$ & all & NC & 0.5 & $x$ & $x$ & $x$ \\
\hline$p_{0} h$ & $\begin{array}{c}\text { Deliberate } \\
\text { violation }\end{array}$ & all & NC & $x$ & $x$ & NC & NC \\
\hline & Legend: & & $\mathrm{NC}=$ no credit & & $x$ & $\begin{array}{l}\text { Identify level o } \\
\text { dependence, th } \\
\text { dependency ec }\end{array}$ & $\begin{array}{l}\text { len use THERP } \\
\text { uation }\end{array}$ \\
\hline
\end{tabular}

THERP Dependency Calculations
\begin{tabular}{|c|c|c|}
\hline $\begin{array}{c}\text { Dependence } \\
\text { Level }\end{array}$ & Equation & $\begin{array}{c}\text { Approximation } \\
\text { for Small HEP }\end{array}$ \\
\hline Zero (ZD) & HEP & HEP \\
\hline Low (LD) & $\begin{array}{c}(1+19 \times \text { HEP) } \\
20\end{array}$ & 0.05 \\
\hline Medium (MD) & $(1+6$ X HEP) $/ 7$ & 0.14 \\
\hline High (HD) & $(1+$ HEP) $/ 2$ & 0.5 \\
\hline Complete (CD) & 1 & 1 \\
\hline
\end{tabular}

\section{From E-3 to E-4 with Recovery}

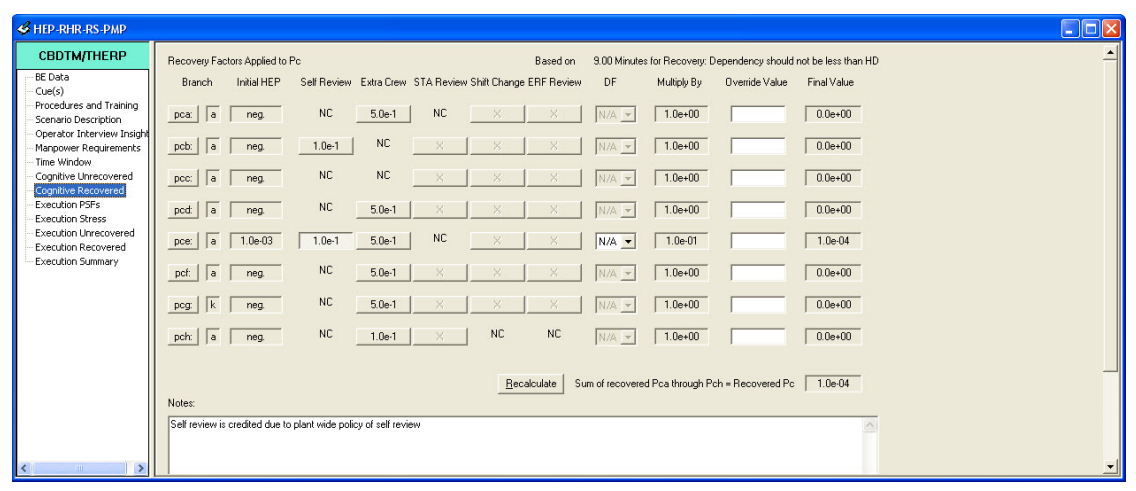

\section{SII Idaho National Laboratory}




\begin{tabular}{|c|c|c|c|c|c|}
\hline \multicolumn{6}{|c|}{ NUREG-1842 Good Practices Summary of CBDT } \\
\hline SCOPE & $\begin{array}{l}\text { UNDERLYING } \\
\text { MODEL }\end{array}$ & $\underset{\text { DATA }}{\substack{\text { UNDERLING } \\
\text { DAT }}}$ & $\begin{array}{l}\text { QUANTIFICATION } \\
\text { APPROACH }\end{array}$ & STRENGTHS & Lnmtations \\
\hline 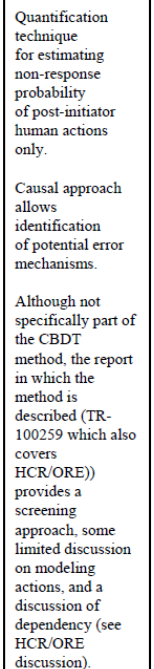 & 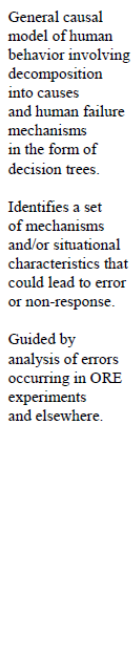 & $\begin{array}{l}\text { HEPs included } \\
\text { in the method's } \\
\text { decision trees } \\
\text { are based on } \\
\text { adapatation of data } \\
\text { from THER } \\
\text { NorRE- } 1278 \\
\text { to the conditions } \\
\text { covered by } \\
\text { the method. }\end{array}$ & 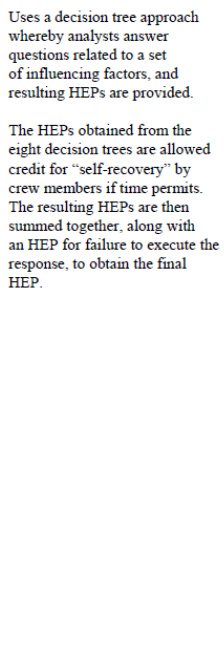 & 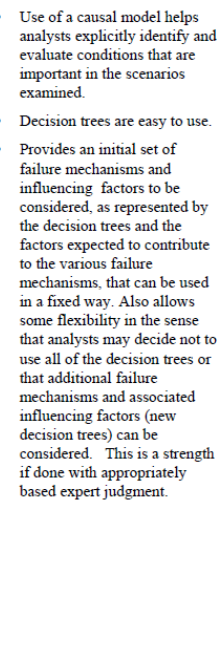 & 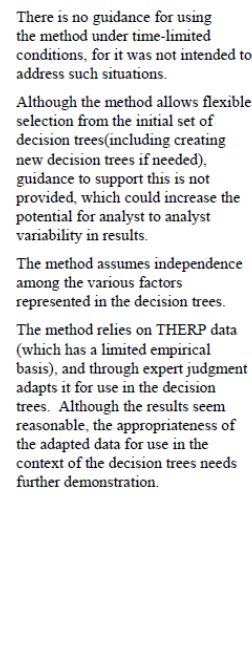 \\
\hline
\end{tabular}

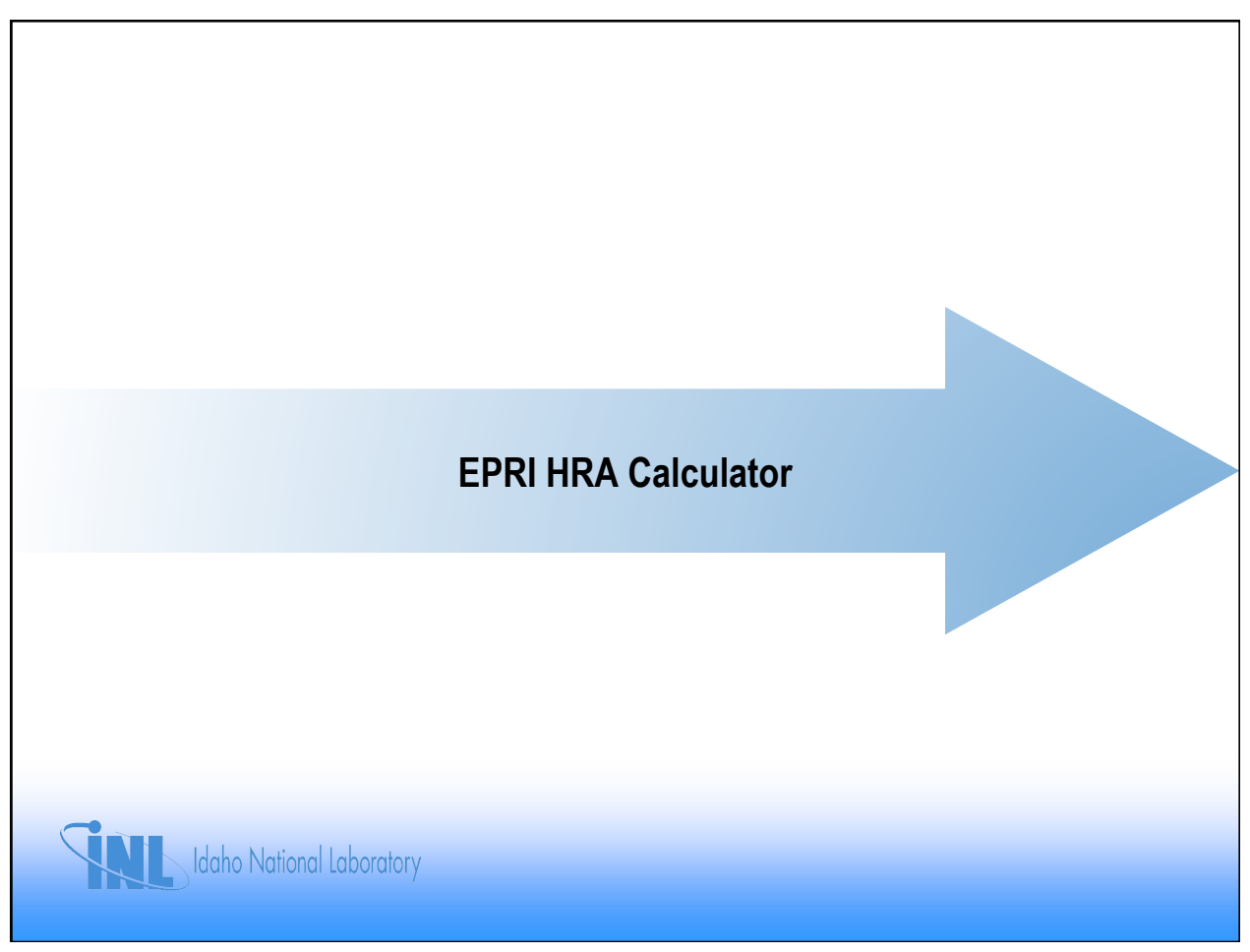


http://scientech.cwfc.com/software/spokes/03_HRAcalculator.htm

The EPRI HRA Calculatorø Human Reliabilty Analysis (HRA)

The EPRI HRA Calculatorin is a software tool designed to facilitate a standardized approach to human reliability analysis (HRA). Wide varieties of methodologies are used for HRA in probabilistic risk assessment ( $P R A)$.

The results from these differing methodologies can vary considerably when comparing results between

similar plants, or even when comparing the actions within the same plant that are evaluated by different analysts. EPRI is sponsoring several initiatives in the development of HRA products and tools to improve the consistency and capability of HRAs. Scientech - in collaboration with EPRI, utilities, and other participants - supports these efforts and put into practice the initiative to develop the EPRI The EPRI HRA Calculator(B) as a tool for standardizing HRA.

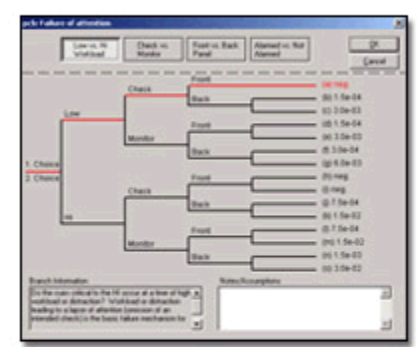

Current version of EPRI HRA Calculator is 5.1

\section{EPRI HRA Calculator ${ }^{\circledR}$ Overview Screen}

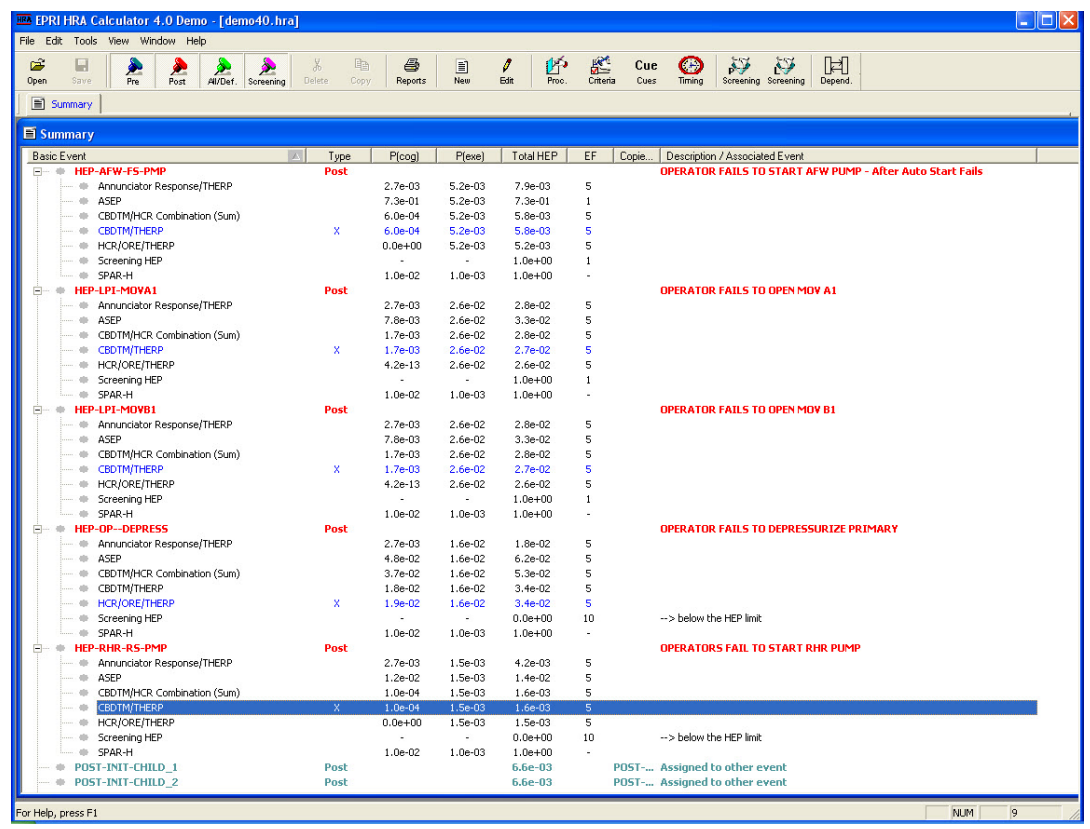




\begin{tabular}{|c|c|c|c|c|c|c|}
\hline \multicolumn{7}{|c|}{ NUREG-1842 Good Practices Summary of HRA Calculator } \\
\hline METHOD & SCOPE & \begin{tabular}{|c|c|} 
UNDERLYING \\
MODEL
\end{tabular} & 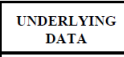 & $\begin{array}{c}\text { QUANTIFICATION } \\
\text { APROACH }\end{array}$ & STRENGTHS & LIMITATIONS \\
\hline $\begin{array}{l}\text { EPRI HRA } \\
\text { Calculator }^{8}\end{array}$ & 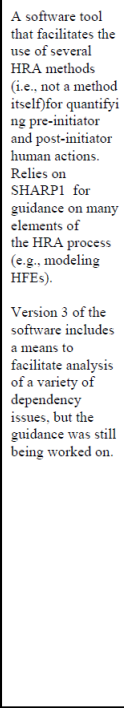 & 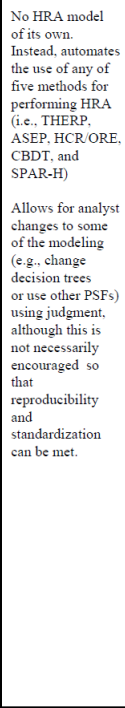 & 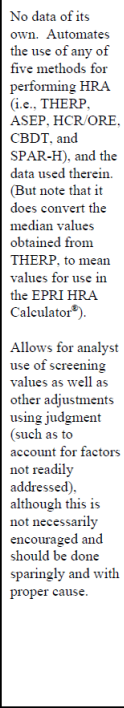 & 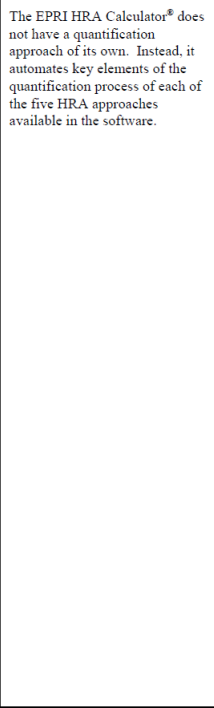 & 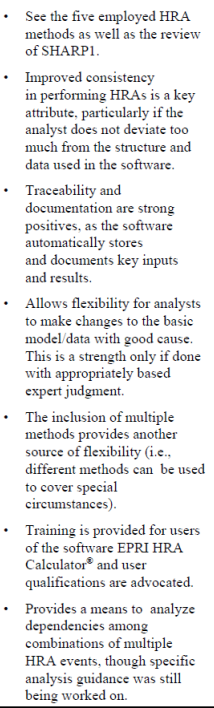 & 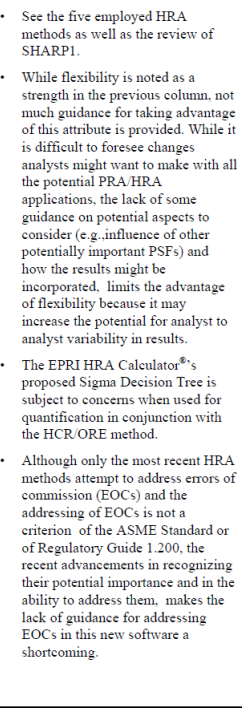 \\
\hline
\end{tabular}

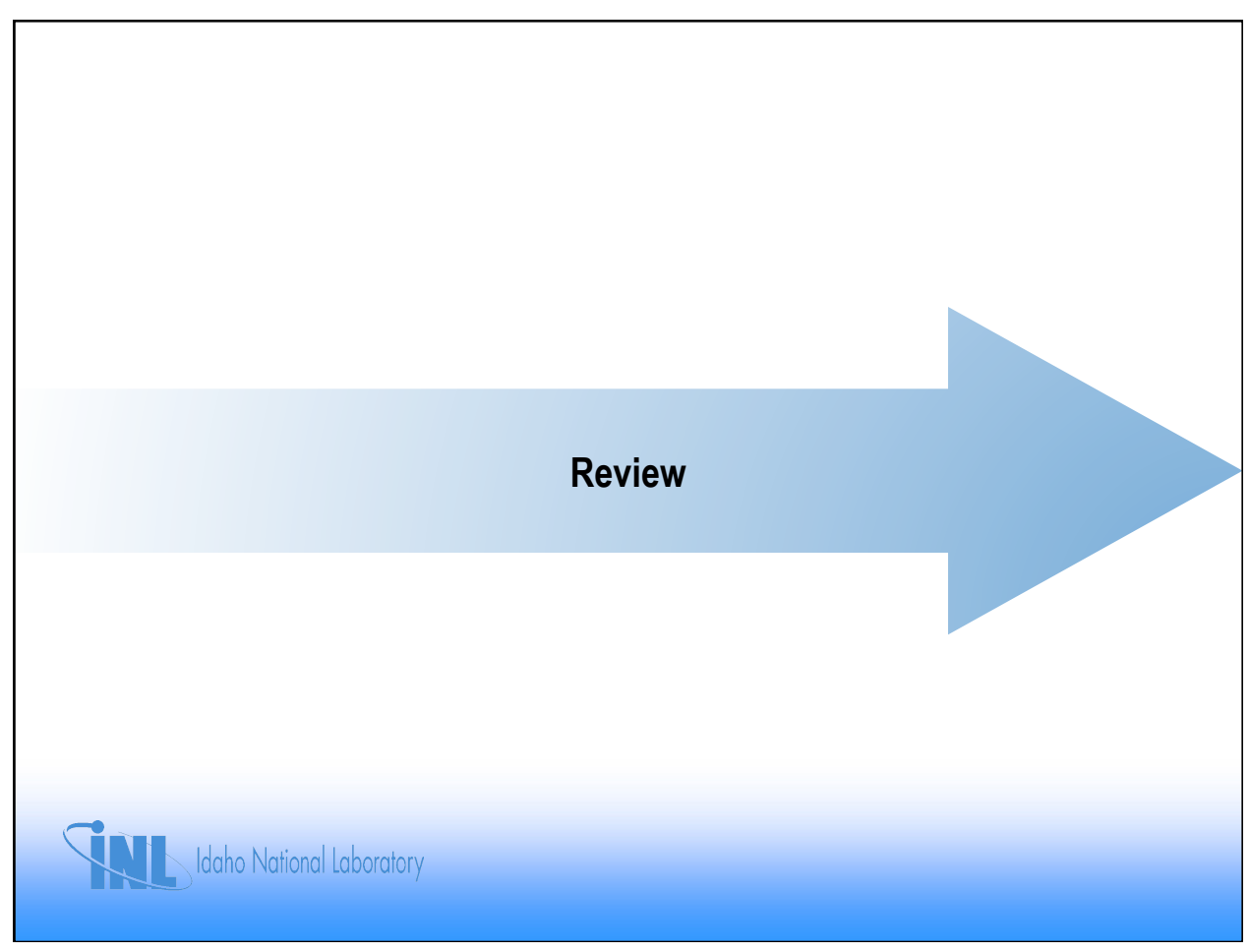




\section{Lesson 8 Review}

- Why and how was the HCR/ORE method developed?

- When is HCR/ORE most appropriately used?

- Why and how was the CBDT method developed?

- What are the major strengths of the CBDT method?

- What are some of the decision trees found in CBDT?

- What are some of the most important considerations/ limitations of the CBDT method?

- What is the EPRI HRA Calculator? Who uses it?

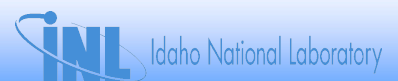

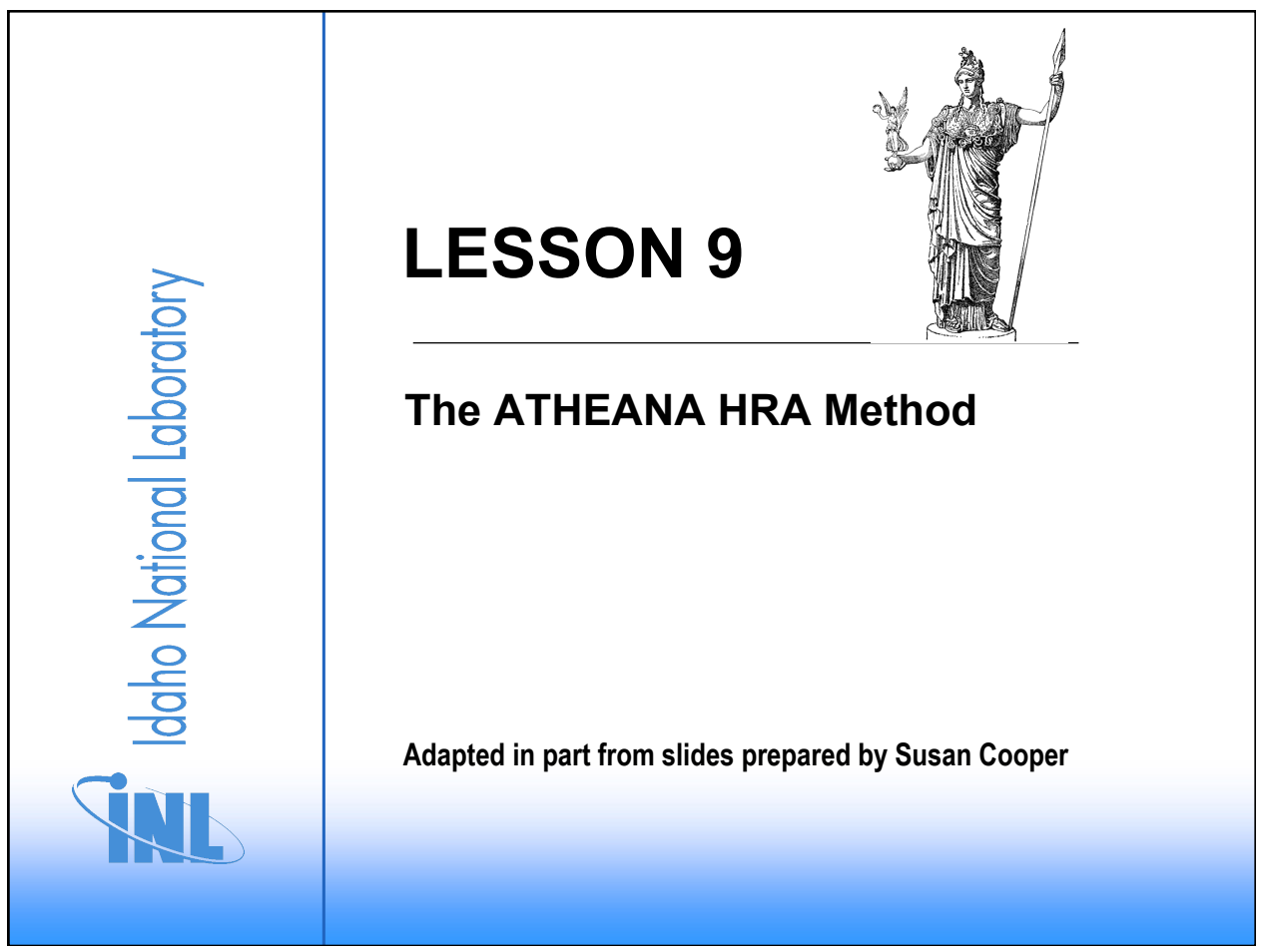




\section{Lesson 9 Objectives}

$\checkmark$ Provide background on development, assumptions, and characteristics of ATHEANA

$\checkmark$ Introduce ATHEANA terminology

$\checkmark$ Review key steps in ATHEANA

$\checkmark$ Review applications of ATHEANA

\section{Idaho National Laboratory}

Introduction to ATHEANA 


\section{Introduction to ATHEANA}

\section{ATHEANA Basics}

- A Technique for Human Error ANAlysis

- Primarily documented in two NUREGs

- NUREG-1624, Rev 1. (2000): Technical Basis and Implementation Guidelines for A Technique for Human Event Analysis (ATHEANA)

- NUREG-1880 (2007): ATHEANA User's Guide

\section{ATHEANA is...}

- A multidisciplinary framework for understanding human error

- An HRA process (including detailed guidance for performing qualitative analysis)

- A search scheme for defining HFEs (including errors of commission)

- A quantification approach using expert estimation

\section{SII Idaho National Laboratory}

\section{ATHEANA's Framework}

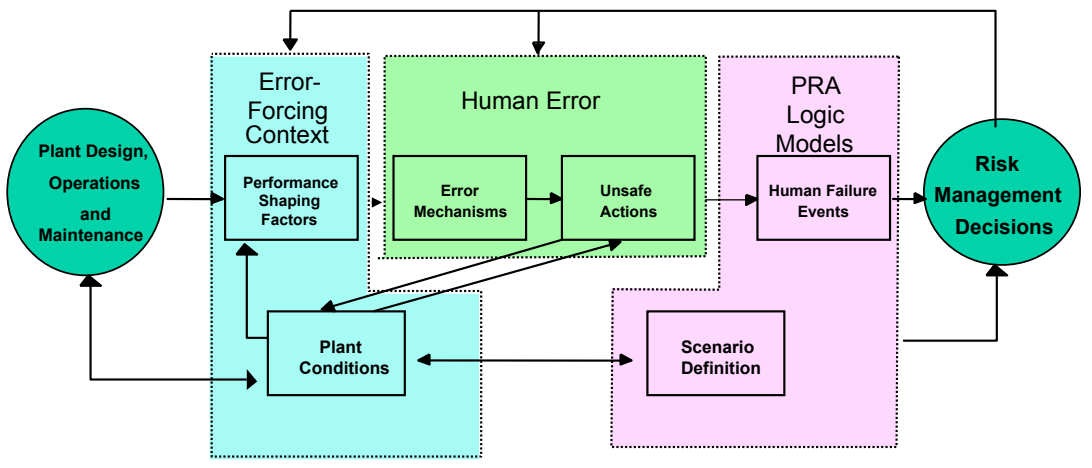

\section{Idaho National Laboratory}




\section{Underlying Model of Operator Behavior}

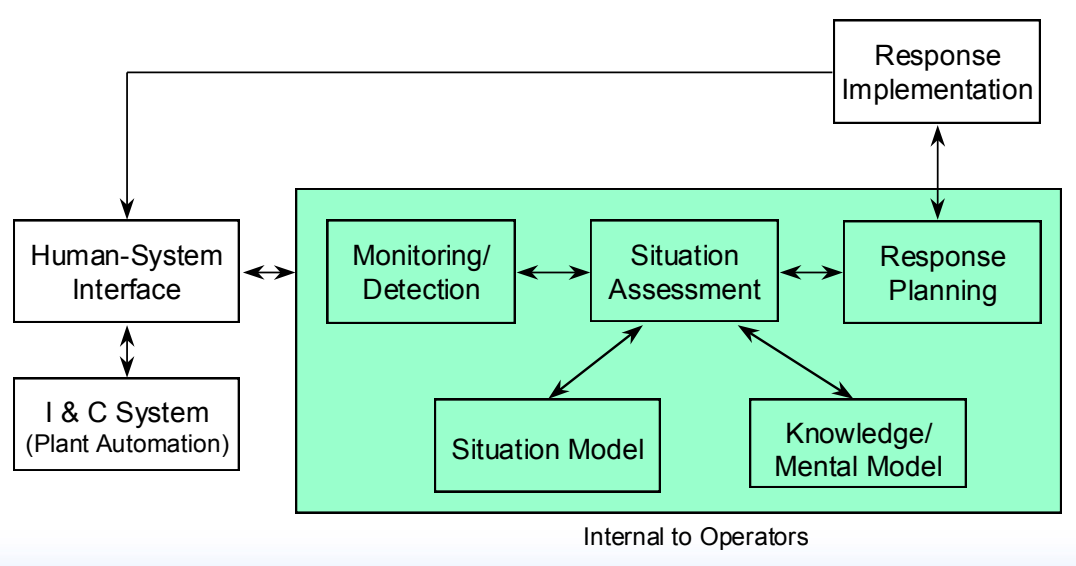

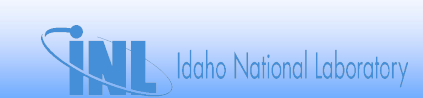

\section{Assumptions in ATHEANA}

The basic premise of ATHEANA:

- People behave "rationally" even if reason for an action (or inaction) is wrong

- Often, when people make errors, they are primed to fail

- People can be primed to fail by contexts that can create the appearance that the wrong response is correct

Analyses of operating experience (particularly those with serious consequences) support this view

- Nuclear power plant events (e.g., recall TMI-2 and Chernobyl)

- Incidents from a variety of other technologies (e.g., aviation, medicine, chemical processing, maritime)

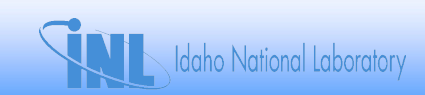




\section{Contextual Factors}

\section{Across industries, the following contextual factors often have been involved in serious events:}

1. The plant behavior is outside the expected range (as represented by procedures, training, and traditional safety analyses)

2. The plant's behavior is not understood

3. Indications of the actual plant state and behavior are not recognized (sometimes due to instrumentation problems)

4. Prepared plans or procedures are not applicable or helpful for the specific plant conditions

\section{Development of ATHEANA}

\section{Principal Objectives}

1. To improve the HRA state-of-the-art, including:

- To more realistically incorporate kinds of humansystem interactions found important in accidents and near misses

- To address dependencies among sequential human actions

- To address errors of commission (EOCs), including their identification and quantification

2. To support the development of insights to improve plant safety and performance from HRA results

3. To support resolution of regulatory and industry issues from HRA results 


\section{Key Characteristics of ATHEANA}

- Focuses on the error-forcing context (EFC)

- The situation that arises when particular combinations of performance shaping factors and plant conditions create an environment in which unsafe actions are more likely to occur

- Uses a structured search for problem scenarios (i.e., error-forcing contexts) and associated unsafe actions (UAs)

- Actions inappropriately taken, or not taken when needed, by plant personnel that result in a degraded plant safety condition

- Develops accident sequences including scenarios that deviate from the expected behavior

- Uses a facilitator-led, expert elicitation approach for quantification

- Allows the plant-specific experience and understanding from operators, operator trainers, and other operations experts to be directly reflected

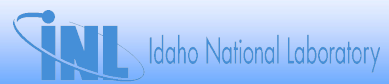

The ATHEANA HRA Process 


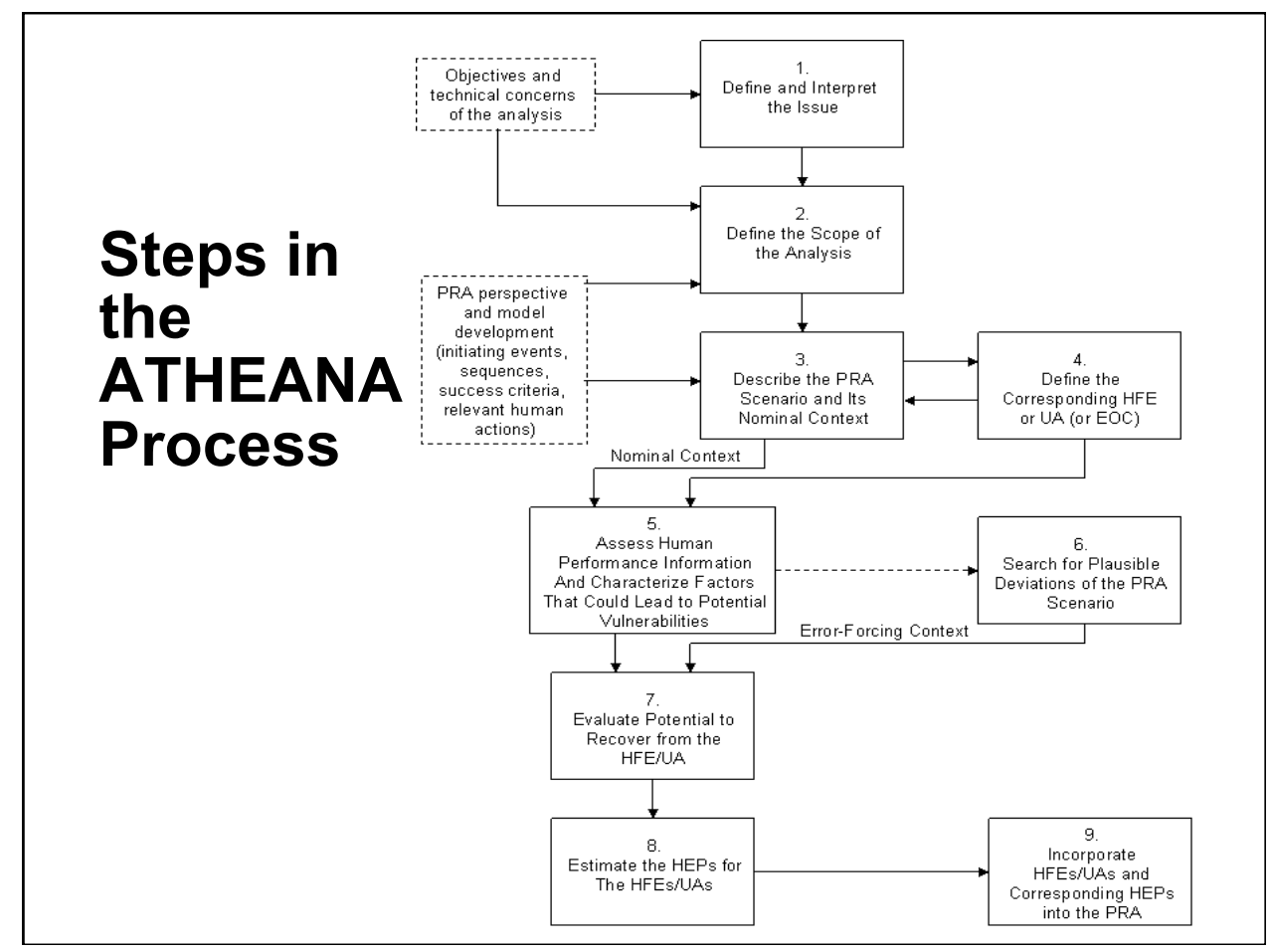

\section{Steps in ATHEANA Process}

- Step 1: Define and interpret issue of concern

- Step 2: Define scope of analysis

- Step 3: Describe base case scenarios

- Step 4: Define HFEs and unsafe actions

- Step 5: Identify potential vulnerabilities

- Step 6: Search for deviations from base case

- Step 7: Evaluate recovery potential

- Step 8: Quantification

- Step 9: Incorporation into PRA (not discussed)

Most of these steps should be performed iteratively

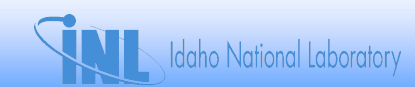




\section{Steps in Performing ATHEANA}

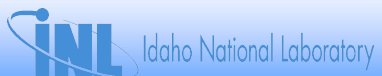

\section{Step 1: Define and Interpret Issue of Concern}

Define objectives of analysis and interpret in context of PRA

- E.g., HRA support to new PRA, refine existing HRA/PRA, upgrade PRA to support risk-informed regulation submittals

\section{Examples}

- Identify and quantify potential human failure events that can contribute to a pressurized thermal shock (PTS) event

- Identify conditions that might induce inappropriate reduction of secondary cooling during loss of steam generator (SG) secondary cooling flow

- Examine the issue of a crew experiencing a partial engine failure and reacting appropriately to conclude the flight safely

- Context that could lead to turning off the wrong engine

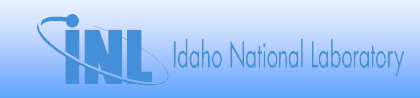




\section{Step 2: Define Scope of Analysis}

\section{Limit scope of analysis based on:}

- Issue of interest

- What are relevant initiating events, functions, related equipment, specific actions, etc.?

- Risk-based priority schemes and plant-specific PRA models

- Highest priority initiating events, functions, modes of operation, etc.

- Practical concerns

- Time, resources, etc.

Note: The scenario to be analyzed is usually defined for a specific initiating event by the end of this step

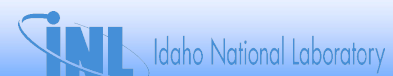

\section{Step 3: Describe the PRA Scenario and Its Nominal Context}

The base case scenario:

- Represents most realistic description of expected plant and operator behavior for selected issue and initiator

- Provides basis to identify and define deviations from such expectations (found in Step 6)

Ideally, base case scenario:

- Is well-defined operationally

- Has well-defined physics

- Is well-documented

- Is realistic

Scenario description often based on Final Safety Analysis Report

(FSAR) or other well-documented analyses

- In practice, the available information defining a base case is usually less than ideal

- Analysts must amend information deficiencies or simply recognize them

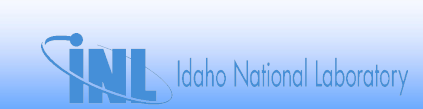




\section{Step 4: Define HFEs and UAs}

Define relevant HFEs based on:

- Issue definition (Step 1)

- Issue definition step may have already defined the HFE/UA

- Or, later steps may require refinements of HFE/UA definitions

- Iteration back to this step may be required

- How operators can fail critical functions in base-case scenario

Define sets of unsafe actions (UAs) that can lead to HFEs

- Several tables and associated guidance are provided to help identify HFEs and UAs (e.g., Table 9-8 in NUREG-1624)

Table 9.8 Example Unsafe Actions for Generalized Equipment Functional Failure Modes

\begin{tabular}{||l|l||}
\hline \multicolumn{1}{|c|}{$\begin{array}{c}\text { Equipment Functional Failure } \\
\text { Mode }\end{array}$} & \multicolumn{1}{|c||}{ Example Unsafe Action(s) } \\
\hline \hline Failure of automatic actuation & $\begin{array}{l}\text { Operators take equipment out of armed or standby status } \\
\text { Operators change equipment configuration from armed, standby, or } \\
\text { normal state } \\
\text { Operators bypass or suppress automatic signals } \\
\text { Onerators disable automatic signals or sensors }\end{array}$ \\
\hline
\end{tabular}

\section{Step 5: Assess Human Performance Information \& Characterize Factors that Could Lead to Potential Vulnerabilities}

Identify and characterize factors (e.g., PSFs) that could contribute to crew performance in responding to the various accident scenarios

- Factors that might increase the likelihood of the HFEs \& UAs of interest

- Helps focus later deviation searches

- The analyst chooses the relevant PSFs—not predefined

Operators and trainers must play a role in this step

- Directly or through question/answer sessions

- Observation of simulator exercises (with relevant scenarios if possible) 


\title{
Step 6: Search for Deviations From the Base Case
}

\section{Identify deviations from base case likely to result in risk-significant unsafe acts}

- Deviations are plant behaviors or conditions that set up unsafe actions by creating mismatches between the proposed plant behavior and:

- Operators' knowledge, expectations, biases and training

- Procedural guidance and timing

\begin{abstract}
ATHEANA search schemes are available to guide analysts to find deviations in plant behavior and conditions
\end{abstract}

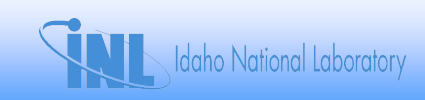

\section{Four Search Schemes for Step 6}

1. Identify deviations from the base case scenario using "HAZOP" guide words

- More, less, quicker, slower, repeat ...

2. Identify deviations for vulnerabilities associated with procedures and informal rules

- Changes in timing, sequencing of decision points, etc.

3. Identify deviations caused by subtle failures in support systems

- Cause problems for operators to identify what's happening

4. Identify deviations that can set up operator tendencies and error types leading towards HFEs/UAs of interest 


\section{Step 7: Evaluate Potential for Recovery}

Possibility of recovering from UAs is considered in this step

- However, recovery is always evaluated given the complete EFC and the occurrence of the UA(s)

- Deviation description is extended to include the scenario characteristics up to the last opportunity for recovery

- Performance of this step linked with quantification

- Iteration between these steps is likely

\section{Sivt

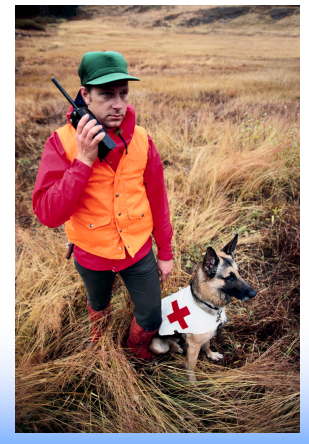

\section{Step 8: Quantification}

Structured, facilitator led, expert opinion elicitation process

- Goal is to arrive at consensus distributions of operator failure probabilities

- Considerations in elicitation process (covered in NUREG-1880):

- Forming the team of experts (include experts familiar with important relevant factors, operator trainers, etc.)

- Controlling for biases when performing elicitations

- Addressing uncertainty
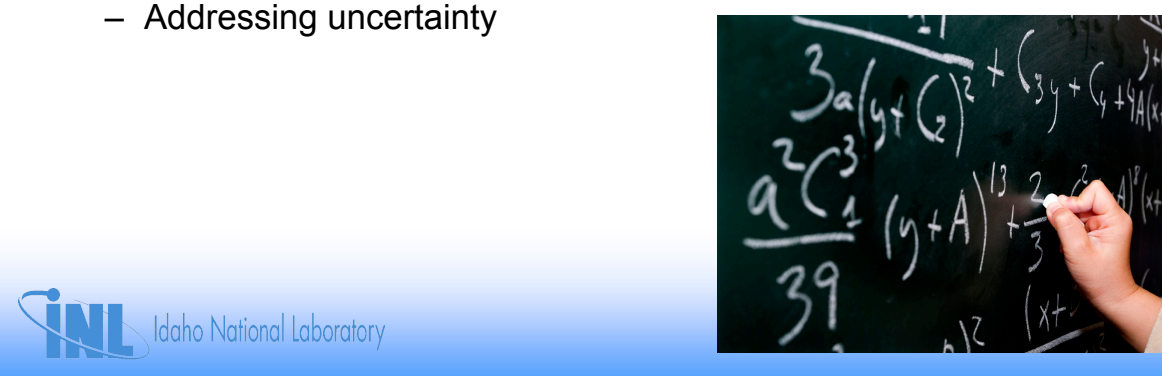


\section{ATHEANA Expert Elicitation}

\section{Ask the Experts Two Questions:}

1. Does the HFE make sense?

- Given the specific PRA scenario or sub-scenario

- Given what is known about operators and operations at this plant

2. What is the likelihood that operators will fail as described in the HFE?

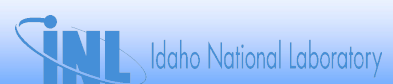

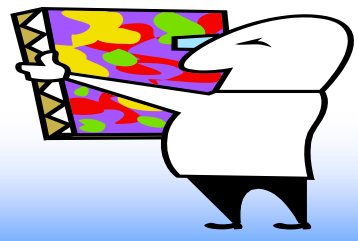

\section{Basic Formulation for Quantification Process}

$$
P(H F E \mid S)=\Sigma P\left(E F C_{i} \mid S\right) \times \underset{i j}{P}\left(U A_{j} \mid E F C_{i}, S\right)
$$

- HFEs are human failure events modeled in PRA

- Modeled for a given PRA scenario (S)

- Can include multiple unsafe actions (UAs) and errorforcing contexts (EFCs)

- First determine probability of the EFC (plant conditions and PSFs) being addressed

- Determine probability of UA given the identified EFC

- If multiple EFCs identified, then quantify a UA given each EFC separately 


\section{Six Steps to ATHEANA Quantification Process}

1. Discuss HFE and possible influences / contexts using a factor "checklist" as an aid

2. Identify "driving" influencing factors and thus most important contexts to consider

3. Compare these contexts to other familiar contexts and each expert independently provide the initial probability distribution for the human error probability (HEP) considering:

- "Likely" to fail

$\sim 0.5$ (5 out of 10 would fail)

- "Infrequently" fails

$\sim 0.1$ (1 out of 10 would fail)

- "Unlikely" to fail

$\sim 0.01$ (1 out of 100 would fail)

- "Extremely unlikely" to fail

0.001 (1 out of 1000 would fail)

\section{Six Steps to Quantification Process (continued)}

4. Experts discuss and justify their HEP

5. Openly discuss opinions and refine the HFE, associated contexts, and/or HEPs (if needed) - each expert independently provides HEP (may be the same as the initial judgment or may be modified)

6. Arrive at a consensus HEP for use in the PRA

- Sometimes easier said than done, but important to control for sources of bias at this stage:

- $\quad$ Group effects (e.g., dominant person)

- $\quad$ Scaling effects (e.g., calculating HEP differently)

- Biases (e.g., not considering all information) 


\section{Example Applications of ATHEANA}

\section{Recent ATHEANA Applications}

- HRA/PRAs in a prospective analysis of regulatory and industry issues such as pressurized thermal shock (PTS) (3 plants Oconee, Beaver Valley, Palisades)

- International HRA Empirical Study (Steam Generator Tube Rupture and Loss of Feedwater scenarios)

- DOE's license application for Yucca Mountain waste repository (preclosure facility)

- Qualitative analyses of spent fuel handling (misloads and cask drops) (NUREG/CR-7016)

- Event analyses and development of a knowledge-base for firespecific human performance issues (NUREG-1921)

- HRA/PRA to evaluate design features of a facility to dismantle chemical weapons

\section{I. Idaho National Laboratory}




\section{Unique Features of ATHEANA}

- Identify operational vulnerabilities the could set up UAs - e.g., procedure weaknesses

- Identify plausible deviations from nominal scenarios

- Identify important PSFs relevant to both nominal and deviation scenarios

- Identify other factors that could significantly affect the likelihood of the HFEs

- Method is extremely flexible and doesn't limit type of analysis that can be performed or where it can be applied

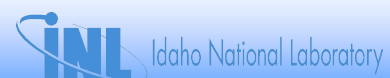

\section{When to Use ATHEANA}

Use ATHEANA if risk-informed decision making requires:

- Understanding vulnerabilities associated with specific UAs instead of generic HFEs

- e.g., submittal that includes procedural change

- Understanding the contexts of specific EFCs (rather than a generic scenario context)

- e.g., need for a more detailed HRA as part of a PRA

- Understanding a wide range of PSFs under different contexts and scenarios

- Analyzing an application for which other HRA methods have not been used or do not fit

\section{7ivi}




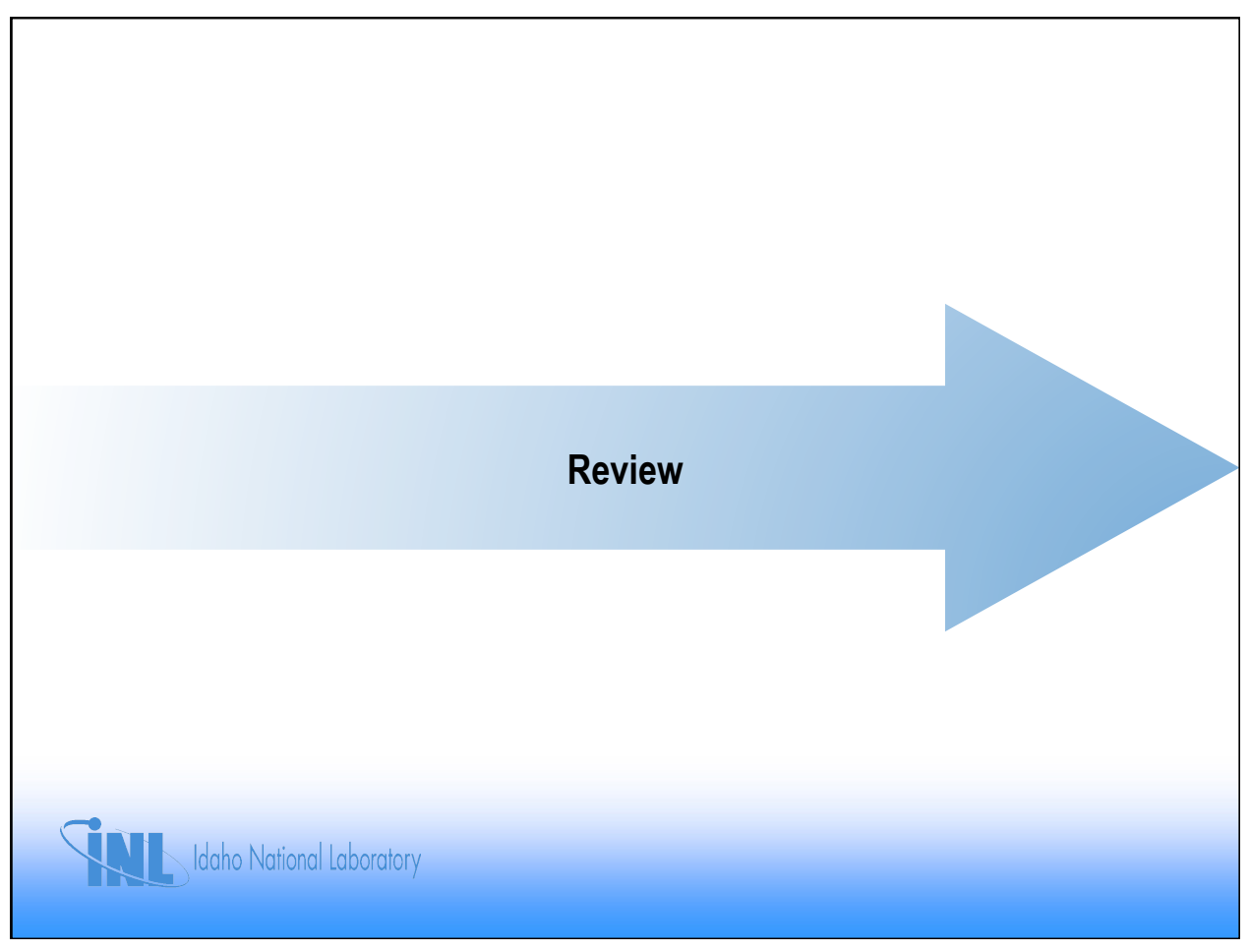

NUREG-1842 Good Practices Summary of ATHEANA

\begin{tabular}{|c|c|c|c|c|c|c|}
\hline МЕTHOD & SCOPE & $\begin{array}{l}\text { UNDERLYING } \\
\text { MODEL }\end{array}$ & $\begin{array}{l}\text { UNDERLYING } \\
\text { DATA }\end{array}$ & $\begin{array}{l}\text { QUANTIFICATION } \\
\text { APPROACH }\end{array}$ & STRENGTHS & LIMITATIONS \\
\hline ATHEANA & $\begin{array}{l}\text { Identification, } \\
\text { modeling, } \\
\text { and quantification } \\
\text { of post-initiator } \\
\text { human actions, } \\
\text { including } \\
\text { treatment of errors } \\
\text { of commisssion. } \\
\text { Addresses } \\
\text { potential cognitive } \\
\text { failures for } \\
\text { a human action, } \\
\text { failures in } \\
\text { implementing } \\
\text { the desired action, } \\
\text { and situations that } \\
\text { could cause them } \\
\text { to occur. } \\
\text { Consideration of } \\
\text { dependencies are } \\
\text { included as part of } \\
\text { the modeling of } \\
\text { the affect of } \\
\text { context on } \\
\text { performance. } \\
\text { Specific } \\
\text { quantitative values } \\
\text { are not provided. }\end{array}$ & \begin{tabular}{|l} 
Based on \\
behavioral \\
sciences view \\
of human \\
performance being \\
in four stages \\
(i.e., monitoring \\
and detection, \\
situation \\
assessment, \\
response planning, \\
and response \\
implementation). \\
Failure in any one \\
stage can lead \\
to failure of \\
the overall action \\
of finterest. \\
The detailed \\
context \\
development \\
process (i.e., \\
defining lant \\
conditions \\
and PSns that are \\
associated with the \\
scenario for the \\
action of interest) \\
is designed to find \\
reasons why \\
a failure might \\
occur in any \\
of the stages.
\end{tabular} & $\begin{array}{l}\text { Since the HEP } \\
\text { estimates come } \\
\text { from expert } \\
\text { elicitation, } \\
\text { judgment is used } \\
\text { in quantification. } \\
\text { This judgment is } \\
\text { to come from } \\
\text { qualified experts } \\
\text { (e.g., operators) } \\
\text { who are } \\
\text { knowledgeable } \\
\text { about the action } \\
\text { and scenario } \\
\text { of interest. Their } \\
\text { judgments will be } \\
\text { based on } \\
\text { information } \\
\text { collected about the } \\
\text { action, their own } \\
\text { experience, and } \\
\text { industry } \\
\text { experience } \\
\text { (as passed on in } \\
\text { ATHEANA } \\
\text { training and } \\
\text { NUREG-1624) } \\
\text { particularly during } \\
\text { events that } \\
\text { resulted in } \\
\text { undesired } \\
\text { consequences. } \\
\text { Emphasizes } \\
\text { observations of } \\
\text { selected simulator } \\
\text { exercises for } \\
\text { general "data" on } \\
\text { aspects of crew } \\
\text { behavior. }\end{array}$ & $\begin{array}{l}\text { Uses a formal, facilitator-led } \\
\text { expert elicitation process } \\
\text { with experts who are particularly } \\
\text { knowledgeable of the actions } \\
\text { and scenarios of interest } \\
\text { (typically yersons from the } \\
\text { operations and training staffs). } \\
\text { Based on consideration of } \\
\text { factors deemed to have the } \\
\text { greatest influence on the action } \\
\text { of interest, as derived during } \\
\text { the context development process } \\
\text { (i.e., a pre-set list of PSFF is not } \\
\text { used, but the important factors, } \\
\text { including PSFs, are identified } \\
\text { based on the scenario context). }\end{array}$ & 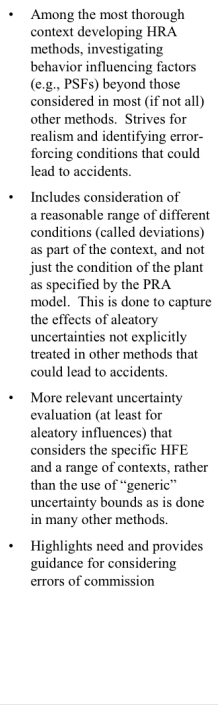 & 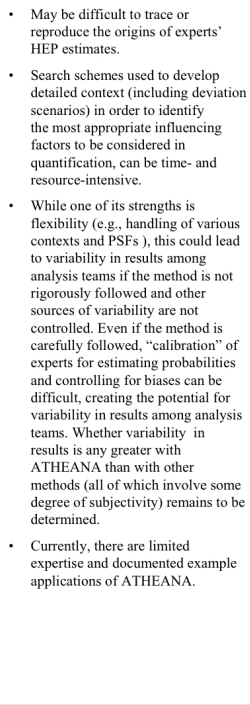 \\
\hline
\end{tabular}




\section{Lesson 9 Review}

- What does ATHEANA stand for?

- What is an error forcing context (EFC)?

- What is an unsafe action (UA)?

- What is the base case in ATHEANA?

- What is a deviation from the base case?

- What are some ATHEANA search schemes?

- How are HEPs calculated in ATHEANA?

-What are some limitations of expert estimation?

- When might it be desirable to use ATHEANA?

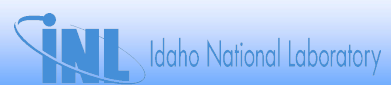

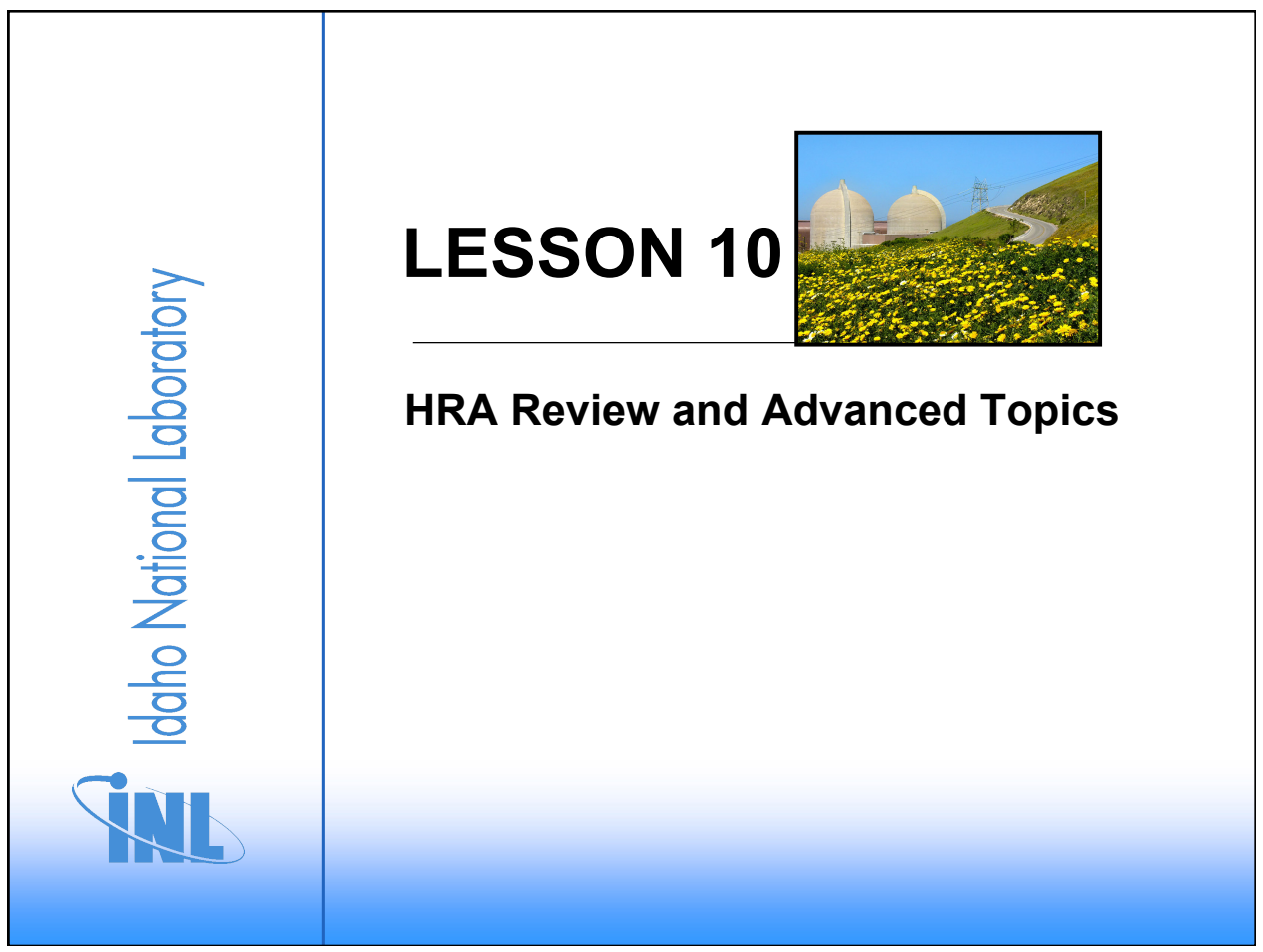




\section{Lesson 10 Objectives}

$\checkmark$ Reiterate key HRA concepts through new developments in the field

$\checkmark$ Understand several practices to ensure the quality of an HRA

$\checkmark$ Understand helpful criteria for selecting among different HRA methods

$\checkmark$ Review HRA being developed for new domains

$\checkmark$ Understand fundamental principles behind the development of the new NRC hybrid approach

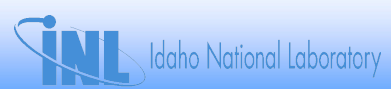

\section{What Makes a Good HRA?}




\section{Four Principles of Quality HRA}

- Complete team

- Thorough qualitative analysis

- Traceable quantification

- Full documentation

These are an amalgam of different sources and represent the good practices in the authors' opinions

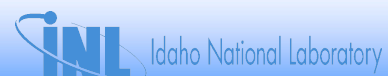

\section{Complete Team}

Different People Bring Different Expertise

- PRA: Probabilistic risk analyst brings insights into the hardware or system failures that may prove risk significant

- HRA: Human reliability analyst understands human error contribution and application of specific HRA methods

- Ops: Operations expert (e.g., simulator trainer) understands the process of using the system and the difficulties that operators may encounter

- Users: Actual operators of the system

- HF: Human factors expert

Don't try to wear all hats yourself

- Build a team and interview people who know the answers
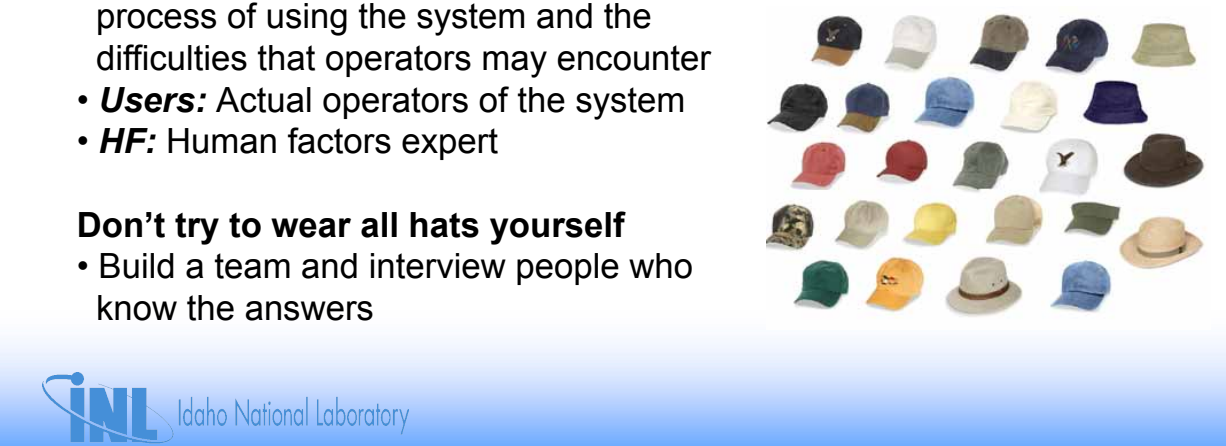


\section{Thorough Qualitative Analysis}

\section{Don't Rush Understanding the Problem Domain}

- Even if the main goal of the analysis is quantification, it is important to perform a good qualitative analysis to:

- Identify all relevant sources of human error

- Understand the unique contexts of human errors

- Understand the factors (e.g., PSFs) that could influence human performance in these unique contexts

A Good Qualitative Analysis Takes Time and Resources

- Performing a complete task analysis can require resources similar to those needed to construct PRA systems models

- Humans are the most complex "component" in the plant

- It takes time and effort to understand the variety of challenges faced by an operator and the actions possible in response to those challenges

\section{ivi}

\section{Traceable Quantification}

It's Important to be able to tell where the numbers come from

- Ideally, numbers would be based on operational history and observed performance

- Realistically, it's necessary to derive HEPs from models and expert estimation

- It doesn't matter whether it's a model-based approach (e.g., SPAR-H) or expert estimation (e.g., ATHEANA)

- Assumptions that influenced HEP need to be declared

- PSFs should not be fine-tuned just to get a value that "looks right"

- Realize that generic PSF lists may not always be relevant for a specialized analysis

- Groups of experts and consensus estimates should be used to control for skewed or biased results

- Use realistic lower HEP bounds (e.g., HEP > 1E-5)

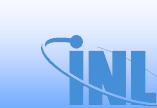




\section{Adequate Documentation}

Your HRA Should Stand on Its Own

- Every step, assumption, and finding of your qualitative and quantitative HRA should be documented

- Too often we see

- PSFs assigned with no explanation why

- HEPs without an explanation behind the value

- HRA should build a firm case for the human errors and HEPs you've determined

Your HRA is a Written Record

- If you go back to your HRA one year later and can't remember what you did or what you found, no one else will be able to either

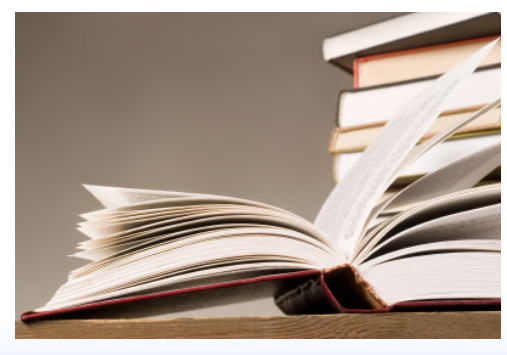

\section{How to Perform a Better Analysis}

\section{Additional Tips Can Be Found}

- Good Practices for Implementing HRA, NUREG-1792, US Nuclear Regulatory Commission, 2005

- SHARP1-A Revised Systematic Human Action Reliability Procedure, TR-101711, EPRI, 1992

- Method-specific documentation

- e.g., Many people use SPAR-H because it's easy to use, but some of these same people do not read the documentation (NUREG/CR-6883) 


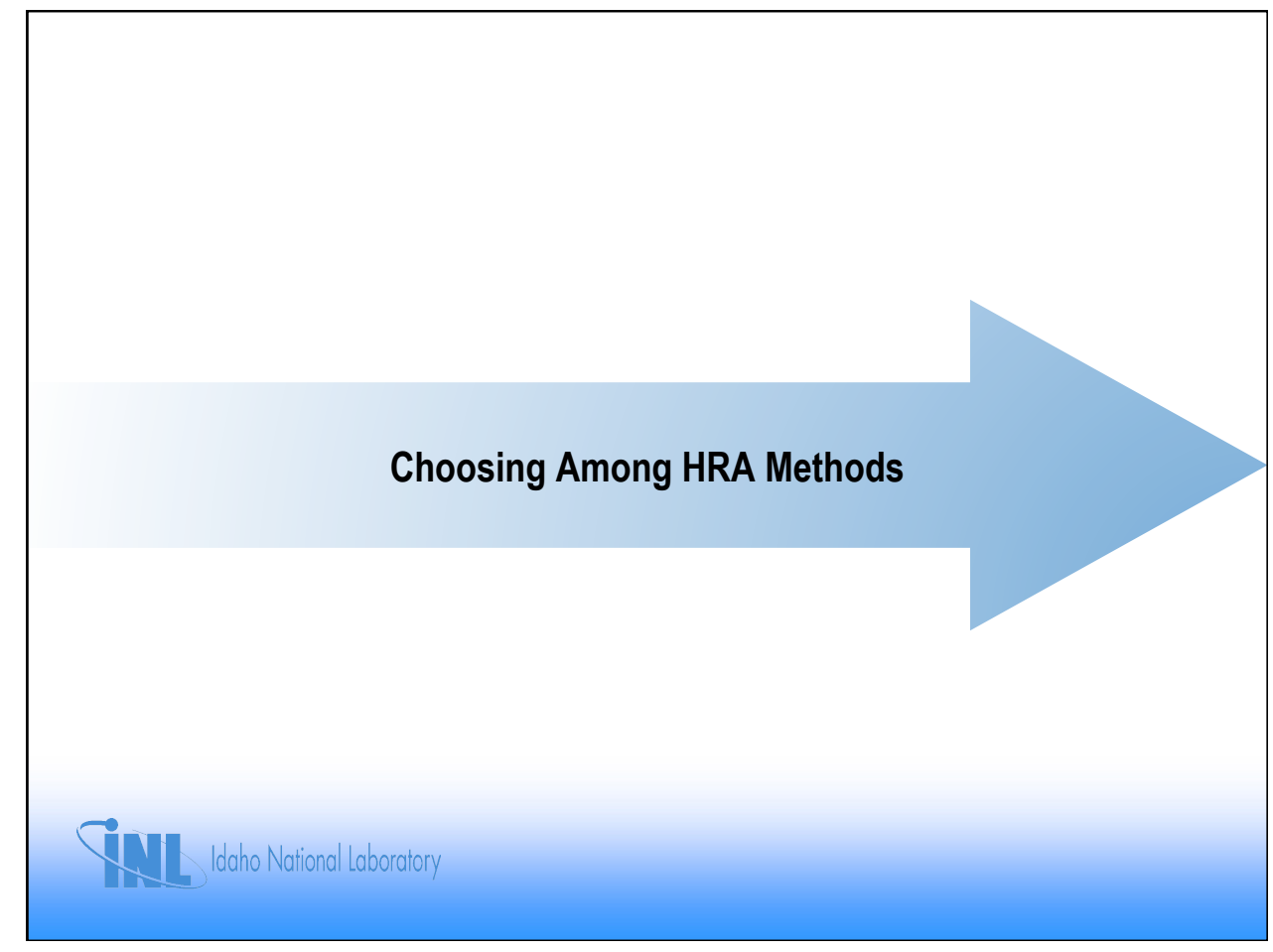

\section{Choosing Among Methods}

Advantages of Each Method

- Full Qualitative Analysis

- THERP, ATHEANA

- Simplicity of Estimation Process

- ASEP, SPAR-H, CBDT

- Flexibility to Cover Unusual Events

- ATHEANA

- Coverage of Cognitive Factors

- SPAR-H, ATHEANA

- Complete Method (Identification, Modeling, Quantification)

- THERP, ATHEANA

There are over 60 HRA methods that may meet particular applications beyond what has been described here 


\section{EPRI's Guide to Method Selection}

\begin{tabular}{|c|c|c|c|}
\hline Plant Condition & Cue/Type & Method & Example \\
\hline Normal operation & Routine activities & $\begin{array}{c}\text { THERP } \\
\text { ASEP }\end{array}$ & Calibration of RWST bistables \\
\hline Normal operation & Alarm or annunciator & Annunciator Response Model & Loss of a CCW pump \\
\hline Post Reactor Trip & Immediate actions & HCR/ORE & Manual reactor trip \\
\hline Post Reactor Trip & Time critical actions & $\begin{array}{c}\text { HCR/ORE } \\
\text { CBDT }\end{array}$ & Establish seal injection within 13 \\
minutes
\end{tabular}

Courtesy EPRI / From 2010 EPRI HRA Calculator Training Module

\section{Idaho National Laboratory}

\section{Other Places to Look for Guidance}

Each Method Has Strengths and Weaknesses, Which Have to a Limited Extent Been Documented

- Alan Swain's Comparative Evaluation of Methods for Human Reliability Analysis (1989, GRS)

- NUREG-1842: Evaluation of Human Reliability Analysis Methods Against Good Practices (2006, NRC)

- Human Reliability Analysis Methods: Selection Guidance for NASA (2006, NASA)

- NUREG/IA-216: International HRA Empirical Study (Multiple Volumes, NRC)

- Review of Human Reliability Assessment Methods (2009, UK HSE)

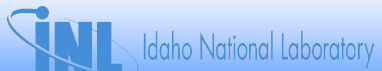




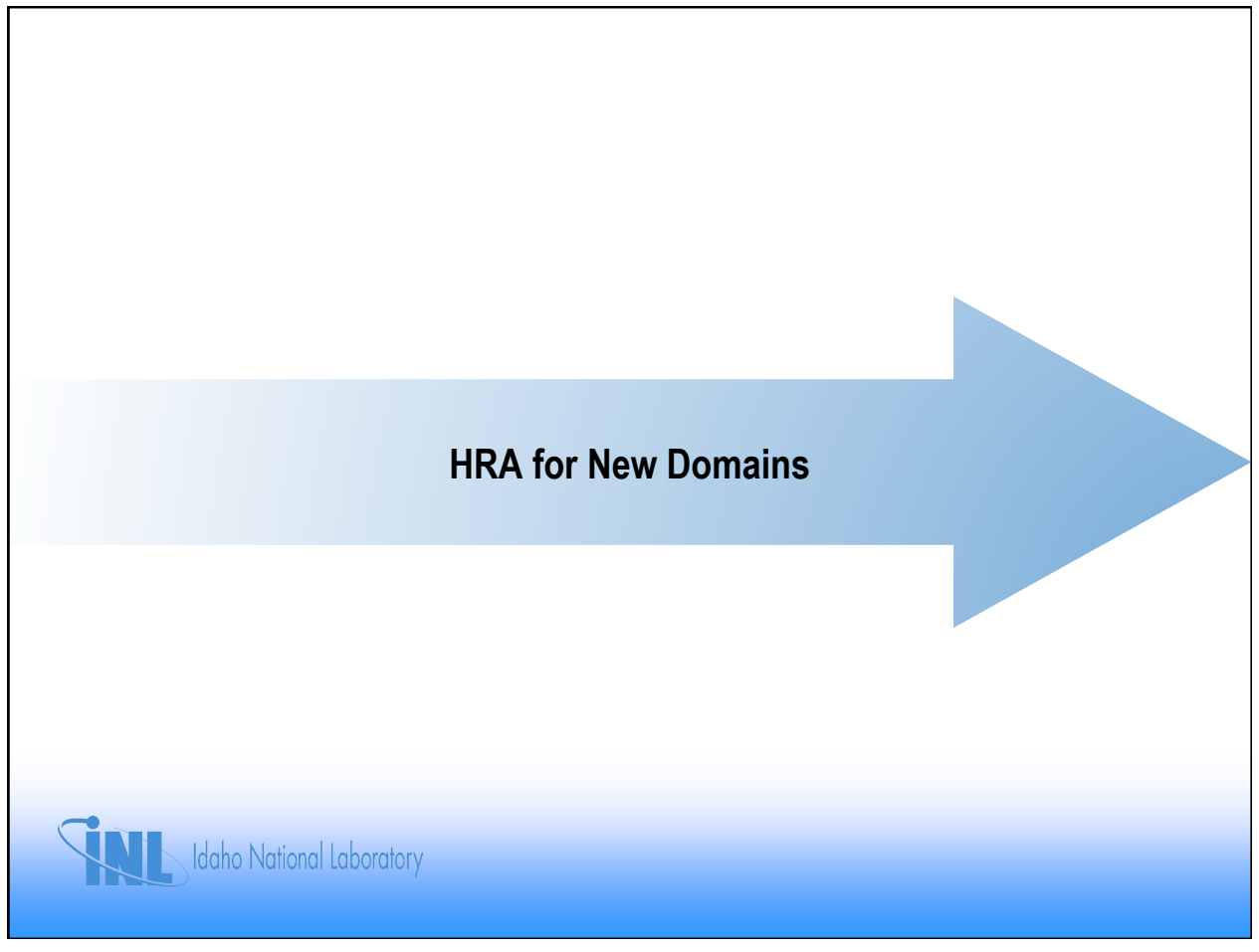

What application is most HRA designed for?

Nuclear power plants

At full power

Control room operations

Analog control room

Can we generalize methods designed for this application to new domains and applications?

What other HRA applications do you have? 


\section{HRA Development for New Domains}

- CARA: EuroControl HRA method for air traffic control

- Spent fuel handling: US NRC ATHEANA method for crane operations and dry cask handling

- EPRI/NRC Fire HRA (NUREG-1921)

- Training available

- US Department of Homeland Security HRA methods for cybersecurity

- CAHR: German HRA method for automobile safety

- Petro-HRA: Norwegian HRA method for offshore oil operations

- MERMOS: French HRA method developed (in part) to address computerized procedures

- UK National Rail HRA method

- NASA HRA tailored for space applications

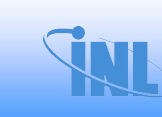

\section{Example: NASA HRA Method for Space Safety}

- Existing HRA methods may produce error estimates that don't fully reflect what is known about human performance in space domains

- Augmenting NASA tools and methods to existing HRA methods increases the ease and fidelity of making HRA estimates for space safety

- Incorporates information from bioastronautics known as the space PSFs (e.g., bone density loss, microgravity, solitude)

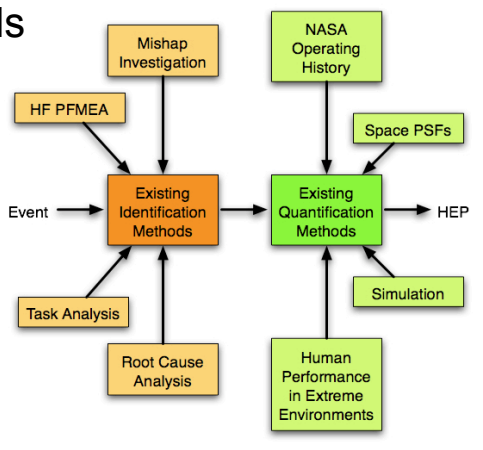




\section{Hybrid Approaches}

\section{Several Recent Efforts Combine HRA Methods}

- EPRI HRA Calculator combines

- HCR/ORE for cognitive errors where time is driving influence

- CBDT for other cognitive errors

- THERP for execution errors

- NASA advocates mixing elements of THERP, CREAM, NARA, and SPAR-H

- Recent US NRC IDHEAS HRA method aimed at finding the best of different HRA methods

- Challenge is that parts of different methods may not always fit together

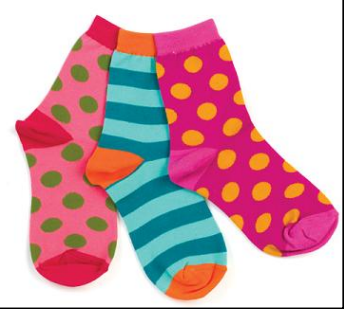

HRA Fire Analysis (NUREG-1921) 


\section{Historical Fire Events}

Browns Ferry, 1975

- Possible wrong indications and spurious actuations

- Smoke hindered recovery actions and fire fighting

- Fire duration 5-10 hours

Oconee, 1989

- Overcooling incident occurred as a result of non-safety switchgear fire Ignalina, 1988

- Breakers opened and equipment tripped inadvertently

Chernobyl, 1991

- Damaged cable initiated the chain of events

Waterford, 1995

- Erratic indications on the control panel

\section{SII Idaho National Laboratory}

\section{Need for NUREG-1921}

In 2001, NUREG/CR-6850, Fire PRA Methodology for Nuclear Facilities, was developed under joint agreement with EPRI

- The process identified:

- Fire related HFEs

- Proposed a method for assigning screening values

- Limited Initial guidance on PSFs

- The NUREG/CR also suggested when a point estimate was needed that a detailed HRA method could be used

- NUREG-1921 developed to address this shortcoming 


\section{What was wrong with this approach?}

- "The authors of the NUREG determined that most HRA methods did not provide fire specific HRA guidance including lack of guidance on fire-specific PSFs and focused, instead, on too much analyst judgment"

- There was a recognized need to

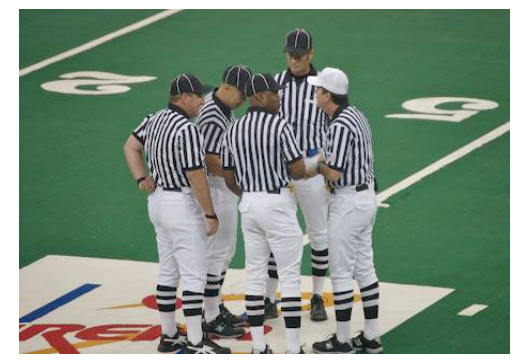
go beyond screening level analysis to scoping or detailed analysis

\section{Sinn

\section{What is covered in the approach?}

- Framework is introduced

- Operator actions post-fire are identified

- Approach presented for qualitative analysis

- Fire-relevant PSFs are identified

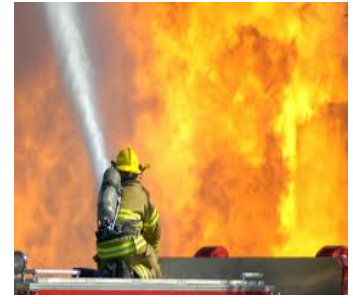

- Screening and scoping (new) quantification are covered

- Detailed quantification (ATHEANA \& HRA Calcultator)

- Recovery defined

- Dependence and uncertainty guidance

- Guidelines for application

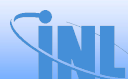




\section{Caveats to the Approach}

- Pre-initiating events (latent errors) not considered

- Improperly restoring suppression equipment after test is thought to be contained in empirical data in

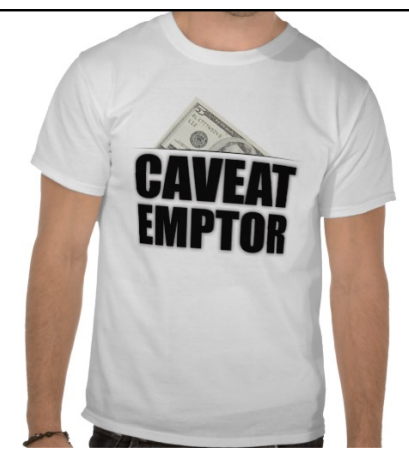
NUREG-6850

- Manual fire detection not included as part of scope

- It is calculated based on the frequency of the roving fire watch

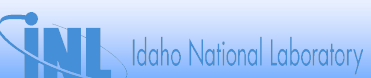

\section{Modeling Assumptions}

- Crew is aware of the fire location within a short time (i.e., within the first 10 minutes)

- Crew is aware of the need for plant trip (i.e., it is not automatic)

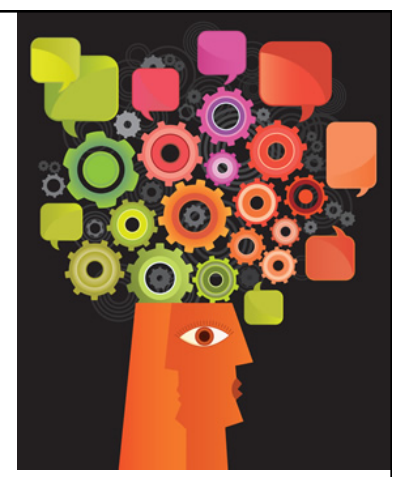

- Crew is aware of the need to implement a fire brigade

- Assigning a crew member to fire brigade does not diminish control room capability

- Crew is aware of potential for unusual plant behavior as a result of the fire 


\section{Fire HRA Steps}

1. Identify operator actions in internal events PRA (response to reactor trip, turbine trip, etc.)

2. Screen out internal event HFEs not associated with fire initiating events (e.g., SGTR)

3. Review fire related event and fault trees

4. Determine each internal event HFE

- Fire impact on instrumentation, impact of timing of cues, success criteria, staffing resources, lighting and access for local actions

\section{What other unique contexts and actions are to be considered?}

- Actions required when equipment is fire damaged,

- Main control room abandonment (uninhabitable)

- Control room response to spurious indication and instruments

- Pre-emptive response to prevent further damage

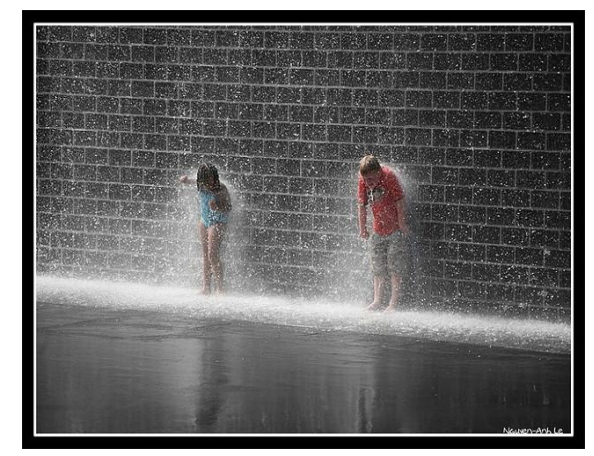




\section{What are the PSFs?}

Procedures

- Will crews execute fire procedures in parallel with, before or after EOPs?

Special equipment and special fitness needs

- Are personnel expected to be wearing plant protective equipment (PPE)?

Cues and indications

- Certain indications credited in the internal events PRA may not be credible if indications are impacted by fire

\section{Others}

- Timing, procedures, complexity, workload, HMI, Environment, crew communications, staffing

\section{YII Idaho National Laboratory}

\section{Three Types of Recovery}

\section{Type 1}

- Recovery from a human error (peer checking)

Type 2

- Recovery of initially unavailable, functions or systems needed to achieve decay heat removal

\section{Type 3}

- Model of the fire brigade and their actions to extinguish to fire (treated by statistical models, from fire suppression event data)

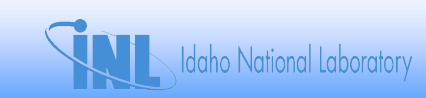




\section{OK, So What Don't We credit?}

- Recovery actions requiring communication while wearing SCBAs

- Recovery that requires travel through fire areas

- Restoring systems damaged by the fire

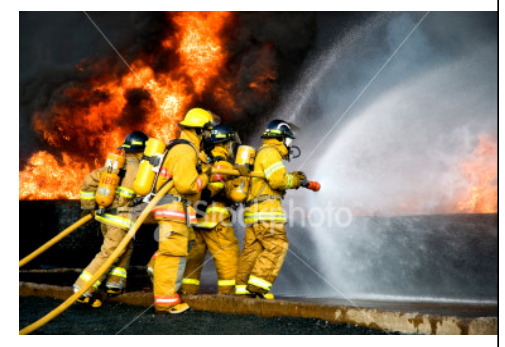

- Actions for which there is insufficient time

- Actions for which there are no procedures

- Situations where there aren't enough staff available

\section{STI. Idaho National Laboratory}

\section{Dependencies, Always Tricky}

- Review cut sets and sequences per ASME PRA STD

- Keep an eye out for new dependencies

- Fire procedures implemented in parallel to the EOP

- Look at common instruments, mindset, resource availability

- Revert to the THERP tables

- Instruction to consider stress as a dependency factor

- Do we double count here? 


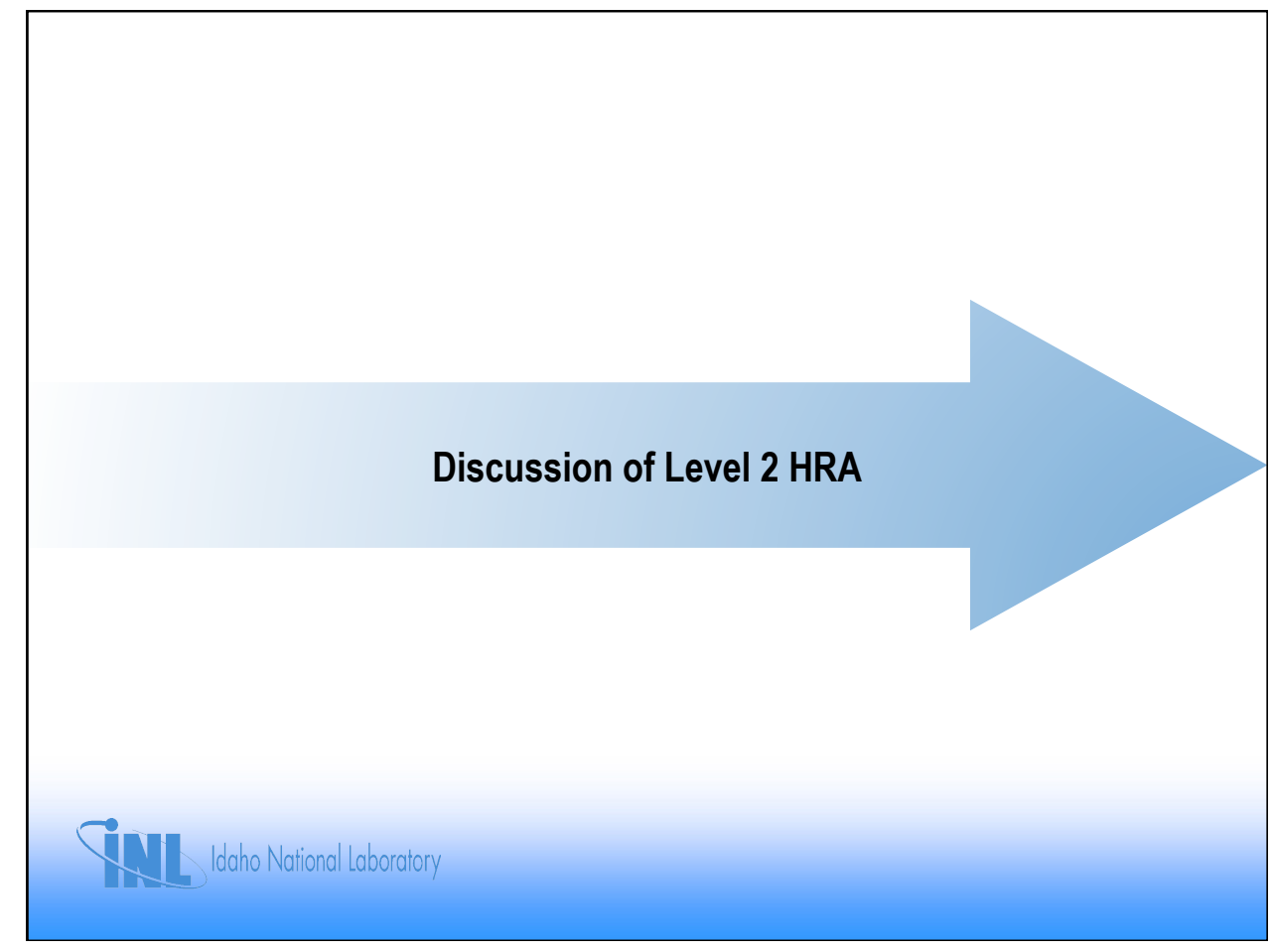

\section{Three Levels of Analysis in PRA}

- Level 1 PSA identifies and quantifies the sequences of events that may lead to the loss of core structural integrity and massive fuel failures

- Level 2 PSA starts from the Level 1 results, and analyses the containment behavior, evaluates the radionuclides released from the failed fuel and quantifies the releases to the environment

- Level 3 PSA starts from the Level 2 results, and analyses the distribution of radionuclides in the environment and evaluates the resulting effect on public health

(CNSC, 2005)

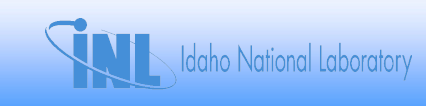




\section{Three Levels of Analysis in HRA}

- Level 1 HRA concentrates on the sequences of human actions that may contribute to loss of core structural integrity

- Level 2 HRA concerns human actions that may contribute to radioactive release after the loss of core structural integrity

- Level 3 HRA starts from the Level 2 results, and considers human actions that may contribute to effects on the environment and public health following the loss of core structural integrity

\section{The Problem}

- Most HRA has been developed for Level 1:

- At power

- Internal events

- Post-initiator

- Control room actions

- Emergency operating procedures (EOPs)

- Very little HRA developed for Level 2:

- Need to develop HRA beyond Level 1 applications

- Need to adapt simplified HRA methods for these complex domains 


\section{Differences Between Level 1 and 2 HRA}

\begin{tabular}{|c|c|c||}
\hline & Level 1 & Level 2 \\
\hline Procedures & EOPs & SAMGs \\
\hline Location & Main Control Room & Technical Support Center \\
\hline Indicators & Available & Degraded \\
\hline Decision-Making & Clear Success Paths & Prioritize Safety Tradeoffs \\
\hline Field Actions & Normal & Difficult \\
\hline Staffing & Optimal Complement & Additional Personnel \\
\hline Equipment/PPE & Normal & FLEX/EME \\
\hline HRA Modeling & Understood & Not Well Developed \\
\hline \multicolumn{3}{|c}{} \\
\\
\hline
\end{tabular}

\section{The Challenge with Level 2 HRA}

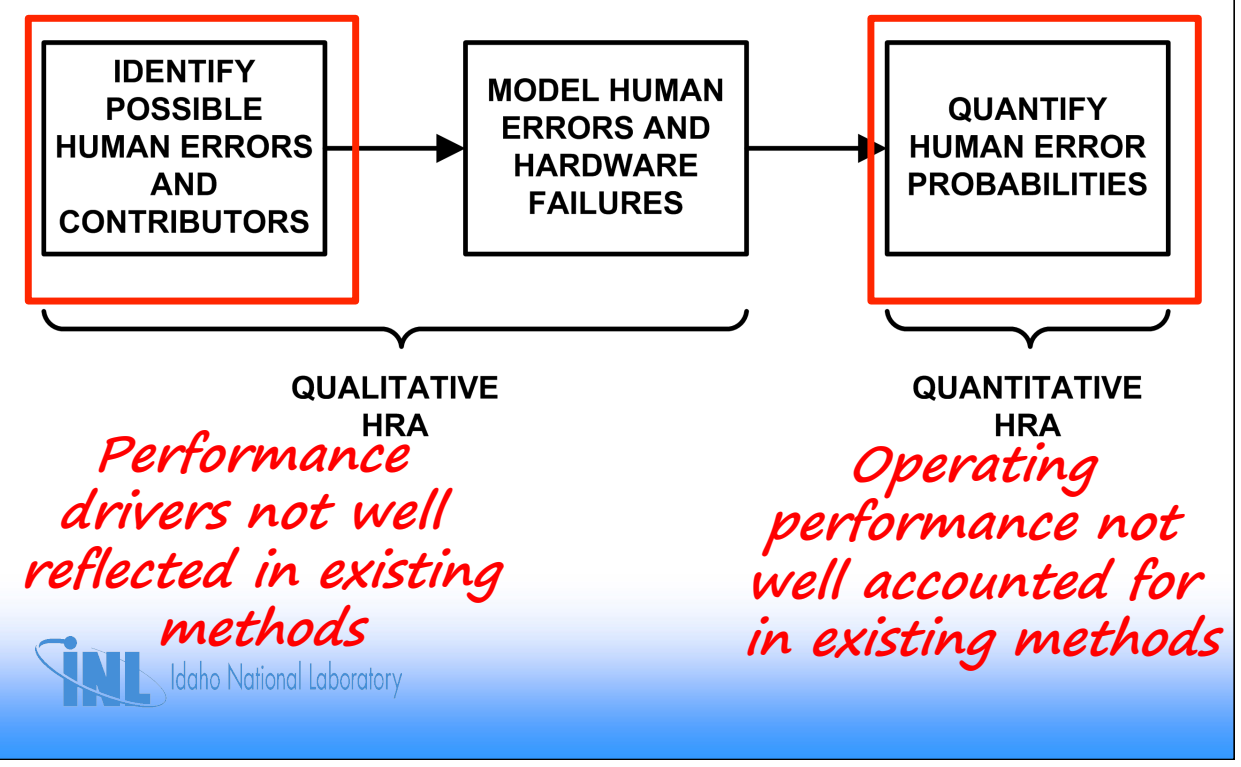




\section{Current Level 2 HRA Efforts (1)}

- Richner's (2006) HRA Quantification Approach for the Beznau Nuclear Power Plant

1. Extended Level 1 HRA methods to include:

- Emergency crews taking control of the plant

- Coordination of multiple emergency crews

- Following SAMGs by emergency crews

2. Results of adapting existing THERP and ASEP HRA methods

- Difficult to adapt these methods

- Yields less accurate performance estimates than Level 1 HRA

\section{Current Level 2 HRA Efforts (2)}

- MacLeod et al.'s (2014) HRA Quantification Approach for FLEX gear

1. Use of decision tree to account for:

- Availability of staff

- Time required to complete tasks

- Accessibility of equipment

- PPE safety limits

- Reliability of communication between groups

- Availability of required equipment

2. Primary focus is on actions required in the field during emergencies but not generalized method 


\section{Current Level 2 HRA Efforts (3)}

- EdF's Méthode d'évaluation de la réalisation des missions opérateur pour la sûreté (MERMOS) HRA method extended to Level 2 HRA (2005)

1. Evaluates performance of the "emergency operating system"

- Plant personnel

- Emergency personnel

- National crisis response teams

2. Requires extensive use of subject matter experts to identify key actions and expert judgment to quantify them

3. Resource intensive, appropriate for large fleet

\section{Current Level 2 HRA Efforts (4)}

- ISRN's Human and Organizational Reliability Aspects in Accident Management (HORAAM) method (2014)

1. Only method developed specifically for Level 2 HRA

2. Identifies seven key influence factors in addressing crisis management

- Not a full-fledged method but rather a way of understanding how to consider these factors in severe accidents

- Does not consider SAMGs 


\section{Current Level 2 HRA Efforts (5)}

\section{- HORAAM (2014)}

\begin{tabular}{|l|l|l|}
\hline $\mathbf{1}$ & Influence factors & Description \\
\hline $\mathbf{1}$ & Time for decision & $\begin{array}{l}\text { The time necessary to obtain, check and process information } \\
\text { and make a decision about the required action. This influence } \\
\text { factor has three modalities "short" "medium" or "long". } \\
\text { This IF refers to the quality, reliability and efficiency of all } \\
\text { measurements and information available in the control room } \\
\text { and means of transmitting them to crisis teams. This influence } \\
\text { factor has two modalities "satisfactory" or "unsatisfactory". }\end{array}$ \\
\hline $\mathbf{3}$ & Decision difficulty & $\begin{array}{l}\text { This IF refers to the difficulty in taking the right decision. This } \\
\text { influence factor has three modalities "easy" "medium" or } \\
\text { "difficult". }\end{array}$ \\
\hline $\mathbf{4}$ & Difficulty for the operator & $\begin{array}{l}\text { The difficulty of the action (quality of the procedures, } \\
\text { experience and knowledge in the control room or in the plant) } \\
\text { is evaluated independently of work conditions. This influence } \\
\text { factor has two modalities "easy" or "difficult". }\end{array}$ \\
\hline $\mathbf{5}$ & $\begin{array}{l}\text { Difficulty induced by environmental } \\
\text { conditions }\end{array}$ & $\begin{array}{l}\text { This IF takes into account the on-site conditions in which the } \\
\text { actions decided upon, have to be performed (radioactivity, } \\
\text { temperature, smoke, gas, exiguity...). This IF has two } \\
\text { modalities "normal" or "difficult". }\end{array}$ \\
\hline $\mathbf{6}$ & $\begin{array}{l}\text { Scenario difficulty } \\
\text { This IF refers to the difficulty of the global context of the } \\
\text { current accident scenario in which a decision must be made. } \\
\text { This influence factor has two modalities "easy" or "difficult". }\end{array}$ \\
\hline $\mathbf{7}$ & $\begin{array}{l}\text { Degree of involvement of the crisis } \\
\text { organization }\end{array}$ & $\begin{array}{l}\text { Local crisis organization on the plant site or the whole national } \\
\text { crisis organization. This influence factor has three modalities } \\
\text { "not involved", "local crisis team involved" or "local and } \\
\text { national crisis teams involved". }\end{array}$ \\
\hline
\end{tabular}

\section{Current Level 2 HRA Efforts (6)}

- SPAR-H Used for Chinese L2 HRA (Wang, 2013)

\begin{tabular}{|c|c|c|}
\hline $\begin{array}{c}\text { Special } \\
\text { Characteristics } \\
\text { of Level } 2 \text { PSA in } \\
\text { terms of HRA } \\
\end{array}$ & Description & $\begin{array}{l}\text { Corresponding } \\
\text { PSFs of SPAR-H } \\
\text { method }\end{array}$ \\
\hline $\begin{array}{l}\text { Extra Emergency } \\
\text { Teams }\end{array}$ & $\begin{array}{l}\diamond \text { extra time for communication between different } \\
\text { emergency teams } \\
\diamond \quad \text { quality of coordination within each emergency } \\
\text { team and between different emergency teams }\end{array}$ & $\begin{array}{l}1 \text { available time } \\
3 \text { complexity } \\
8 \text { work process }\end{array}$ \\
\hline SAMG & $\begin{array}{l}\diamond \quad \text { clarity and complexity of SAMGs } \\
\diamond \quad \text { team members' experience in SAMGs }\end{array}$ & $\begin{array}{l}3 \text { complexity } \\
4 \text { experience/training } \\
5 \text { procedures }\end{array}$ \\
\hline $\begin{array}{ll}\text { New } & \text { Severe } \\
\text { Accident } & \\
\text { Scenarios } & \end{array}$ & $\begin{array}{l}\Leftrightarrow \text { severity of the accident } \\
\diamond \text { adverse environment that plant staff may work in } \\
\text { (heat, smoke, radioactive release, etc) } \\
\diamond \text { team members' experience in severe accident } \\
\text { scenarios }\end{array}$ & $\begin{array}{l}1 \text { available time } \\
2 \text { stress } \\
4 \text { experience/training } \\
6 \text { ergonomics } \\
7 \text { fitness for duty } \\
8 \text { work process }\end{array}$ \\
\hline $\begin{array}{l}\text { Accessible to local } \\
\text { places }\end{array}$ & $\begin{array}{l}\text { During severe accident, some local place may be } \\
\text { difficult to access or totally inaccessible. So plant } \\
\text { staff's activities may be delayed or not able to } \\
\text { perform. }\end{array}$ & $\begin{array}{l}1 \text { available time } \\
\text { * If the local place is } \\
\text { inaccessible, HEP }= \\
1 .\end{array}$ \\
\hline $\begin{array}{l}\text { Need to Special } \\
\text { Tools }\end{array}$ & $\begin{array}{l}\diamond \quad \text { During severe accident, plant staff may need } \\
\text { some necessary special tools to perform their } \\
\text { activities. The special tools may be difficult to } \\
\text { access or totally inaccessible. } \\
\text { The staff's experience in using these special tools } \\
\text { will also impact HEPs. }\end{array}$ & $\begin{array}{l}1 \text { available time } \\
3 \text { complexity } \\
4 \text { experience/training } \\
* \text { If a special tool is } \\
\text { inaccessible, HEP = } \\
1 .\end{array}$ \\
\hline
\end{tabular}




\section{Current Level 2 HRA Efforts (7)}

- General Shortcomings of Level 2 Approaches

1. Some approaches oversimplify to the extent of becoming screening analysis approaches

2. Others require extensive expert elicitation exercises to use

3. Many approaches omit some crucial aspect of Level 2 activities like SAMGs or FLEX

4. Most approaches do not provide clear route to quantification

- Edge effects where human performance starts to break down are beyond current models
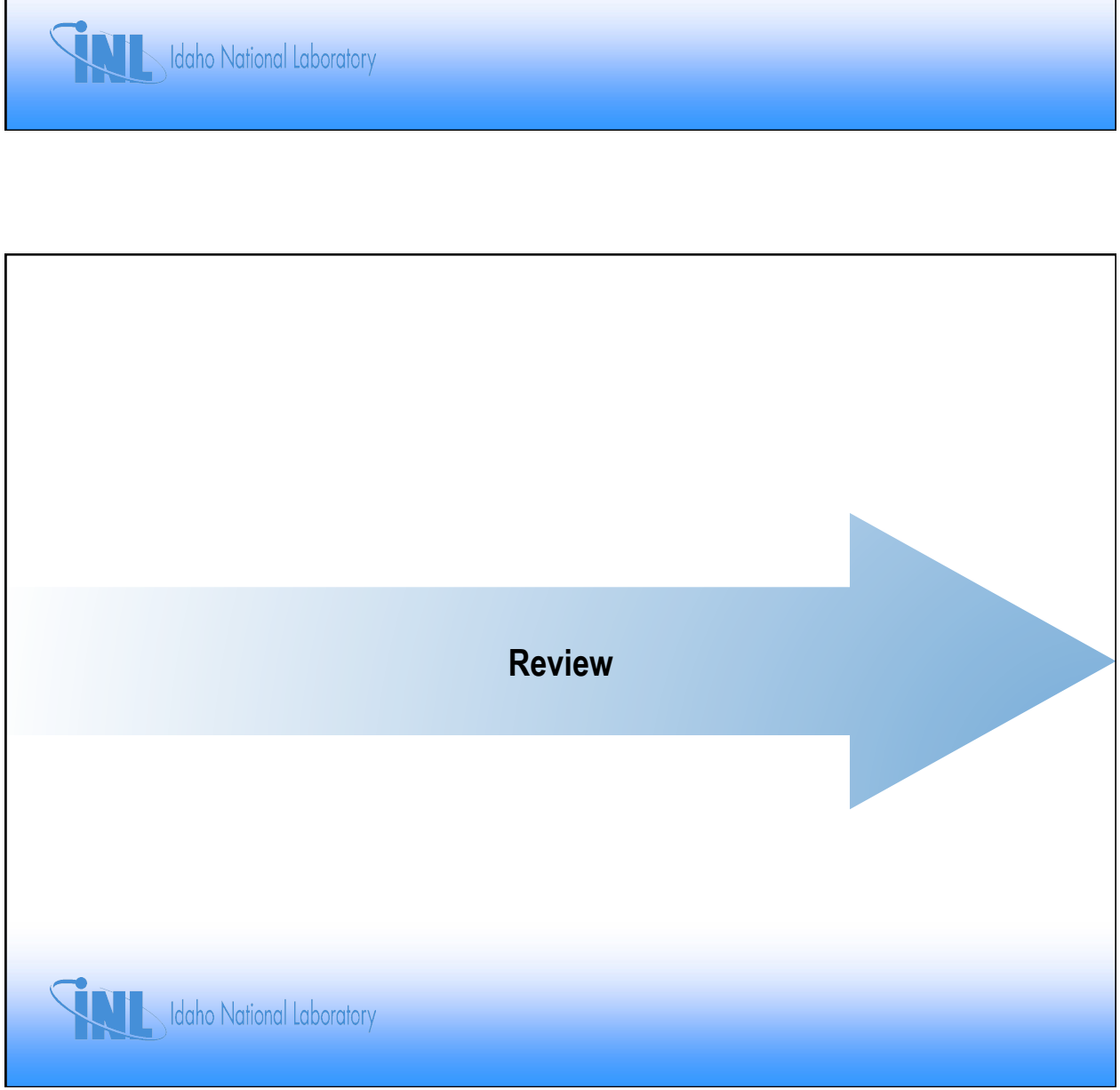


\section{Lesson 10 Review}

- What are some practices to ensure the quality of an HRA?

-Who should be on an HRA team?

- Why is a thorough qualitative analysis important?

- When would you use THERP? SPAR-H? CBDT? ATHEANA?

- What are some differences between nuclear and nonnuclear applications of HRA?

- How is the Fire HRA method related to ATHEANA?

- What are some considerations for Level 2 modeling in HRA?

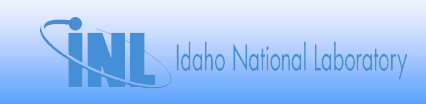

\section{HRA Questions?}

- Ronald Boring

ronald.boring@inl.gov

- David Gertman

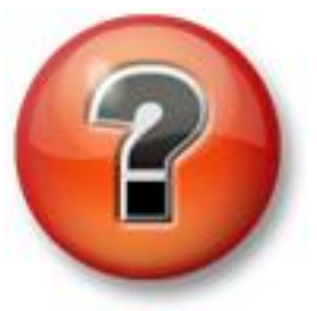

david.gertman@inl.gov 
APPENDIX A

The Fallible Engineer 


\section{The Fallible Engineer}

Australian engineers feel that they are being blamed for accidents and failures that are beyond their control. They want the public to understand that experts are only human.

Sharon Beder

At four o'clock in the morning of 30 April 1988, a railway embankment near the coastal town of Coledale in New South Wales collapsed, sending tons of mud and water down a hill. The debris crushed a house, killing a woman and child who were inside. The area was prone to subsidence and evidence given at the inquest suggested that the designers of the embankment had not taken proper account of this. Four people, two of them engineers, were subsequently charged with endangering passengers on a railway. One, a principal geotechnical engineer with the State Rail Authority of New South Wales, was also charged with two counts of manslaughter.

Though none of them was convicted, the engineering profession was horrified that engineers should be charged in this way, and rallied to their support. Peter Miller, chairman of the standing committee on legal liability of the Institution of Engineers, Australia, argued that criminal prosecutions against engineers set a precedent that could change the way engineering was practiced. He said it was likely to result in engineers becoming more conservative in their assessments and decisions. Although this was not in itself a bad thing, it would mean higher costs for engineering work, he claimed.

The institution was also concerned about individual blame being apportioned to engineers who work as part of a team in organizations operating under financial constraints. Bill Rourke, who retired last month as the institution's chief executive, pointed out in its magazine, Engineers Australia, that safety margins are closely related to the availability of funds. He argued that the provider of those funds, in this case the community, should carry a significant responsibility for safety levels.

The issue of who should take responsibility when things go wrong is becoming a central concern for the engineering profession worldwide. At the end of last year the Australian institution sent all its members a discussion paper entitled Are you at risk? Managing Expectations. More than 3000 engineers replied, the largest response the institution has ever had on any issue. In the preface to the paper, the institution's president, Mike Sargent, said that the trend towards criminal prosecutions for negligence and escalation of civil law claims against engineers "constitute a significant threat to the ability of our profession to serve the community and might even threaten its continued existence."

Miller, too, believes that the profession is at risk. "Engineers are being put in untenable positions," he says. "they are being asked to make decisions over matters they cannot control and being forced to take responsibility for these decisions." What Miller and his colleagues at the Institution of Engineers are proposing is nothing short of a radical change in the relationship between engineer and society. The engineering profession seems to be approaching a turning point. 
Miller and his colleagues believe that if people are more aware of the uncertainties surrounding engineering work and the limitations of mathematical models, then they would not so readily blame engineers for failures. The institution's discussion paper pointed out that engineers had presented a falsely optimistic and idealistic view of their work. They are now paying the price for having raised unjustifiably high the public's expectations of what they can deliver. "We know (or should know) that our models are limited as to their ability to represent real systems, and we use (or should use) them accordingly. The trouble is that we are so inordinately proud of them that we do not present their limitations to the community, and leave the community with the impression that the models are precise and comprehensive."

The discussion paper quotes the 1946 chairman of the Scottish branch of Britain's Institution of Structural Engineers as saying: "Structural engineering is the art of modeling materials we do not wholly understand into shapes we cannot precisely analyse so as to withstand forces we cannot properly assess in such a way that the public at large has no reason to suspect the extent of our ignorance."

Why have engineers misled the public in this way? Gavan McDonnell, an engineer and supervisor of the graduate program in science and society at the University of New South Wales, says: "It is the very nature of professions to fill the role of a sort of priesthood with transcendental access to superior knowledge. Engineers have assumed this role, too. They have protected their professional status as possessors of special knowledge and have not been inclined to discuss the limitations of that knowledge with those outside the profession." McDonnell admits that there is a large element of technocratic arrogance in this stance, but says that modern societies require this division of knowledge in order to function. There is, however, an important rider: "Previously the community trusted in the probity and ethical rightness of the expert," he says. "But as experts are increasingly seen to be working for particular interests in society, that trust is disappearing."

Miller, too, points to the breakdown of the social contract between engineers and society. He says that the contract involved a commitment by engineers to always put the public interest first and a commitment by the public to allow engineers to regulate themselves. "That contract is now seen to be broken by both parties," he says. The institution's discussion paper is the first step in a process of re-establishing trust between engineers and the public. Miller, one of the authors of the paper, was at first hesitant about sending it out. He was worried that engineers might not be interested in questions that don't have clear-cut answers, and concerned that they would not want to discus philosophy-even engineering philosophy. He has been gratified to find an unsuspected hunger for such a discussion.

The philosophy set out in the paper is that engineering is an art rather than a science, and as such depends heavily on judgment. The widespread use in engineering of heuristics, or "rules of the thumb," requires judgment to be used properly. Billy Vaughn Koen, professor of mechanical engineering at the University of Texas at Austin, defines a heuristic device as "anything that provides a plausible aid or direction in the solution of a problem but is in the final analysis unjustified, incapable of justification and infallible." Heuristics is used in the absence of better knowledge or as a short-cut method of working out something that would be too expensive or too time-consuming to work out more scientifically. 
An example of a heuristic device is a "factor of safety," sometimes referred to as a "factor of ignorance." Engineers have to work with materials that vary widely in strength and other characteristics, and design for a range of operating conditions and loads. To cope with these variations and uncertainties they employ factors of safety. Henry Petroski, an American engineer who has written extensively on engineer accidents, explains: "Factors of safety are intended to allow for the bridge built of the weakest imaginable batch of steel to stand up under the heaviest imaginable truck going over the largest imaginable pothole and bouncing across the roadway in a storm."

However, the concept of a factor of safety is often misunderstood by those outside the profession as implying some large safety margin on a predictable design. Barry McMahon, a Sydney-based geotechnical engineer, has found his clients believe that as factor of safety implies "certainty" plus a bit more. He says they are far more concerned with the financial risk of "conservative" design (design that errs on the safe side) than they are with other sources of risk. Conservative design tends to be more expensive, which means that there is always pressure to reduce factors of safety. For a factor of safety to be effective, the means of failure must be known and the cause of the failure determinable by experiment. For example concrete columns may be designed to cope with 10 times the compression stresses the engineer estimates they will have to bear. In this case the factor of safety is 10. But this assumes that if the columns are going to fail it will be as a result of compression.

If the columns are subject to unexpected forces from another direction-so that they are stretched instead of compressed, for example - then their extra ability to take compression will not be of much help. The ability of a concrete column to bear a particular stress is determined by experiments done repeatedly on concrete columns in the laboratory.

All engineering structures incorporate factors of safety and yet some still fail, and when this happens the factor of safety for similar structures built subsequently might be increased. Conversely, when a particular type of structure has been used often without failure, there is a tendency for engineers to suspect that these structures are overdesigned and that the factor of safety can be reduced. Petroski says: "The dynamics of raising the factor of safety in the wake of accidents and lowering it in the absence of accidents can clearly lead to cyclic occurrences of structural failures." He points out that this cyclic behaviour occurred with suspension bridges following the failure of the Tacoma Narrows Bridge, which collapsed spectacularly in 1940 in mild winds.

Cutting safety margins to reduce costs in the face of success happens in all engineering disciplines. William Starbuck and Frances Milliken, researchers at New York University, have studied the catastrophic failure of the challenger space shuttle in January 1986 and concluded in their paper "Challenger: fine-tuning the odds until something breaks" (Journal of Management Studies, Vol. 25, July 1988) that the same phenomenon was present there. They argue that, as successful launches accumulated, the engineering managers at NASA and Thiokol, the firm responsible for designing and building the rocket boosters for the shuttle, grew more confident of future successes. NASA relaxed its safety procedures, treating the shuttle as an "operational" 
technology rather than a risky experiment, and no longer tested or inspected as thoroughly as they had the early launches.

\section{Signs of Failure}

The O-rings sealing the joints in the shuttle's solid-fuel rocket booster, which were eventually found to have played a major role in the accident ("Why Challenger Failed," New Scientist, 11 September 1986), had shown signs of failure in after three of the five flights during 1984 and after eight of nine flights during 1985. But since this damage had not impeded the shuttle launch, engineering managers at NASA and Thiokol came to accept this damage as "allowable erosion" and "acceptable risk." Lawrence Mulloy, manager of the solid rocket booster project, is quoted by Starbuck and Milliken as saying: "Since the risk on O-ring erosion was accepted and indeed expected, it was no longer considered an anomaly to be resolved before the next flight."

Brian Wynne, a researcher at the University of Lancaster, has also studied the Challenger disaster and other accidents. He says that O-ring damage and leakage had come to be accepted as "the new normality." Wynne argues that implementing designs and operating technological systems involve "the continual invention and negotiation of new rules and relationship" and that if this did not happen most technological systems would come to a halt. Starbuck and Milliken agree with respect to the space shuttle. They point out that NASA had identified nearly 300 special "hazards" associated with the launch of Challenger. "But if NASA's managers had viewed these hazards so seriously that any one of them could readily block a launch, NASA might never have launched any shuttles."

Wynne says there is a tendency to refer to "human error" when accidents occur, as if there has been some "drastic departure from normal rule-bound operating practices, and as if we were exonerating a supposedly separate mechanical, nonsocial part of the system." He suggests that part of the problem may be that technological systems are designed as if organizations can operate with perfect communication and that people are not prone to distraction, illogic or complacency. Jean Cross, professor of safety science at the University of New South Wales, agrees that engineers have a tendency to neglect what she calls the "human/technology interface" in their designs. For example, they do not take account of how long it takes people to process information and how people behave when they are under stress.

The institution's paper gives some recognition to this. It says that the notional probability of failure implicit in engineering codes does not give sufficient weight to human factors. "It deals mainly with those issues for which we can rationally compute factors of safety." Miller is keen for engineers to give more consideration to the human/technology interface. This is one of the areas that will be covered in a second discussion paper, which is being put together at the moment.

For Starbuck, Milliken, Wynne, Petroski and many others, all engineering design involves experimentation. According to Petroski, "each novel structural concept - be it a sky walk over a hotel lobby, a suspension bridge over a river, or a jumbo jet capable of flying across the oceans - is the hypothesis to be tested first on paper and possibly in the laboratory but ultimately 
to be justified by its performance of its function without failure." Failures will occasionally occur. They are unavoidable, he argues, unless innovation is completely abandoned.

Wynne goes further, arguing that the experimental nature of engineering extends beyond the designing stage: "If technology involves making up rules and relationships as its practitioners go along, it is a form of social experiment on the grand scale." Similarly, Starbuck and Milliken say that "fine tuning is real-life experimentation in the face of uncertainty."

If engineering is based on incomplete models and on judgment and experimentation, who should be held responsible when engineering projects fail, causing loss of life and property, and damage to the environment? For many engineers this is not a useful question. Mark Tweeddale, professor of risk engineering at the University of Sydney, argues that finding who is to blame for an accident is a fruitless way of going about things. "If someone makes a mistake, you need to ask what caused them to make that mistake? Was it the stress they were under? Was it that they were not properly trained? Should they never have been hired for the job? All these questions lead back to management, but management is also human and the same questions apply. It's like peeling an onion: in the end you are left with nothing." This does not mean an accident shouldn't be investigated. But Tweeddale feels that legal proceedings to establish blame are unhelpful in sorting out the lessons to be learnt from an accident, because the sub judice laws that come into play during a court case restrict free and open public discussion of what happened.

Engineers feel that the public is increasingly looking for someone to blame when accidents happen, rather than accepting accidents as an inevitable part of life. They are frustrated at what seems to be the public's requirement for complete safety. Simon Schubach, a consulting engineer who does risk assessments for the New South Wales planning department, is often asked at public meetings: "Will it be safe?" But the audience seldom accepts his answer, which tends to be along the lines of: "On the basis of the assumptions we made, and the limited applicability of the models we used, our assessment is that the project will meet acceptable risk criteria." Schubach finds the public's demand for certainty naïve, unreasonable, and ill-founded: "Engineering is just not like that."

McDonnell is also concerned about the increasing tendency for lawyers to look for someone to hold liable whenever anything undesirable happens after engineers have given advice. However, he argues that the law still has a part to play where there has been gross negligence and dereliction of duty. This may mean criminal prosecutions of engineers in some instances," he says. "Engineers simply can't expect to be immune from this."

Australia's Society for Social Responsibility in Engineering believes that engineers should accept responsibility for safety of their work even if this means they will be held criminally liable. Philip Thornton, president of the society, says: "If an engineer makes a structure stronger because the risk of being charged if that structure collapses is too high, then the risk of someone being killed or injured is also too high." Thornton argues that if engineers are concerned about being personally liable for accidents and failures then they are less likely to bow to economic pressure to reduce safety margin. "Caution is a good thing." 
The dilemma for engineers today is how to tell the public of the extent of their ignorance without losing the community's confidence. Getting public acceptance of new or controversial technologies is greatly assisted by portraying them as perfectly predictable and controllable. "Concern for public reassurance produces artificially purified public accounts of scientific and technological methods and processes," says Wynne. "When something goes wrong, this background is an ever more difficult framework against which to explain that even when people act competently and responsibly, unexpected things can happen and things go wrong."

The emerging recognition that this situation cannot go on is leading Australian engineers to question their role as "problem solver" who design projects and advocate them as the "right" solutions to community problems. The Institution of Engineers is suggesting a shift to a different role for engineers as "technical advisers" who put forward options for the community to choose from. This means forgoing some of their autonomy and status as technological decision makers in favor of sharing the decisions, in order to share the responsibility of things go wrong. McDonnell argues that the social contract between engineers and the community will not disintegrate if ways can be developed of consulting the public and allowing the community to monitor and vet projects.

It will not be easy for people like Miller and his like-minded colleagues in the Institution of Engineers to bring engineers around to this sharing of responsibility and decision making, and to open and frank dialogue with the community. The change will require a lot more discussion within the profession and changes in engineering education and perhaps public education. Yet Miller is heartened by the overwhelmingly positive response he has had from engineers in Australia.

Sharon Beder is a member of the Institution of Engineers, Australia, and of the Society for Social Responsibility in Engineering. She is currently environmental education coordinator at the University of Sydney.

Tom Wyatt is read in structural design in the Department of Civil Engineering at Imperial College, London.

Further reading: Are you at Risk? Managing Expectations. Institution of Engineers, Australia, 1990; Henry Petroski, To Engineer is Human: The Role of failure in Successful Design, MacMillan 1985; Brian Wynne, "Unruly technology: Practical rules, impractical discourses and public understanding," Social Studies of Science, Vol 18, 1988; William Starbuck and Frances Milliken, "Chalenger: fine-tuning the odds until something breaks," Journal of Management Studies, Vol 25, July 1988. 
APPENDIX B

THERP TABLE 20 
Ch. 20. Tables of Estimated HEPs

Overview

CHAPTER 20. TABLES OF ESTIMATED HUMAN ERROR PROBABILITIES

\section{Overview}

This chapter summarizes the estimated human error probabilities (HEPs) and their uncertainty bounds (UCBs) (or error factors [EFs]) presented in Part III. The tables in this chapter are duplicates of data tables in Part III except for changes to footnotes and table references to make them appropriate to Chapter 20. Not all data tables in Part III are included in this chapter; those that are included are sufficient for most human reliability analyses (HRAs) conducted as part of a probabilistic risk assessment (PRA). These tables are intended for use as quick references and are cross-referenced to the chapters from which they are drawn. The user is urged to familiarize himself with the source chapters for the proper use of the error terms and the assumptions on which they are based.

This chapter begins with a brief discussion of performance shaping factors (PSFs), followed by a search scheme for the use of the tables, with an explanatory talk-through of the search scheme. The chapter concludes with a list of tables, a quick-reference guide to the tables, and the set of tables.

For users conducting HRAs, the search scheme provides guidance to the appropriate tables at each stage of the analysis. The quick-reference guide is intended for general use and will help the analyst locate any table of interest.

\section{Performance Shaping Factors}

All of the estimated HEPs in the data tables are nominal HEPs, $i . e .$, they represent HEPs before plant-specific PSFs have been taken into account. When these latter are evaluated, a nominal HEP may be modified upward or downward.

Chapter 3 describes the usual PSFs that influence HEPs in industrial settings. PSFs specific to classes of activities are discussed in detail in Part III. As a rule, the HEPs in the Handbook are based on "average" industrial conditions. We define average industrial conditions as those that do not subject a worker to an unusual degree of discomfort and that are fairly representative of the industry. The user may modify the tabled HEPs if the PSFs for his specific application are not average. Some guidance is given to help the analyst to determine the average conditions applicable to each group of HEPs, but most of this information is presented in Part III.

PSFs such as temperature, noise level, lighting, and others related to the comfort or health of the worker will usually be average (or better) in nuclear power plants (NPPs). This is because regulatory agencies such as the Nuclear Regulatory Commission and the occupational Safety and Health Administration have developed "guidelines" or "recommended limits" for most controllable factors affecting workers. The plants' managements will work 
to meet the standards set by such agencies, and organizational units such as employee unions and professional organizations will usually report any deviations from these standards.

The PSFs related to ergonomics considerations are not subject to regulation. Hence, considerable variations exist from plant to plant as well as within any given plant. The estimated HEPs summarized here are based on conditions observed in a number of operating U.S. and foreign plants. In some cases, differences in PSFs have been estimated in the breakdown of the HEPs. For example, modifications to HEPs based on the PSFs of display type and information displayed have been defined in the data tables. Display types such as analog neters, digital indicators, chart recorders, etc., have been analyzed for the effect they have on human performance; the HEPs for errors made in dealing with displays have been modified to account for these effects. Very small differences in performance that might result from relatively minor differences in human factors engineering of displays, e.g., indicator needle length and width, are not represented in the estimated HEPs.

In other cases, it is not possible to provide quantitative estimates of substantial differences in levels of a PSF. For example, for the PSF of the quality of administrative control, the user will have to be content with rating this PSF as "good," "average," or "poor," making a subjective decision about the effect of this PSF on any particular task. Guidance is given for evaluating the effects of these types of PSFs, but considerable judgment by the analyst will be required.

The UCBs (or EFs) for an HEP reflect the estimated range of variability in performance attributable to differences in relevant PSFs, differences between and within people, differences in analysis, modeling uncertainty, and uncertainty about the actual HEPs. The tabled UCBs are speculative; the analyst may wish to expand them to indicate greater uncertainty. The tables Iist the EFs or UCBs for most of the HEPs, and Table 20-20 presents guidelines for estimating them for the other HEPs and for adjusting the tabled UCBs for stress and type of task, e.g., dynamic rather than step-by-step, as defined in Table 20-16.

\section{Search Scineme for Use of Chapter 20 Tables}

A search scheme is presented in Figure 20-1 to aid the analyst in considering all tables of HEPs that he should consult in an HRA. This search scheme is organized according to the outline of a Technique for Human Error Prediction (THERP) procedure for HRA, as presented in Figure 5-6 and discussed in Chapter 5. The heavy lines in the search scheme represent the paths of HRA activities we have most often employed in HRAs of NPP operations. Ordinarily, the analyst will have completed an initial task analysis and a set of first-cut HRA event trees before using the search scheme. He is now ready to assign HEPs to the failure limbs in the trees. The search scheme uses the flowchart format to guide the analyst through the essential steps in the conduct of an HRA, indicating the appropriate tables to which to refer at each stage of the analysis. It is assumed that if the 

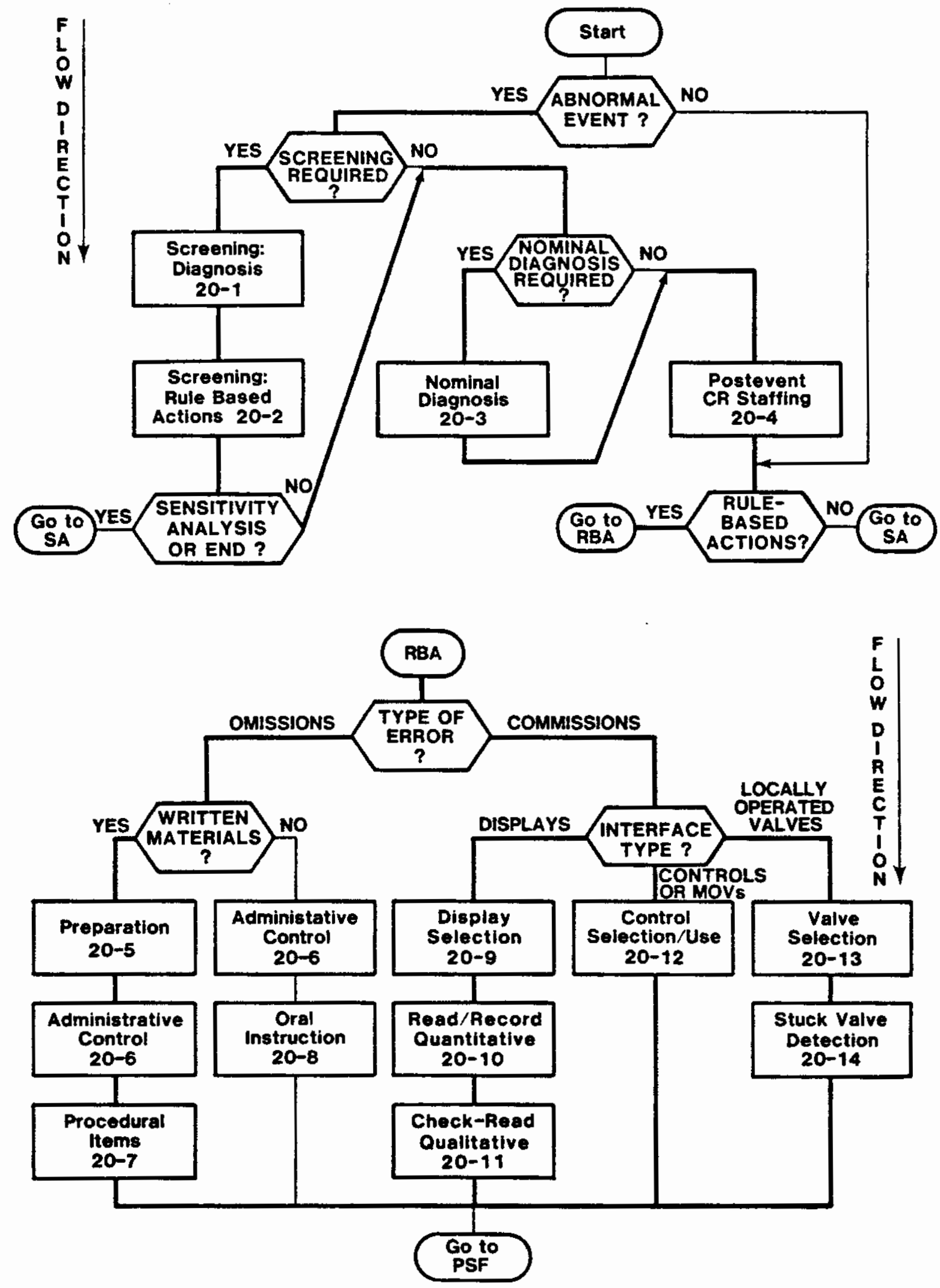

Figure 20-1 Search scheme for use of Chapter 20 tables ( 1 of 3 ). 


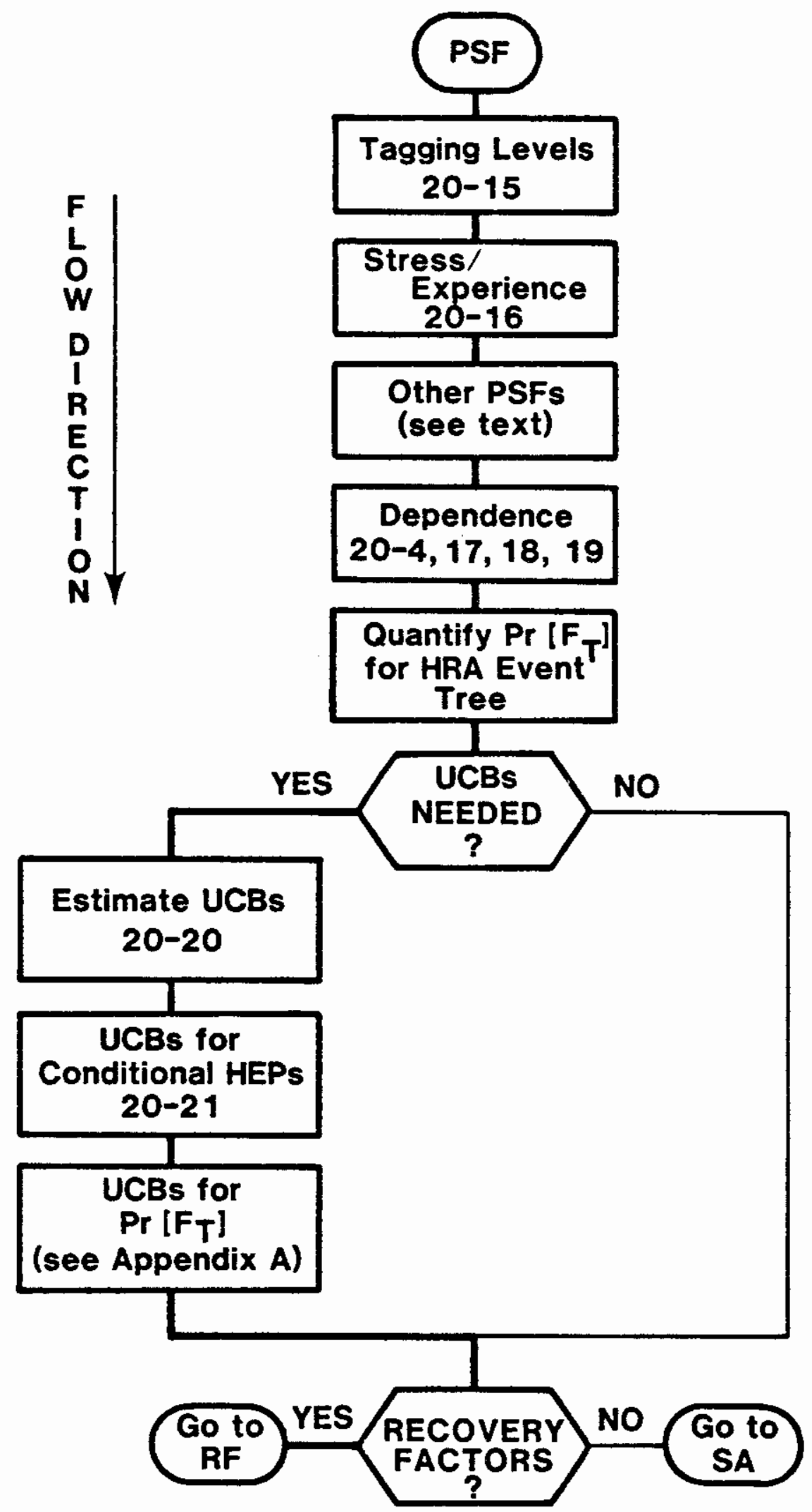

Figure 20-1 Search scheme for use of Chapter 20 tables (p 2 of 3 ). 


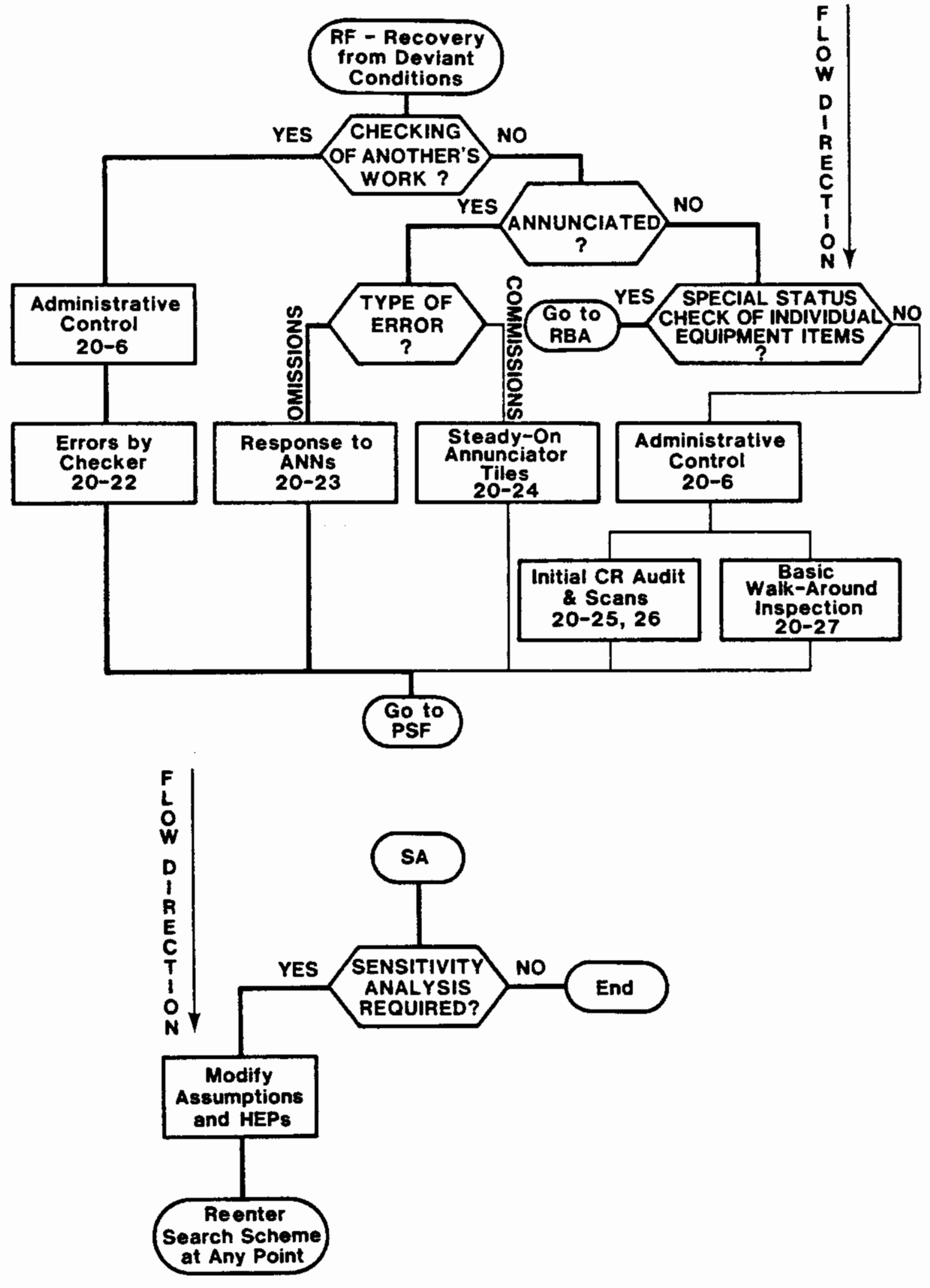

Figure 20-1 Search scheme for use of Chapter 20 tables ( 3 of 3 ). 
analyst is directed to the appropriate table, he can select the item in the table that most closely approximates the task and conditions being evaluated. However, any tabled HEP may have to be modified according to plantspecific PSFs.

If the table to which the analyst is directed does not list an item that closely approximates the analysis task, he may select an item from some other table that matches the underlying behavioral processes identified in the task analysis. Alternatively, he may rely on judgment or seek other data sources. Some guidance is presented later, in the section entitled, "The Data Tables."

Figure 20-1 is presented here and also at the end of this chapter for the convenience of the analyst.

\section{A Talk-Through of the Search Scheme}

The search scheme in Figure 20-1 represents an iterative process, and the analyst may enter the figure at any point in the logic. The ellipses represent reference points, the hexagons represent decision nodes, and the rectangles represent action items.

To illustrate the use of the search scheme, we will enter at the "Start" ellipse and proceed through a hypothetical, complete HRA of the type described in NUREG/CR-2254. Every table will be considered in the following sequence. This talk-through is, of course, generic. To illustrate application of the search scheme for a specific sample HRA, see the first example problem in Chapter 21.

(1) ABNORMAI EVENT? This is the first decision node after "Start." Generally, the abnormal events of major interest in a HRA for a PRA are loss-of-coolant accidents (LOCAs) and transients. If addressing a LOCA or transient, follow the YES path.

(2) SCREENING REQUIRED? As described in Chapter 5, this is the next decision node on the YES path. Screening involves the assignment of very high failure probabilities to each human task. If the very high HEPs do not have a material effect on the system analysis, the task(s) may be dropped from further consideration. The decision as to whether screening is required will be made in conjunction with the system analysts. Assume YES.

(3) Screening values may be obtained for diagnostic performance and for subsequent rule-based actions (RBAs), using Tables 20-1 and 20-2.

(4) SENSITIVITY ANALYSIS OR END? For some purposes, the analysis will end with a screening analysis, or it may be followed by a sensitivity analysis (SA). For either of these cases, follow the YES path. The "Go to SA" ellipse transfers the analyst to the bottow of page 3 of the figure, where he may perform a sensitivity analysis or exit from the flowchart. If postscreening HRA is required, follow the No path. Assume No. 
(5) NOMINAI DIAGNOSIS REQUIRED? The nominal model for diagnostic performance lists HEPs that are more realistic than the HEPs in the screening model. In most PRAs, the nominal HEPs for diagnostic performance are of interest. Assume YES.

(6) The HEPs for the nominal diagnosis model are listed in Table 20-3 and are used to estimate the probability of control room (CR) personnel failing to properly diagnose one or more abnormal events within the time constraints given by the system analysts.

(7) Table 20-4 lists the CR staffing assumptions as a function of time after recognition of an abnormal event. These assumptions enable the analyst to consider the effects of personnel interaction in modifying the nominal HEPs for postevent activities (e.g., rulebased actions).

(8) RULE-BASED ACTIONS? Usually, RBAs will be evaluated in an HRA. Assume YES and go to the RBA ellipse.

(9) TYPE OF ERROR? This decision node does not have a YES/NO division. The section of the flowchart branching from this decision node and reuniting at the PSF ellipse encompasses all the rule-based tasks usually addressed in an HRA. Tables 20-5 through 20-14 list the HEPs for all the rule-based tasks specified by the action rectangles in this section. The analyst will follow the appropriate path through this section for each rule-based task being evaluated. In many HRAs, all the paths will be used. We will assume that this is the case for this HRA. All the paths flowing from the TYPE OR ERROR? hexagon will be considered before going to the "PSF" ellipse to adjust the nominal HEPs for relevant PSFs. We will address errors of omission first.

(9A) WRITTEN MATERIALS? This decision node applies to whether written materials are mandated for the task. Written materials include formal procedures, ad hoc procedures, and oral instructions that are written down by the recipient as he receives them.

- If YES, Tables 20-5, 20-6, and 20-7 list the HEPs for the preparation of written materials, for the initiation of the task and for the misuse of procedures, and for the omission of procedural items when using written materials. (Note that Table 20-5 includes errors of commission as well as errors of omission, but for convenience is placed onjy in the OMISSION path from the TYPE OF ERROR? hexagon.)

- If NO, the worker is relying on memory. Table 20-6 provides the HEPs for initiation of the task and Table 20-8 the HEPs in carrying out oral instructions as a function of the number of items to be remembered.

- Returning to the TYPE OF ERROR? hexagon, we will now consider errors of commission. 
A Talk-Through of the Search scheme

(9B) INTERFACE TYPE? Displays, controls (including switches for motoroperated valves [MOVs]), and locally operated valves are the three types of man-machine interfaces studied in HRAs.

- For some frequently practiced tasks, the analyst may judge that the probabilities of errors of commission are negligible. See the fourth example in Chapter 21.

- If DISPLAYS, the following tables list the HEPs for selection of displays (20-9), for reading and recording quantitative information from displays (20-10), and for noting the general state of displays $(20-12)$.

- If CONTROLS or MOVs, Table 20-12 lists HEPs for selection and use of switches, connectors, and other manual controls.

- If LOCALIY OPERATED VALVES, Table 20-13 lists HEPs for selecting these valves, and Table 20-14 lists HEPs for recognizing that a valve is not fully open or closed because it sticks.

(10) Transfer to the "PSF" ellipse on page 2 of Figure 20-1. These rectangles list the PSFs that should be considered when evaluating the HEPs for RBAs. The nominal HEPs in any table may not accurately represent a plant-specific situation. Depending on the quality of PSFs observed, the nominal HEP may be raised or lowered by the analyst.

(10A) Table 20-15 indicates the modifiers to be applied to HEPs for changing or restoring the normal states of safety-related components as a function of the tagging level in use. No modification of HEPs is required if the plant uses the usual level 2 tagging system.

(10B) Table 20-16 lists modifiers to be applied to HEPs for different stress levels under which a task is to be performed, according to the experience level of the personnel on duty. If a task will be performed under different levels of stress at different times, or if different experience levels of personnel will be on duty at different times, the HRA event trees must represent such fractionation, as described in Chapter 5.

(10C) The "Other PSFs" rectangle is a reminder to consider the many other PSFs mentioned in the Handbook that are not listed in the tables. In addition, almost always there are plant-specific PSFs that the analyst will observe in the course of his site visits, which should be included at this point, using judgment to estimate their effects.

(IOD) Tables 20-17, 20-18, and 20-19 present equations and tabled HEPs to be applied to the nominal HEPs to allow for the effects of different levels of dependence that may be assessed between tasks performed by one person or for the effects of dependence between people working jointly. (Table 20-4 provides initial estimates of dependence among $\mathrm{CR}$ personnel in carrying out procedures after an abnormal event.) 
(11) At this stage, the analyst following the HRA sequence shown in Figure 5-6 is ready to perform his first cut at quantifying the total-failure term, $\operatorname{Pr}\left[F_{T}\right]$, for each HRA event tree. It is at this point in a PRA that certain human error terms may be dropped from further consideration if, as determined by the system analysts, they have no material impact on the system failure events of interest.

(12) UCBE NEEDED? If point estimates of HEPs without any UCBs are adequate, follow the No path. Usually, the YES path will be followed:

- Table 20-20 provides guidelines for assigning UCBs (or EFs) to individual HEPs in the analysis. The upper and lower UCBs may be used as one form of SA, as described in Chapter 7.

- Table 20-21 provides UCBs for conditional HEPs based on use of the dependence model.

- Appendix A presents the methodology for propagation of UCBs through an HRA event tree so that UCBs may be assigned to the total-failure term, $\operatorname{Pr}\left[F_{T}\right]$, for each HRA event tree. This term plus its UCBs constitute the usual input to the system analyst for inclusion in the overall PRA.

(13) RECOVERY FACTORS? Usually recovery factors (RF) will be considered at this point in the HRA. Assume YES. Transfer to the top of page 3 of the search scheme to the "Recovery from Deviant Conditions" ellipse.

(14) CHECKING of ANOTHER'S WORK? The recovery factor from any deviant condition under normal operating conditions may depend on the direct checking of someone's work (the YES path) or on inspections of plant indications of deviant conditions. In an HRA, both paths are generally followed. We will begin with the YES path.

(15) The YES path leads to Table 20-6, which provides HEPs for the initiation of the task of the checker, and to Table 20-22, which lists HEPs for errors of omission and comission in the checker's task.

(16) The No path leads to the ANNUNCIATED? hexagon. The recovery cues may be annunciated or unannunciated. We will address both modes.

(16A) If YES, the decision node, TYPE OF ERROR?, leads to one of two tables:

- Table 20-23 presents the Annunciator Response Model listing the HEPs for an operator to initiate intended corrective action to one or more annunciators.

- Table 20-24 lists HEPs for remembering to respond to a steady-on annunciator tile after an interruption or for noticing an important steady-on annunciator tile during the initial audit or subsequent hourly scans. 
(16B) If NO, proceed to the decision node, SPECIAL STATUS CHECK OF INDIVIDUAL EQUIPMENT ITEMS? If certain displays are read according to a schedule, or if the operator is otherwise directed to read some display, follow the YES path to the "RBA" ellipse on page 1 of the flowchart. If there is no specific requirement to check the status of individual equipment items, that is, the checking is more of a general inspection, the No path leads to four tables:

- Table 20-6 lists the HEP for initiation of a scheduled checking or inspection function.

- Table 20-25 lists HEPs for detecting deviant unannunciated indications on different types of displays during the initial audit and on subsequent hourly scans.

- Table 20-26 modifies the HEPs from Table 20-25 when more than one (up to 5 ) displays are presenting deviant indications.

- Table 20-27 lists HEPs for failure of the basic walk-around inspection to detect unannunciated deviant indications of equipment within 30 days.

(17) At this point, having considered all important recovery factors, the analyst will proceed to the "PSF" ellipse to consider modifications of the recovery HEPs by relevant PSFs. After the PSFs have been considered, follow the NO path from the RECOVERY FACTORS? decision node at the bottom of page 1 of the flowchart and proceed to the "SA" ellipse on page 3 .

(18) SENSITIVITY ANALYSIS REQUIRED? The last thing done in a complete HRA is an SA, although it may be done at other times in the URA also. The $S A$ is important since it provides a means of ascertaining whether different assumptions or estimates result in materially different effects in the overall PRA. Assume YES.

(18A) As indicated in the rectangle, the analyst may use SA to modify any assumptions or HEPs, following the procedure described in Chapters 5 and 7. He may then reenter the search scheme at any point to assess changes resulting from these modifications. Reentry will take him back to the "PSF" ellipse on page 2 of the flowchart and to the recalculation of the end-failure term, $\operatorname{Pr}\left[F_{T}\right]$, using new values.

(18B) The search scheme will always take the analyst back to the SENSITIVITY ANALYSIS REQUIRED? decision node on page 3 of the flowchart. When sufficient SA has been accomplished for purposes of the PRA, the NO path from this decision node leads to the "END" ellipse, signifying the completion of the HRA.

\section{List of Chapter 20 Data Tables}

The data tables from Part III that are repeated in this chapter are listed below. Note that at the end of the title of each table, there appears in 
parentheses the table number in Part III to which the Chapter 20 table corresponds. This reference to Part III table numbers will enable the reader to quickly find background discussion of PSFs that does not appear in Chapter 20. For users familiar with the draft Handbook, Table $F-2$ in Appendix $F$ provides a cross-index of the table numbers in the revised Chapter 20 with the table numbers from the same chapter in the draft Handbook (Swain and Guttmann, 1980).

Ch. 20

Table No. Title of Table

20-1 Initial-screening model of estimated HEPs and EFs for diagnosis within time $T$ by control room personnel of abnormal events annunciated closely in time (from Table 12-2)

20-2 Initial-screening model of estimated HEPs and EFs for rulebased actions by control room personnel after diagnosis of an abnormal event (from Table 12-3)

20-3 Nominal model of estimated HEPs and EFs for diagnosis within time $T$ by control room personnel of abnormal events annunciated closely in time (from Table 12-4)

20-4 Number of reactor operators and advisors available to cope with an abnormal event and their related levels of dependence: assumptions for PRA (from Table 18-2)

20-5 Estimated HEP per item (or perceptual unit) in preparation of written material (from Tabie 15-2)

20-6 Estimated HEPs related to failure of administrative control (from Table 16-1)

20-7 Estimated probabilities of errors of amission per item of instruction when use of written procedures is specified (from Table 15-3)

20-8 Estimated probabilities of errors in recalling oral instruction items not written down (from Table 15-1)

20-9 Estimated probabilities of errors in selecting unannunciated displays for quantitative or qualitative readings (from Table $(1-2)$

20-10 Estimated HEPs for errors of commission in reading and recording quantitative information from unannunciated displays (from Table $(1-3)$

20-11 Estimated HEPs for errors of commission in checking-reading displays (from Table 11-4) 
Ch. 20

Table No.

$20-12$

$20-13$

$20-14$

$20-15$

$20-16$

$20-17$

$20-18$

$20-19$

$20-20$

$20-21$

$20-22$

$20-23$

$20-24$

$20-25$

Title of Table

Estimated probabilities of errors of commission in operating manual controls (from Table 13-3)

Estimated HEPs for selection errors for locally operated valves (from Table 14-1)

Estimated HEPs in detecting stuck locally operated valves (from Table 14-2)

The four levels of tagging or locking systems (from Table 16-2)

Modifications of estimated HEPs for stress and experience levels (from Table 18-1)

Equations for conditional probabilities of success and failure on Task "N," given success or failure on preceding Task "N-1," for different levels of dependence (from Table 10-2)

Conditional probabilities of success or failure for Task "N" for the five levels of dependence, given FAILURE on preceding Task "N-1" (from Table 10-3)

Conditional probabilities of success or failure for Task "N" for the five levels of dependence, given success on preceding Task "N-1" (from Table 10-4)

Guidelines for estimating uncertainty bounds for estimated HEPs (from Table 7-2)

Approximate CHEPs and their UCBs for dependence levels given FAIIURE on the preceding task (from Table 7-3)

Estimated probabilities that a checker will fail to detect errors made by others (from Table 19-1)

The Annunciator Response Model: estimated HEPs for multiple annunciators alarming closely in time (from Table 11-13)

Estimated HEPs for annunciated legend lights (from Table $11-12)$

Estimated probabilities of failure to detect one (of one) unannunciated deviant display at each scan, when scanned hourly (from Table 11-7) 
Ch. 20

Table No.

$20-26$

$20-27$ mitle of Table

\begin{abstract}
Estimated probabilities of failing to detect at least one of one to five unannunciated deviant displays as a function of the BHEP for detection of a single deviant display during periodic scanning (from Table 11-6)

Estimated probabilities that the basic walk-around inspection will fail to detect a particular deviant indication of equipment outside the control room within 30 days (from Table 19-4)
\end{abstract}

This section presents the 27 data tables extracted from Part III. TO facilitate rapid access to these tables, a table designator for each table is shown in large print in the outer upper corner of the page on which the table appears. The table designators are expressed without the chapter prefix (e.g., Table 20-6 is expressed as 6).

Figure 20-2, which precedes the first table, is a quick reference guide to the tables, organized under the seven major headings that are used in the search scheme (Figure 20-1). For convenience, Figure 20-2 also appears as the last page in Chapter 20.

We remind the user that the tables in this chapter do not stand alone. They must be considered in association with the descriptive material in those chapters that include the original versions of the tables. It is not possible to include all of the relevant PSFs in each table; the complete Handbook must be used.

Obviously, the tables cannot list every act or task that could take place in an NPP--only the most frequently observed tasks are listed. When a task is being evaluated for which we have no tabled HEPs, we assign a nominal HEP of .003 as a general error of omission or commission if we judge there is some probability of either type of error. When evaluating abnormal events, we assign a nominal HEP of .001 to those tasks for which the tables or text indicate that the HEP is "negligible" under normal conditions. The nominal HEP of .001 allows for the effects of stress that are associated with abnormal events.

Most of the tables list the EFs or UCBs for the HEPs. For cases in which the EFs or UCBs are not listed, Table 20-20 presents guidelines for estimating them. In the course of an SA, the nominal HEP for some task may change significantly as different assumptions are evaluated. Note that the EFs may change when a nominal HEP is changed; for example, under certain assumptions, some task may have a tabled HEP of, say, .008, with an EF of 3. If the assumptions are modified so that the HEP is doubled (to .016), the EF would change frow 3 to 5 (see the second and third items in Table 20-20). Also remember that stress and other PSFs may increase the EFs, as indicated in Table 20-20. 
Figure 20-2

Screening $\left[\begin{array}{l}\text { Diagnosis } 1 \\ \text { Rule-Based Actions } 2\end{array}\right.$

Diagnosis

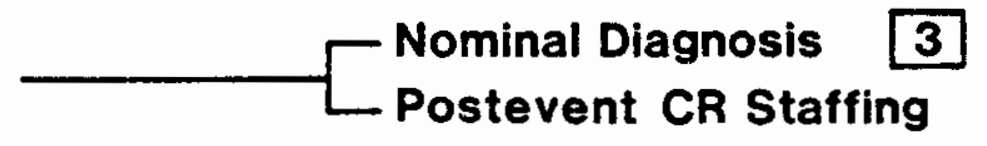

4

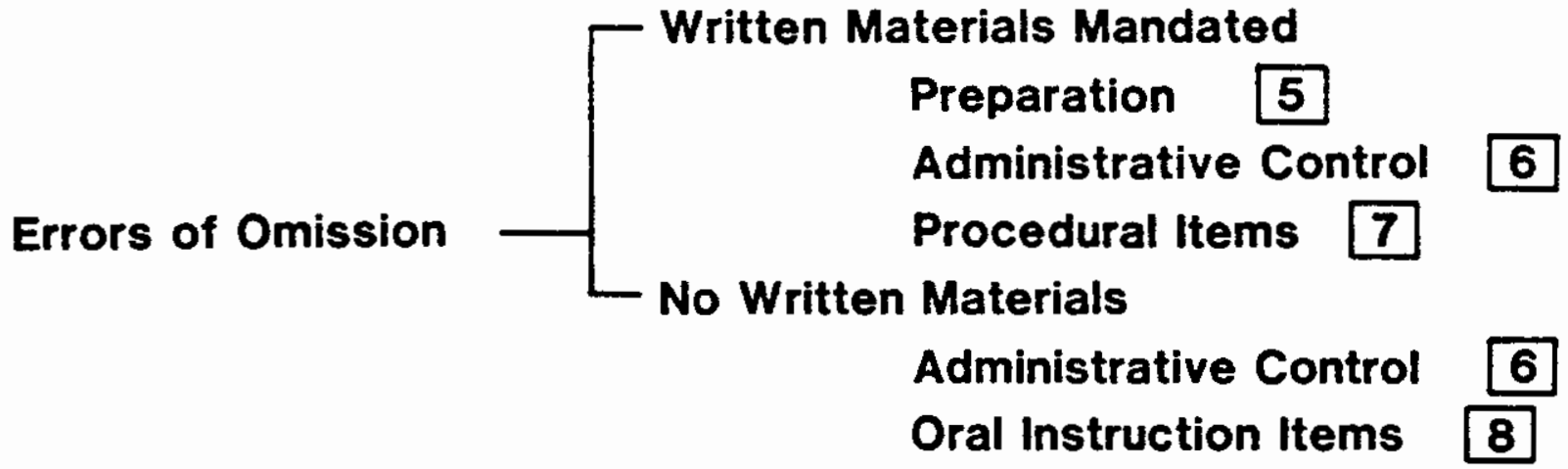

Displays Display Selection 9

Read/Record Quantitative 10

Errors of Commission Check-Read Quantitative 11

- Control \& MOV Selection \& Use 12

- Locally Operated Valves

Valve Selection 13

Stuck Valve Detection 14

PSFs $1 \begin{aligned} & \text { Tagging Levels } 15 \\ & \text { Stress/Experience } 16 \\ & \text { Dependence } 17 \\ & \text { Other PSFs (see text) }\end{aligned}$

Uncertainty Bounds - Estimate UCBs 20

Recovery Factors $-\left[\begin{array}{l}\text { Errors by Checker } \\ \text { Annunciated Cues } 22 \\ \text { Control Room Scanning } \\ \text { Basic Walk-Around Inspection }\end{array}\right.$

Figure 20-2 Quick reference guide to Chapter 20 tables. 
For record-keeping convenience in an HRA, the left-most column for most of the tables is headed by the word, "Item." In keeping a record of which tabled entries are used in an HRA, reference can be made to a particular table and item number, e.g., T20-1, \#1. In some of the tables, e.g., Table 20-8, it is convenient to use small letters to designate separate columns of estimated HEPs. For example, in Table 20-8, Item 1 a refers to the HEP of $.001(E F=3)$, which is the top listing in the first column of HEPs. Record keeping for an HRA is illustrated in the first case study in Chapter 21 . 
THIS PAGE INTENTIONALLY LEFT BLANK 
Table 20-1 Initial-screening model of estimated HEPs and EFS for diagnosis within time $T$ by control room personnel of abnormal events annunciated closely in time (from Table 12-2)

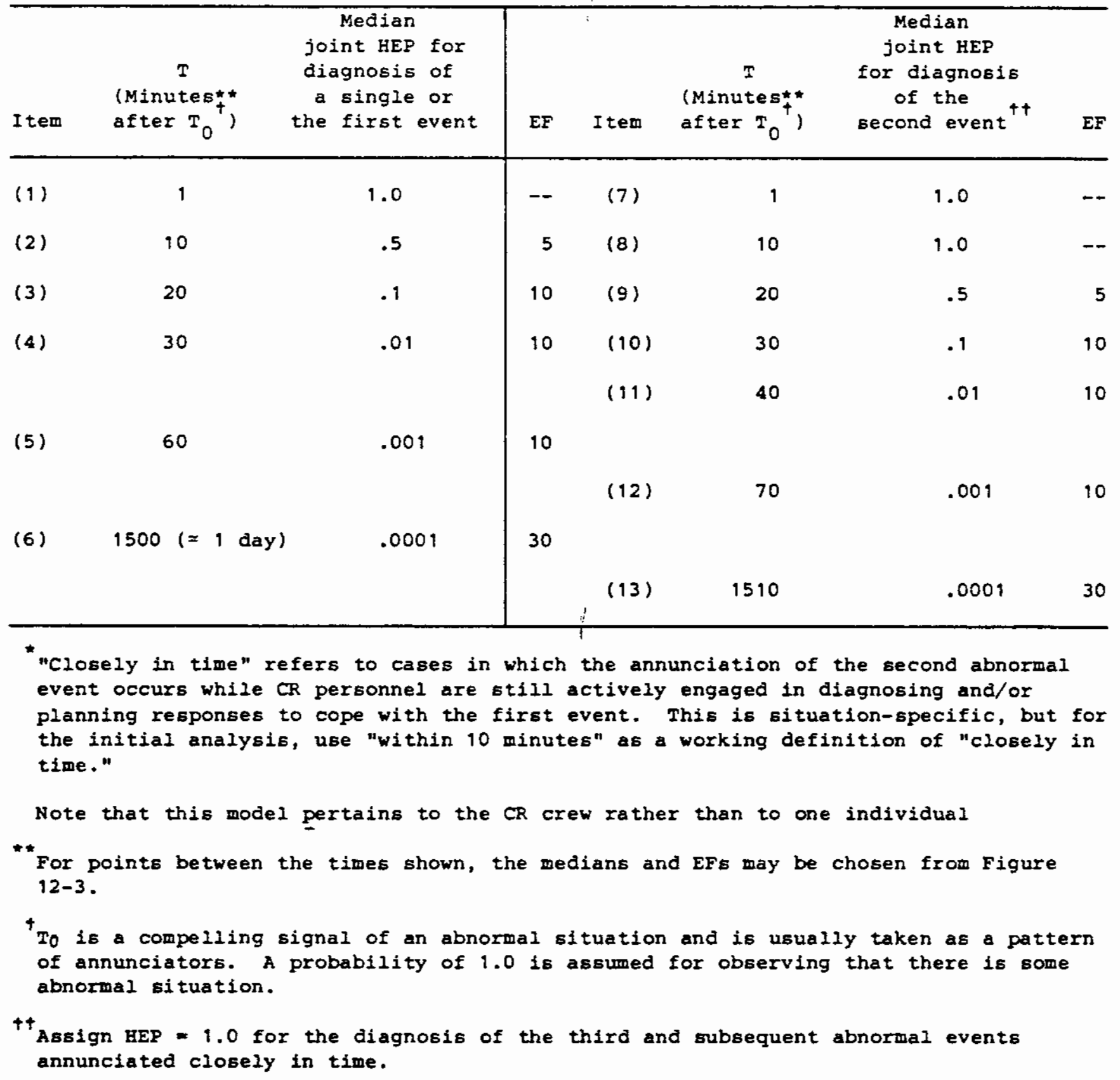


Table 20-2 Initial-screening model of estimated HEPs and EFS for rule-based actions by control room personnel after diagnosis of an abnormal event* (from Table 12-3)

\begin{tabular}{lllll}
\hline Item & Potential Errors & HEP & EF \\
\hline
\end{tabular}

Failure to perform ruze-based actions correctly when written procedures are available and used:

(1)

(2)

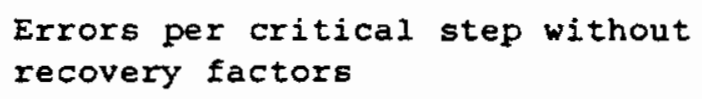

Failure to perform rule-based actions correctly when written procedures are not available or used:

$$
\begin{aligned}
& \text { Errors per critical step with or } \\
& \text { without recovery factors }
\end{aligned}
$$

1.0

*

Note that this model pertains to the $\mathrm{CR}$ crew rather than to one individual. 


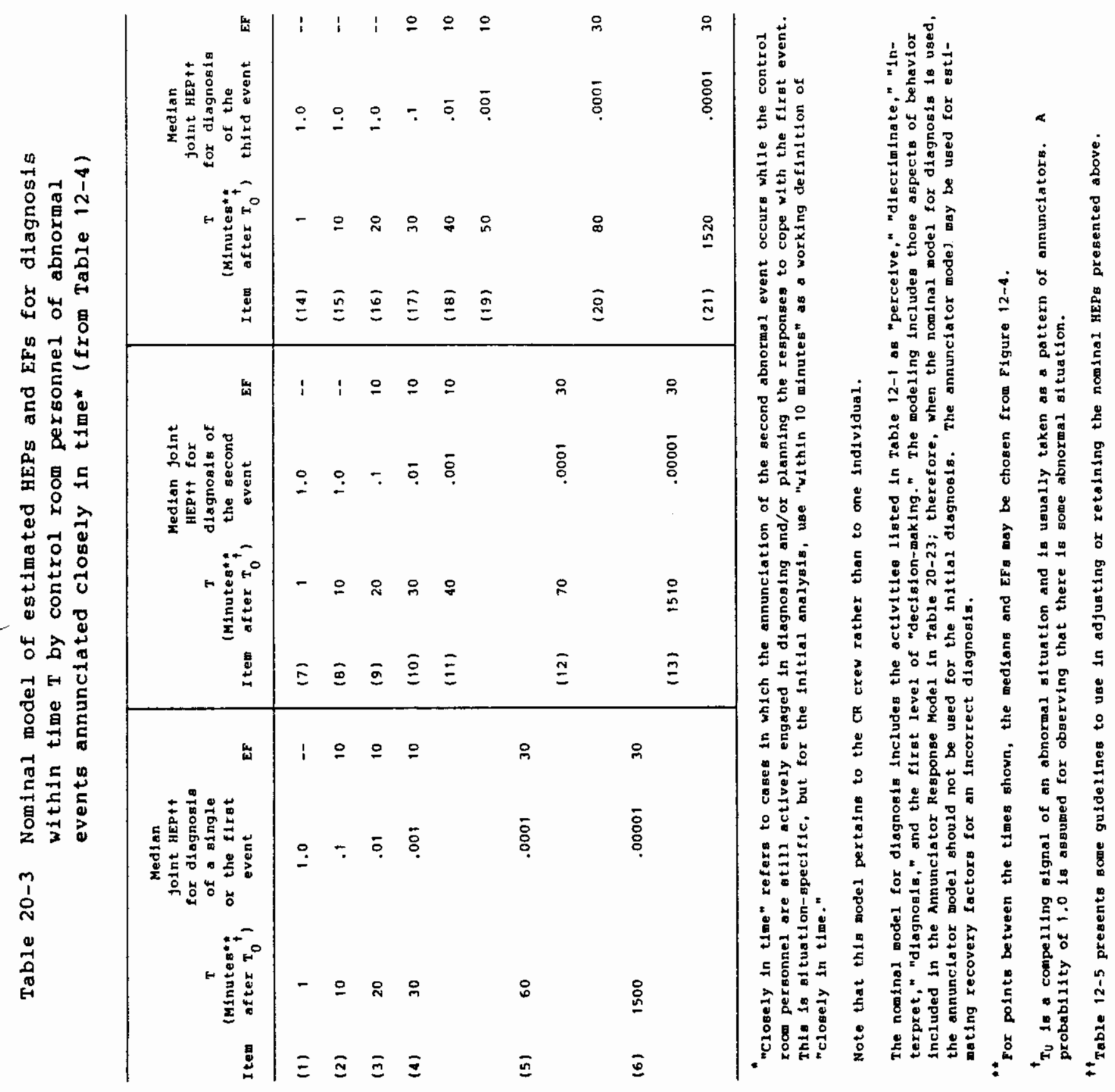


Table 20-4 Number of reactor operators and advisors available to cope with an abnormal event and their related leveis of dependence: assumptions for PRA* (from Table 18-2)

\section{Time after recognition* of an abnormal event}

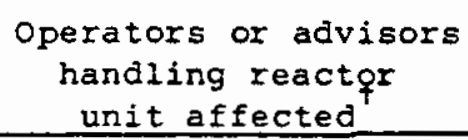

\section{Dependence levels \\ with others ${ }^{+t}$}

Item

(1)

(2)

(3)

(4)
0 to 1 minute

at 1 minute

at 5 minutes

at 15 minutes

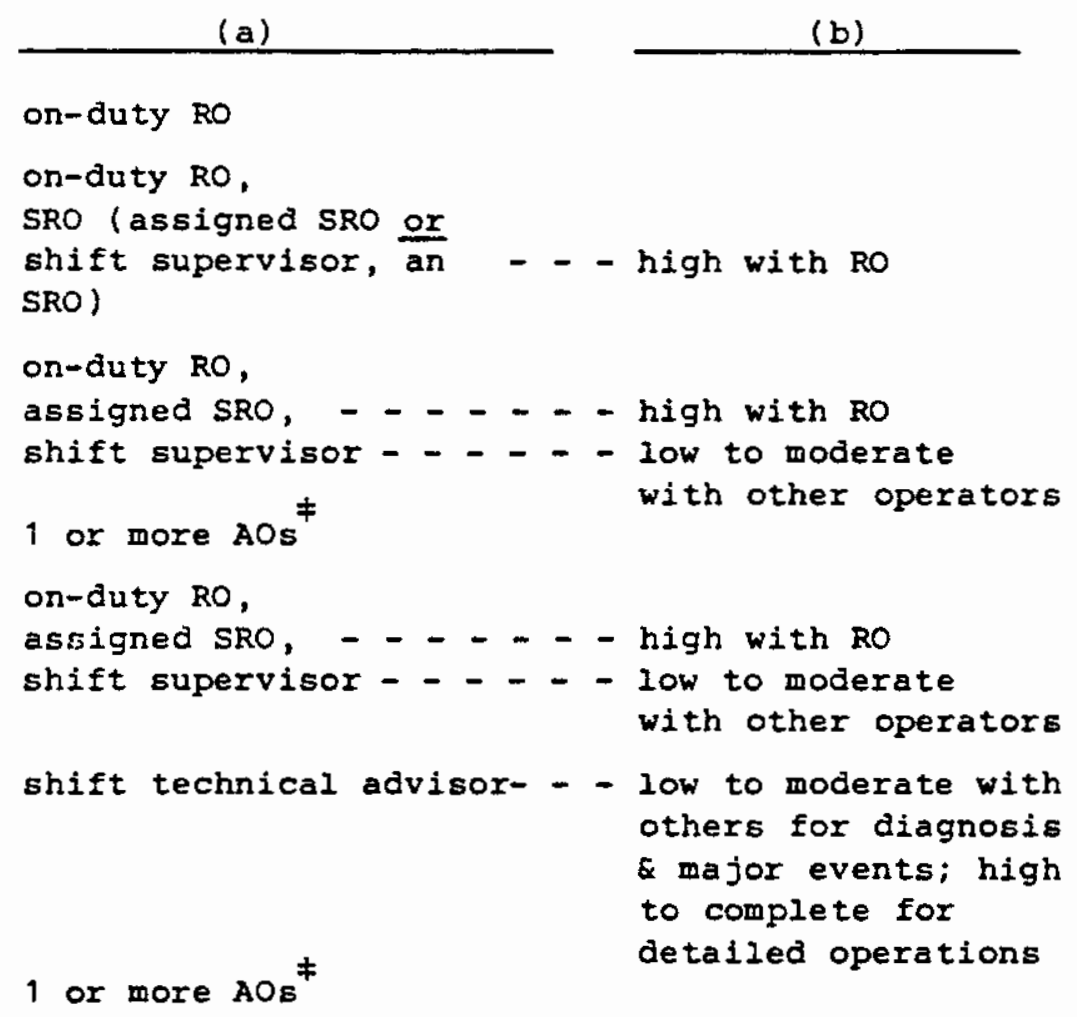


Table 20-5 Estimated HEP per item (or perceptual unit) in preparation of written material* (from Table 15-2)

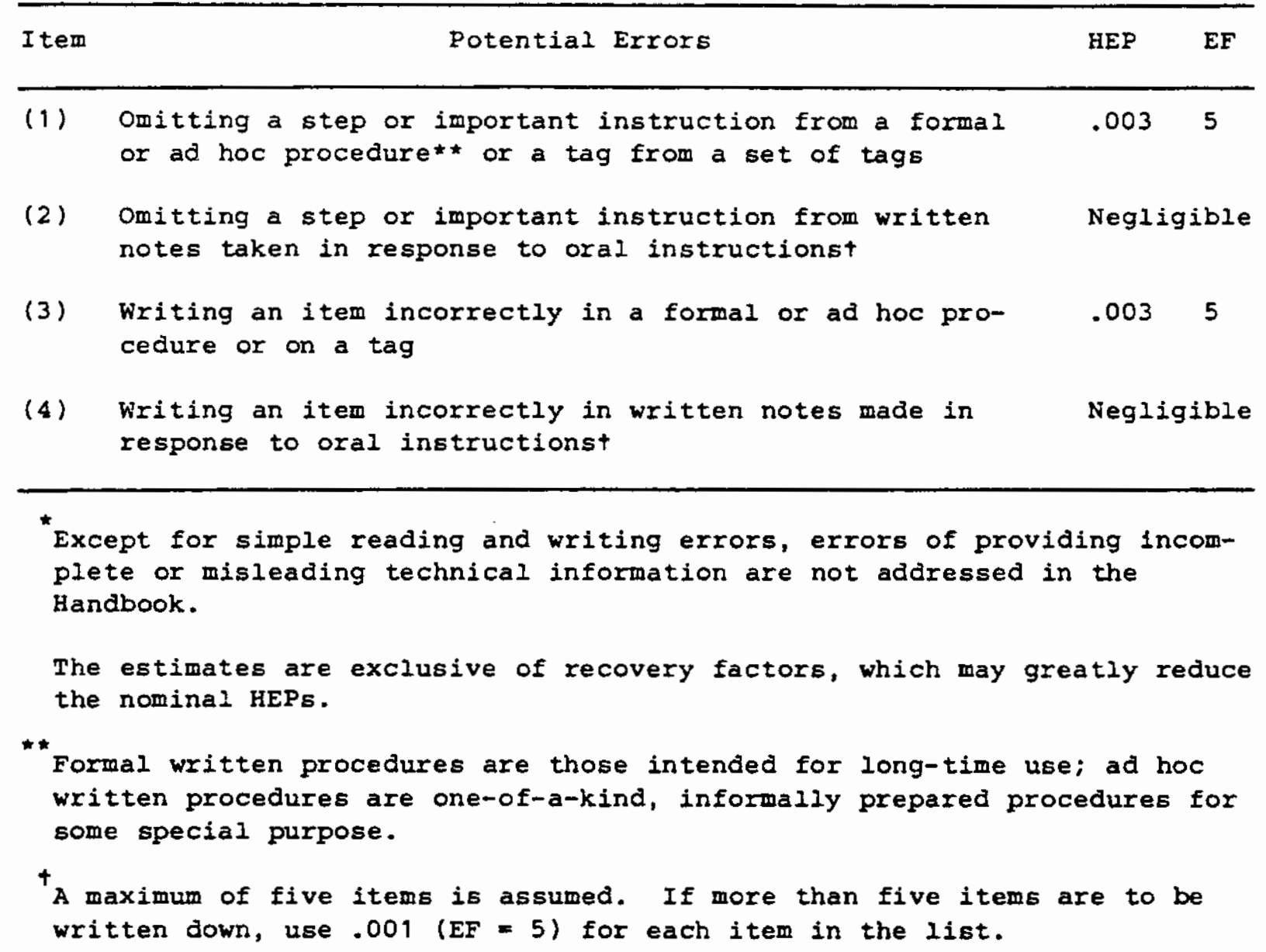


Table 20-6 Estimated HEPs relatea to failure of

administrative control (from Table 16-1)

\begin{tabular}{llll}
\hline Item & \multicolumn{1}{c}{ Task } & HEP & EF \\
\hline (1) & $\begin{array}{l}\text { Carry out a plant policy or scheduled tasks } \\
\text { such as periodic tests or maintenance per- } \\
\text { formed weekly, monthly, or at longer intervals }\end{array}$ & .01 & 5 \\
& $\begin{array}{l}\text { Initiate a scheduled shiftly checking or } \\
\text { inspection function* }\end{array}$ & .001 & 3 \\
(2) & Use written operations procedures under & & \\
& $\quad$ normal operating conditions & .01 & 3 \\
(3) & abnormal operating conditions & .005 & 10 \\
(4) & Use a valve change or restoration list & .01 & 3 \\
(5) & Use written test or calibration procedures & .05 & 5 \\
(7) & Use written maintenance procedures & .3 & 5 \\
(8) & Use a checklist properly* & .5 & 5 \\
\hline
\end{tabular}

\footnotetext{
*Assumptions for the periodicity and type of control room scans are discussed in Chapter 11 in the section, "A General Display Scanning Mode1." Assumptions for the periodicity of the basic walk-around inspection are discussed in Chapter 19 in the section, "Basic WalkAround Inspection."

$\star \star$

Read a single item, perform the task, check off the item on the list. For any item in which a display reading or other entry must be written, assume correct use of the checklist for that item.
} 
THERP

Table 20-7 Estimated probabilities of errors of omission per item of instruction when use of written procedures is specified* (from Table 15-3)

Item*

Omission of item:

HEP

EF

When procedures with checkoff, provisions are correctly used ${ }^{\dagger}$ :

(1)

$$
\begin{aligned}
& \text { Short list, }<10 \text { items } \\
& \text { Long list, }>10 \text { items }
\end{aligned}
$$$$
.0013
$$

When procedures without checkoff provisions are used, or when checkoff provisions are incorrectly used ${ }^{t+}$ :

$$
\begin{aligned}
& \text { Short list, } \leqslant 10 \text { items } \\
& \text { Long list, }>10 \text { items } \\
& \text { When written procedures are avail- } \\
& \text { able and should be used but are not used }
\end{aligned}
$$

$\begin{array}{ll}.003 & 3 \\ .01 & 3 \\ .05^{*} & 5\end{array}$

$\star$

The estimates for each item (or perceptual unit) presume zero dependence among the items (or units) and must be modified by using the dependence model when a nonzero level of dependence is assumed.

**

"The term "item" for this column is the usual designator for tabled entries and does not refer to an item of instruction in a procedure.

tCorrect use of checkoff provisions is assumed for items in which written entries such as numerical values are required of the user.

${ }^{+t}$ Table 20-6 lists the estimated probabilities of incorrect use of checkoff provisions and of nonuse of available written procedures.

"If the task is judged to be "second nature," use the lower uncertainty bound for .05, i.e., use .01 (EF $=5$ ). 
Table 20-8 Estimated probabilities of errors in recalling oral instruction items not written down* (from Table 15-1)

HEPs as a function of number of items to be remembered**

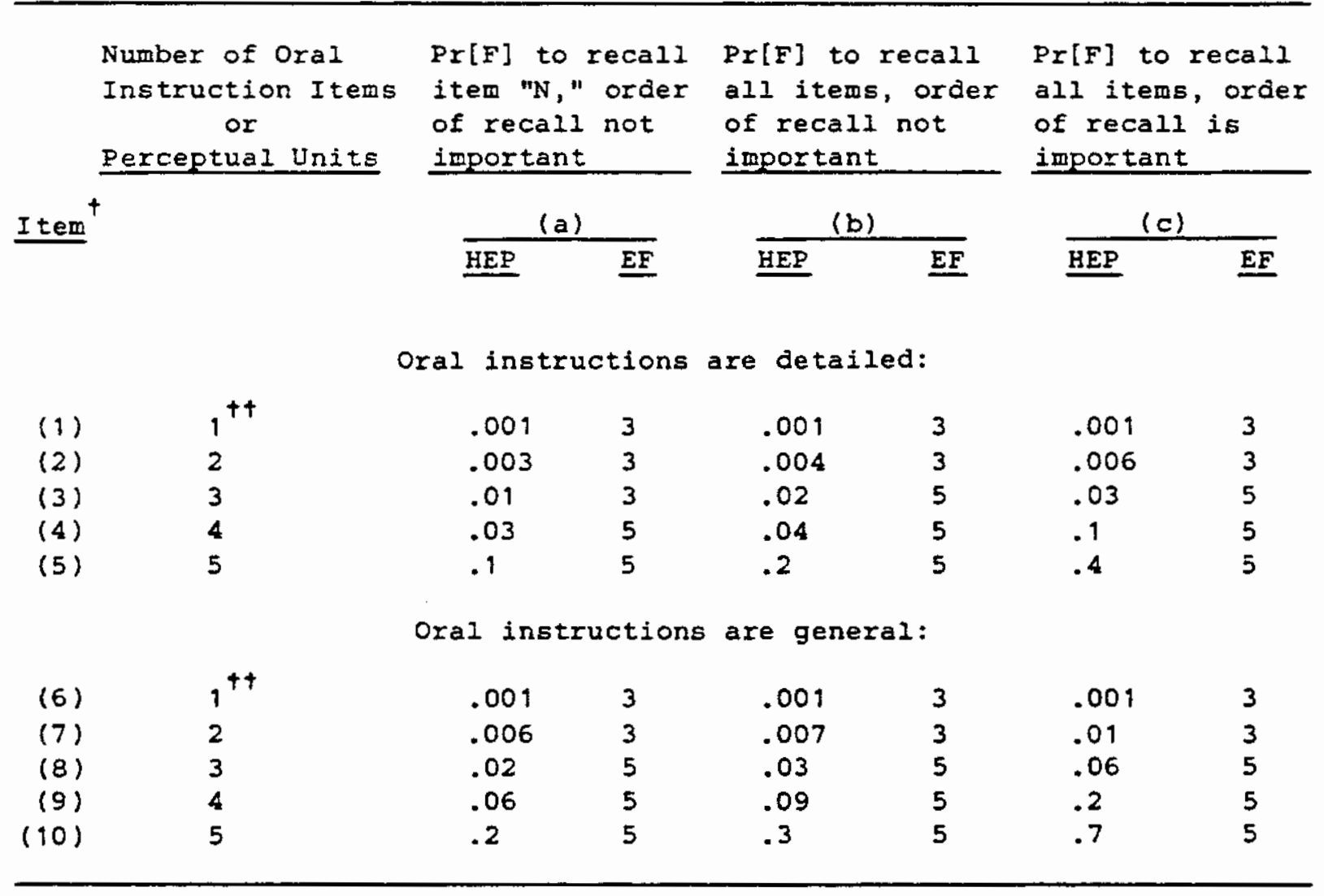

*It is assumed that if more than five oral instruction items or perceptual units are to be remembered, the recipient will write them down. If oral instructions are written down, use Table 20-5 for errors in preparation of written procedures and Table 20-7 for errors in their use.

* The first column of HEPs (a) is for individual oral instruction items, e.9., the second entry, .003 (item 2a), is the Px[F] to recall the second of two items, given that one item was recalled, and order is not important. The HEPs in the other columns for two or more oral instruction items are joint HEPs, e.g., the .004 in the second column of HEPs is the Pr[F] to recall both of two items to be remembered, when order is not important. The .006 in the third column of HEPs is the Pr[F] to recall both of two items to be remembered in the order of performance specified. For all columns, the EFs are taken from Table 20-20 as explained in Chapter 15.

the term "item" for this column is the usual designator for tabled entries and does not refer to an oral instruction item.

tThe Pr[F]s in rows 1 and 6 are the same as the Pr[F] to initiate the task. 
Table 20-9 Estimated probabilities of errors in selecting unannunciated displays for quantitative or qualitative readings (from Table 11-2)

(4)

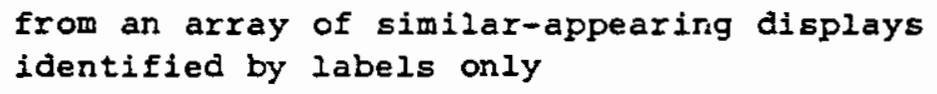

$\star$

The listed HEPs are independent of recovery factors. In some cases, the content of the quantitative or qualitative indication from an incorrect display may provide immediate feedback of the selection error, and the total exror can be assessed as negligible.

$\star \star$

This assumes the operator knows the characteristics of the display for which he is searching. 
THERP

Table 20-10 Estimated HEPs for errors of commission in reading and recording quantitative information from unannunciated displays (from Table 11-3)

\begin{tabular}{|c|c|c|c|}
\hline I tem & Display or Task & HEP * & $\underline{E F}$ \\
\hline (1) & Analog meter & .003 & 3 \\
\hline (2) & Digital readout ( $<4$ digits) & .001 & 3 \\
\hline (3) & Chart recorder & .006 & 3 \\
\hline (4) & $\begin{array}{l}\text { Printing recorder with large } \\
\text { number of parameters }\end{array}$ & .05 & 5 \\
\hline (5) & Graphs & .01 & 3 \\
\hline$(6)$ & $\begin{array}{l}\text { Values from indicator lamps } \\
\text { that are used as quanti- } \\
\text { tative displays }\end{array}$ & .009 & 3 \\
\hline (7) & $\begin{array}{l}\text { Recognize that an instrument } \\
\text { being read is jammed, if } \\
\text { there are no indicators } \\
\text { to alert the user }\end{array}$ & .1 & 5 \\
\hline & $\begin{array}{l}\text { Recording task: Number of } \\
\text { digits or letters* to be } \\
\text { recorded }\end{array}$ & & \\
\hline$(8)$ & $<3$ & Negligible & - \\
\hline (9) & $>3$ & $\begin{array}{r}.001 \text { (per } \\
\text { symbol) }\end{array}$ & 3 \\
\hline$(10)$ & $\begin{array}{l}\text { Simple arithmetic calcula- } \\
\text { tions with or without } \\
\text { calculators }\end{array}$ & .01 & 3 \\
\hline$(11)$ & $\begin{array}{l}\text { Detect out-of-range } \\
\text { arithmetic calculations }\end{array}$ & .05 & 5 \\
\hline
\end{tabular}

*Multiply HEPs by 10 for reading quantitative values under a high level of stress if the design violates a strong populational stereotype; e.g., a horizontal analog meter in which values increase from right to left.

"In this case, "letters" refer to those that convey no meaning. Groups of letters such as MOV do convey meaning, and the recording HEP is considered to be negligible. 
TTHERP

Table 20-11 Estimated HEPs for errors of commission in check-reading displays* (from Table 11-4)

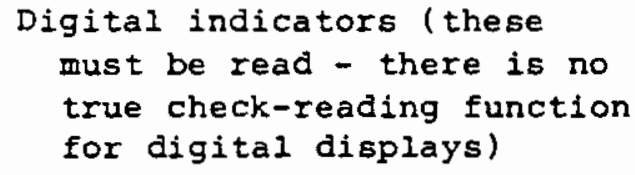
true check-reading function for digital displays)

Analog meters:

$\begin{array}{lll}\text { with easily seen limit marks } & .001 & 3 \\ \begin{array}{l}\text { with difficult-to-see limit } \\ \text { marks, such as scribe lines }\end{array} & .002 & 3 \\ \text { without limit marks } & .003 & 3\end{array}$

Analog-type chart recorders:

$\begin{array}{lll}\text { with limit marks } & .002 & 3 \\ \text { without limit marks } & .006 & 3\end{array}$

Confirming a status change Negligible** on a status lamp

Misinterpreting the indication on the indicator lamps

Negligible ${ }^{+}$

\footnotetext{
"Check-reading" means reference to a display merely to see if the indication is within allowable limits; no quantitative reading is taken. The check-reading may be done from memory or a written checklist may be used. The HEPs apply to displays that are checked individually for some specific purpose, such as a scheduled requirement, or in response to some developing situation involving that display. 
THERP

Table 20-12 Estimated probabilities of errors of commission in operating manual controls* (from Table 13-3)

\begin{tabular}{|c|c|c|c|}
\hline I tem & Potential Errors & HEP & EF \\
\hline (1) & $\begin{array}{l}\text { Inadvertent activation of a control } \\
\text { select wrong control on a panel from an array of } \\
\text { similar-appearing controls**: }\end{array}$ & see text, & Ch. 13 \\
\hline (2) & identified by labels only & .003 & 3 \\
\hline (3) & arranged in weli-delineated functional groups & .001 & 3 \\
\hline (4) & $\begin{array}{l}\text { which are part of a well-defined mimfc layout } \\
\text { Turn rotary control in wrong direction (for two- } \\
\text { position switches, see } 1 \text { tem } 8 \text { ): }\end{array}$ & .0005 & 10 \\
\hline (5) & $\begin{array}{l}\text { when there is no violation of populational } \\
\text { stereotypes }\end{array}$ & .0005 & 10 \\
\hline$(6)$ & $\begin{array}{l}\text { when design violates a strong populational } \\
\text { stereotype and operating conditions are } \\
\text { normal }\end{array}$ & .05 & 5 \\
\hline (7) & $\begin{array}{l}\text { when design violates a strong populational } \\
\text { stereotype and operation is under high } \\
\text { stress }\end{array}$ & .5 & 5 \\
\hline (8) & $\begin{array}{l}\text { Turn a two-position switch in wrong direction or } \\
\text { leave it in the wrong betting }\end{array}$ & + & \\
\hline (9) & $\begin{array}{l}\text { Set a rotary control to an incorrect setting } \\
\text { (for two-position switches, see item 8) }\end{array}$ & .001 & $10^{+t}$ \\
\hline$(10)$ & $\begin{array}{l}\text { Failure to complete change of state of a } \\
\text { component if switch must be held until change } \\
\text { is completed }\end{array}$ & .003 & 3 \\
\hline & $\begin{array}{l}\text { Select wrong circuit breaker in a group of } \\
\text { circuit breakers*t: }\end{array}$ & & \\
\hline (11) & densely grouped and identified by labels only & .005 & 3 \\
\hline (12) & $\begin{array}{l}\text { in which the PSFs are more favorable } \\
\text { (see Ch. 13) }\end{array}$ & .003 & 3 \\
\hline (13) & $\begin{array}{l}\text { Improperly mate a connector (this includes } \\
\text { failures to seat connectors completely and } \\
\text { fallure to test locking features of connectors } \\
\text { for engagement) }\end{array}$ & .003 & 3 \\
\hline
\end{tabular}

\footnotetext{
The HEPs axe for errors of comission only and do not include any errors of decision as to which controls to activate.

- If controls or circuit breakers are to be restored and are tagged, adjust the tabled HEPs according to rable 20-15.

tDivide HEPs for rotary controls (1tems 5-7) by 5 (use same EFs). $++$

This error is a function of the elarity with which indicator position can be determined: designs of control knobs and thetr position indications vary greatly. For plant-specific anelyses, an EF of 3 may be used.
} 
THERP

Table 20-13 Estimated HEPs for selection errors for locally operated valves (from Table 14-1)

Item Potential Errors

HEP EF

Making an error of selection in changing or restoring a locally operated valve when the valve to be manipulated is

(1) Clearly and unambiguously labeled, set apart .001 3 from valves that are similar in all of the following: size and shape, state, and presence of tags*

(2) Clearly and unambiguously labeled, part of $.003 \quad 3$ a group of two or more valves that are similar in one of the following: size and shape, state, or presence of tags*

(3) Unclearly or ambiguously labeled, set apart .005 3 from valves that are similar in all of the following: size and shape, state, and presence of tags*

(4) Unclearly or ambiguously labeled, part of a .0083 group of two or more valves that are similar in one of the following: size and shape, state, or presence of tags*

(5) Unclearly or ambiguously labeled, part of a $.01 \quad 3$ group of two or more valves that are similar in all of the following: size and shape, state, and presence of tags*

*Unless otherwise specified, Level 2 tagging is presumed. If other levels of tagging are assessed, adjust the tabled HEPs according to Table 20-15. 


\section{THERP}

Table 20-14 Estimated HEPs in detecting stuck locally operated valves (from Table 14-2)

Given that a locally operated valve sticks as it is being changed or restored, the operator fails to notice the sticking valve, when it has

A position indicator* only .0013

A position indicator* and a rising stem .0023

A rising stem but no position indicator** $.005 \quad 3$

\footnotetext{
*Equipment reliability specialists have estimated that the probability of a valve's sticking in this manner is approximately .001 per manipulation, with an error factor of 10 . $\star \star$

A position indicator incorporates a scale that indicates the position of the valve relative to a fully opened or fully closed position. A rising stem qualifies as a position indicator if there is a scale associated with it.
} 
Modifications

to Nominal

Level

Description

HEPS *

1 A specific number of tags is issued for each job Each tag is numbered or otherwise uniquely identified. A record is kept of each tag, and a record of each tag issued is entered in a suspense sheet that indicates the expected time of return of the tag; this suspense sheet is checked each shift by the shift supervisor. An operator is assigned the job of tagging controller as a primary duty. For restoram tion, the numbers on the removed tags are checked against the item numbers in the records, as a recovery factor for errors of omission or selection. OR The number of keys is carefully restricted and under direct control of the shift supervisor. A signout board is used for the keys. Keys in use are tagged out, and each incoming shift supervisor takes an inventory of the keys.

2 Tags are not accounted for individually--the operator

Use nominal HEPs may take an unspecified number and use them as required. In such a case, the number of tags in his possession does not provide any cues as to the number of items remaining to be tagged. For restoration, the record keeping does not provide a thorough checking for errors of omission or selection. If an operator is assigned as tagging controller, it is a collateral duty, or the position is rotated among operators too frequently for them to maintain adequate control tags and records and to retain skill in detecting errors of omission or selection. OR The shift supervisor retains control of the keys and records their issuance but does not use visual aids such as signout boards or tags.

3 Tags are used, but record keeping is inadequate to Use upper UCBs provide the shift supervisor with positive knowledge of every item of equipment that should be tagged or restored. No tagging controller is assigned. OR Keys are generally available to users without logging requirements.

4 No tagging system exists. OR No locks and keys are used.

Perform separate analysis

\footnotetext{
"The nominal HEPs are those in the Handbook that relate to tasks involving the application and removal of tags and, unless otherwise specified, are based on Level 2 tagging.
} 


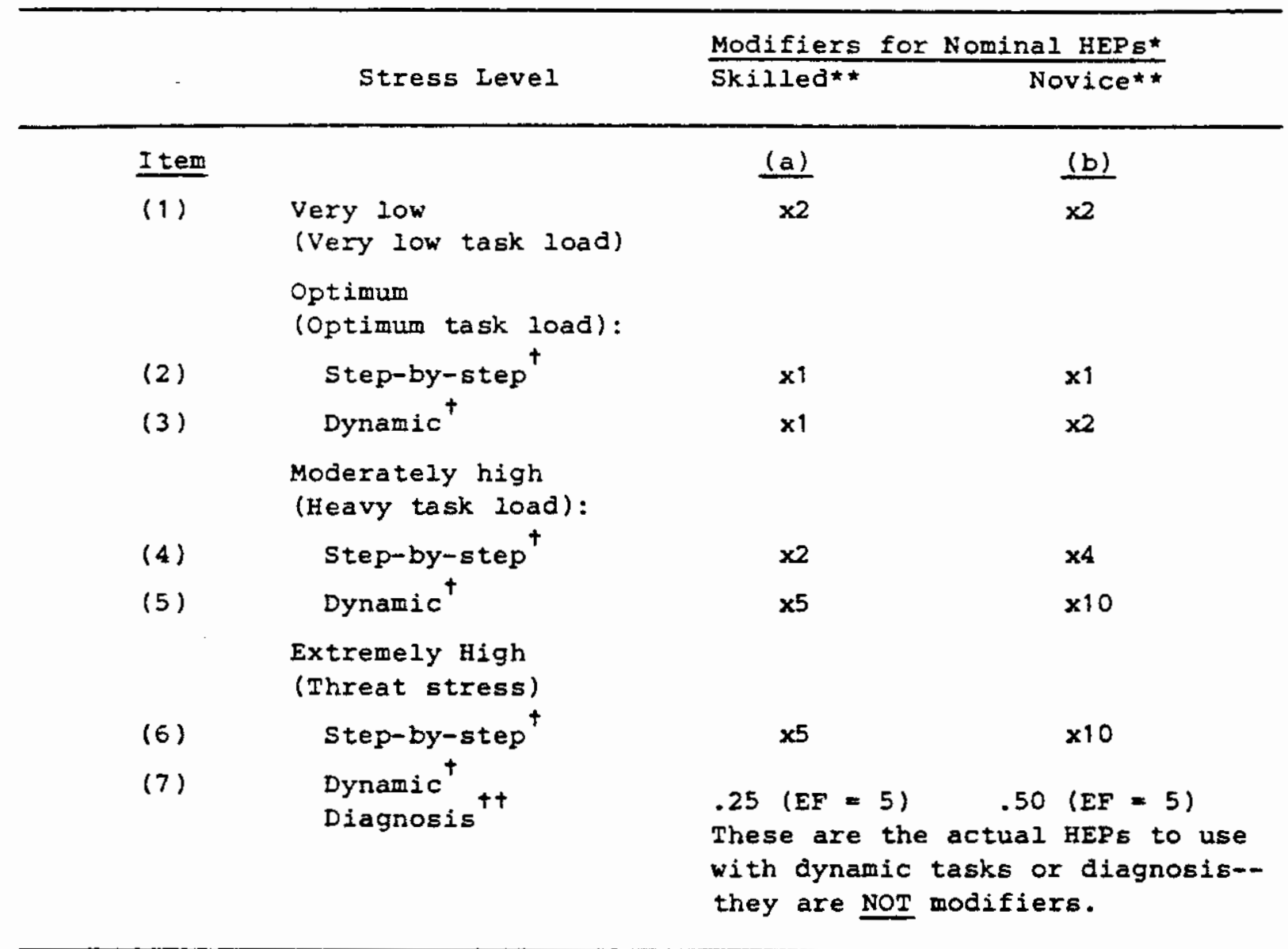

The nominal HEPs are those in the data tables in Part III and in Chapter 20. Error factors (EFs) are listed in Table 20-20. **

A skilled person is one with 6 months or more experience in the tasks being assessed. A novice is one with less than 6 months or more experience. Both levels have the required licensing or certificates.

$+$

${ }^{\dagger}$ step-by-step tasks are routine, procedurally guided tasks, such as carrying out written calibration procedures. Dynamic tasks require a higher degree of man-machine interaction, such as decision-making, keeping track of several functions, controlling several functions, or any combination of these. These requirements are the basis of the distinction between step-by-step tasks and dynamic tasks, which are often involved in responding to an abnormal event.

${ }^{t+}$ Diagnosis may be carried out under varying degrees of stress, ranging from optimum to extremely high (threat stress). For threat stress, the HEP of .25 is used to estimate performance of an individual. Ordinarily, more than one person will be involved. Tables 20-1 and 20-3 list joint HEPs based on the number of control room personnel presumed to be involved in the diagnosis of an abnormal event for various times after annunciation of the event, and their presumed dependence levels, as presented in the staffing model in Table 20-4. 


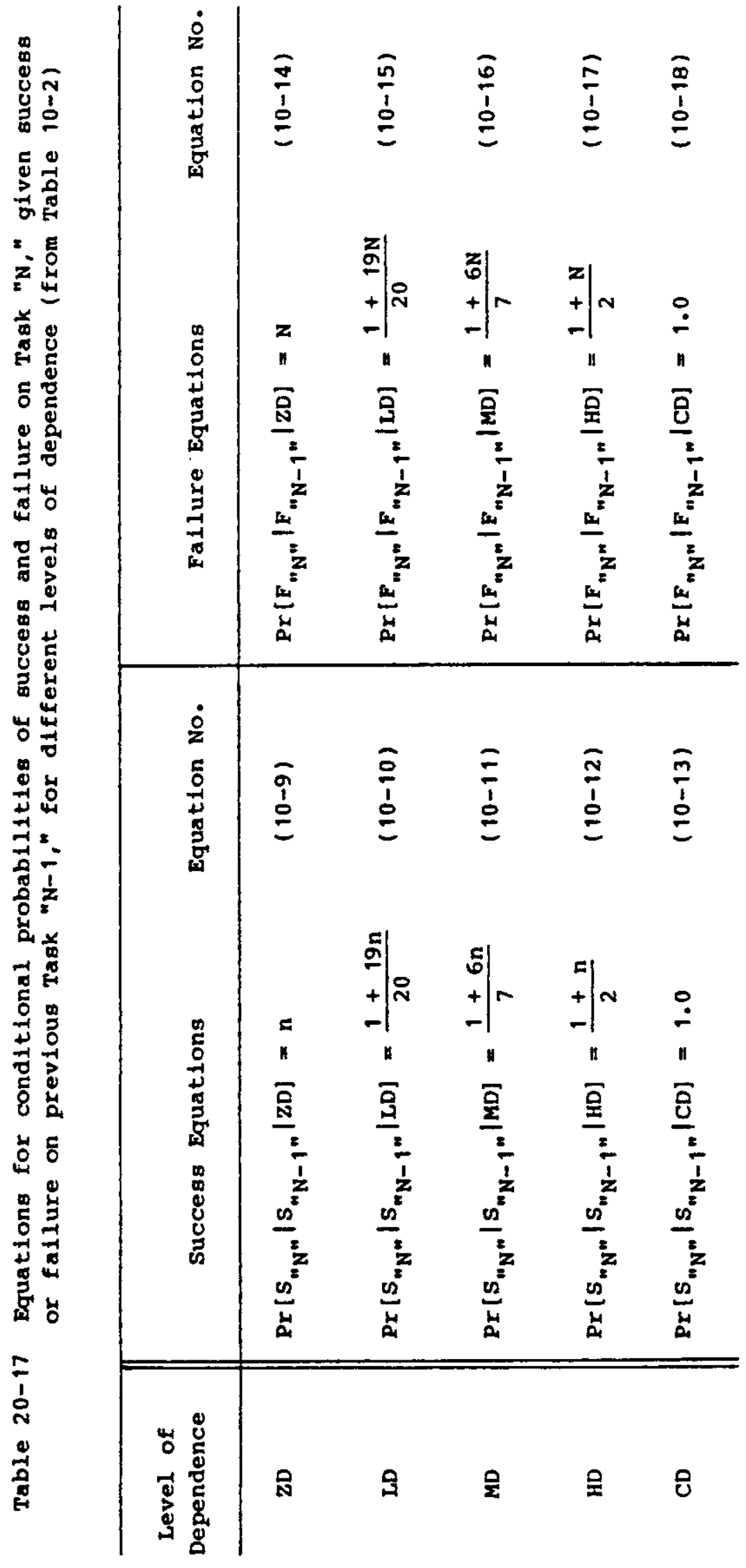


18

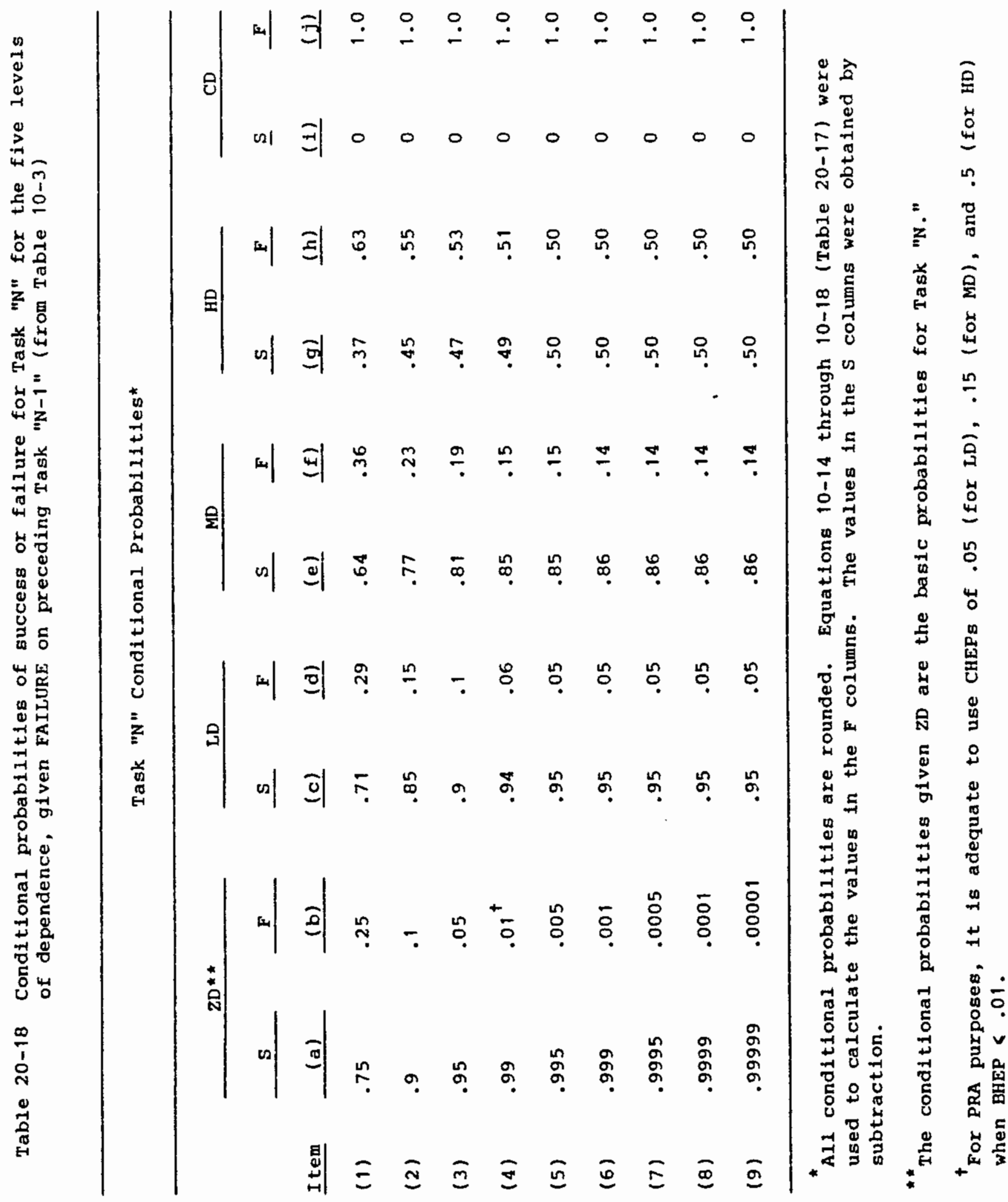




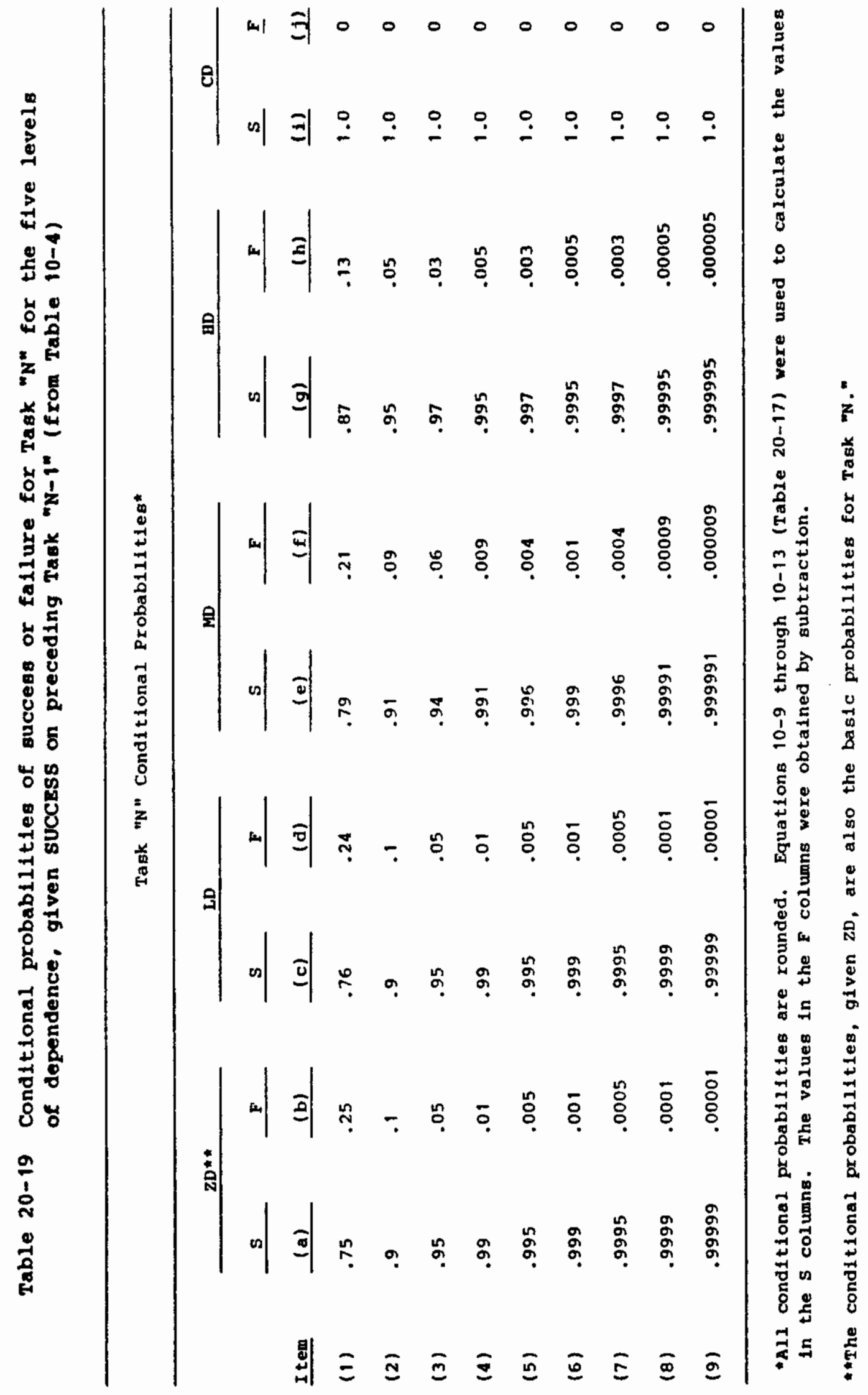


Table 20-20 General guidelines for estimating uncertainty bounds for estimated HEPs* (from Table 7-2)

Item Task and HEP Guidelines* EF $^{\dagger}$

Task consists of performance of step-by-step procedure ${ }^{+\dagger}$ conducted under routine circumstances (e.g., a test, maintenance, or calibration task); stress level is optimal:

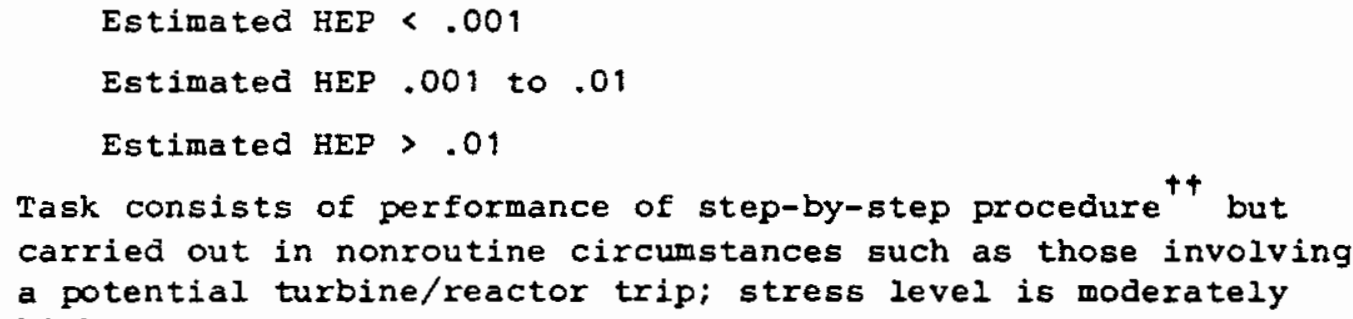

Estimated HEP > .01

Task consists of performance of step-by-step procedure ${ }^{+t^{+}}$but carried out in nonroutine circumstances such as those involving a potential turbine/reactor trip; stress level is moderately high:

$$
\text { Estimated HEP }<.001
$$

Task consists of relatively dynamic ${ }^{+\dagger}$ interplay between operator and system indications, under routine conditions, e.g., increasing or reducing power; stress level is optimal

$$
\begin{aligned}
& \text { Estimated HEP < .001 } \\
& \text { Estimated HEP > .001 } \\
& \text { Task consists of relatively dynamic }{ }^{++} \text {interplay between operator } \\
& \text { and system indications but carried out in nonroutine circum- } \\
& \text { stances; stress level is moderately high } \\
& \text { Any task performed under extremely high stress conditions, } \\
& \text { e.g., large LocA; conditions in which the status of EsFs is not } \\
& \text { perfectly clear; or conditions in which the initial operator } \\
& \text { responses have proved to be inadequate and now severe time } \\
& \text { pressure is felt (see Ch. } 7 \text { for rationale for EF = 5) }
\end{aligned}
$$

\footnotetext{
* The estimates in this table apply to experienced personnel. The performance of novices is discussed in Chapter 18.

**For UCBs for HEPs based on the dependence model, see Table 20-21.

the highest upper bound is 1.0 .

See Appendix A to calculate the UCBs for Pr[F $F_{T}$, the total-failure term of an HRA event tree.

${ }^{+t}$ See Table 20-16 for definitions of step-by-step and dynamic procedures.
} 
Table 20-21 Approximate CHEPs and their UCBs for dependence levels* given FAILURE on the preceding task (from Table 7-3)

\begin{tabular}{|c|c|c|c|c|}
\hline & $\begin{array}{c}\text { Levels } \\
\text { of } \\
\text { Dependence }\end{array}$ & \multicolumn{2}{|r|}{ BHEPS } & \multirow[b]{2}{*}{ (c) } \\
\hline Item & & (a) & (b) & \\
\hline \multirow[t]{3}{*}{ (1) } & $Z D * *$ & $\begin{array}{l}6.01 \\
(d) \\
\end{array}$ & $\begin{array}{c}.05 \quad(E F=5) \\
(e) \\
\end{array}$ & $\begin{array}{c}.1 \quad(E F=5) \\
(E) \\
\end{array}$ \\
\hline & & $.15(E F=5)$ & $.2 \quad(E F=5)$ & $.25 \quad(E F=5)$ \\
\hline & $\begin{array}{c}\text { Levels } \\
\text { of } \\
\text { Dependence }\end{array}$ & \multicolumn{3}{|c|}{ Nominal CHEPs and (Lower to Upper UCBs) ${ }^{\dagger}$} \\
\hline Item & & (a) & (b) & (c) \\
\hline (2) & LD & $.05(.015$ to .15$)$ & $.1(.04$ to .25$)$ & $.15(.05$ to .5$)$ \\
\hline (3) & $M D$ & $.15(.04$ to .5$)$ & $.19(.07$ to .53$)$ & .23 (.1 to .55$)$ \\
\hline (4) & $\mathrm{HD}$ & $.5(.25$ to 1.0$)$ & $.53(.28$ to 1.0$)$ & $.55(.3$ to 1.0$)$ \\
\hline (5) & $\mathrm{CD}$ & $\begin{array}{c}1.0 \quad(.5 \text { to } 1.0) \\
\text { (d) }\end{array}$ & $\begin{array}{c}1.0 \quad(.53 \text { to } 1.0) \\
(\mathrm{e}) \\
\end{array}$ & $\begin{array}{c}1.0(.55 \text { to } 1.0) \\
(f)\end{array}$ \\
\hline (2) & LD & $.19(.05$ to .75$)$ & $.24(.06$ to 1.0$)$ & $.29(.08$ to 1.0$)$ \\
\hline (3) & MD & $.27(.1$ to .75$)$ & $.31(.1$ to 9.0$)$ & $.36(.13$ to 1.0$)$ \\
\hline (4) & HD & $.58(.34$ to 1.0$)$ & $.6(.36$ to 1.0$)$ & $.63(.4$ to 1.0$)$ \\
\hline (5) & $C D$ & $1.0 \quad(.58$ to 1.0$)$ & $1.0(.6$ to 1.0$)$ & $1.0(.63$ to 1.0$)$ \\
\hline
\end{tabular}

*Values are rounded from calculations based on Appendix A. All values are based on skilled personnel (i.e., those with $>6$ months experience on the tasks being analyzed.

$\star *$

$Z D=$ BHEP. EFs for BHEPs should be based on Table 20-20.

Iinear interpolation between stated CHEPs (and UCBs) for values of BHEPG between those listed is adequate for most PRA studies. 
Table 20-22 Estimated probabilities that a checker will fail to detect errors made by others* (from Table 19-1)

\section{I tem}

Checking Operation

HEP EF

(1) Checking routine tasks, checker using written

15

materials (includes over-the-shoulder inspections, verifying position of locally operated valves, switches, circuit breakers, connectors, etc., and checking written lists, tags, or procedures for accuracy)

(2) Same as above, but without written materials

$\begin{array}{ll}.2 & 5 \\ .05 & 5 \\ .01 & 5 \\ .5 & 5\end{array}$

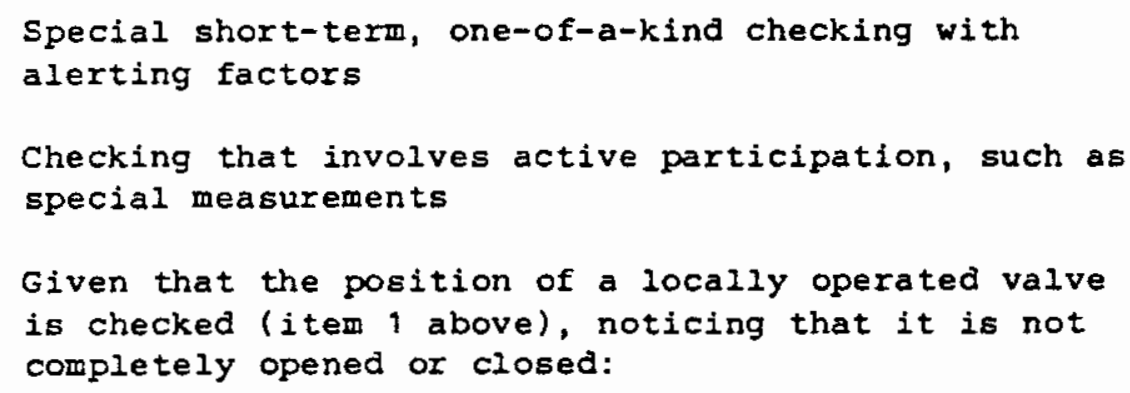

Given that the position of a locally operated valve
is checked (item 1 above), noticing that it is not completely opened or closed:

Checking that involves active participation, such as special measurements

\begin{tabular}{|c|c|}
\hline Position indicator** only & .1 \\
\hline Position indicator** and a rising stem & .5 \\
\hline Neither a position indicator* nor a rising stem & .9 \\
\hline $\begin{array}{l}\text { ecking by reader/checker of the task performer in } \\
\text { two-man team, or checking by a second checker, } \\
\text { utine task (no credit for more than } 2 \text { checkers) }\end{array}$ & .5 \\
\hline $\begin{array}{l}\text { ecking the status of equipment if that status } \\
\text { fects one's safety when performing his tasks }\end{array}$ & .001 \\
\hline $\begin{array}{l}\text { operator checks change or restoration tasks } \\
\text { cformed by a maintainer }\end{array}$ & $\begin{array}{l}\text { Above } \\
\text { HEPs } \\
\div 2\end{array}$ \\
\hline
\end{tabular}

*

This table applies to cases during normal operating conditions in which a person is directed to check the work performed by others either as the work is being performed or after its completion.

** A position indicator incorporates a scale that indicates the position of the valve relative to a fully opened or fully closed position. A rising stem qualifies as a position indicator if there is a scale associated with it. 


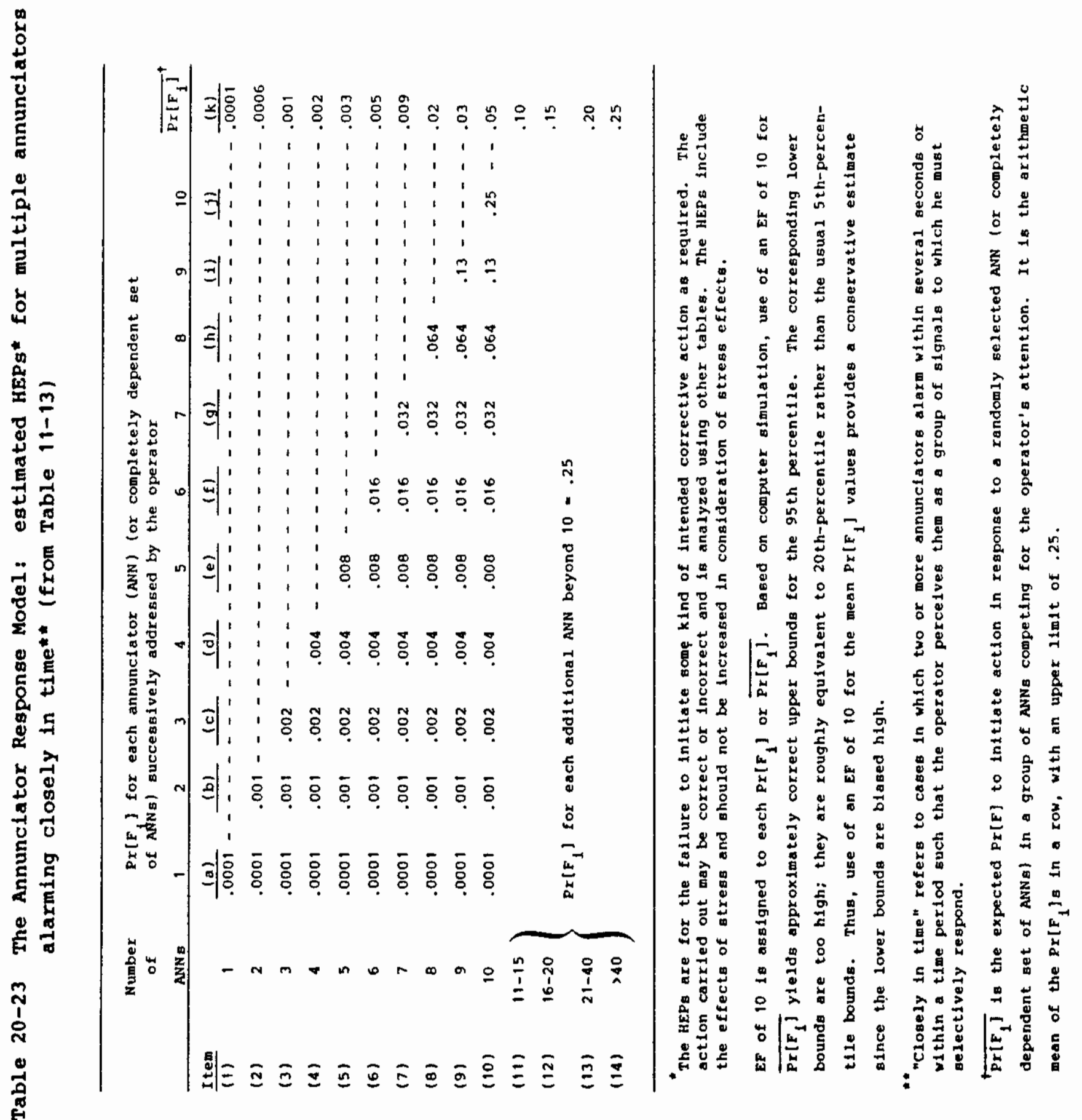


Table 20-24 Estimated HEPs for annunciated legend lights* (from Table 11-12)

Item Task HEP EF

(4)

$$
\text { Respond to a steady-on legend }
$$$$
.90
$$

Respond to a steady-on legend

\footnotetext{
*No written materials are used.

** "Respond" means to initiate some action in response to the indicator whether or not the action is correct. It does not include the initial acts of canceling the sound and the blinking; these are assumed to always occur.
} 
Table 20-25 Estimated probabilities of failure to detect one (of one) unannunciated deviant display* at each scan, when scanned hourly* (from Table 11-7)

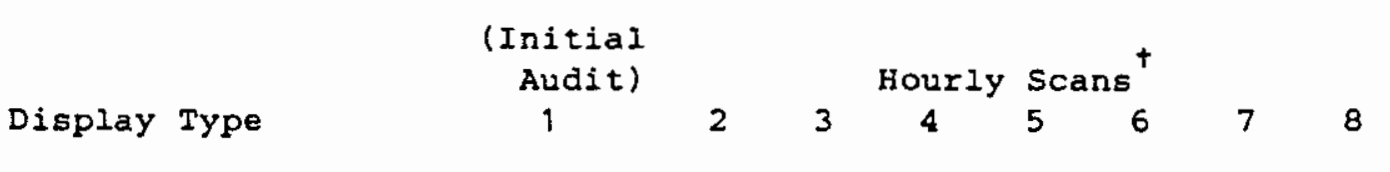

Analog meters:

with limit marks

without limit marks

6) Iegend light ${ }^{+t}$ other than annunciator ilght

Analog-type chart recorders:

$\begin{array}{llllllll}.05 & .31 & .50 & .64 & .74 & .81 & .86 & .90 \\ .15 & .47 & .67 & .80 & .87 & .92 & .95 & .97\end{array}$

$\begin{array}{llllllll}.10 & .40 & .61 & .74 & .83 & .89 & .92 & .95\end{array}$

$\begin{array}{llllllll}.30 & .58 & .75 & .85 & .91 & .94 & .97 & .98\end{array}$

$\begin{array}{llllllll}.9 & .95 & .95 & .95 & .95 & .95 & .95 & .95\end{array}$

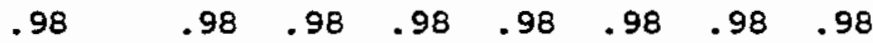

$\begin{array}{llllllll}.99 & .99 & .99 & .99 & .99 & .99 & .99 & .99\end{array}$

\footnotetext{
" "One display" refers to a single display or a group of completely dependent displays, i.e., a perceptual unit. 
Table 20-26 Estimated probabilities of failing to detect at least one* of one to five unannunciated deviant displays as a function of the BHEP for detection of a single deviant display during periodic scanning** (from Table 11-6)

Number of Deviant Indications

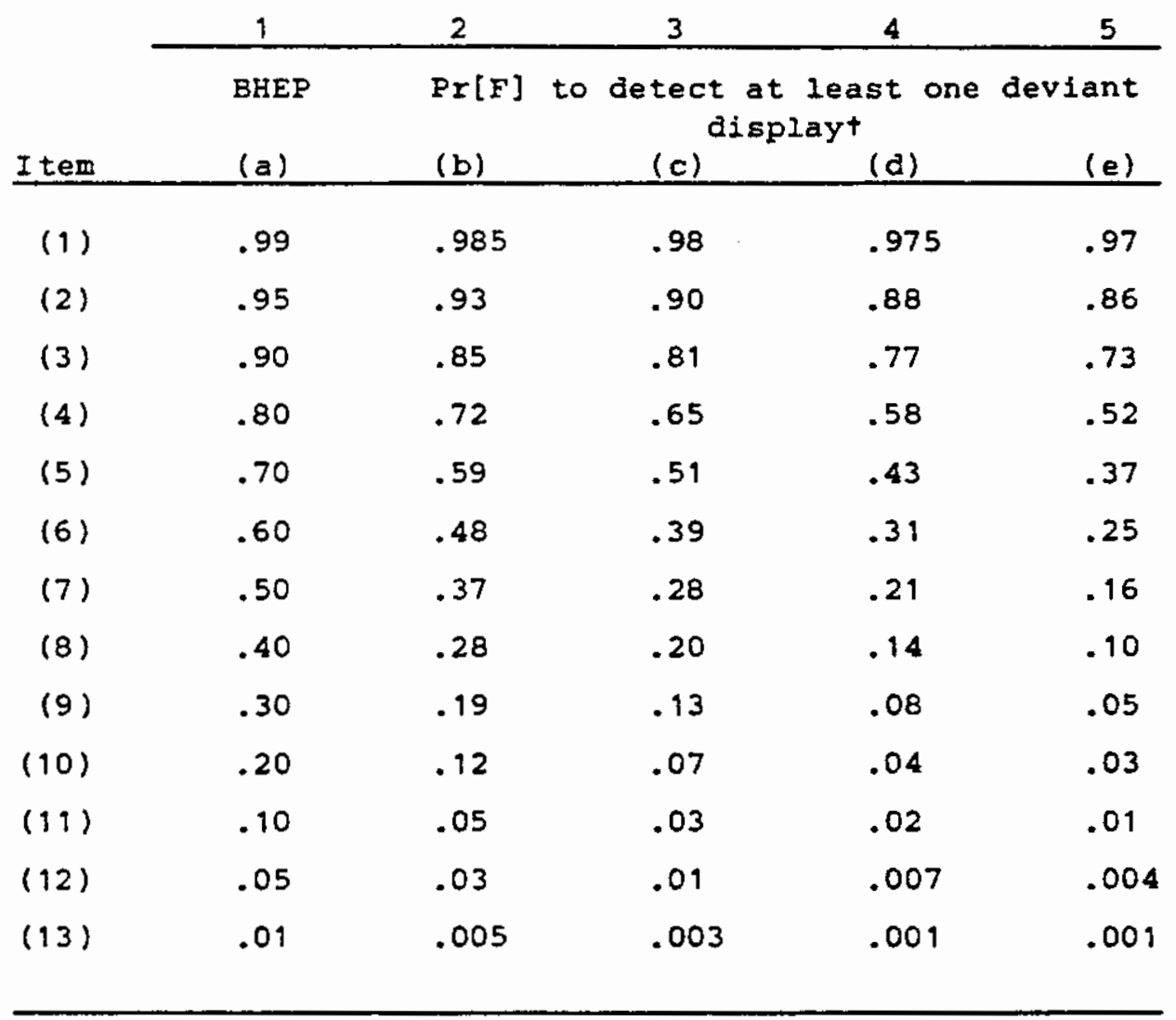

* To estimate the HEP for failure to detect other concurrent unannunciated deviant displays when one has been detected, use the HEP for the initial audit for those displays that are not functionaliy related to the display detected (from Table 20-25) and use the annunciator response model for those displays that are functionally related to the display detected (from Table 20-23). The HEPs apply when no written materials are used.

**

Except for column (a), the entries above are the complements of the entries in Table 11-5.

For EFs, refer to Table 20-20. 
Table 20-27 Estimated probabilities that the basic walk-around inspection* will fail to detect a particular deviant indication of equipment outside the control room within 30 days** (from Table 19-4)

\begin{tabular}{|c|c|c|}
\hline Item & $\begin{array}{l}\text { Number of days } \\
\text { between } \\
\text { walk-arounds } \\
\text { per inspector }\end{array}$ & $\begin{array}{l}\text { Cumulative Pr[F] } \\
\text { within } 30 \text { days } \\
\text { given one } \\
\text { inspection per shiftt }\end{array}$ \\
\hline (1) & $\begin{array}{l}1 \text { (daily walk-around } \\
\text { for each inspector) }\end{array}$ & .52 \\
\hline (2) & 2 & .25 \\
\hline (3) & 3 & .05 \\
\hline (4) & 4 & .003 \\
\hline (5) & 5 & .0002 \\
\hline (6) & 6 & .0001 \\
\hline (7) & $\begin{array}{l}7 \text { (weekly walk-around } \\
\text { for each inspector) }\end{array}$ & .0001 \\
\hline
\end{tabular}

* See Chapter 19 for the assumptions for the basic walk-around inspection. One of these assumptions is that no written procedure is used; if a written procedure is used for a walk-around, use the tables related to errors of omission and commission for performance of rule-based tasks (Figure 20-1, p 1 ).

* *

Three shifts per day are assumed. If not, use the appropriate equations in Chapter 19.

'It is assumed that all inspectors have the same number of days between walk-arounds. For other assumptions, modify the relevant equations in Chapter 19.

${ }^{+t}$ For EFs, use the procedure in Appendix $A$, or use EF $=10$ as an approximation. 

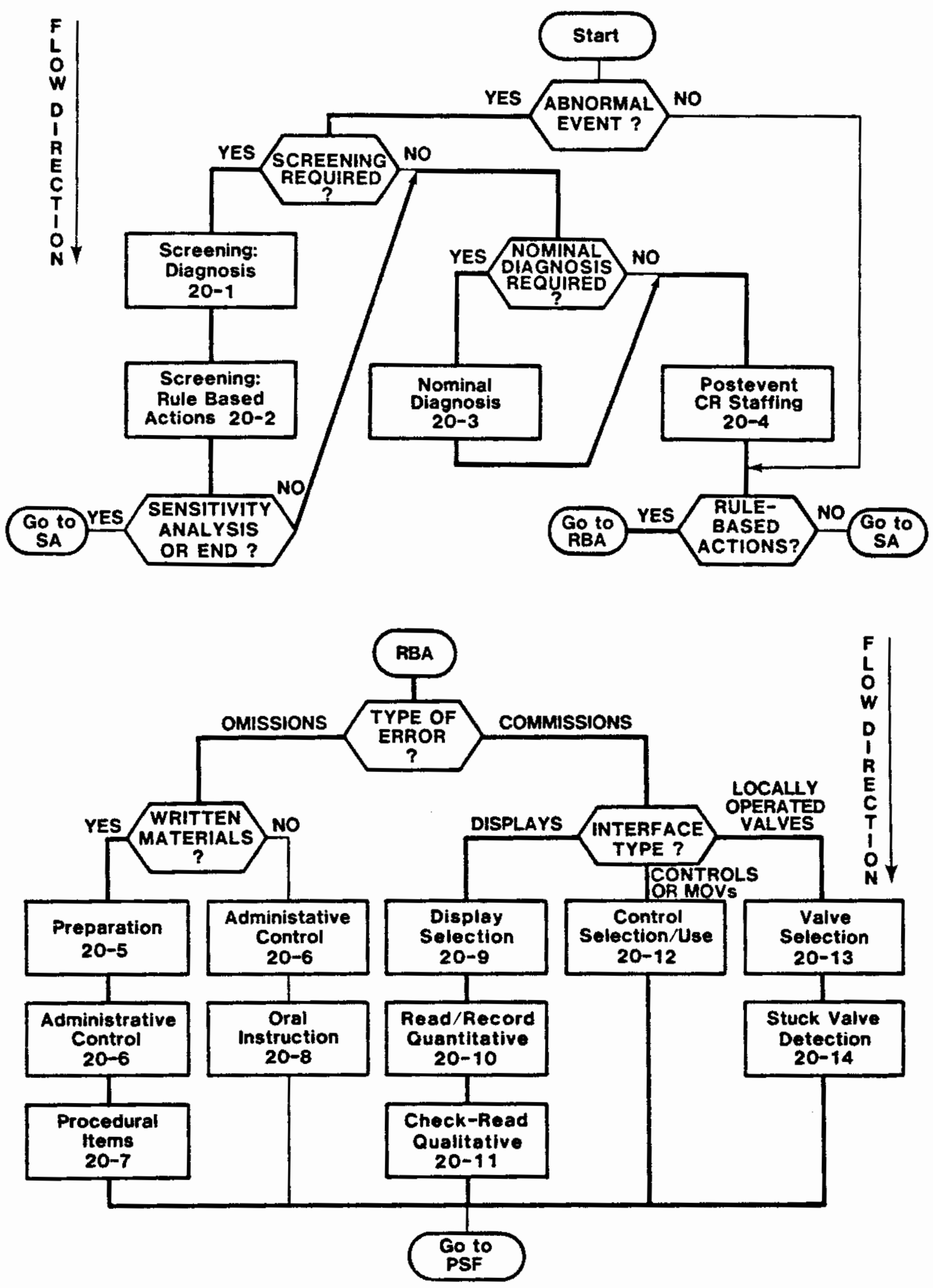

Figure 20-1 Search scheme for use of Chapter 20 tables ( $p 1$ of 3 ). 


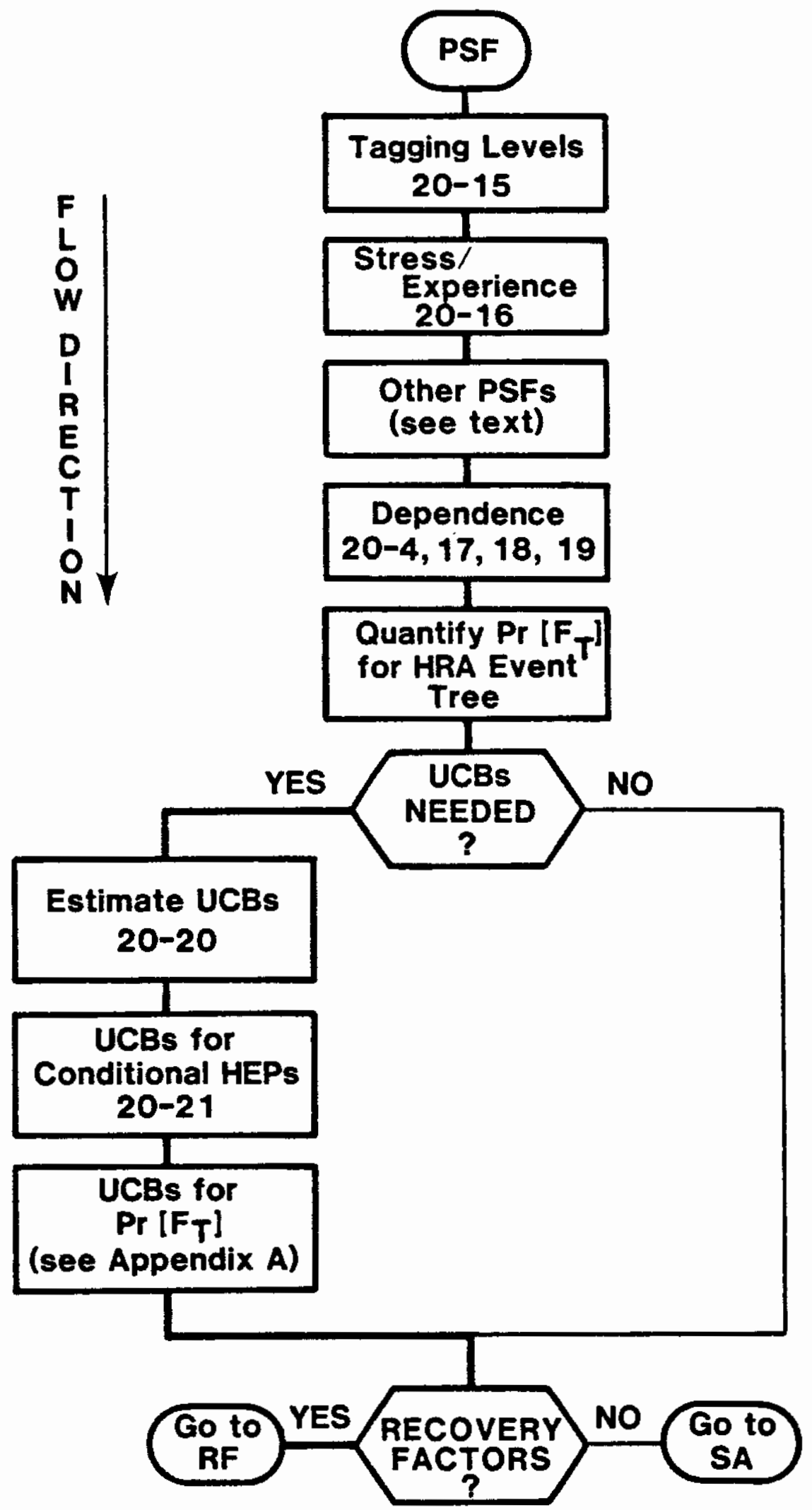

Figure 20-1 Search scheme for use of Chapter 20 tables ( $\left.\begin{array}{llll}p_{2} & \text { of } & 3\end{array}\right)$. 

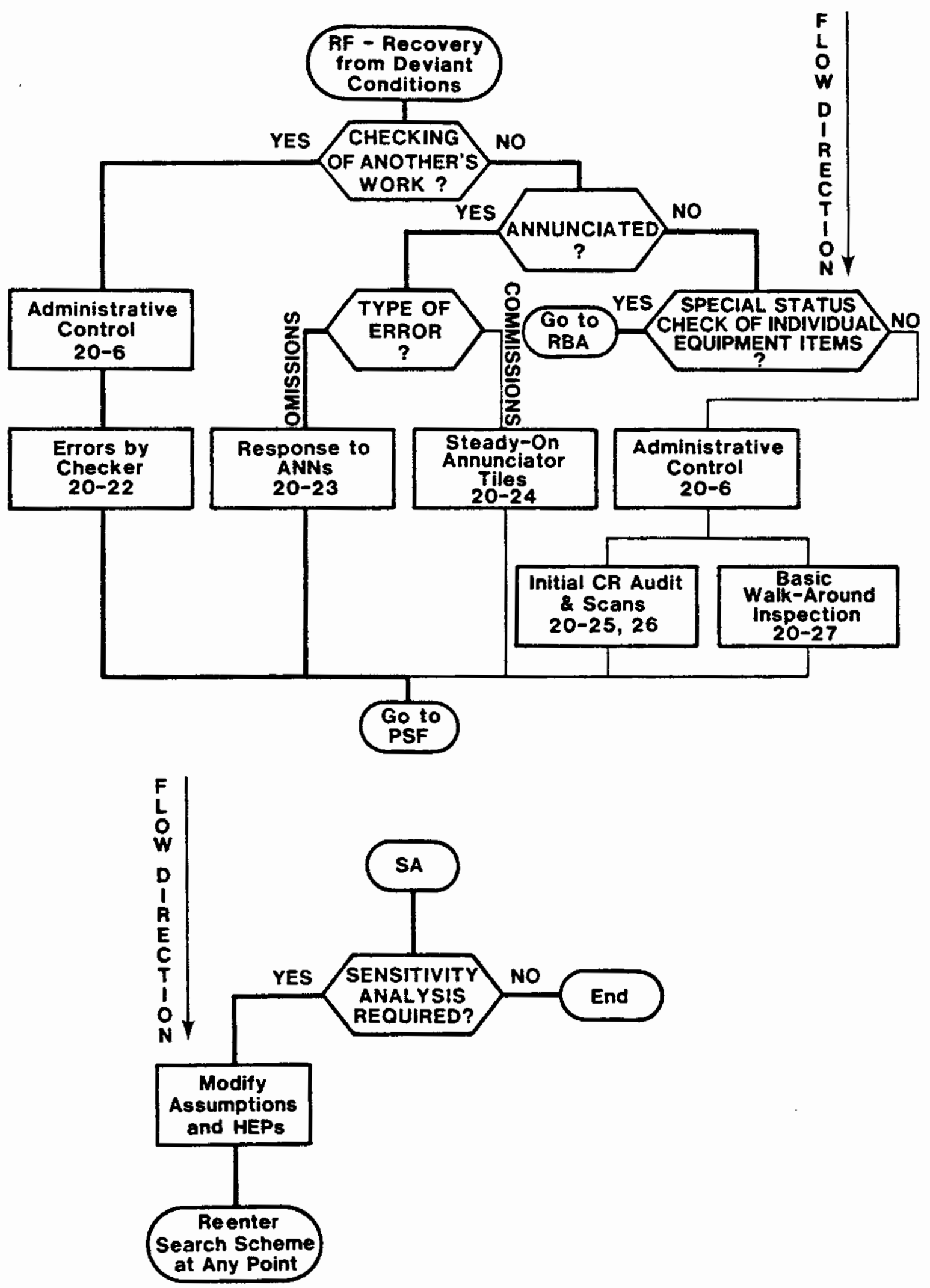

Figure 20-1 Search scheme for use of Chapter 20 tables ( 33 of 3 ). 


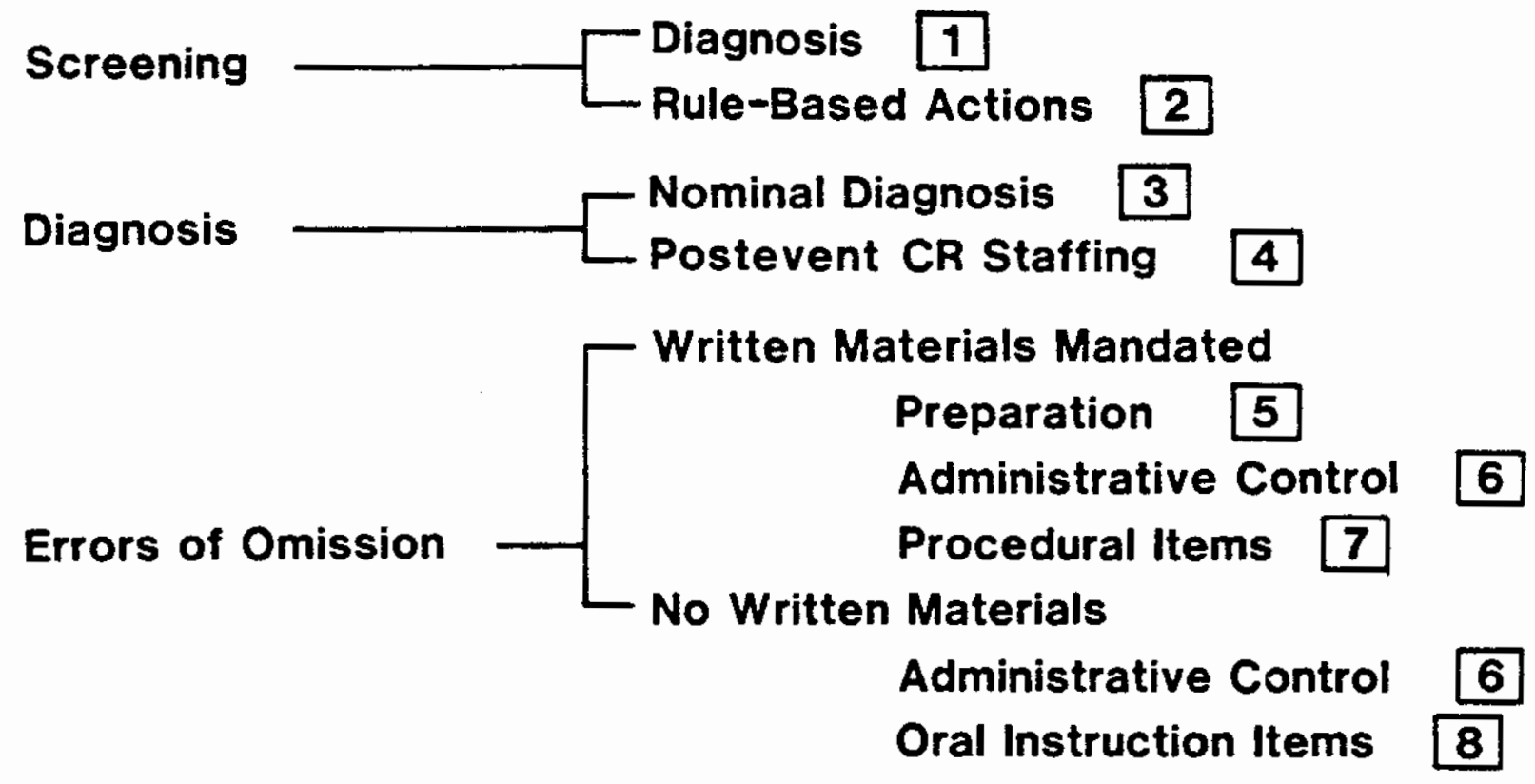

Errors of Commission $-\left[\begin{array}{ll}\text { Displays } & \begin{array}{l}\text { Display Selection } \\ \text { Read/Record Quantitative } \\ \text { Check-Read Quantitative }\end{array} \\ \text { Control \& MOV Selection \& Use } \\ \text { Locally Operated Valves }\end{array}\right.$

Valve Selection 13

Stuck Valve Detection 14

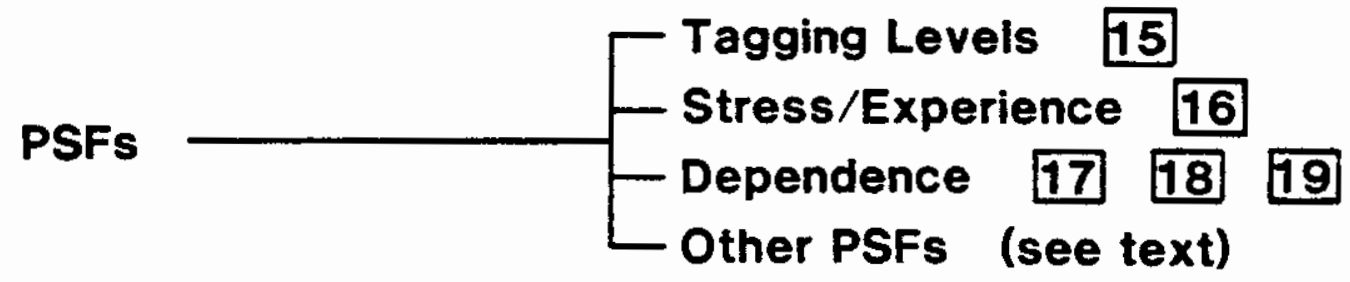

Uncertainty Bounds $-\left[\begin{array}{l}\text { Estimate UCBs } 20 \\ \text { Conditional HEPs and UCBs 21 }\end{array}\right.$

Recovery Factors $-\left\{\begin{array}{l}\text { Errors by Checker } \\ \text { Annunciated Cues } \\ \text { Control Room Scanning } \\ \text { Basic Walk-Around Inspection }\end{array}\right.$

Figure 20-2 Quick reference guide to Chapter 20 tables. 


\section{8}


APPENDIX C

THERP EXERCISE 


\section{Exercises for THERP}

Refer to the system flow diagram and event tree shown on the following pages. We will examine an interfacing system loss of coolant accident (ISLOCA) that begins with internal failure of one of the pairs of check valves that isolate the high-pressure reactor coolant system (RCS) from the interfacing low-pressure residual heat removal (RHR) system. Failure of a pair of these check valves will challenge the RHR discharge relief valves, which lift at 600 psig (valves 1ND31 and 1ND64). However, the relief capacity of these valves (400 gpm) is too small to mitigate the pressure rise in the RHR system. The flanges in the RHR system are not likely to fail as a result of overpressurization, nor are the valves. The most likely location for a large break is the tube-side cylinder of the RHR heat exchangers. If there is a rupture in the RHR system, the scenario will proceed to core damage unless the operators can detect, diagnose, and isolate the break.

From the event tree, we see there are five human failure events (HFEs) of interest. OP-FTC-2 represents operator failure to isolate the LOCA by closing safety injection isolation motoroperated valves (MOV) 1NI-173A and 1NI-178B, following diagnosis of the ISLOCA. These actions are directed by an Emergency Operating Procedure (EOP) for LOCA Outside Containment, which is entered upon correct diagnosis of the ISLOCA (event DIAG-LOCA).

We first illustrate the use of THERP to model event OP-FTC-2. The modeling assumes that the Control Room Supervisor (CRS) is functioning as the procedure reader and that the Reactor Operator (RO) performs actions directed by the procedure. Threat stress is assessed for all subtasks, because this event immediately follows the detection of an auxiliary building high radiation alarm. A moderate level of dependence was assessed between the CRS and RO. The THERP event tree for this action is shown below.

Answer the following questions regarding this THERP analysis.

1. What might be a feasible recovery action for subtask A? Why might no credit have been given for this recovery?

2. What recovery actions are modeled in this THERP tree?

3. The nominal HEPs are shown in the THERP tree. Calculate the basic and conditional HEPs, and find the overall HEP for event OP-FTC-2. Assume all actions are step-by-step in nature.

Now consider event DIAG-LOCA in the event tree. The success criterion for this event is correct transition from the Reactor Trip/Safety Injection EOP to the EOP for LOCA Outside Containment. The entry condition is auxiliary building high radiation alarm, EMF-41. Construct and quantify a THERP event tree for failure of the RO to diagnose an ISLOCA according to this criterion. 


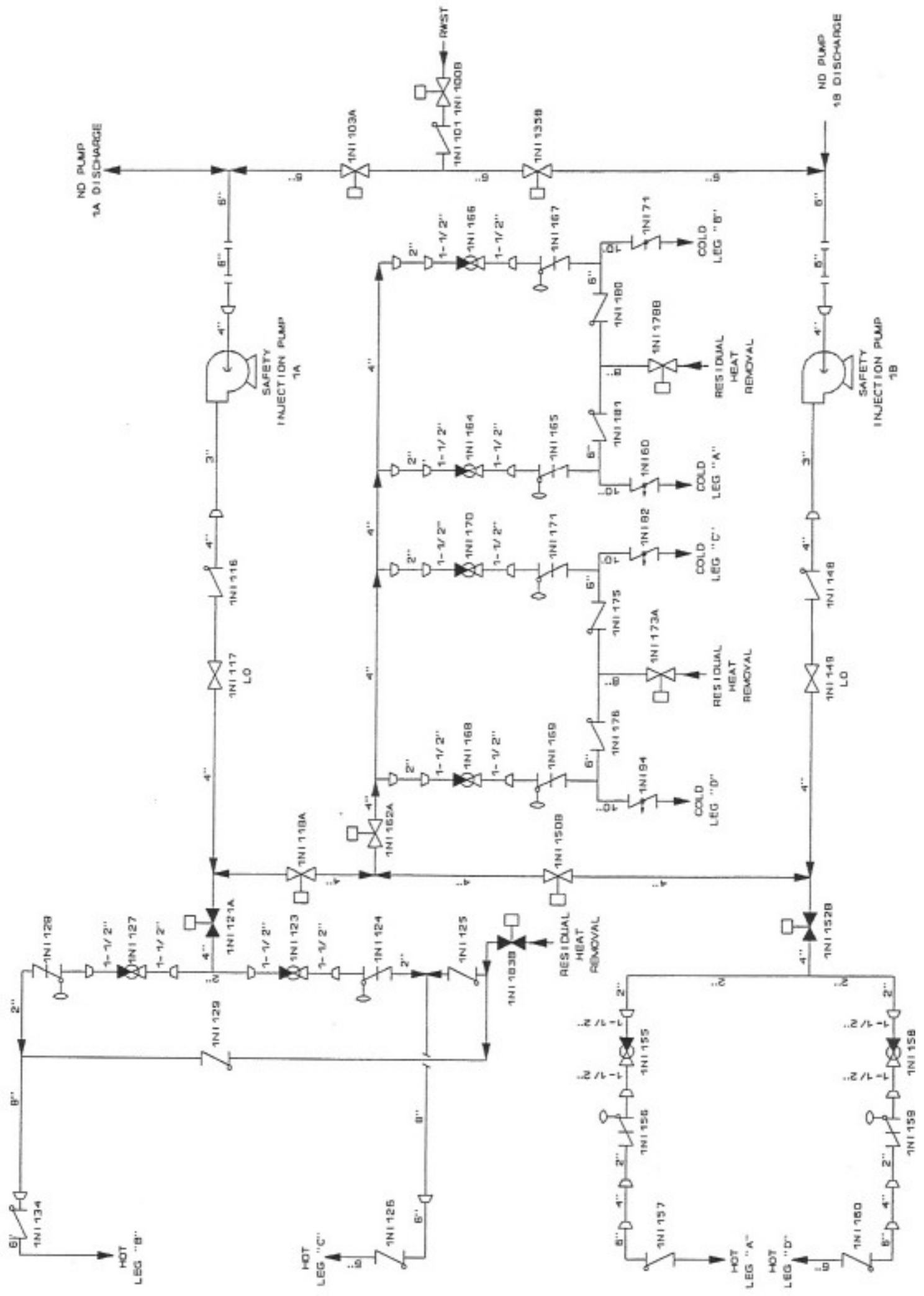




\section{8}

要点

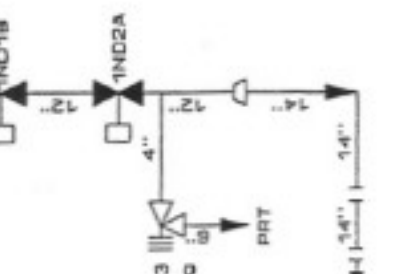

)

起亭

)
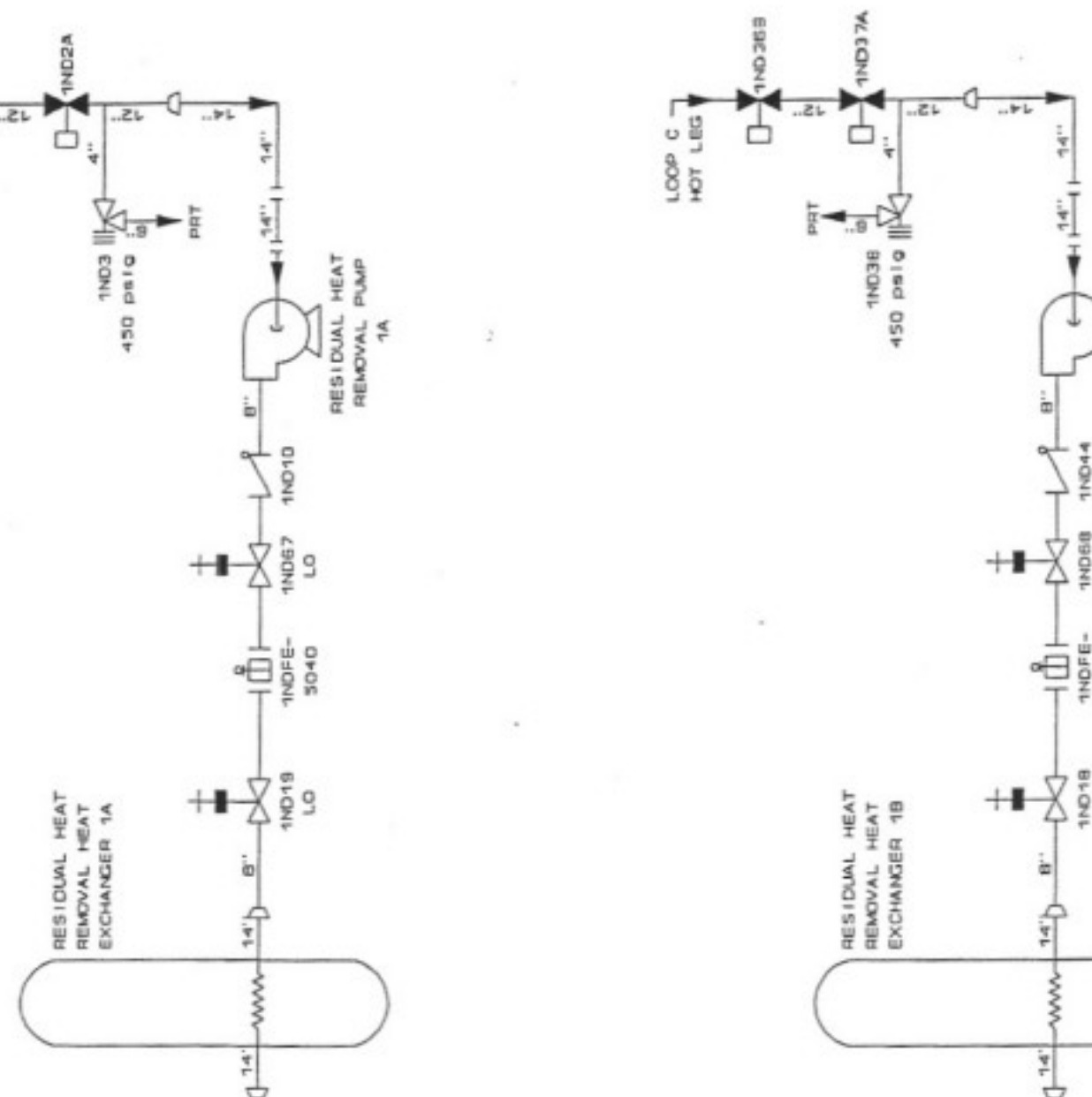

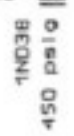

(1)
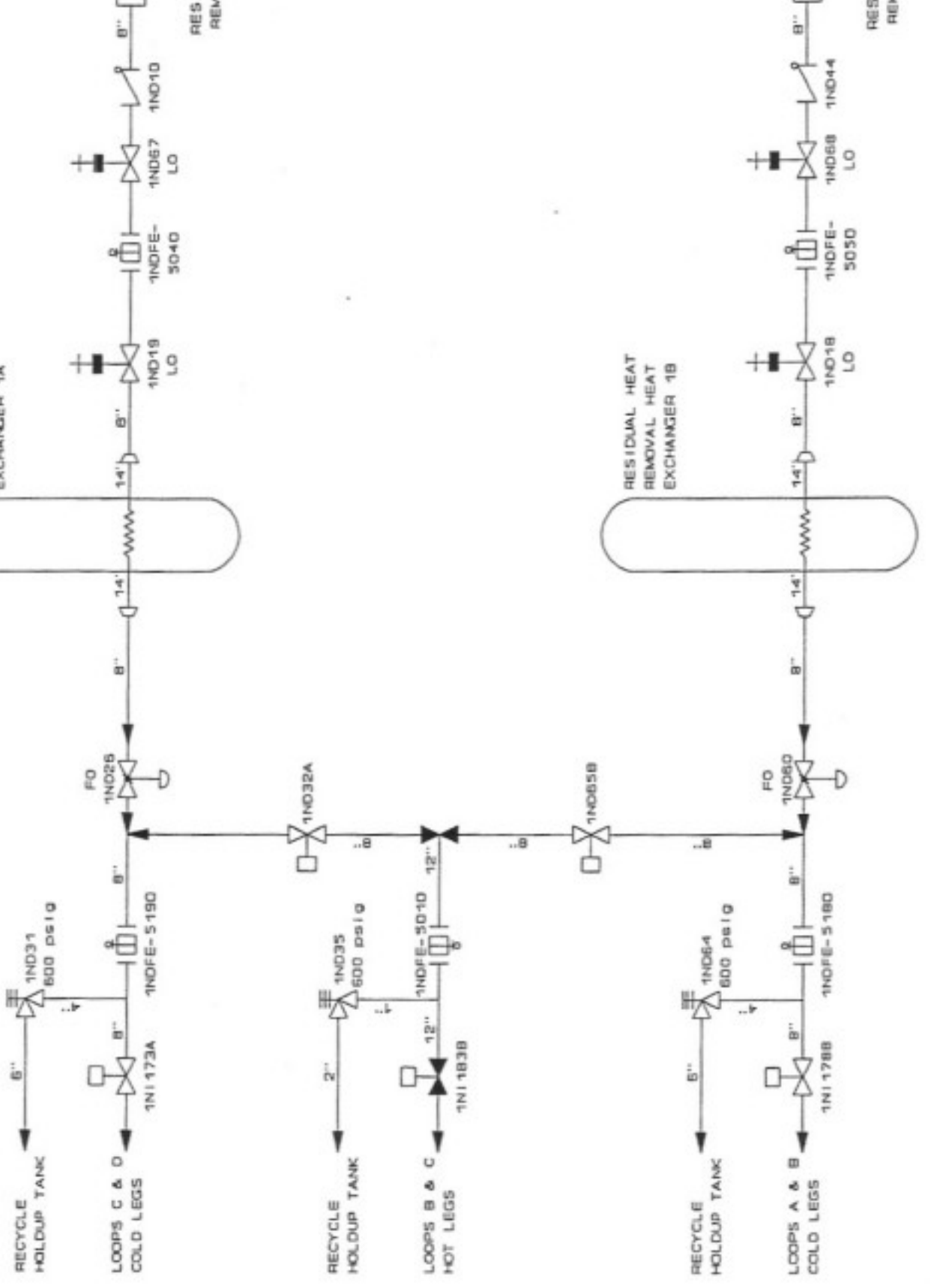


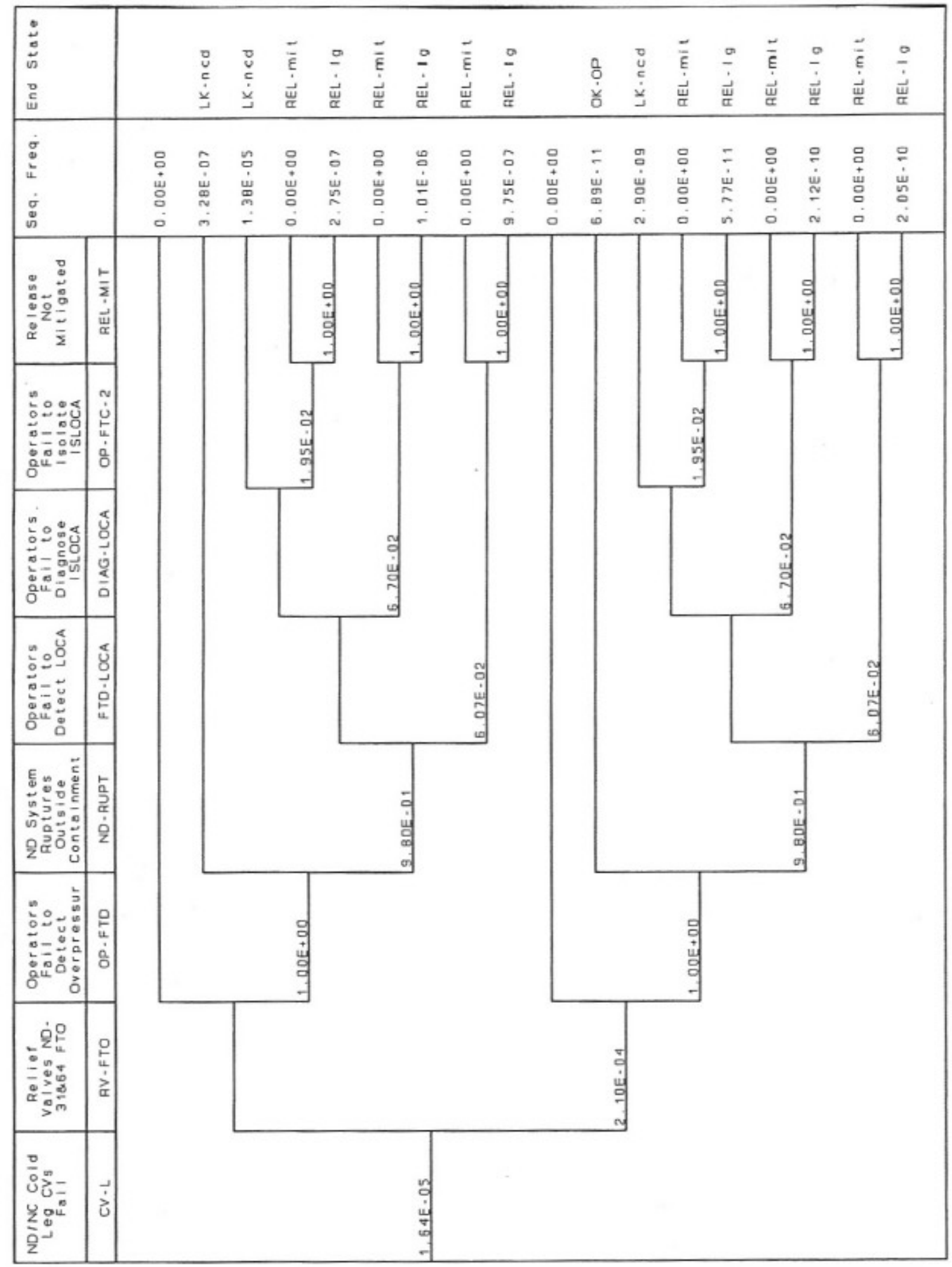




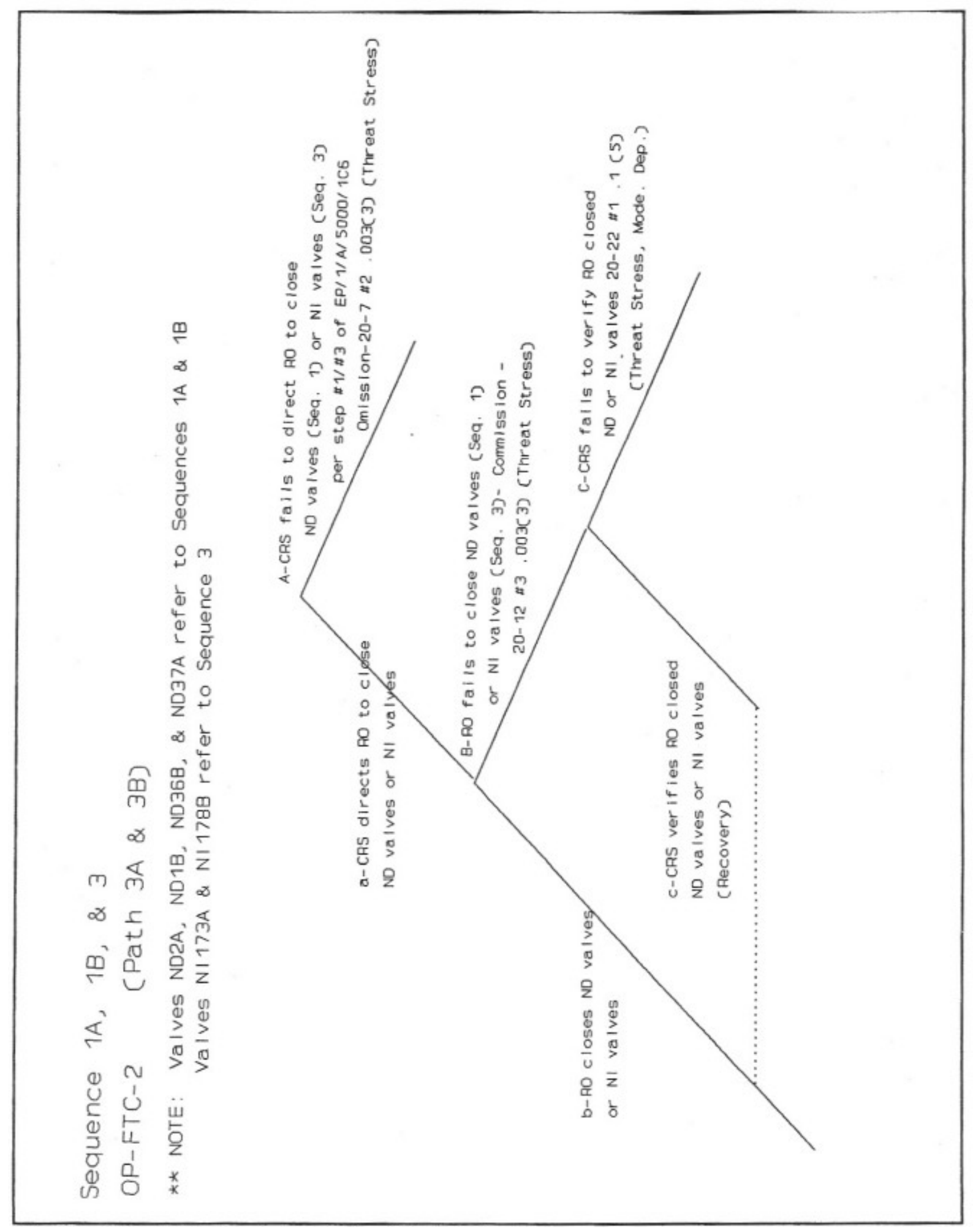




\section{APPENDIX D}

\section{SPAR-H WORKSHEETS}




\section{HRA Worksheets for At-Power \\ SPAR HUMAN ERROR WORKSHEET}

Plant: Initiating Event:

Basic Event : Event Coder:

\section{Basic Event Context:}

\section{Basic Event Description:}

Does this task contain a significant amount of diagnosis activity? YES $\square$ (start with Part I-Diagnosis) NO $\square$ (skip Part I - Diagnosis; start with Part II - Action) Why?

PART I. EVALUATE EACH PSF FOR DIAGNOSIS

A. Evaluate PSFs for the Diagnosis Portion of the Task, If Any.

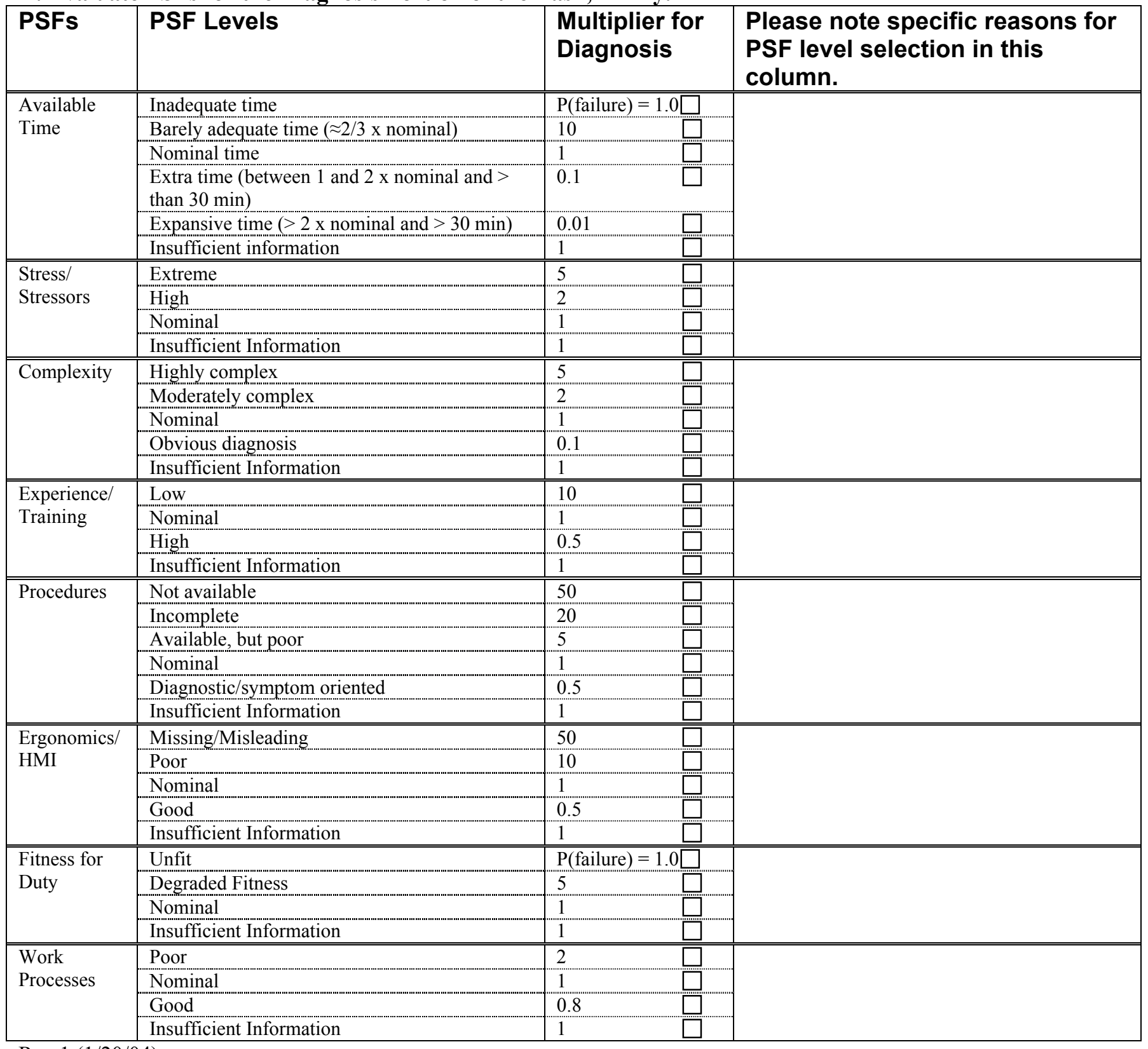

$\operatorname{Rev} 1(1 / 20 / 04)$

Reviewer: 
Plant: Initiating Event:

Basic Event Context:

Basic Event Description:

\section{B. Calculate the Diagnosis Failure Probability.}

(1) If all PSF ratings are nominal, then the Diagnosis Failure Probability $=1.0 \mathrm{E}-2$

(2) Otherwise, the Diagnosis Failure Probability is: 1.0E-2 x Time x Stress or Stressors x Complexity x Experience or Training x Procedures x Ergonomics or HMI x Fitness for Duty x Processes

Diagnosis: $1.0 \mathrm{E}-2 \mathrm{x}$ $\mathrm{x}$ $\mathrm{x}$ $\mathrm{x}$ $\mathrm{x}$ $\mathrm{x}$ X $\mathrm{X}$

\section{Calculate the Adjustment Factor IF Negative Multiple ( $\geq 3)$ PSFs are Present.}

When 3 or more negative PSF influences are present, in lieu of the equation above, you must compute a composite PSF score used in conjunction with the adjustment factor. Negative PSFs are present anytime a multiplier greater than 1 is selected. The Nominal HEP (NHEP) is 1.0E-2 for Diagnosis. The composite PSF score is computed by multiplying all the assigned PSF values. Then the adjustment factor below is applied to compute the HEP:

$$
H E P=\frac{N H E P \cdot P S F_{\text {composite }}}{N H E P \cdot\left(P S F_{\text {composite }}-1\right)+1}
$$

Diagnosis HEP with Adjustment Factor $=$

\section{Record Final Diagnosis HEP.}

If no adjustment factor was applied, record the value from Part B as your final diagnosis HEP. If an adjustment factor was applied, record the value from Part C.

$$
\text { Final Diagnosis HEP }=
$$


Plant:

\section{Basic Event Context:}

Basic Event Description:

\section{Part II. EVALUATE EACH PSF FOR ACTION}

A. Evaluate PSFs for the Action Portion of the Task, If Any.

\begin{tabular}{|c|c|c|c|}
\hline PSFs & PSF Levels & $\begin{array}{l}\text { Multiplier fo } \\
\text { Action }\end{array}$ & $\begin{array}{l}\text { Please note specific reasons for } \\
\text { PSF level selection in this } \\
\text { column. }\end{array}$ \\
\hline \multirow{6}{*}{$\begin{array}{l}\text { Available } \\
\text { Time }\end{array}$} & Inadequate time & $\mathrm{P}($ failure $)=1.0$ & \\
\hline & Time available is $\approx$ the time required & 10 & \\
\hline & Nominal time & 1 & \\
\hline & Time available $\geq 5 x$ the time required & 0.1 & \\
\hline & Time available is $\geq 50 \mathrm{x}$ the time required & 0.01 & \\
\hline & Insufficiecient Information & 1 & \\
\hline \multirow{4}{*}{$\begin{array}{l}\text { Stress/ } \\
\text { Stressors }\end{array}$} & 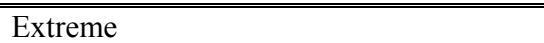 & $\overline{55}$ & \\
\hline & High & 2 & \\
\hline & Nominal & 1 & \\
\hline & Insufficient Information & 1 & \\
\hline \multirow[t]{4}{*}{ Complexity } & Highly complex & 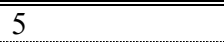 & \\
\hline & Moderately complex & 2 & \\
\hline & Nominal & 1 & \\
\hline & Insufficient Information & 1 & \\
\hline \multirow{4}{*}{$\begin{array}{l}\text { Experience/ } \\
\text { Training }\end{array}$} & Low & 3 & \\
\hline & Nominal & 1 & \\
\hline & High & 0.5 & \\
\hline & Insufficient Information & 1 & \\
\hline \multirow[t]{5}{*}{ Procedures } & Not available & 250 & \\
\hline & Incomplete & 20 & \\
\hline & Available, but poor & 5 & \\
\hline & Nominal & 1 & \\
\hline & Insufficient Information & 1 & \\
\hline \multirow{5}{*}{$\begin{array}{l}\text { Ergonomics/ } \\
\text { HMI }\end{array}$} & "Missing/Misleading & $\overline{50}$ & \\
\hline & Poor & 10 & \\
\hline & Nominal & 1 & \\
\hline & Good & 0.5 & \\
\hline & Insufficient Information & 1 & \\
\hline \multirow{4}{*}{$\begin{array}{l}\text { Fitness for } \\
\text { Duty }\end{array}$} & Unfit & $\mathrm{P}($ failure $)=1.0$ & \\
\hline & Degraded Fitness & 5 & \\
\hline & Nominal & 1 & \\
\hline & Insufficient Information & 1 & \\
\hline \multirow{4}{*}{$\begin{array}{l}\text { Work } \\
\text { Processes }\end{array}$} & Poor & $\overline{55}$ & \\
\hline & Nominal & 1 & \\
\hline & Good & 0.5 & \\
\hline & Insufficient Information & 1 & \\
\hline
\end{tabular}

Reviewer: 


\section{Basic Event Context:}

\section{Basic Event Description:}

\section{B. Calculate the Action Failure Probability.}

(1) If all PSF ratings are nominal, then the Action Failure Probability $=1.0 \mathrm{E}-3$

(2) Otherwise, the Action Failure Probability is: 1.0E-3 x Time x Stress or Stressors x Complexity x Experience or Training $\mathrm{x}$ Procedures $\mathrm{x}$ Ergonomics or HMI x Fitness for Duty $\mathrm{x}$ Processes

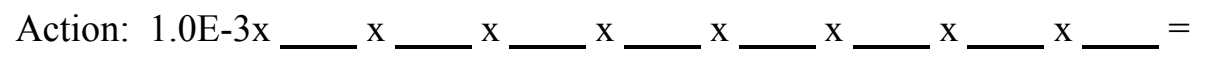

\section{Calculate the Adjustment Factor $\underline{\text { IF }}$ Negative Multiple ( $\geq 3)$ PSFs are Present.}

When 3 or more negative PSF influences are present, in lieu of the equation above, you must compute a composite PSF score used in conjunction with the adjustment factor. Negative PSFs are present anytime a multiplier greater than 1 is selected. The Nominal HEP (NHEP) is 1.0E-3 for Action. The composite PSF score is computed by multiplying all the assigned PSF values. Then the adjustment factor below is applied to compute the HEP:

$$
H E P=\frac{N H E P \cdot P S F_{\text {composite }}}{N H E P \cdot\left(P S F_{\text {composite }}-1\right)+1}
$$

\section{Action HEP with Adjustment Factor $=$}

\section{Record Final Action HEP.}

If no adjustment factor was applied, record the value from Part B as your final action HEP. If an adjustment factor was applied, record the value from Part $\mathrm{C}$.

$$
\text { Final Action HEP = }
$$




\section{Basic Event Context:}

\section{Basic Event Description:}

\section{PART III. CALCULATE TASK FAILURE PROBABILITY WITHOUT FORMAL DEPENDENCE (P/OD)}

Calculate the Task Failure Probability Without Formal Dependence $\left(\mathrm{P}_{\mathrm{w} / \mathrm{od}}\right)$ by adding the Diagnosis Failure Probability from Part I and the Action Failure Probability from Part II. In instances where an action is required without a diagnosis and there is no dependency, then this step is omitted.

$$
\mathrm{P}_{\mathrm{w} / \mathrm{od}}=\text { Diagnosis HEP }
$$
+ Action HEP $=$

\section{Part IV. DEPENDENCY}

For all tasks, except the first task in the sequence, use the table and formulae below to calculate the Task Failure Probability With Formal Dependence $\left(\mathrm{P}_{\mathrm{w} / \mathrm{d}}\right)$.

If there is a reason why failure on previous tasks should not be considered, such as it is impossible to take the current action unless the previous action has been properly performed, explain here:

\section{Dependency Condition Table}

\begin{tabular}{|c|c|c|c|c|c|c|}
\hline $\begin{array}{l}\text { Condition } \\
\text { Number }\end{array}$ & $\begin{array}{c}\text { Crew } \\
\text { (same or } \\
\text { different) }\end{array}$ & $\begin{array}{l}\text { Time } \\
\text { (close in time } \\
\text { or not close } \\
\text { in time) }\end{array}$ & $\begin{array}{l}\text { Location } \\
\text { (same or } \\
\text { different) }\end{array}$ & $\begin{array}{c}\text { Cues } \\
\text { (additional or } \\
\text { no } \\
\text { additional) } \\
\end{array}$ & Dependency & $\begin{array}{c}\text { Number of Human Action Failures Rule } \\
\square \text { - Not Applicable. } \\
\text { Why? }\end{array}$ \\
\hline 2 & \multirow{5}{*}{$\mathrm{S}$} & \multirow{3}{*}{$\mathrm{c}$} & $\mathrm{s}$ & a & complete & \multirow{10}{*}{$\begin{array}{l}\text { When considering recovery in a series } \\
\text { e.g., } 2^{\text {nd }}, 3^{\text {rd }}, \text { or } 4^{\text {th }} \text { checker } \\
\text { If this error is the } 3 \text { rd error in the } \\
\text { sequence, then the dependency is at } \\
\text { least moderate. }\end{array}$} \\
\hline 3 & & & \multirow[t]{2}{*}{$\mathrm{d}$} & na & high & \\
\hline 4 & & & & $a$ & high & \\
\hline 7 & & \multirow{2}{*}{$\mathrm{nc}$} & \multirow[t]{2}{*}{$\mathrm{d}$} & na & moderate & \\
\hline 8 & & & & a & low & \\
\hline 9 & \multirow[t]{4}{*}{$\mathrm{d}$} & \multirow[t]{4}{*}{$\mathrm{c}$} & \multirow[t]{2}{*}{$\mathrm{s}$} & na & moderate & \\
\hline 10 & & & & a & moderate & \\
\hline 11 & & & \multirow[t]{2}{*}{$\mathrm{d}$} & na & moderate & \\
\hline 12 & & & & $\mathrm{a}$ & moderate & \\
\hline 17 & & & & & zero & \\
\hline
\end{tabular}

Using $\mathrm{P}_{\mathrm{w} / \mathrm{od}}=$ Probability of Task Failure Without Formal Dependence (calculated in Part III):

For Complete Dependence the probability of failure is 1 .

For High Dependence the probability of failure is $\left(1+\mathrm{P}_{\mathrm{w} / \mathrm{od}}\right) / 2$

For Moderate Dependence the probability of failure is $\left(1+6 \times \mathrm{P}_{\mathrm{w} / \mathrm{od}}\right) / 7$

For Low Dependence the probability of failure is $\left(1+19 \times \mathrm{P}_{\mathrm{w} / \mathrm{od}}\right) / 20$

For Zero Dependence the probability of failure is $\mathrm{P}_{\mathrm{w} / \mathrm{od}}$

Calculate $\mathrm{P}_{\mathrm{w} / \mathrm{d}}$ using the appropriate values:

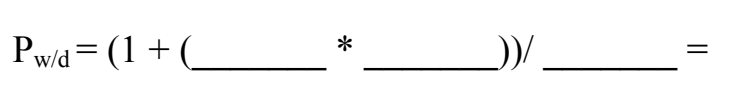

Reviewer: 


\section{HRA Worksheets for LP/SD}

SPAR HUMAN ERROR WORKSHEET

Plant:

Initiating Event:

Basic Event :

Event Coder:

\section{Basic Event Context:}

\section{Basic Event Description:}

Does this task contain a significant amount of diagnosis activity? YES $\square$ (start with Part I-Diagnosis) NO (skip Part I - Diagnosis; start with Part II - Action) Why?

\section{PART I. EVALUATE EACH PSF FOR DIAGNOSIS}

A. Evaluate PSFs for the Diagnosis Portion of the Task.

\begin{tabular}{|c|c|c|c|}
\hline PSFs & PSF Levels & $\begin{array}{l}\text { Multiplier for } \\
\text { Diagnosis }\end{array}$ & $\begin{array}{l}\text { Please note specific reasons for } \\
\text { PSF level selection in this } \\
\text { column. }\end{array}$ \\
\hline \multirow{6}{*}{$\begin{array}{l}\text { Available } \\
\text { Time }\end{array}$} & Inadequate time & $\mathrm{P}($ failure $)=1.0 \square$ & \\
\hline & Barely adequate time $(\approx 2 / 3 \times$ nominal $)$ & 10 & \\
\hline & Nominal time & $\square$ & \\
\hline & $\begin{array}{l}\text { Extra time (between land } 2 \times \text { nominal and }> \\
30 \mathrm{~min} \text { ) }\end{array}$ & 0.1 & \\
\hline & Expansive time $>2 x$ nominal $\&>30 \mathrm{~min}$ & 0.1 to 0.01 & \\
\hline & Insufficient Information & $\square$ & \\
\hline \multirow{4}{*}{$\begin{array}{l}\text { Stress/ } \\
\text { Stressors }\end{array}$} & Extreme & $\square$ & \\
\hline & High & 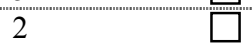 & \\
\hline & Nominal & $\square$ & \\
\hline & Insufficient Information & $\square$ & \\
\hline \multirow[t]{5}{*}{ Complexity } & Highly complex & $\bar{\square}$ & \\
\hline & Moderately complex & 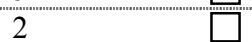 & \\
\hline & Nominal & $\square$ & \\
\hline & Obvious diagnosis & 0.1 & \\
\hline & Insufficient Information & 1 & \\
\hline \multirow{4}{*}{$\begin{array}{l}\text { Experience/ } \\
\text { Training }\end{array}$} & Low & 10 & \\
\hline & Nominal & 1 & \\
\hline & High & 0.5 & \\
\hline & Insufficient Information & 1 & \\
\hline \multirow{6}{*}{ Procedures } & Not available & 50 & \\
\hline & Incomplete & 20 & \\
\hline & Available, but poor & 5 & \\
\hline & Nominal & 1 & \\
\hline & Diagnostic/symptom oriented & 0.5 & \\
\hline & Insufficient Information & 1 & \\
\hline \multirow{5}{*}{$\begin{array}{l}\text { Ergonomics/ } \\
\text { HMI }\end{array}$} & Missing/Misleading & 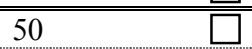 & \\
\hline & Poor & 10 & \\
\hline & Nominal & 1 & \\
\hline & Good & 0.5 & \\
\hline & Insufficient Information & 1 & \\
\hline \multirow{4}{*}{$\begin{array}{l}\text { Fitness for } \\
\text { Duty }\end{array}$} & Unfit & $\mathrm{P}$ (failure) $=1.0 \square$ & \\
\hline & Degraded Fitness & $\square$ & \\
\hline & Nominal & $\square$ & \\
\hline & Insufficient Information & 1 & \\
\hline \multirow{4}{*}{$\begin{array}{l}\text { Work } \\
\text { Processes }\end{array}$} & Poor & 2 & \\
\hline & Nominal & $\square$ & \\
\hline & Good & 0.8 & \\
\hline & Insufficient Information & 1 & \\
\hline
\end{tabular}

Rev $1(1 / 20 / 04)$ 


\section{Basic Event Context:}

\section{Basic Event Description:}

\section{B. Calculate the Diagnosis Failure Probability.}

(1) If all PSF ratings are nominal, then the Diagnosis Failure Probability $=1.0 \mathrm{E}-2$

(2) Otherwise, the Diagnosis Failure Probability is: 1.0E-2 x Time x Stress or Stressors x Complexity x Experience or Training x Procedures x Ergonomics or HMI x Fitness for Duty x Processes

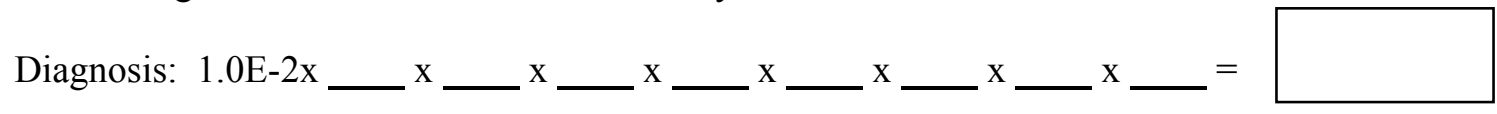

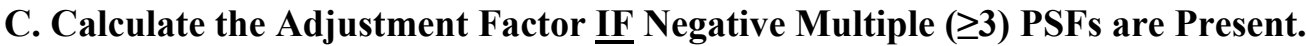

When 3 or more negative PSF influences are present, in lieu of the equation above, you must compute a composite PSF score used in conjunction with the adjustment factor. Negative PSFs are present anytime a multiplier greater than 1 is selected. The Nominal HEP (NHEP) is 1.0E-2 for Diagnosis. The composite PSF score is computed by multiplying all the assigned PSF values. Then the adjustment factor below is applied to compute the HEP:

$$
H E P=\frac{N H E P \cdot P S F_{\text {composite }}}{N H E P \cdot\left(P S F_{\text {composite }}-1\right)+1}
$$

$$
\text { Diagnosis HEP with Adjustment Factor }=
$$

\section{Record Final Diagnosis HEP.}

If no adjustment factor was applied, record the value from Part B as your final diagnosis HEP. If an adjustment factor was applied, record the value from Part C.

Final Diagnosis HEP = 
Plant:

Initiating Event:

Basic Event :

Event Coder:

Basic Event Context:

Basic Event Description:

Part II. EVALUATE EACH PSF FOR ACTION

A. Evaluate PSFs for the Action Portion of the Task, If Any.

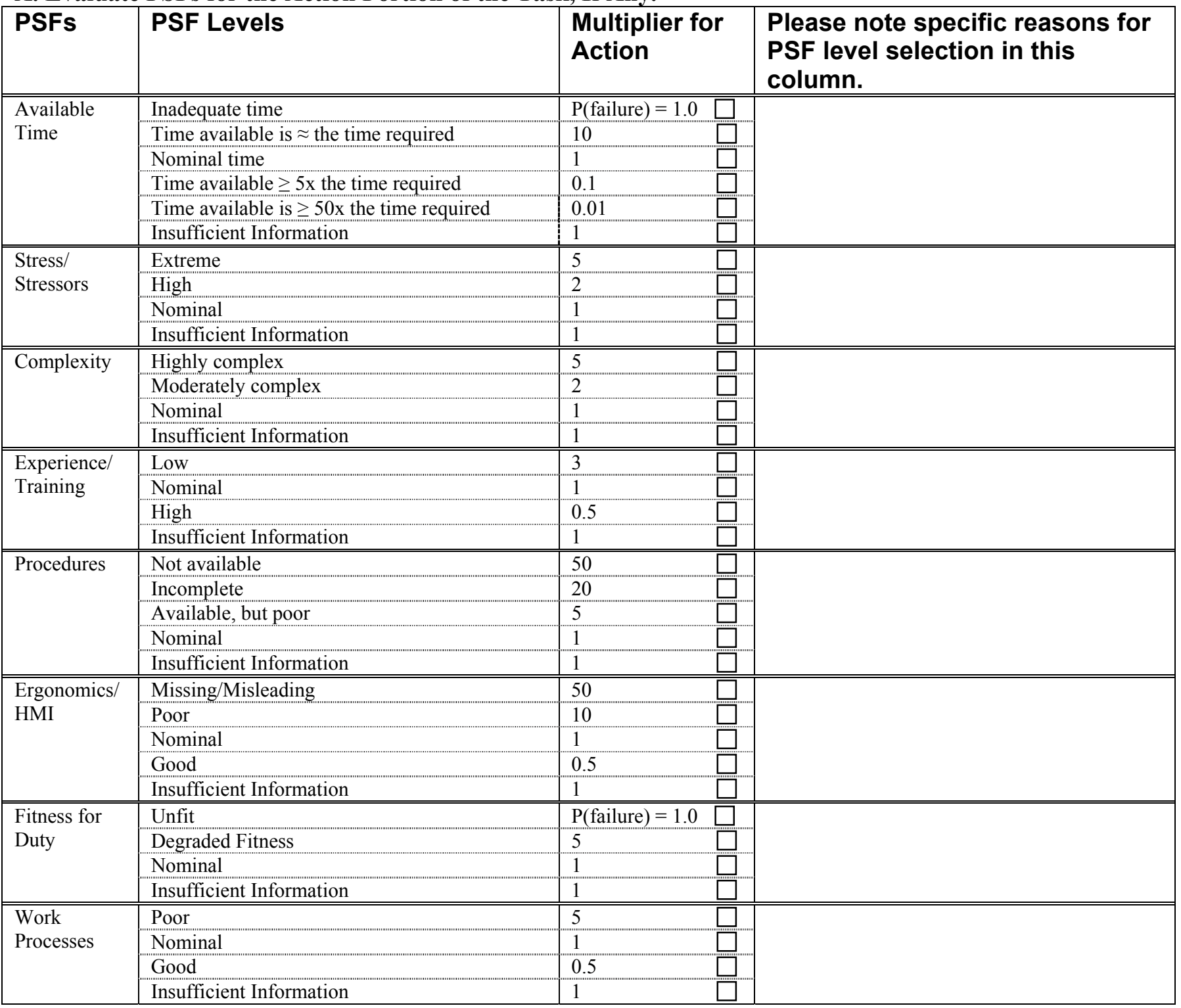

Reviewer: 


\section{Basic Event Context:}

\section{Basic Event Description:}

\section{B. Calculate the Action Failure Probability.}

(1) If all PSF ratings are nominal, then the Action Failure Probability $=1.0 \mathrm{E}-3$

(2) Otherwise, the Action Failure Probability is: 1.0E-3 x Time x Stress or Stressors x Complexity x Experience or Training $\mathrm{x}$ Procedures $\mathrm{x}$ Ergonomics or HMI x Fitness for Duty $\mathrm{x}$ Processes

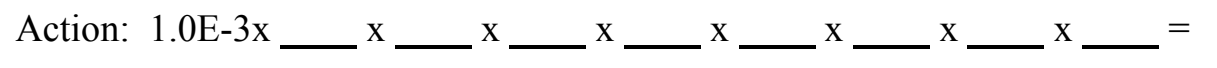

\section{Calculate the Adjustment Factor $\underline{\text { IF }}$ Negative Multiple ( $\geq 3)$ PSFs are Present.}

When 3 or more negative PSF influences are present, in lieu of the equation above, you must compute a composite PSF score used in conjunction with the adjustment factor. Negative PSFs are present anytime a multiplier greater than 1 is selected. The Nominal HEP (NHEP) is 1.0E-3 for Action. The composite PSF score is computed by multiplying all the assigned PSF values. Then the adjustment factor below is applied to compute the HEP:

$$
H E P=\frac{N H E P \cdot P S F_{\text {composite }}}{N H E P \cdot\left(P S F_{\text {composite }}-1\right)+1}
$$

\section{Record Final Action HEP.}

If no adjustment factor was applied, record the value from Part B as your final action HEP. If an adjustment factor was applied, record the value from Part C.

Final Action HEP = 


\section{Basic Event Context:}

\section{Basic Event Description:}

\section{PART III. CALCULATE TASK FAILURE PROBABILITY WITHOUT FORMAL DEPENDENCE (P/OD)}

Calculate the Task Failure Probability Without Formal Dependence $\left(\mathrm{P}_{\mathrm{w} / \mathrm{od}}\right)$ by adding the Diagnosis Failure Probability from Part I and the Action Failure Probability from Part II. In instances where an action is required without a diagnosis and there is no dependency, then this step is omitted.

$$
\mathrm{P}_{\mathrm{w} / \mathrm{od}}=\text { Diagnosis HEP }
$$
+ Action HEP $=$

\section{Part IV. DEPENDENCY}

For all tasks, except the first task in the sequence, use the table and formulae below to calculate the Task Failure Probability With Formal Dependence $\left(\mathrm{P}_{\mathrm{w} / \mathrm{d}}\right)$.

If there is a reason why failure on previous tasks should not be considered, such as it is impossible to take the current action unless the previous action has been properly performed, explain here:

Dependency Condition Table

\begin{tabular}{|c|c|c|c|c|c|c|}
\hline $\begin{array}{c}\text { Condition } \\
\text { Number }\end{array}$ & $\begin{array}{c}\text { Crew } \\
\text { (same or } \\
\text { different) }\end{array}$ & $\begin{array}{l}\text { Time } \\
\text { (close in time } \\
\text { or not close } \\
\text { in time) }\end{array}$ & $\begin{array}{l}\text { Location } \\
\text { (same or } \\
\text { different) }\end{array}$ & $\begin{array}{c}\text { Cues } \\
\text { (additional or } \\
\text { no } \\
\text { additional) } \\
\end{array}$ & Dependency & $\begin{array}{l}\text { Number of Human Action Failures Rule } \\
\square \text { - Not Applicable. } \\
\text { Why? }\end{array}$ \\
\hline 2 & \multirow{5}{*}{$\mathrm{s}$} & \multirow{3}{*}{$\mathrm{c}$} & $\mathrm{s}$ & a & complete & \multirow{10}{*}{$\begin{array}{l}\text { When considering recovery in a series } \\
\text { e.g., } 2^{\text {nd }}, 3^{\text {rd }}, \text { or } 4^{\text {th }} \text { checker } \\
\text { If this error is the } 3 \text { rd error in the } \\
\text { sequence, then the dependency is at } \\
\text { least moderate. }\end{array}$} \\
\hline 3 & & & \multirow[t]{2}{*}{$\mathrm{d}$} & na & high & \\
\hline 4 & & & & a & high & \\
\hline 7 & & \multirow{2}{*}{ nc } & \multirow[t]{2}{*}{$\mathrm{d}$} & na & moderate & \\
\hline 8 & & & & $a$ & low & \\
\hline 9 & \multirow[t]{4}{*}{$\mathrm{d}$} & \multirow[t]{4}{*}{$\mathrm{c}$} & \multirow[t]{2}{*}{$\mathrm{s}$} & na & moderate & \\
\hline 10 & & & & $a$ & moderate & \\
\hline 11 & & & \multirow[t]{2}{*}{$\mathrm{d}$} & na & moderate & \\
\hline 12 & & & & a & moderate & \\
\hline 17 & & & & & zero & \\
\hline
\end{tabular}

Using $\mathrm{P}_{\mathrm{w} / \mathrm{od}}=$ Probability of Task Failure Without Formal Dependence (calculated in Part III):

For Complete Dependence the probability of failure is 1 .

For High Dependence the probability of failure is $\left(1+\mathrm{P}_{\mathrm{w} / \mathrm{od}}\right) / 2$

For Moderate Dependence the probability of failure is $\left(1+6 \times \mathrm{P}_{\mathrm{w} / \mathrm{od}}\right) / 7$

For Low Dependence the probability of failure is $\left(1+19 \times \mathrm{P}_{\mathrm{w} / \mathrm{od}}\right) / 20$

For Zero Dependence the probability of failure is $\mathrm{P}_{\mathrm{w} / \mathrm{od}}$

Calculate $\mathrm{P}_{\mathrm{w} / \mathrm{d}}$ using the appropriate values:

$$
\mathrm{P}_{\mathrm{w} / \mathrm{d}}=(1+(
$$

Reviewer: 
APPENDIXE

SPAR-H EXERCISE 


\section{Exercises for SPAR-H}

Requantify events OP-FTC-2 and DIAG-LOCA from the THERP exercise using SPAR-H. Note that task decomposition is not required for SPAR-H, in contrast to the approach of THERP. Assume that the time available from the initiator until the onset of severe core damage is 1.5 hours. 


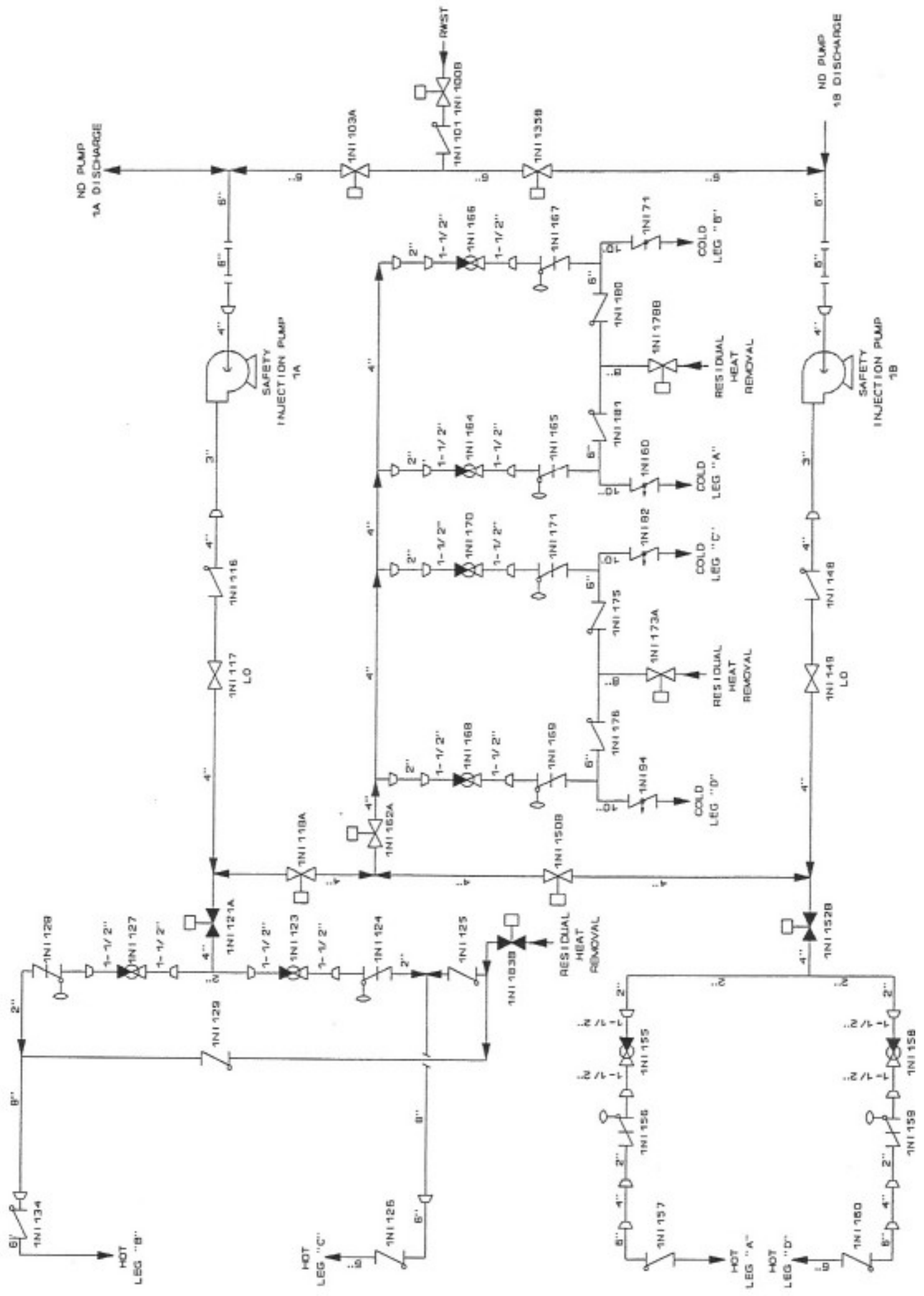




\section{8}

象总

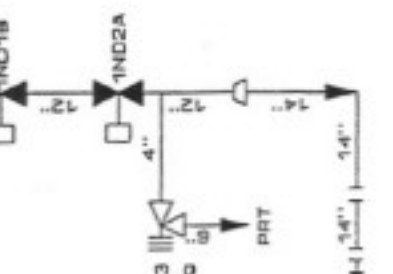

)

起亭

)
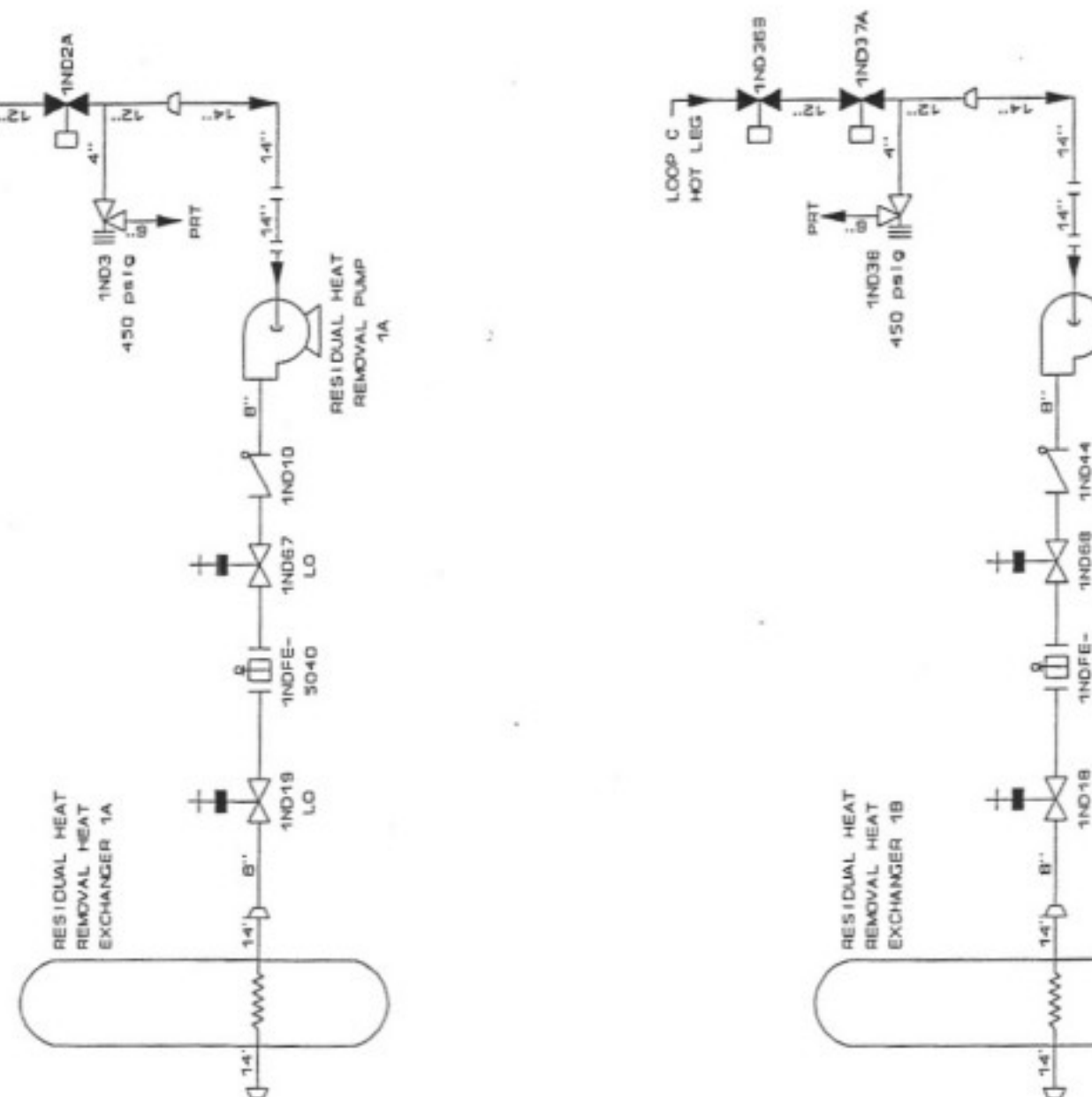

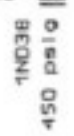

(1)
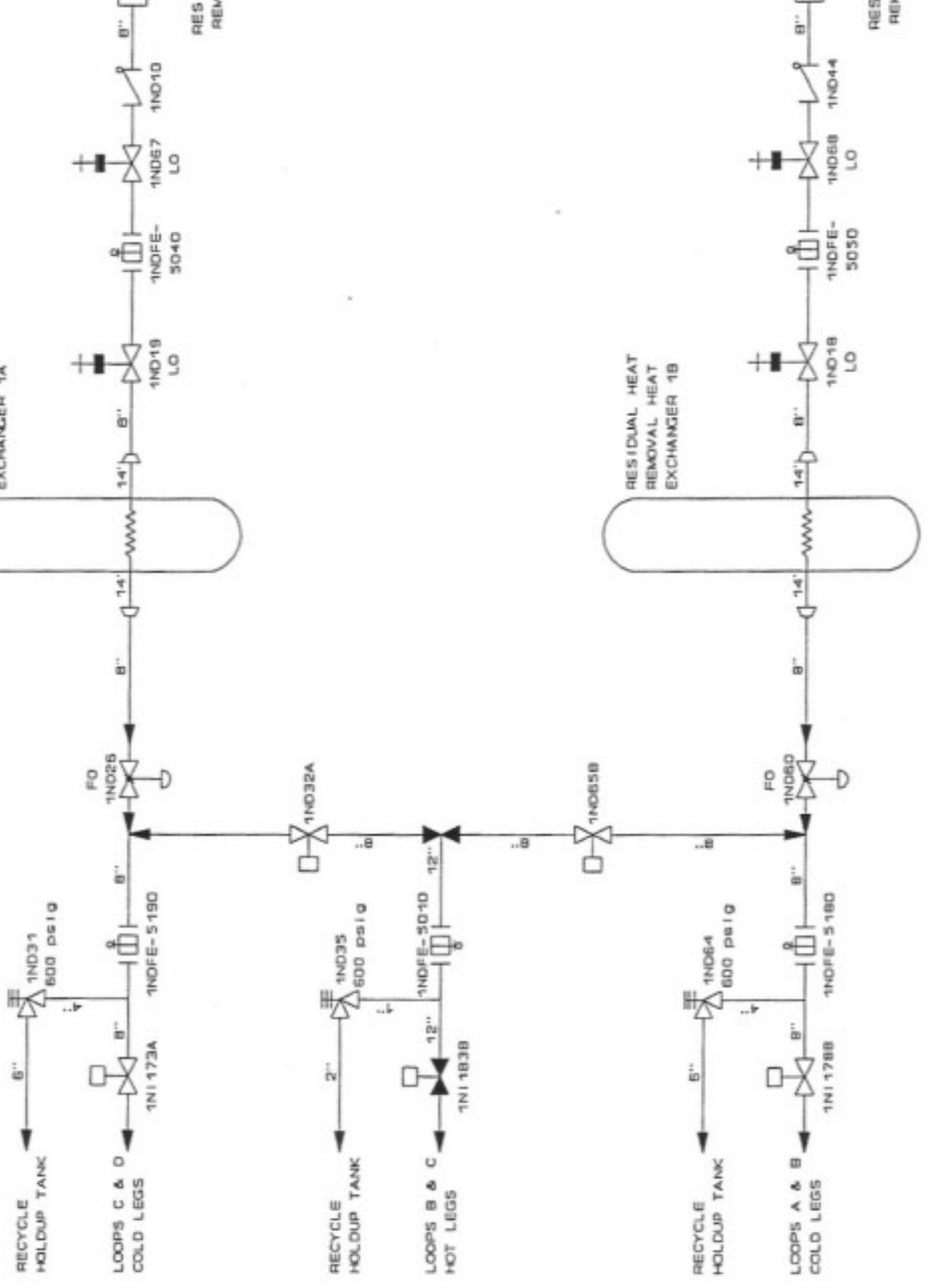


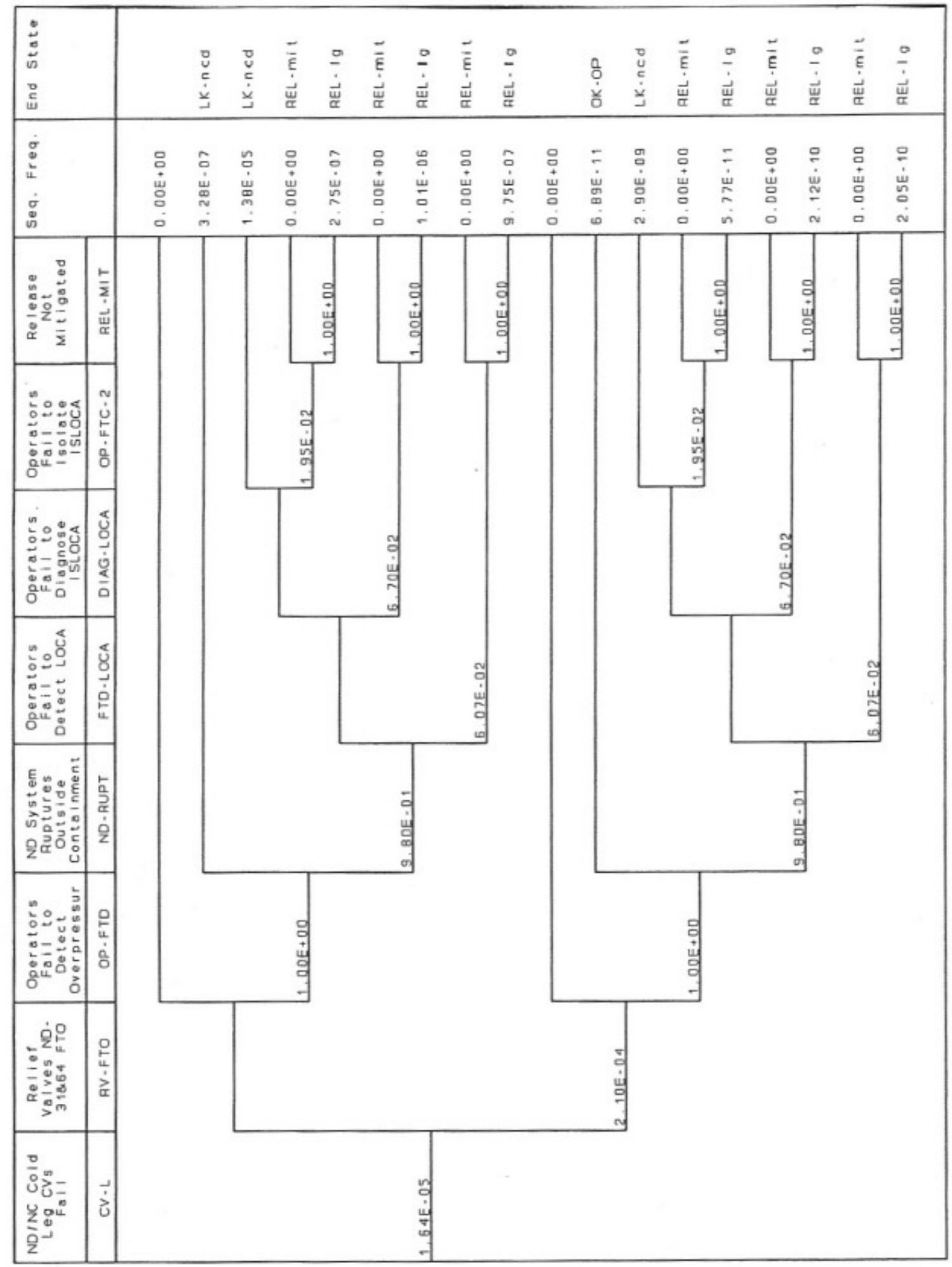




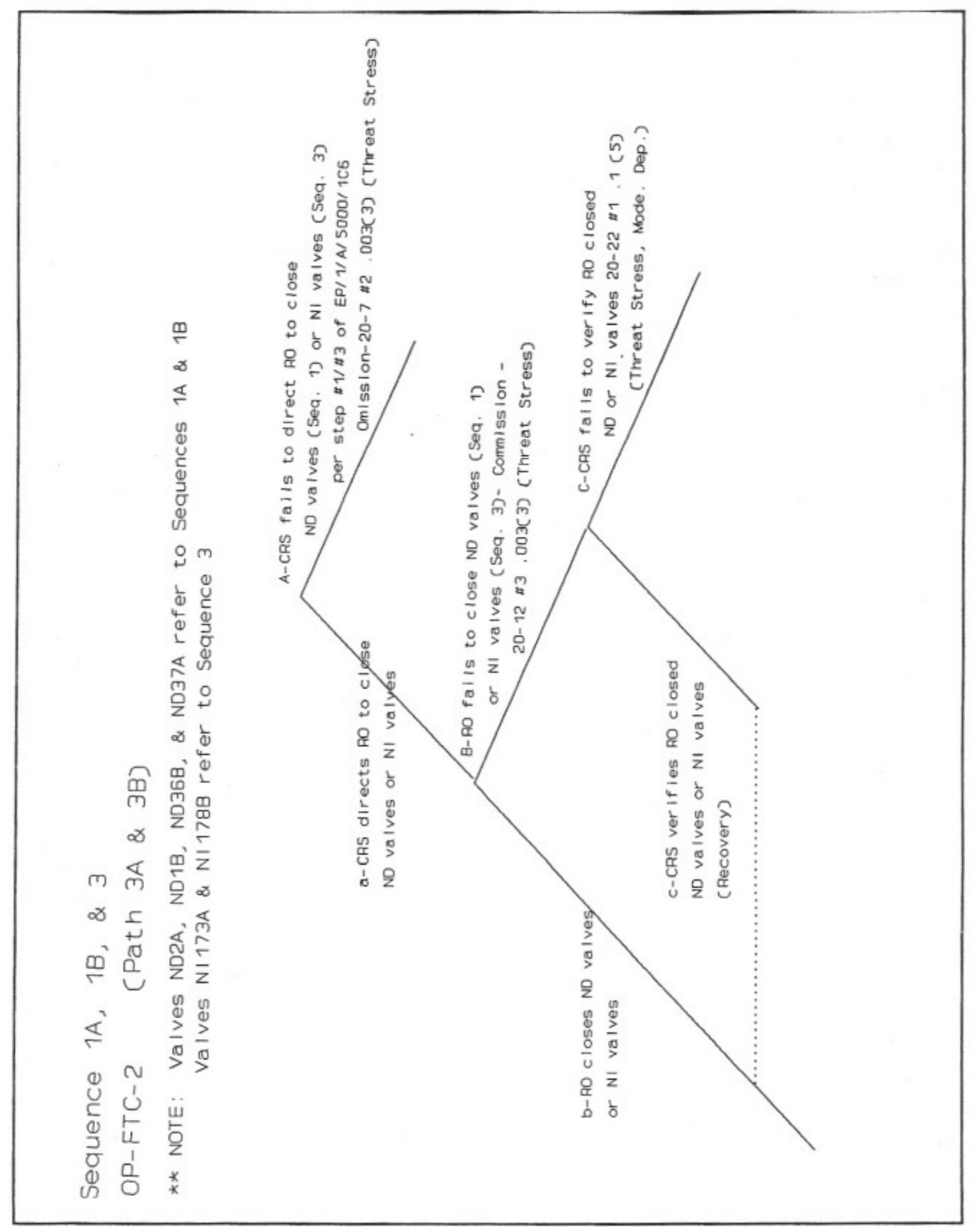


APPENDIX F

\section{CBDT BACKGROUND INFORMATION}




\section{CBDT Details}

The following $\mathbf{4 5}$ slides show the structure and the detailed questions used within each of the $8 \mathrm{P}_{\mathrm{c}}$ decision trees. The last $\mathbf{5}$ slides, describe the criteria used for determining $P_{c}$ recovery.

The information is extracted from EPRI TR-100259, indirectly from the EPRI HRA Calculator ${ }^{\circledR}$ and from various training courses provided by EPRI

Special thanks and acknowledgement to Stuart Lewis of EPRI and Kaydee Holhepp of Scientech (Curtiss Wright)

\section{Taking a Quick Stroll through the CBDTM "Forest"}

- The following slides show each tree, highlighting and elaborating on each question for that tree

- After listing each question separately, a slide shows all the questions for that tree. This summary slide can serve as a job aid for future examples or work.

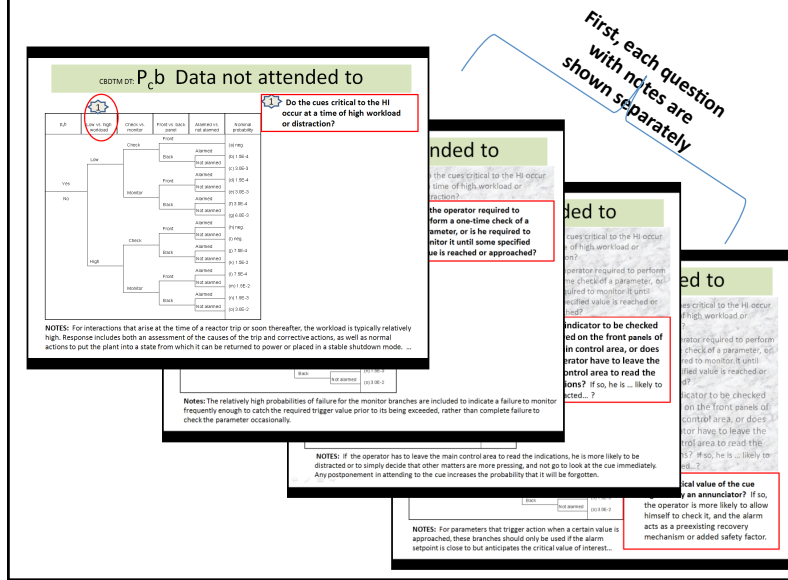

Then a summary slide shows all questions but no notes

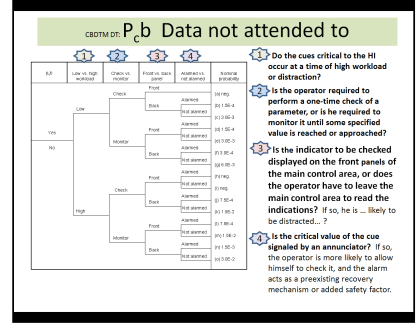




\section{$\mathrm{P}_{\mathrm{c}}$ a Data not available}

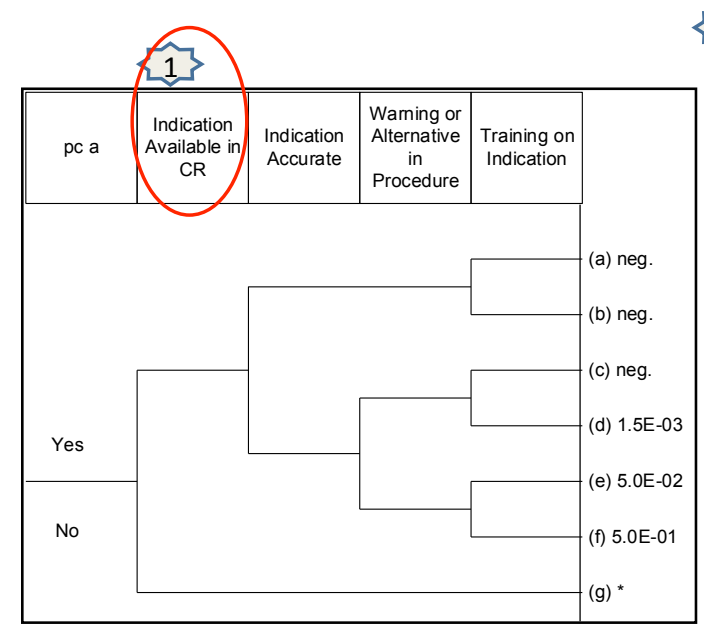

13 is the required Indication available in the control room?

\section{$\mathrm{P}_{\mathrm{c}} \mathrm{a}$ Data not available}

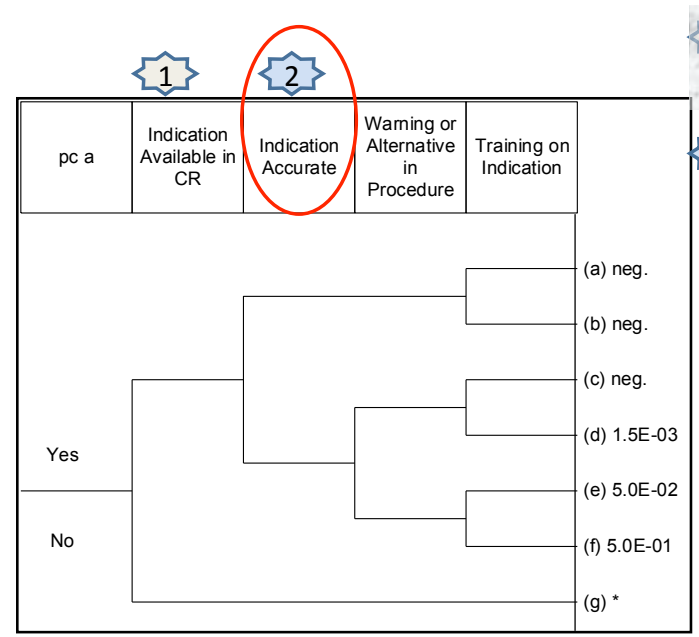

Is the required Indication available in the control room?

23 Are the Indications that are available accurate? If they are they known to be inaccurate (e.g., due to degradation because of local extreme environmental conditions or Isolation of the Instrumentation) then select No. 

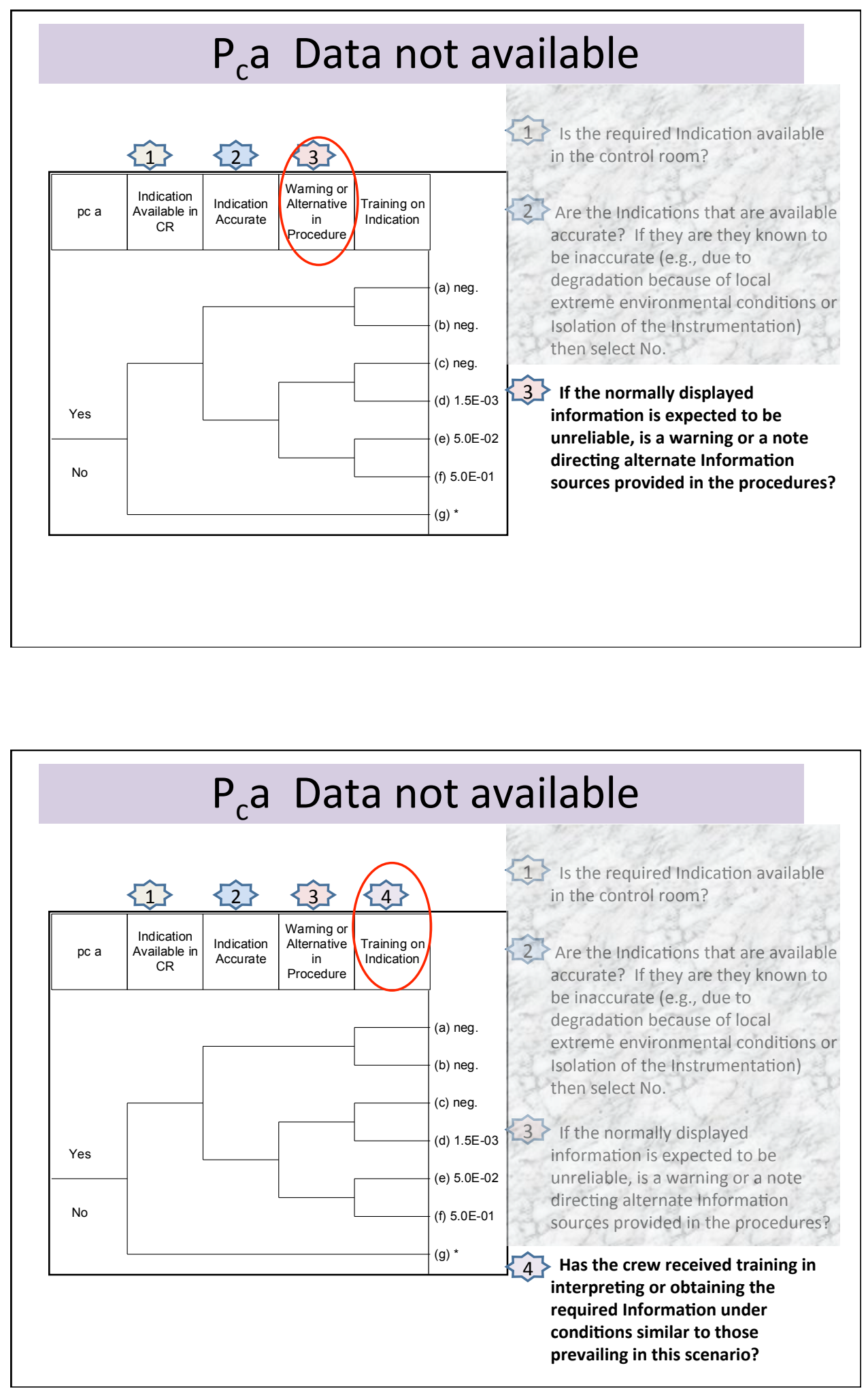


\section{$\mathrm{P}_{\mathrm{c}}$ a Data not available}
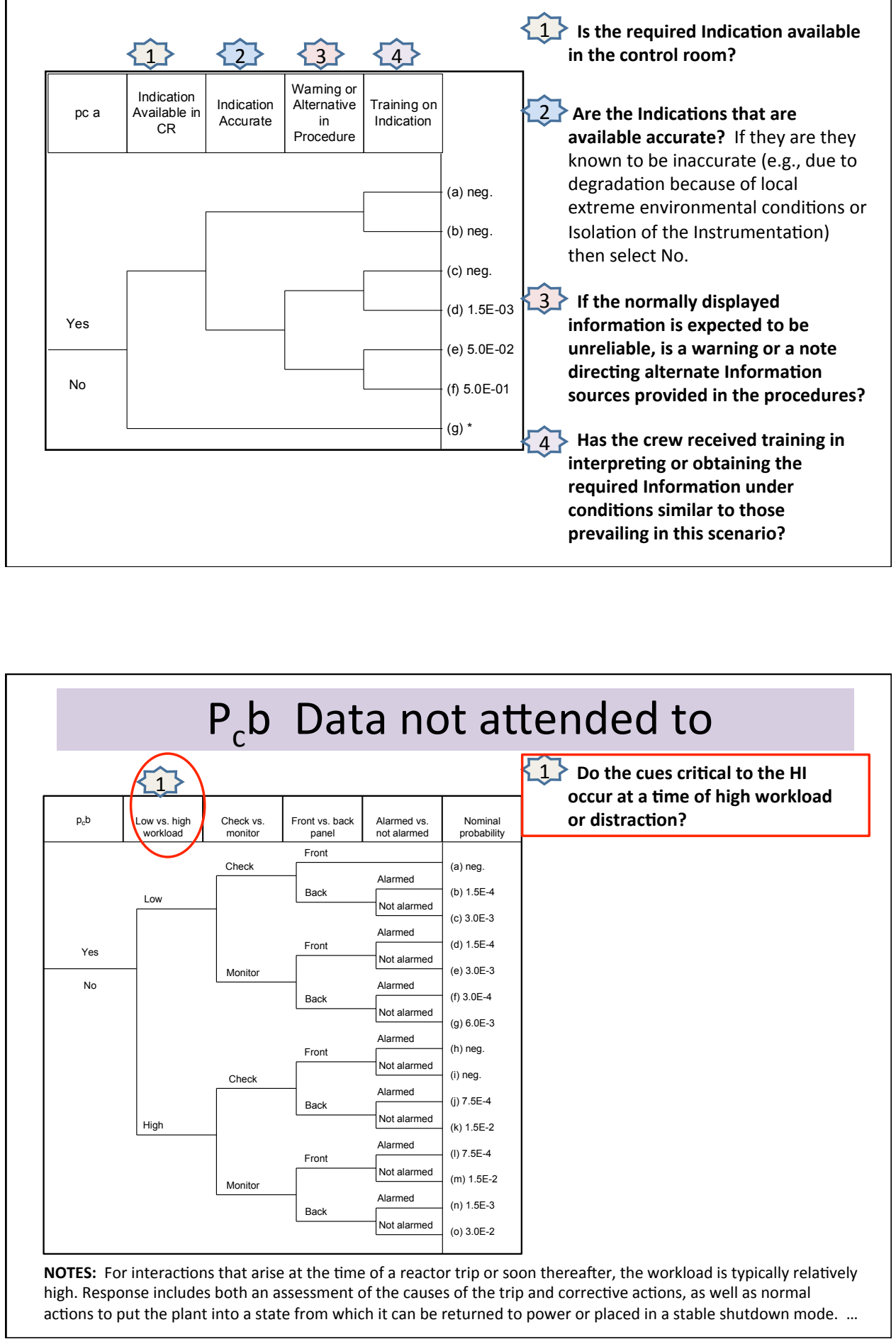

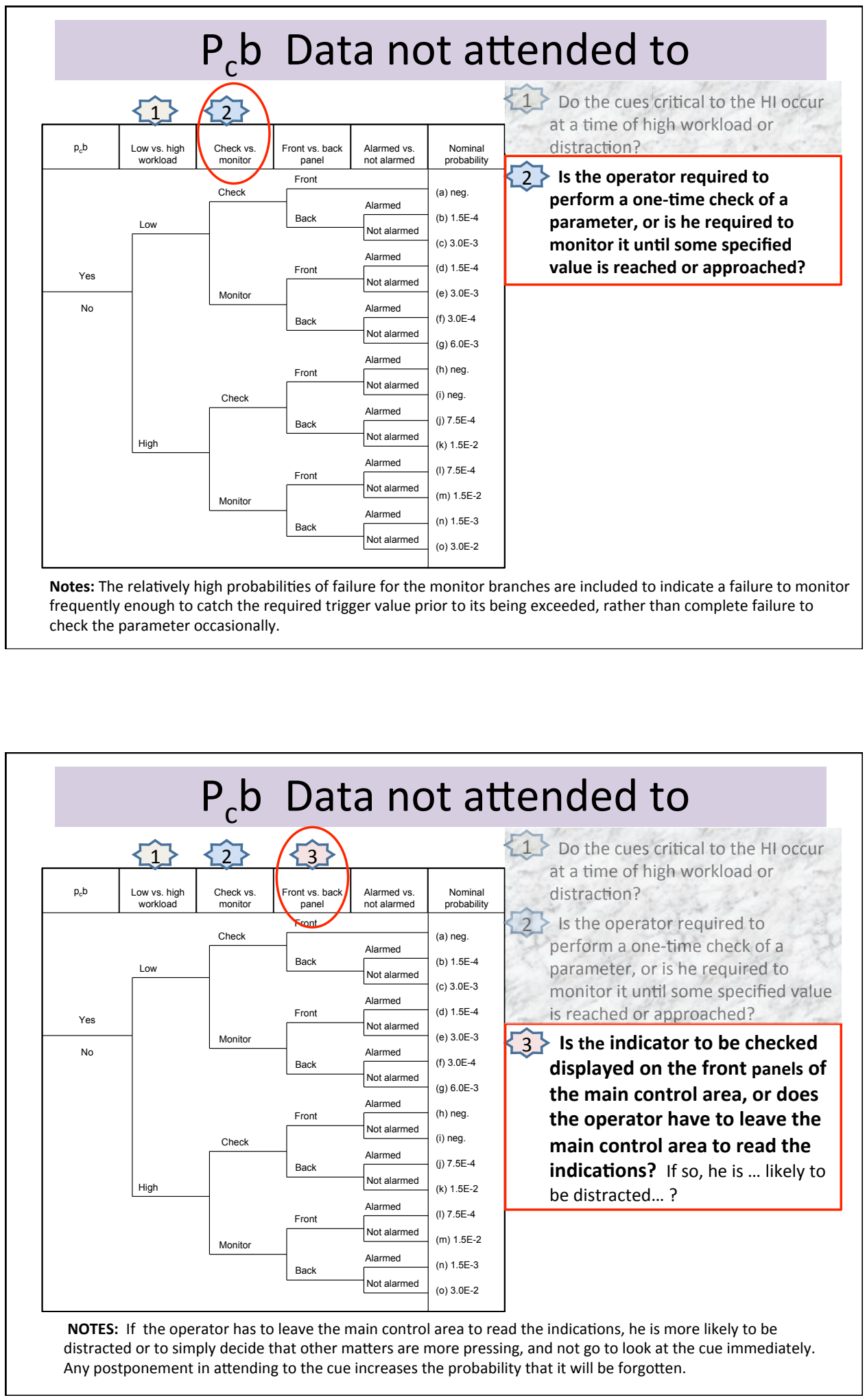

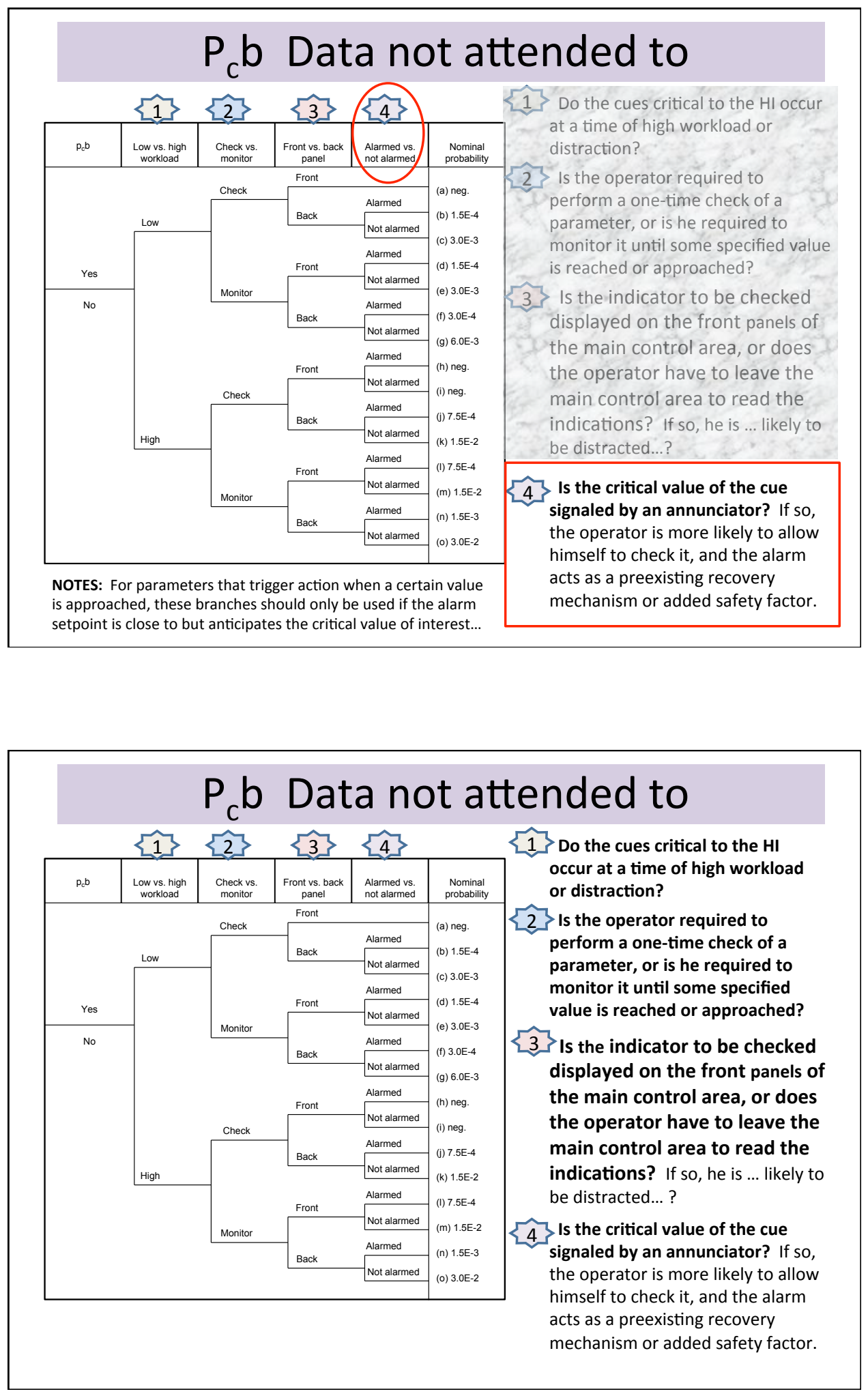


\section{$\mathrm{P}_{\mathrm{c}} \mathrm{c}$ Data misread or miscommunicated}

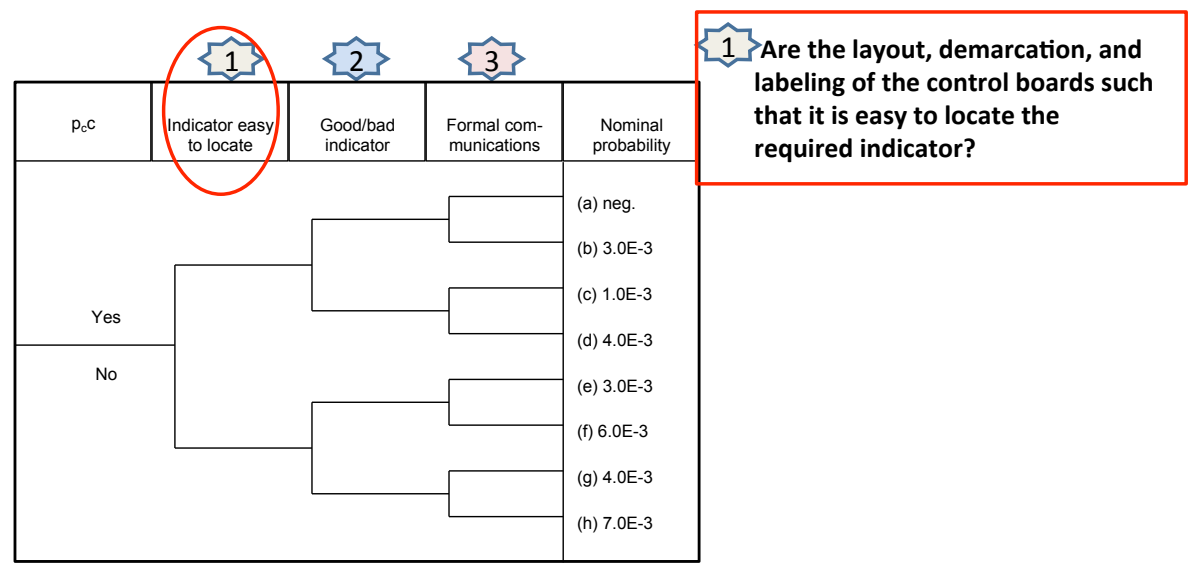

Notes: The answer is no if there are obvious human factors deficiencies in these areas and the plausible candidates for confusion with the correct indicator are sufficiently similar that the values displayed would not cause the operator to recheck the identity of the indicator after reading it.

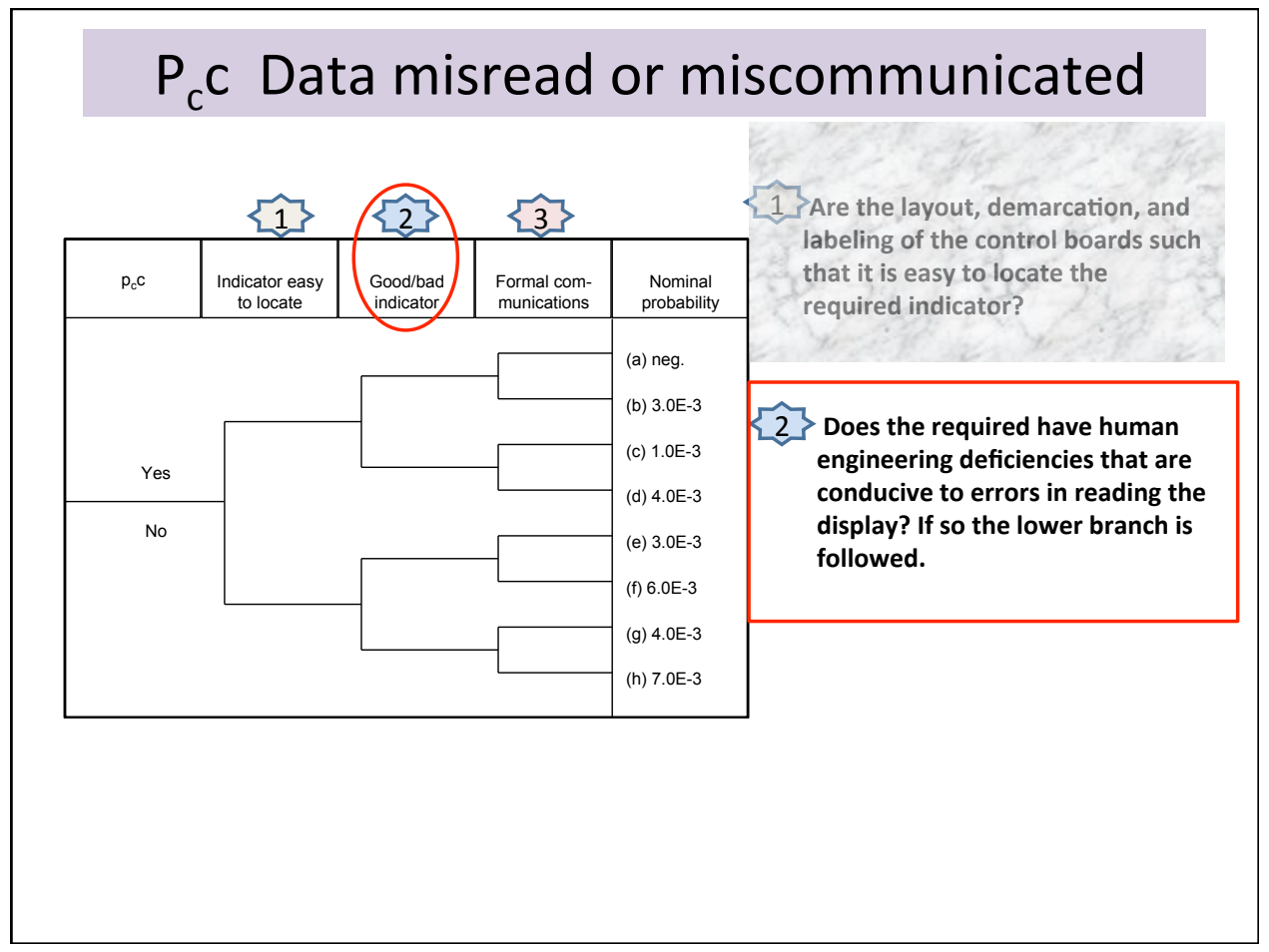



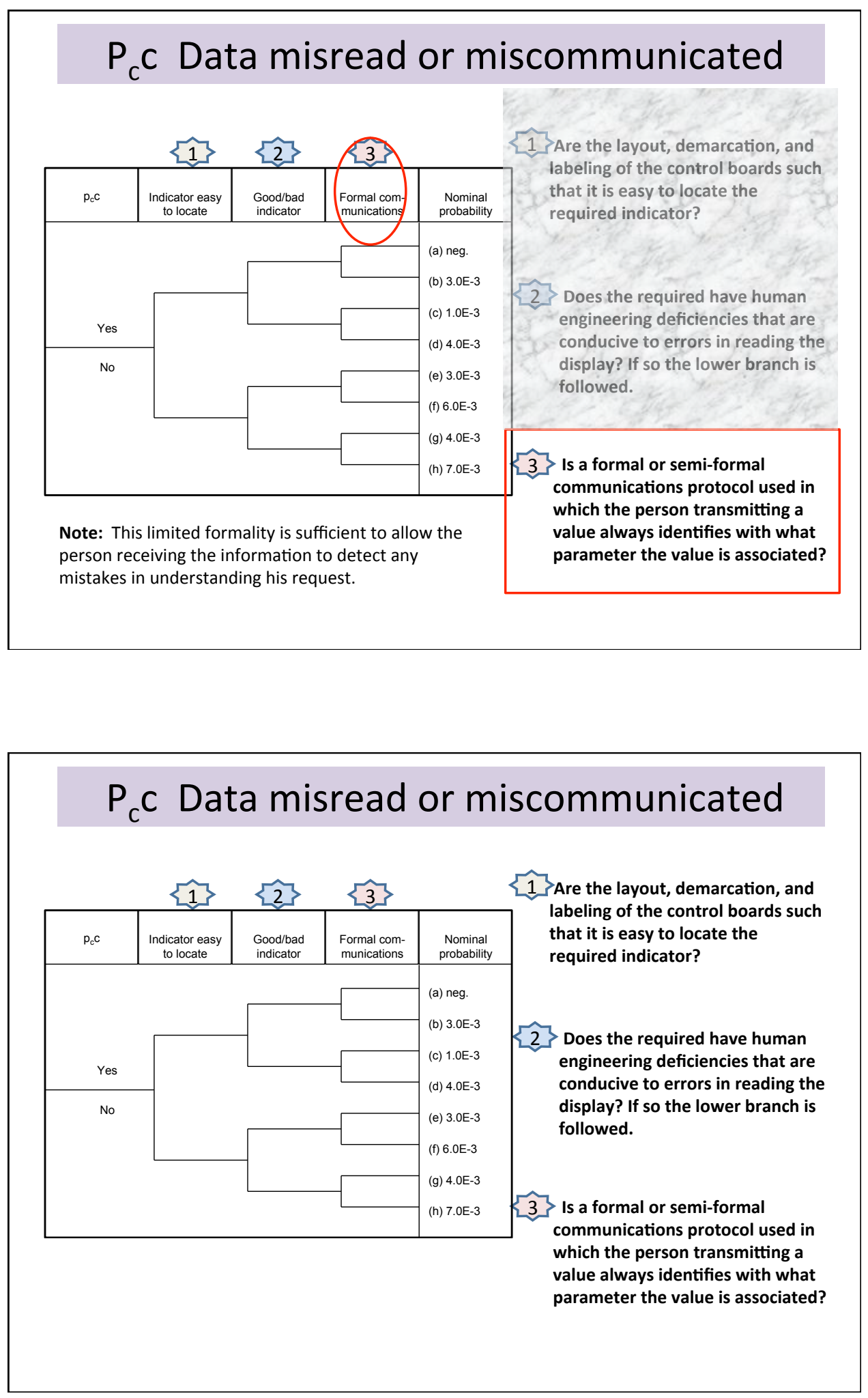


\section{$P_{c} d$ Information misleading}

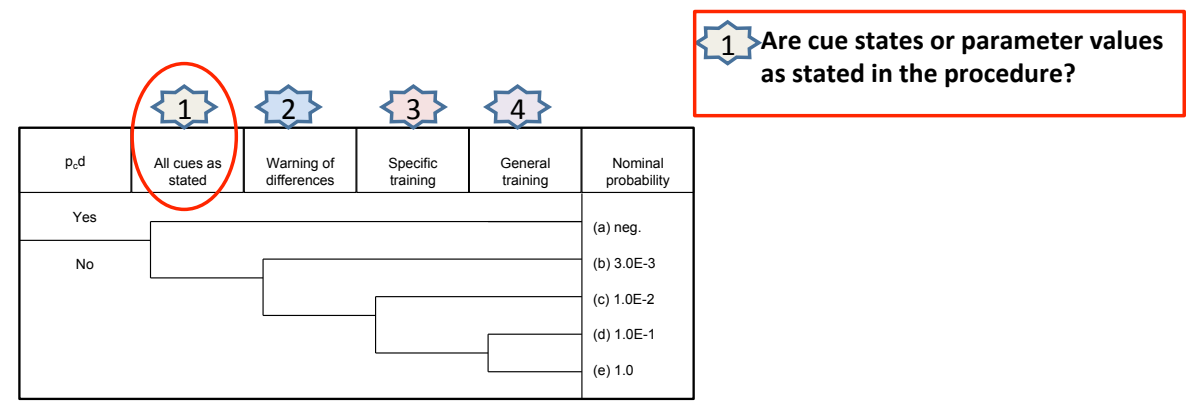

Notes: For example, if high steamline radiation is given as one of the criteria for decision or action, the steamline radiation indicators will read high, rather than normal. The "No" branch is to be used if an indicator is not obviously failed but would not give the value stated in the procedure (as, for example, if the steamline were isolated).

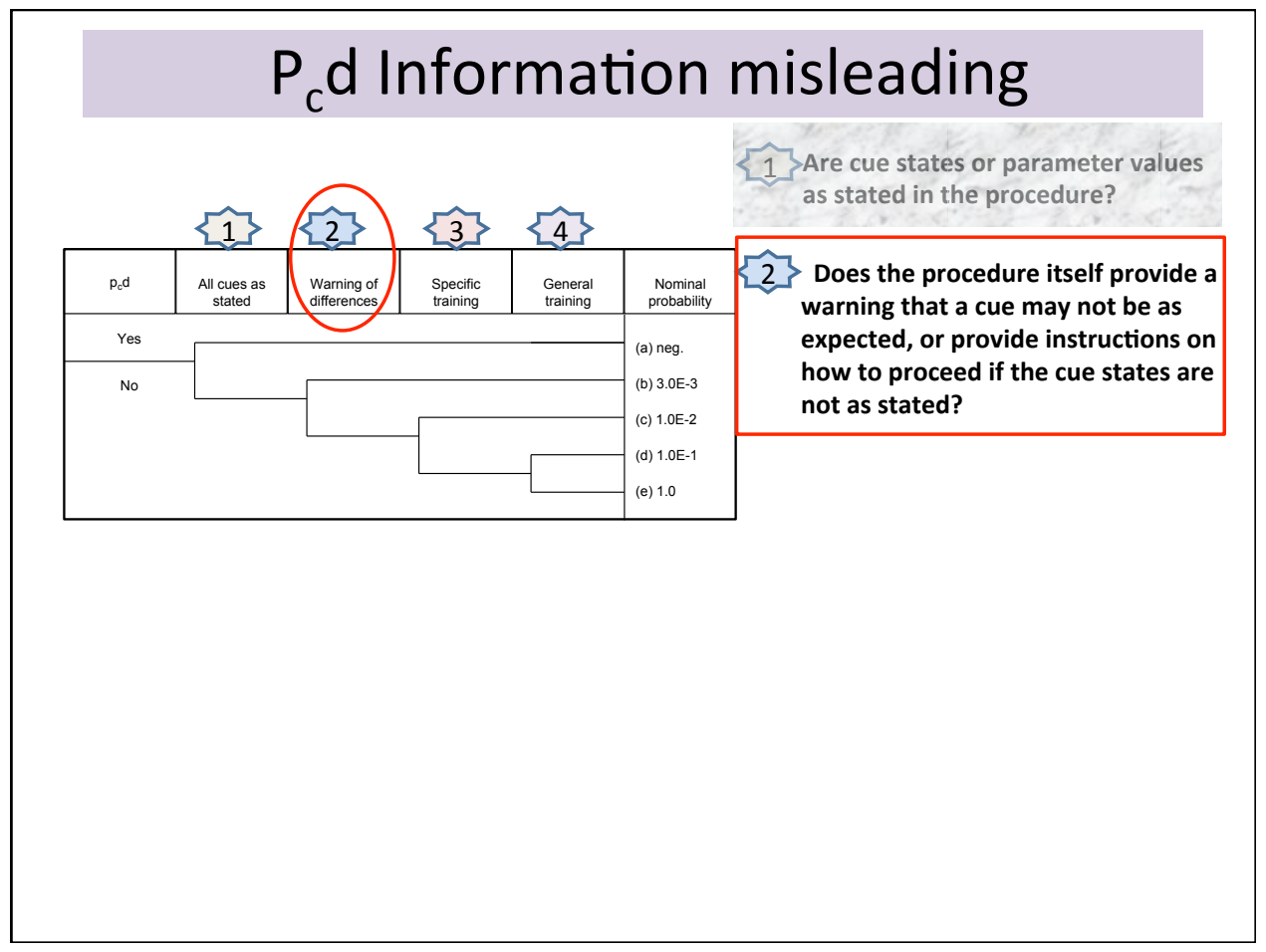




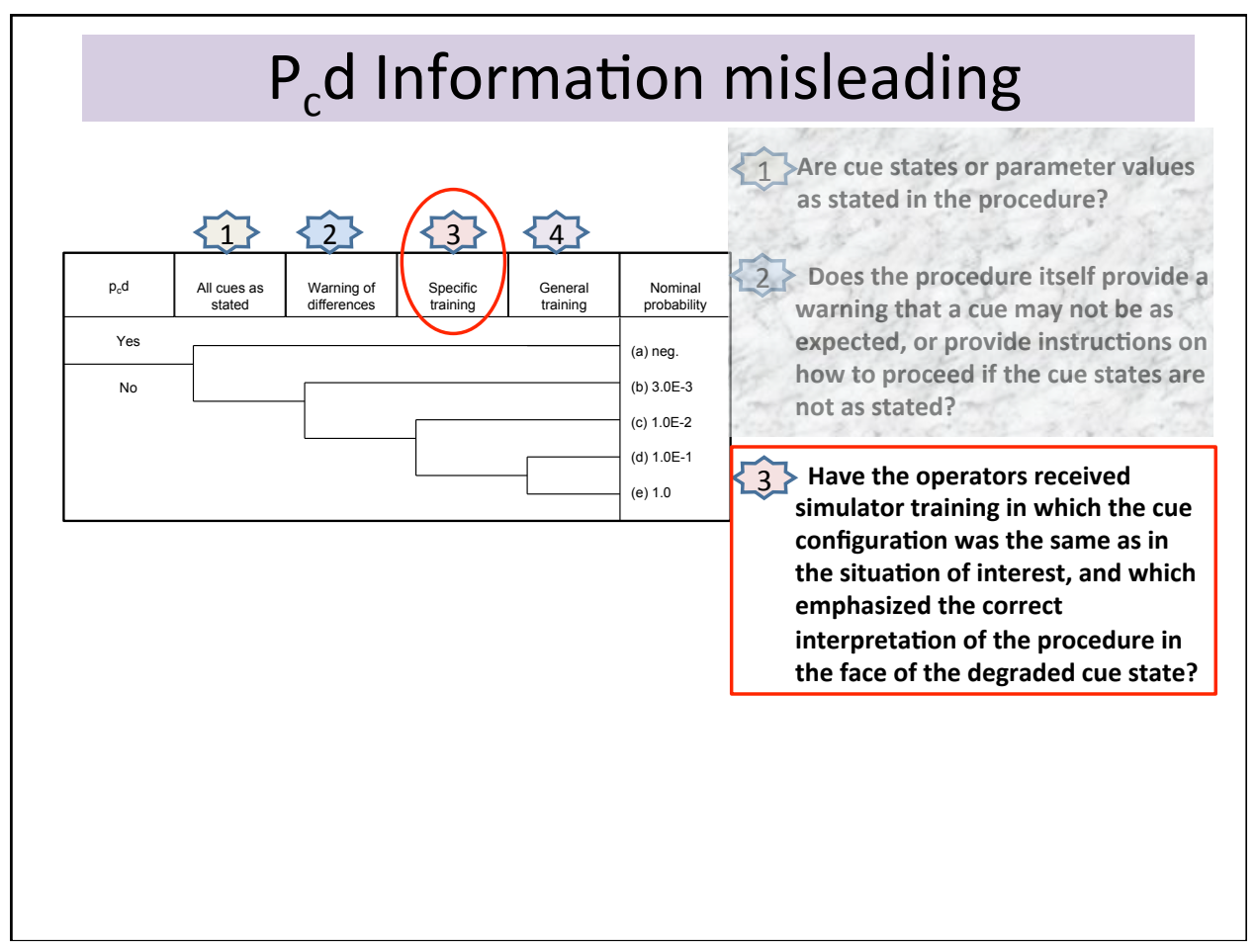

\section{$\mathrm{P}_{\mathrm{c}} \mathrm{d}$ Information misleading}

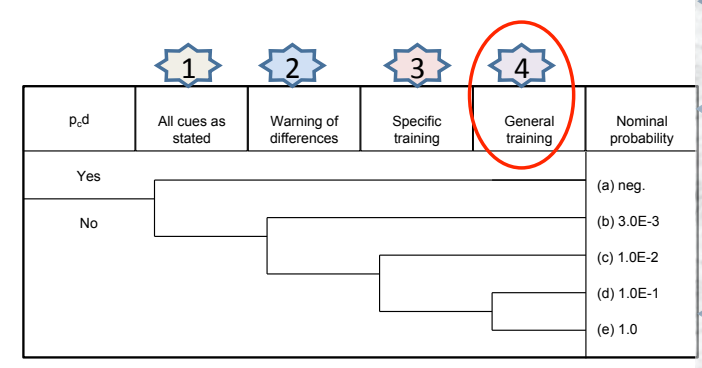

Notes: That is, is it something that every licensed operator is expected to know? For the example of the radiation monitor on the isolated steamline, the answer is "yes" because isolations are so common; for instrument abnormalities that only occur under a very special set of circumstances, the answer would be "no" unless the particular situation had received some emphasis in training. Operators cannot be expected to reason from their general knowledge of instrumentation to the behavior of a specific indicator in a situation where they are not forewarned and there are many other demands on their time and attention.
13 Are cue states or parameter values as stated in the procedure?

$2\}$ Does the procedure itself provide a warning that a cue may not be as expected, or provide instructions on how to proceed if the cue states are not as stated?

3 Have the operators received simulator training in which the cue configuration was the same as in the situation of interest, and which emphasized the correct

interpretation of the procedure in the face of the degraded cue state?

\{43 Have the operators received training that should allow them to recognize that the cue information is not correct in the circumstances? 


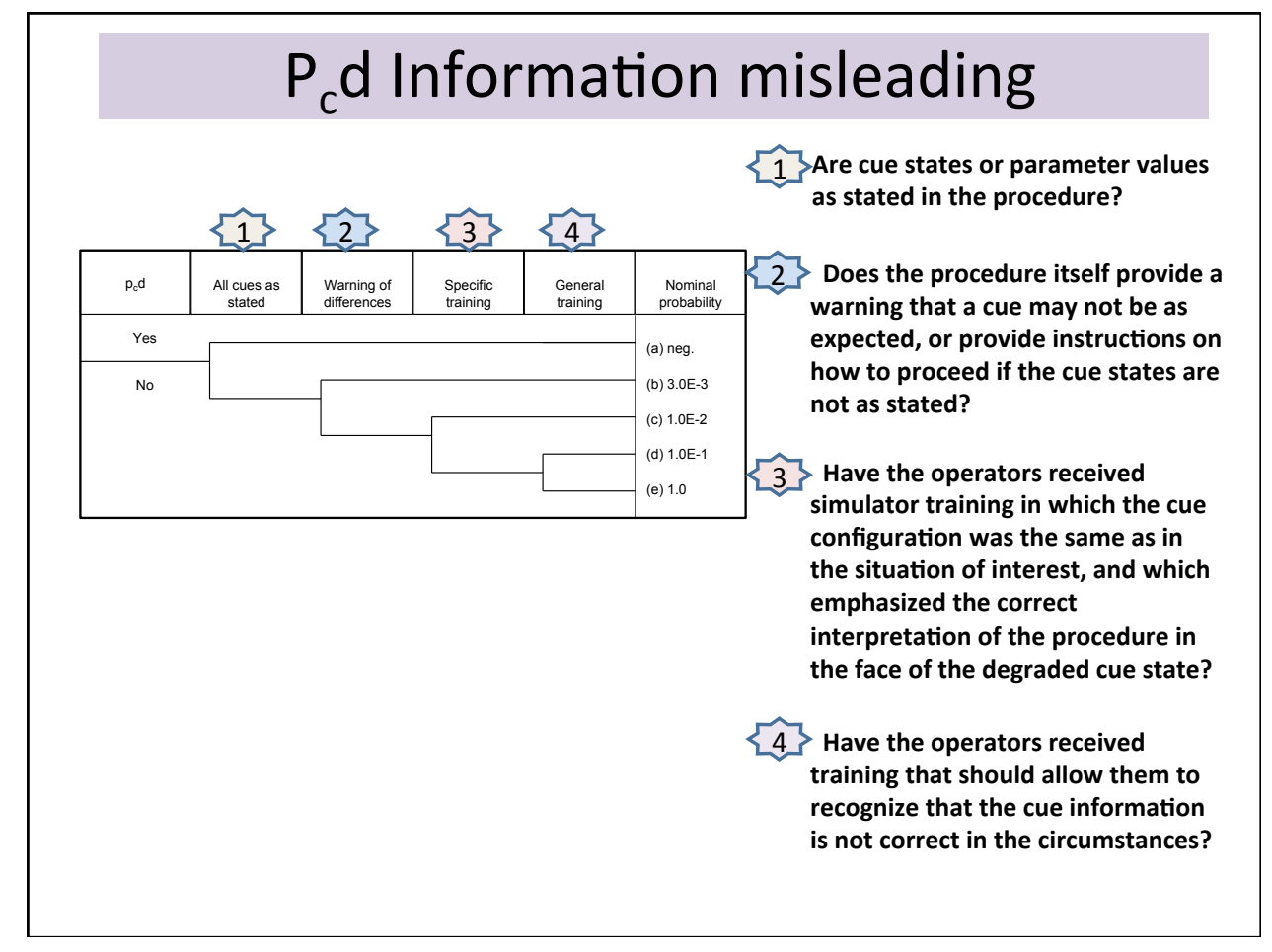

\section{$\mathrm{P}_{\mathrm{c}} \mathrm{e}$ Relevant step in procedure}

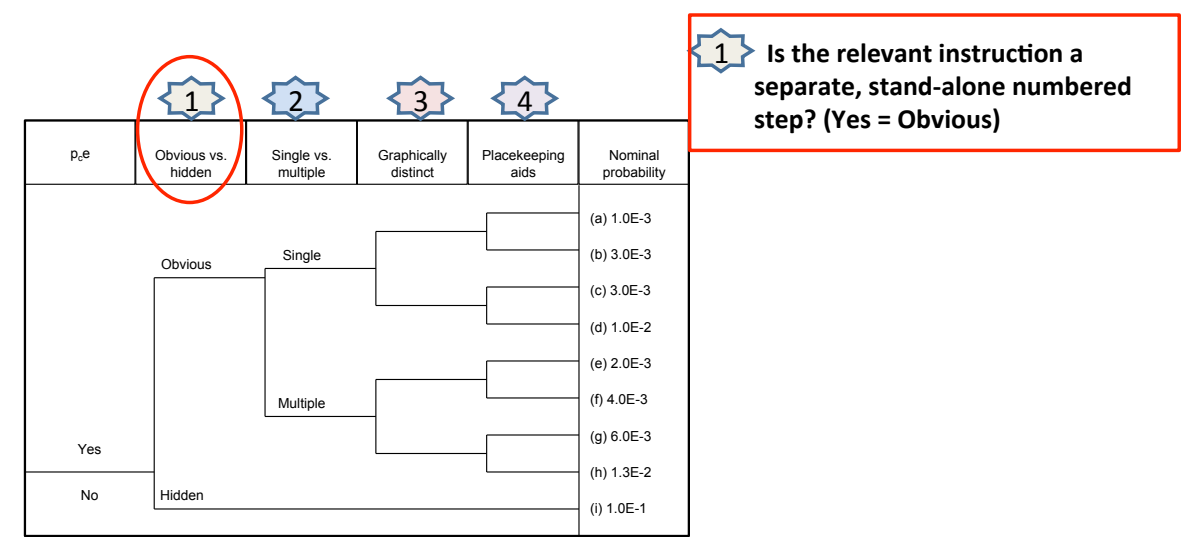

Notes: Or is it "hidden" in some way that makes it easy to overlook, e.g., one of several statements in a paragraph, in a note or caution, or on the back of a page? 


\section{$\mathrm{P}_{\mathrm{c}} \mathrm{e}$ Relevant step in procedure}

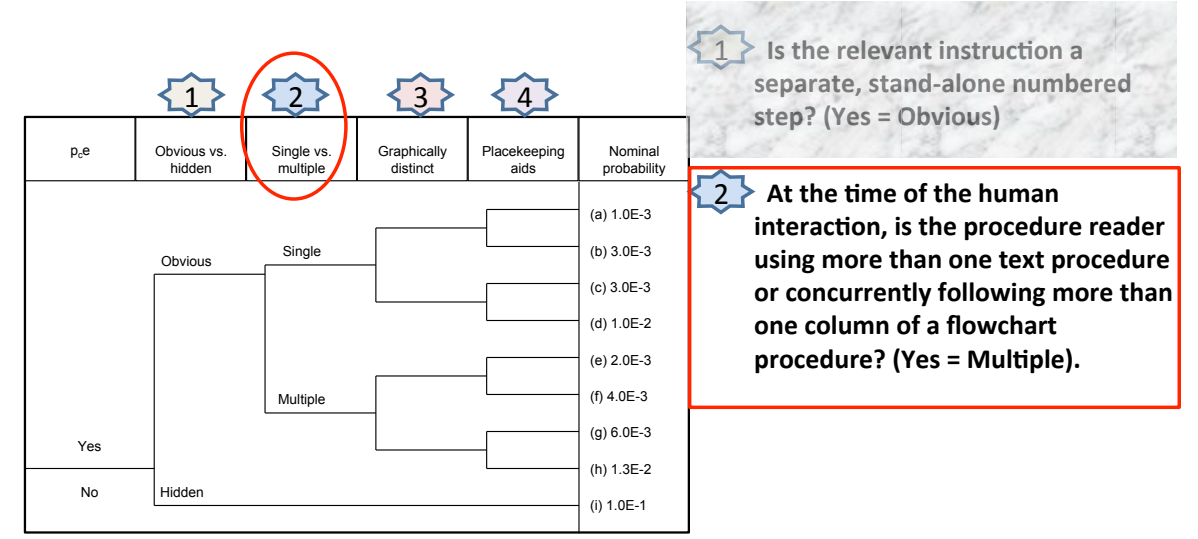

Notes: Most plants assert that, when an EOP is in us, it is the only procedure in force. Still, it is common practice to transition from one EOP to another, and possibly to visit abnormal or other procedures along the way. In these cases, the "multiple" branch should be selected, since the transitions among procedures may make it easier to overlook a step. This may also be the case for BWRs, where conditions may result in following flowpaths on separate procedure charts simultaneously.

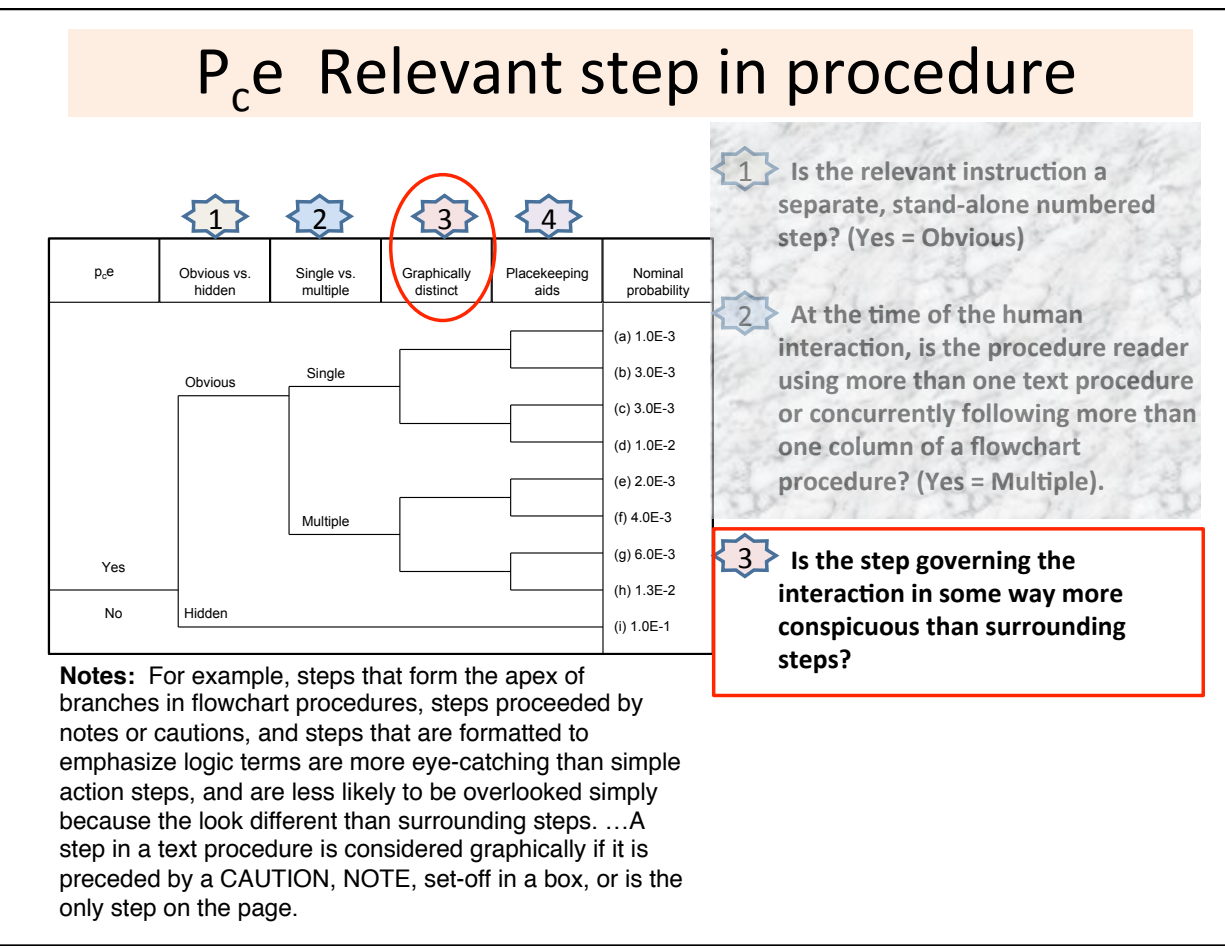




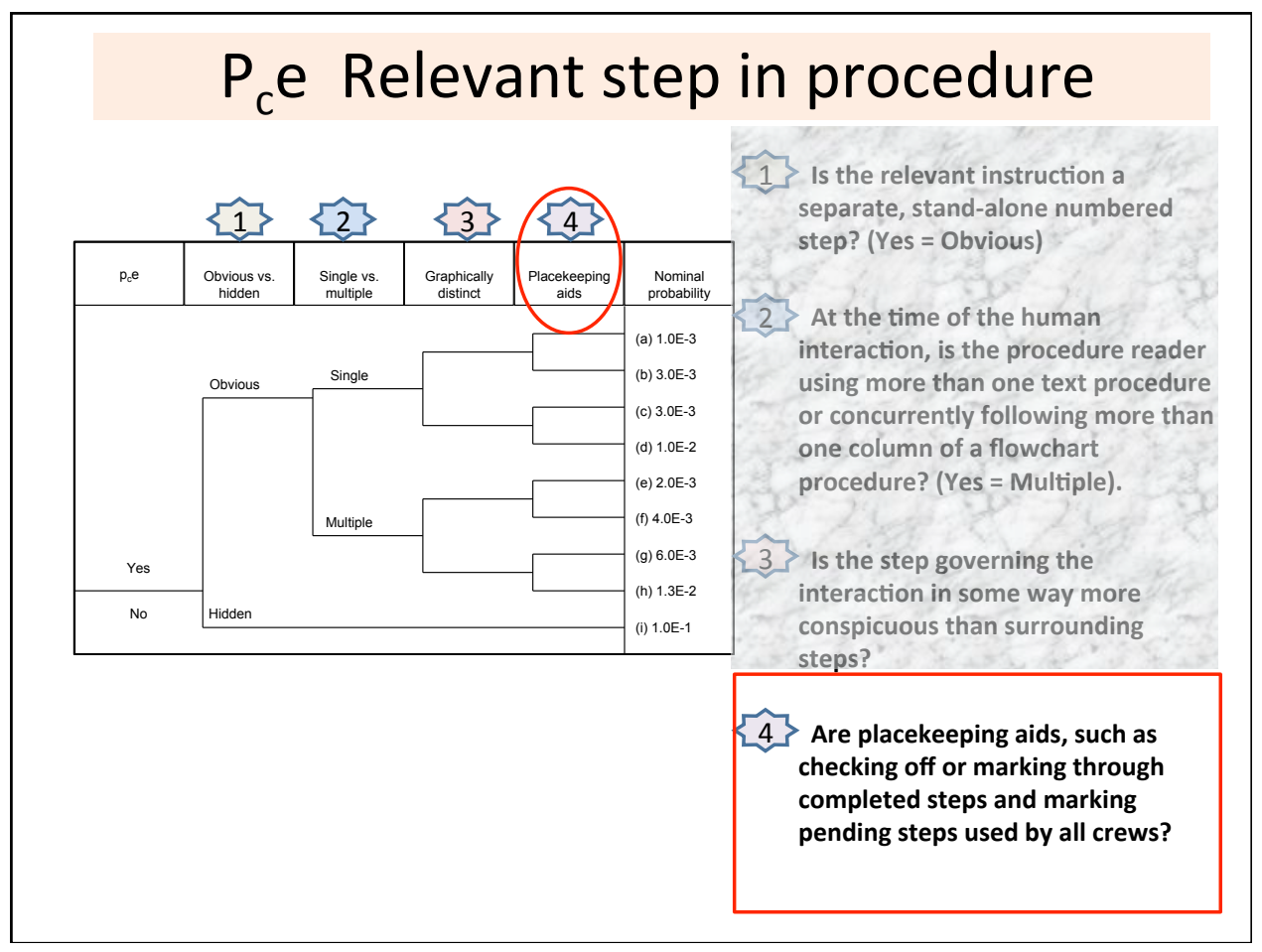

\section{$\mathrm{P}_{\mathrm{c}} \mathrm{e}$ Relevant step in procedure}

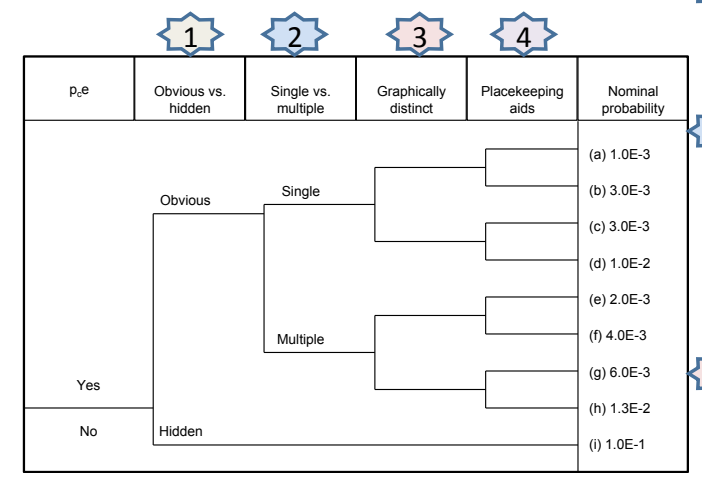

$\{1\}$ Is the relevant instruction a separate, stand-alone numbered step? (Yes = Obvious)

2 At the time of the human interaction, is the procedure reader using more than one text procedure or concurrently following more than one column of a flowchart procedure? (Yes $=$ Multiple).

3 Is the step governing the interaction in some way more conspicuous than surrounding steps?

4 Are placekeeping aids, such as checking off or marking through completed steps and marking pending steps used by all crews? 


\section{$P_{c} f$ Misinterpret instruction}
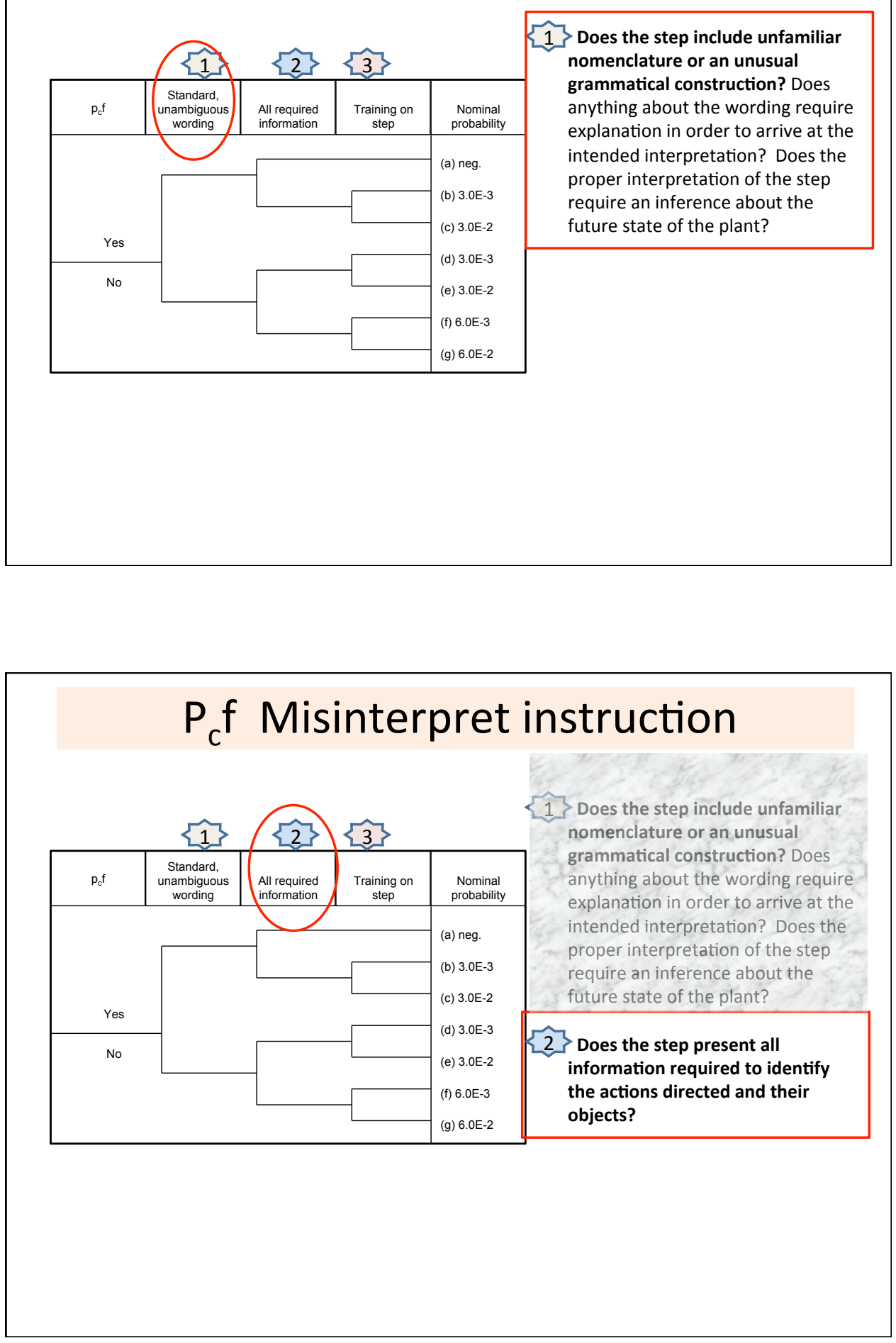


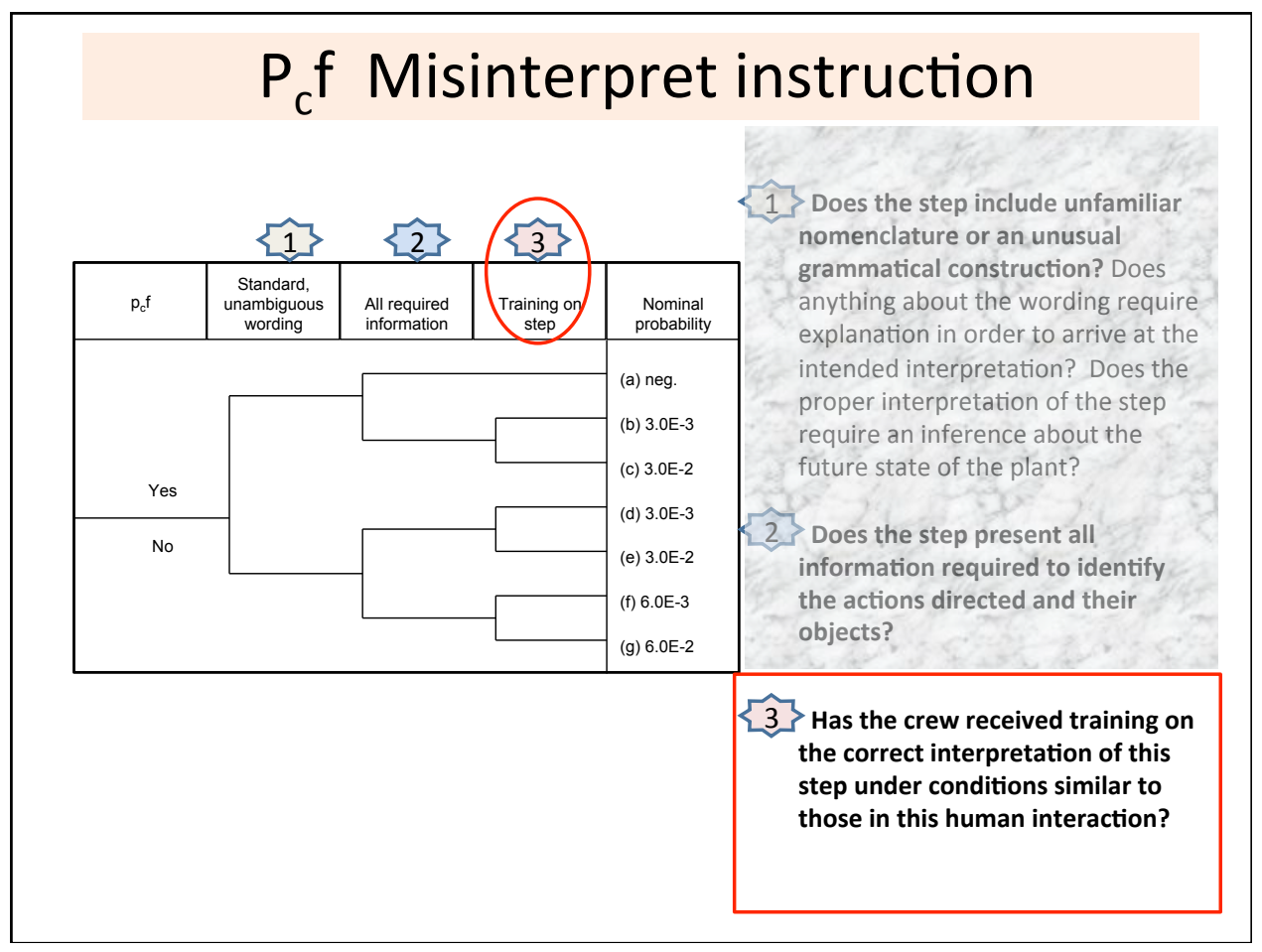

\section{$P_{c} f$ Misinterpret instruction}

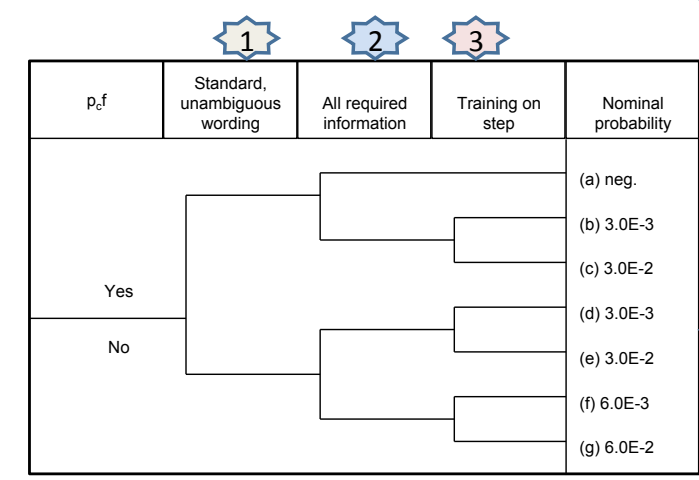

$\{1\}$ Does the step include unfamiliar nomenclature or an unusual grammatical construction? Does anything about the wording require explanation in order to arrive at the intended interpretation? Does the proper interpretation of the step require an inference about the future state of the plant?

2 Does the step present all information required to identify the actions directed and their objects?

3 Has the crew received training on the correct interpretation of this step under conditions similar to those in this human interaction? 

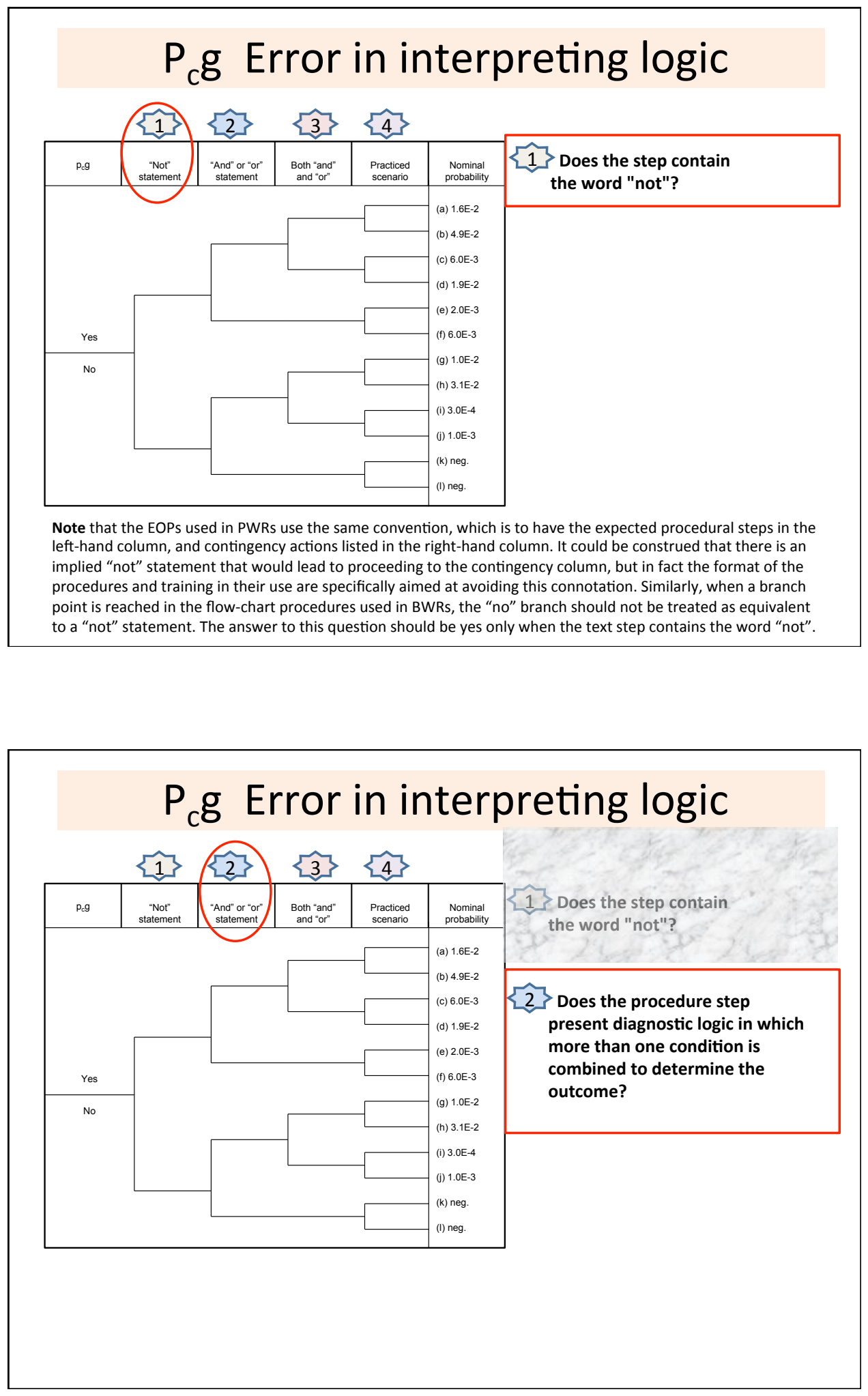

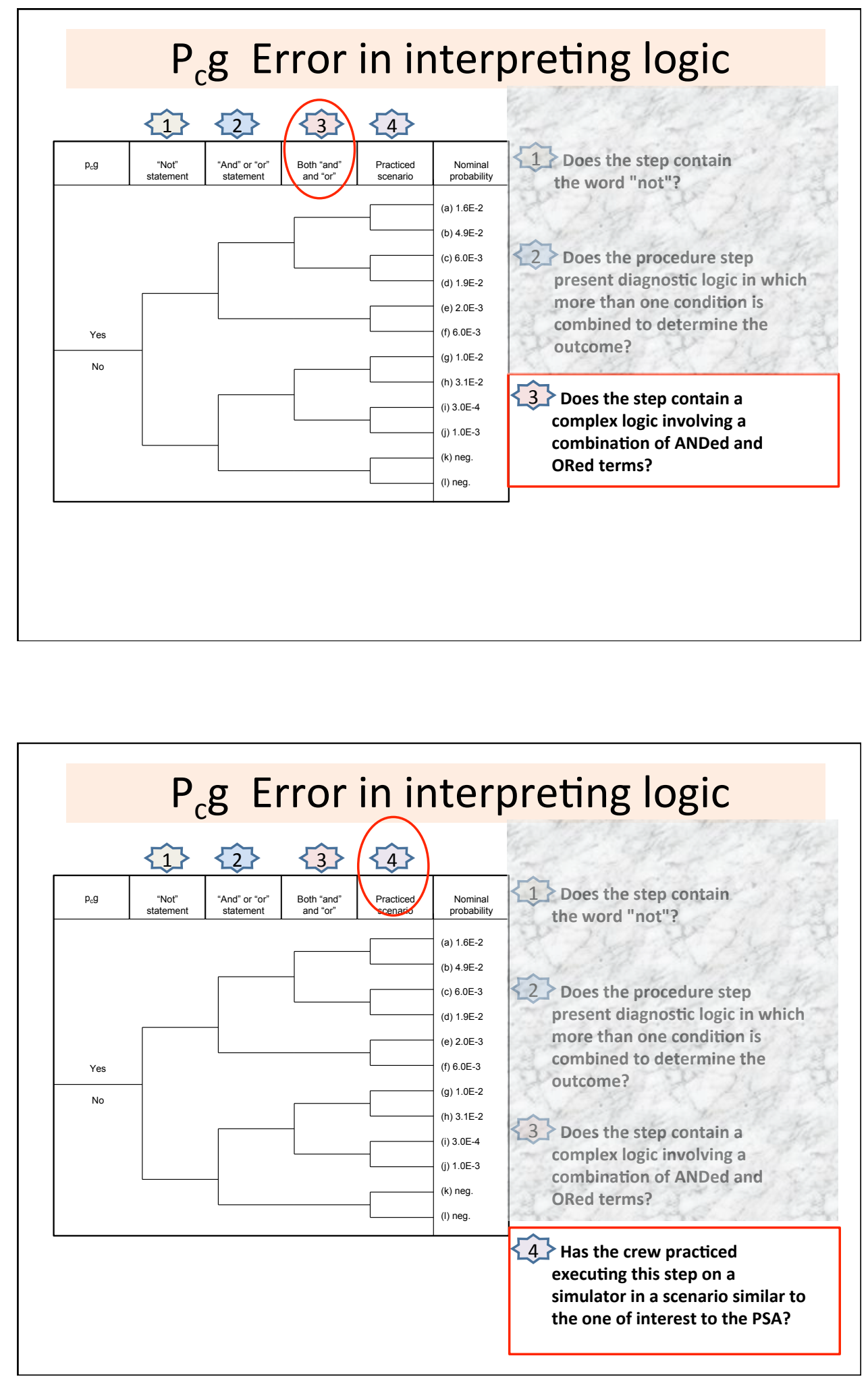

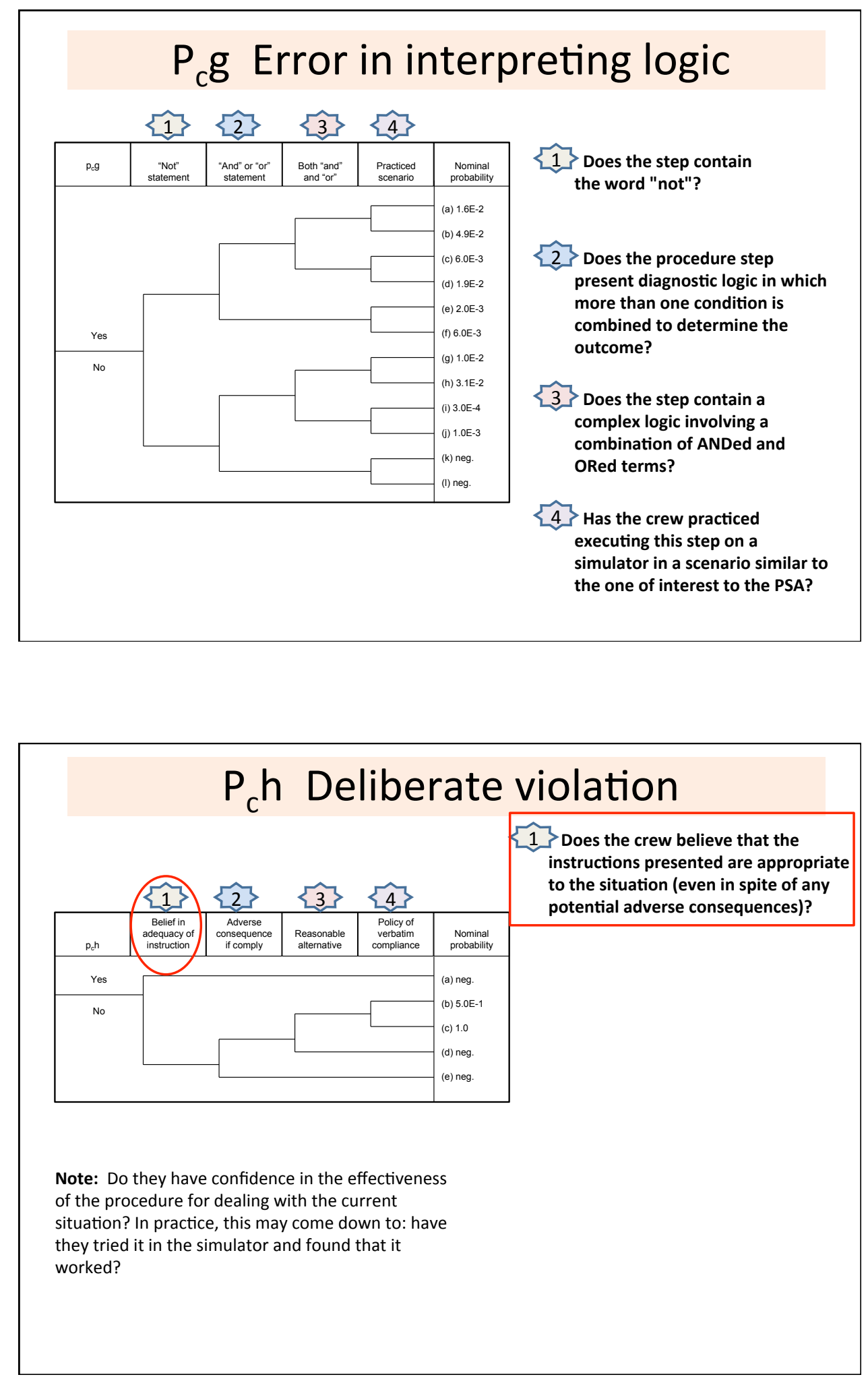


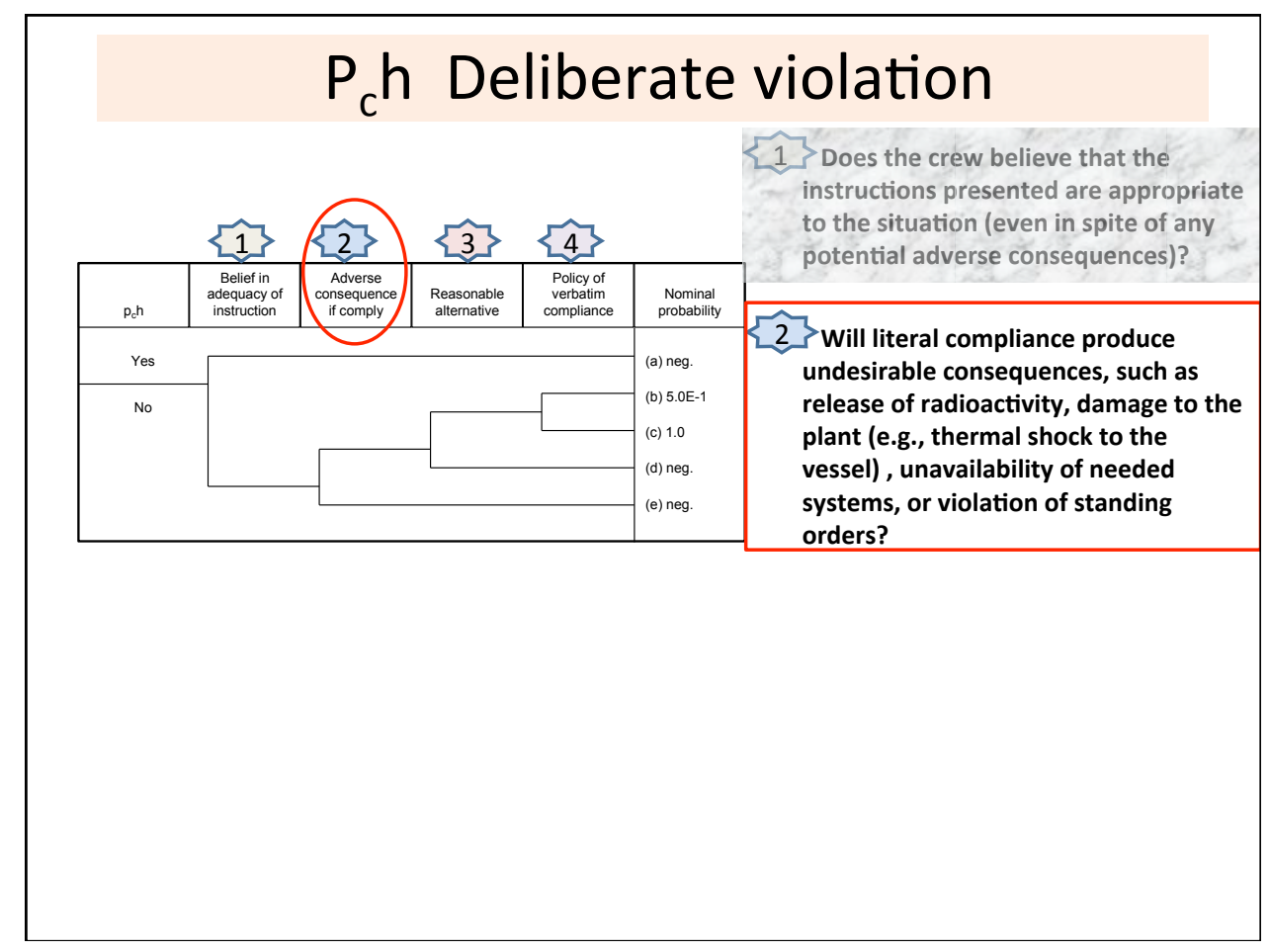

\section{$\mathrm{P}_{c} \mathrm{~h}$ Deliberate violation}

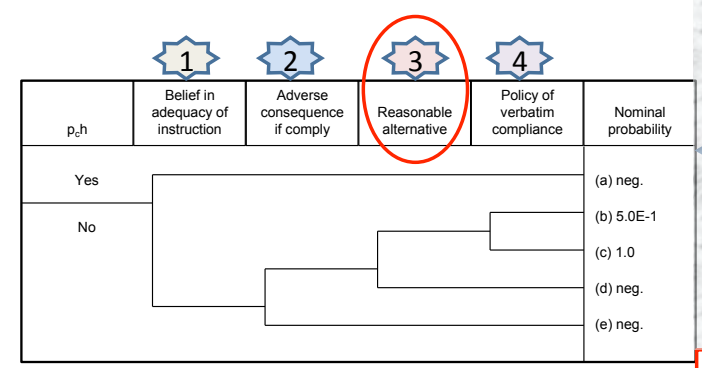

Note: Does simply delaying implementation appear to offer a reasonable hope for averting undesirable consequences? Note that simply delaying all or part of the response may not be considered a violation if the response is ultimately executed successfully.
1 Does the crew believe that the instructions presented are appropriate to the situation (even in spite of any potential adverse consequences)?

2 Will literal compliance produce undesirable consequences, such as release of radioactivity, damage to the plant ..., unavailability of needed systems, or violation of standing orders?

3 Are there any fairly obvious alternatives (e.g. partial compliance or use of different systems) that appear to accomplish some or all of the goals of the step without the adverse consequences produced by the step as written? 


\section{$\mathrm{P}_{\mathrm{c}} \mathrm{h}$ Deliberate violation}

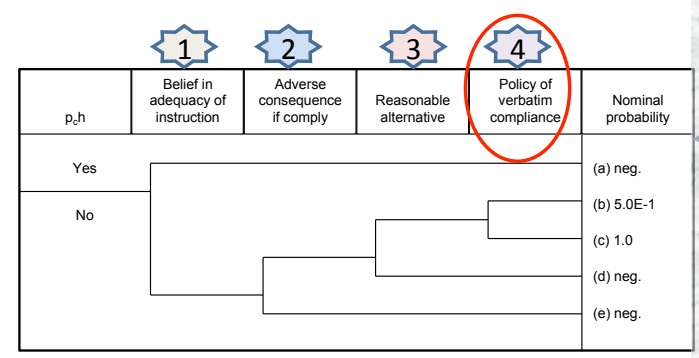

Note: Does simply delaying implementation appear to offer a reasonable hope for averting undesirable consequences? Note that simply delaying all or part of the response may not be considered a violation if the response is ultimately executed successfully.
Does the crew believe that the instructions presented are appropriate to the situation (even in spite of any potential adverse consequences)?

2 Will literal compliance produce undesirable consequences, such as release of radioactivity, damage to the plant ..., unavailability of needed systems, or violation of standing orders?

$\{3$ Are there any fairly obvious alternatives (e.g. partial compliance or use of different systems) that appear to accomplish some or all of the goals of the step without the adverse consequences produced by the step as written?

4 Does the utility have and enforce a policy of strict verbatim compliance with EOPs and other procedures?

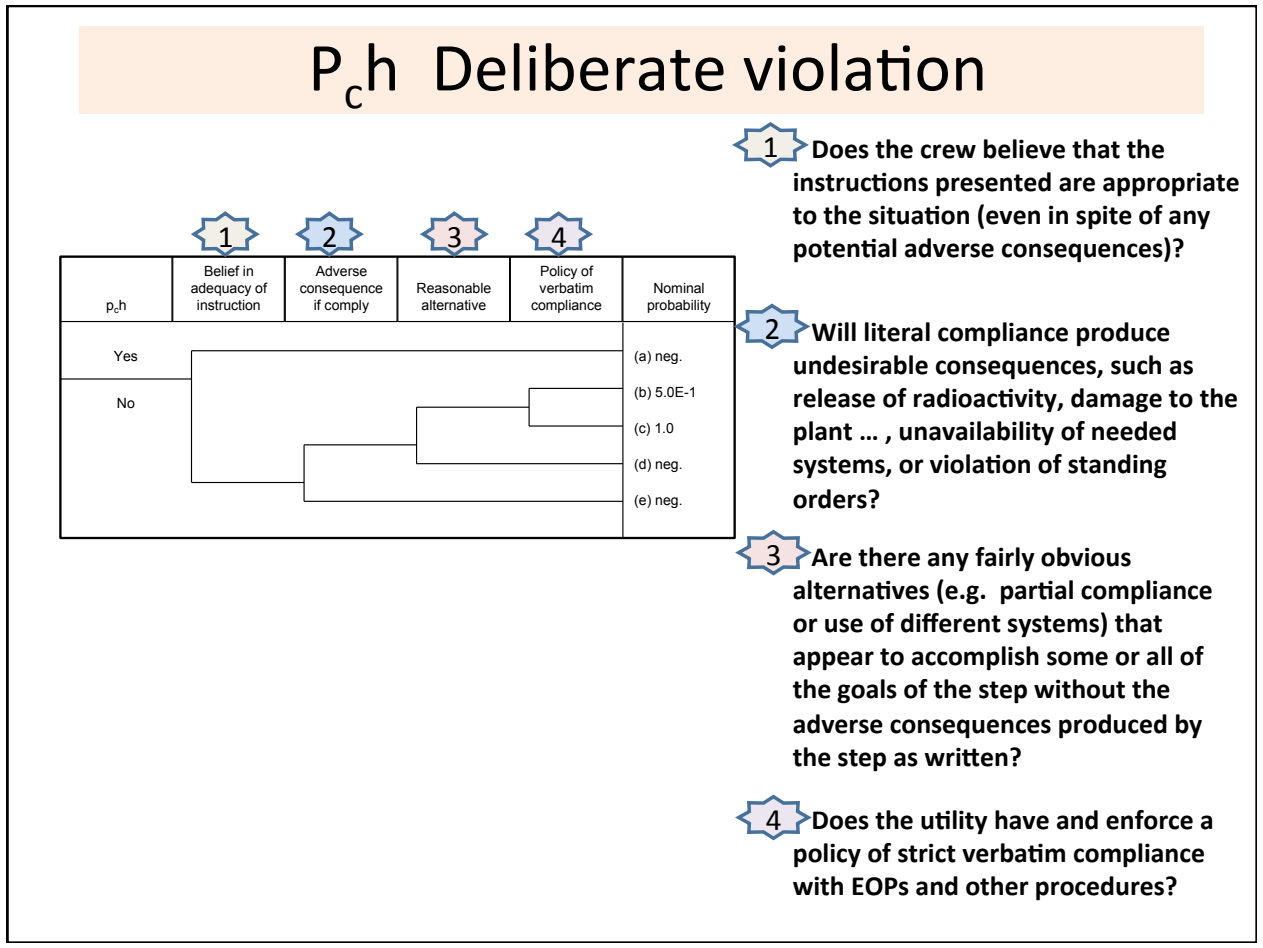




\section{CBDTM Recovery Factors: Self Review}

- Is there a subsequent cue, other that the initial cue, that would prompt the operator to revisit the decision?

- Is there a procedural step that either returns the operator to the initial step where the error was made, or that repeats the initial instruction?

- Is the procedure iterative e.g. an STA reviewing the CSFSTs every 15 minutes?

\section{CBDTM Recovery Factors: Extra Crew}

- Will crew members other than the procedure reader and the STA be in a position to note the incorrect decision?

- Is there a mechanism, based on either explicit procedure or by general training of the control room staff, by which the additional crew members may alert the supervisor to the need to reconsider the decision? 


\section{CBDTM Recovery Factors: STA Review}

- Will the STA be in the control room prior to or soon after the indications of the need for action were received?

- Special Time Note: Credit timeframe is 10-15 minutes after the trip

- Will the nature of the interaction give rise to cues that would normally be tracked by the STA?

\section{CBDTM Recovery Factors: ERF/TSC}

- Is the interaction part of a scenario where the TSC and ERF are constituted per the facility's emergency plan?

- Will the interaction arise late enough (or have a long enough time window) that the ERF and TSC would be staffed and functioning effectively?

- Special time note: The Emergency Response Facility (ERF)/TSC Review recovery factor is not applied if the human interaction takes place less than 1 hour into the sequence, or if the time available for the human interaction is less than 1 hour.

- Will the nature of the interaction and the cues that would give rise to it fall within the types of plant conditions and events for which it would be reasonable to expect the TSC or ERF to provide meaningful inputs? 


\section{CBDTM Recovery Factors: Shift Change}

- Is the time window long enough for effective input from an oncoming shift?

- Special time note: This is taken to be at least $6 \mathrm{hr}$ for a plant that employs an 8-hr shift, and $9 \mathrm{hr}$ for one for which a 12-hr shift is the normal practice

- Is there sufficient information available for the oncoming shift to make an accurate assessment of the status of the plant and to determine the need for the relevant action? 